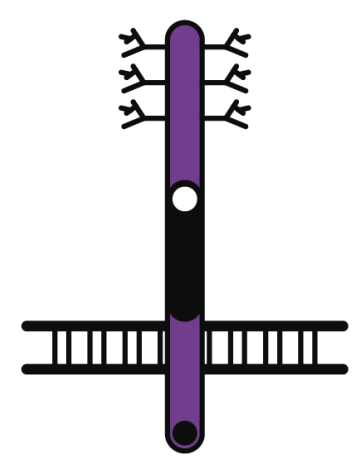

Tesis Doctoral

\title{
LA ENDOGLINA DE MEMBRANA $Y$ LA ENDOGLINA SOLUBLE MODULAN LA RESPUESTA INFLAMATORIA
}

\section{Laura Ruiz Remolina}

Dep. de Fisiología y Farmacología

\author{
VNIVERSIDAD \\ BSALAMANCA
}

CAMPUS DE EXCELENCIA INTERNACIONAL 
LA DOCTORA ALICIA RODRIGUEZ BARBERO, DEL DEPARTAMENTO DE FISIOLOGÍA Y FARMACOLOGÍA DE LA UNIVERSIDAD DE SALAMANCA,

\section{CERTIFICA:}

Que el presente trabajo, titulado "La endoglina de membrana y la endoglina soluble modulan la respuesta inflamatoria", presentado por Laura Ruiz Remolina para optar al Grado de Doctor por la Universidad de Salamanca, ha sido realizado bajo su dirección en el Área de Fisiología del Departamento de Fisiología y Farmacología de la Universidad de Salamanca, y considerando que cumple las condiciones necesarias, lo consideran finalizado y autorizan su presentación a fin de que pueda ser defendido ante el tribunal correspondiente.

Y para que así conste, expiden y firman el presente certificado, en Salamanca, a 11 de abril de 2018.

Dra. Alicia Rodriguez Barbero 
ÍNDICE 
ÍNDICE

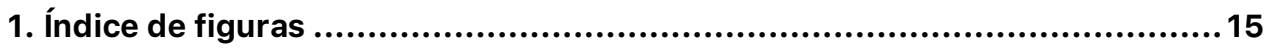

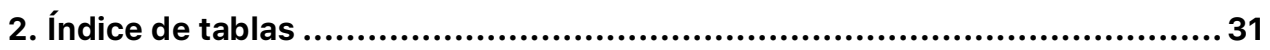

ABREVIATURAS Y GLOSARIO .............................................................. 33

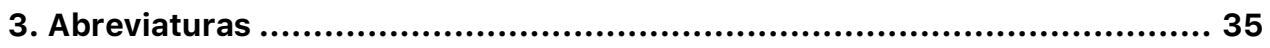

4. Glosario de términos en inglés ..........................................................41

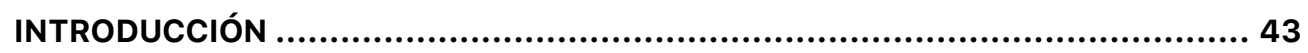

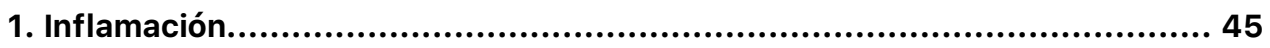

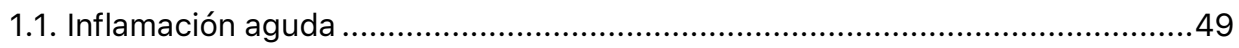

1.1.1. Principales citoquinas implicadas en la inflamación ..................................... 51

1.1.2. Inducción de la inflamación aguda...........................................................53

1.1.2.1. Inflamación aguda pulmonar.............................................................54

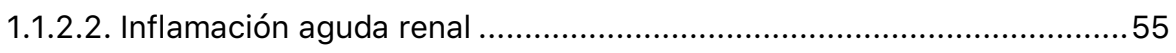

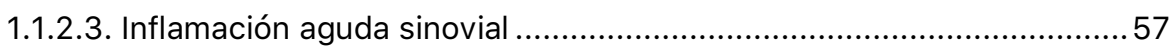

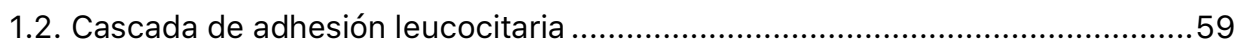

1.2.1. Interacciones leucocito-endoteliales en vénulas postcapilares .................. 61

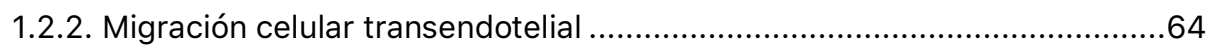

1.2.3. Rotura de la pared venular tras la migración transendotelial.......................66

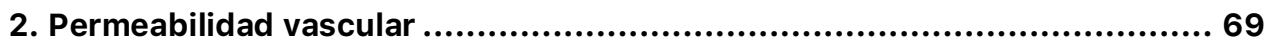

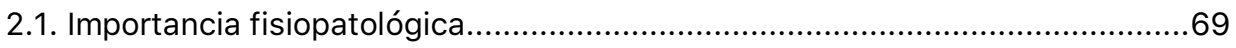


2.2.1. El orgánulo vesículo-vacuolar ........................................................... 72

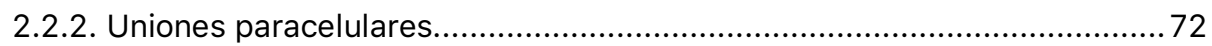

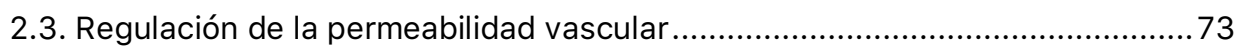

2.4. Permeabilidad vascular y migración transendotelial ......................................74

3. Endoglina..................................................................... 77

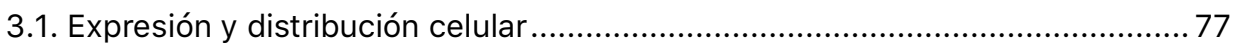

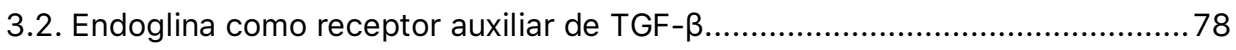

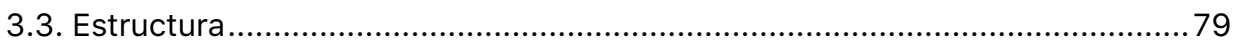

3.3.1. El dominio extracelular de endoglina ...............................................79

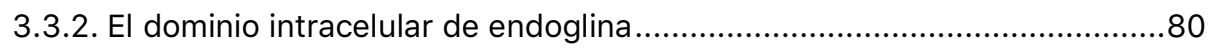

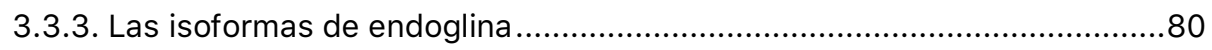

3.3.3.1. Funciones diferenciales de las isoformas de endoglina ....................82

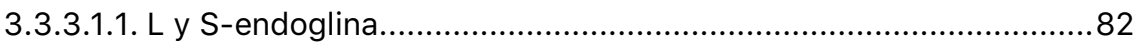

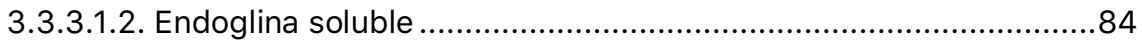

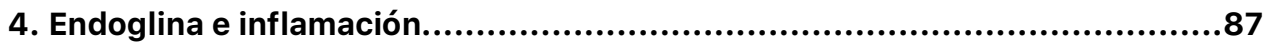

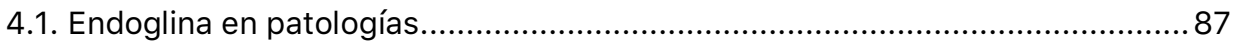

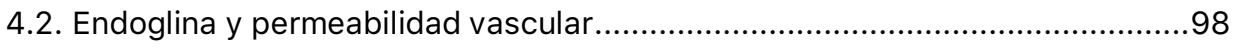

4.3. Relevancia y aplicabilidad del estudio ................................................... 100 
MATERIALES Y MÉTODOS ........................................................... 105

1. Materiales ........................................................................... 107

2. Ratones que sobreexpresan endoglina larga (L-ENG+), endoglina corta (S-

ENG+) y endoglina soluble (sEng+) 109

2.1. Caracterización de los ratones que sobreexpresan endoglina larga ( $L-E N G+)$, endoglina corta (S-ENG+) y endoglina soluble (sEng+)

2.2. Mantenimiento y manipulación de los animales

2.3. Determinación del genotipo de los ratones

3. Técnicas de experimentación animal

3.1. Extracción de sangre del seno venoso submandibular

3.2. Extracción directa de sangre del corazón.

3.3. Inyección en el seno venoso retroorbital

4. Daño pulmonar agudo inducido por LPS 119

4.1. Lipopolisacárido: propiedades y administración .119

4.2. Cirugía: lavado broncoalveolar (BAL) 120

5. Inyección intravenosa de FITC-Dextrano tras daño pulmonar agudo inducido por LPS 125

5.1. Inyección retroorbital de FITC-Dextrano 125

6. Inflamación inducida por carragenina en air pouch 127 
6.2. Modelo del air pouch

6.2.1. Día 0: Creación del pouch 128

6.2.2. Día 3: Mantenimiento del pouch 128

6.2.3. Día 6: Inyección de carragenina 129

6.2.4. Día 7: lavado del pouch 129

7. Isquemia-reperfusión renal 131

7.1. Cirugía: Isquemia renal.

8. Métodos de cultivo celular 135

8.1. Línea de células endoteliales EA.hy926 135

8.2. Técnicas básicas en cultivos celulares 135

8.2.1. Tripsinización celular. 135

8.2.2. Recuento celular 135

8.2.3. Congelación y descongelación de líneas celulares 136

9. Evaluación de la permeabilidad vascular 137

9.1. Recuento del número de células 137

9.2. Determinación de la concentración de proteínas 137

9.3. Presencia de FITC-Dextrano en el lavado broncoalveolar 137

9.4. Ratio peso húmedo/peso seco 138 
10. Análisis histológico

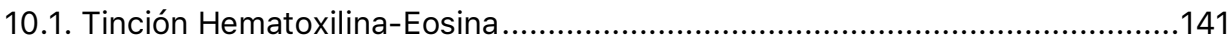

10.2. Valoración histológica cuantitativa........................................................... 142

11. Análisis del nivel de expresión de proteínas por Western blot .............. 143

11.1. Obtención de extractos de proteínas de tejidos y células ........................... 143

11.2. Determinación de la concentración de proteínas........................................... 144

11.3. Preparación de las muestras y electroforesis ......................................... 144

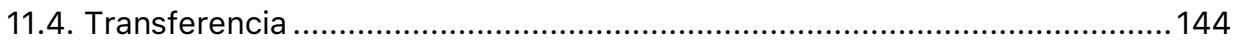

11.5. Bloqueo e incubación con los anticuerpos............................................... 145

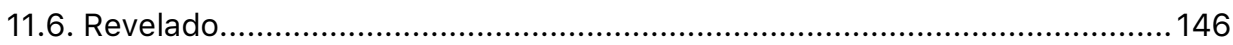

12. Análisis del nivel de expresión génica por qPCR ........................... 147

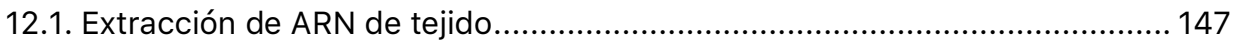

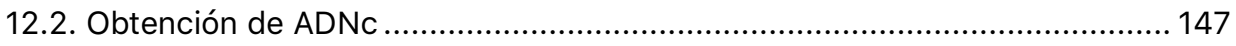

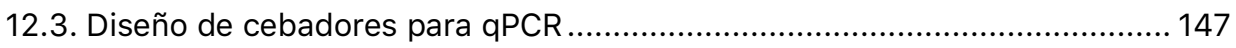

12.4. PCR cuantitativa, qPCR o PCR a tiempo real............................................. 148

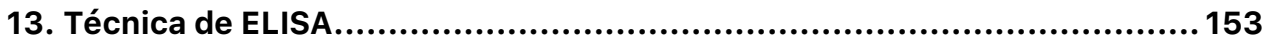

14. Tratamiento de los datos y análisis estadísticos............................. 155

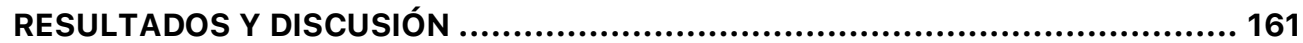




\section{Estudio del papel de las isoformas de membrana de endoglina en el proceso}

1.1. Estudio del papel de las isoformas de membrana de endoglina en el reclutamiento leucocitario 164

1.1.1. Valoración histológica del efecto de las isoformas de membrana de endoglina en el daño tisular inducido por estímulos inflamatorios 164

1.1.1.1. Alteraciones en pulmón tras tratamiento con LPS 165

1.1.1.2. Alteraciones en la piel tras tratamiento con carragenina 167

1.1.1.3. Alteraciones en riñón tras isquemia-reperfusión. 169

1.1.2. Infiltrado leucocitario 172

1.1.3. Expresión y concentración de citoquinas quimiotácticas e inflamatorias 179

1.1.3.1. Análisis de la expresión de CXCL12 179

1.1.3.2. Análisis de la expresión de IL1ß e IL6 181

1.1.3.3. Análisis de la concentración de IL6, TNFa e IL10 184

1.2. Estudio del papel de las isoformas de membrana de endoglina en la permeabilidad vascular. 192

1.2.1. Concentración de proteínas 192

1.2.2. Edema pulmonar 194

1.2.3. Evaluación de la permeabilidad vascular pulmonar al FITC-Dextrano .....194

1.2.4. Análisis de la expresión de VE-cadherina 195 
1.3. Expresión de moléculas de adhesión.

2. Estudio del papel de la endoglina soluble en el proceso inflamatorio

2.1. Estudio del efecto de endoglina soluble en el reclutamiento leucocitario .....207

2.1.1. Valoración histológica del efecto de endoglina soluble en el daño tisular inducido por estímulos inflamatorios

2.1.1.1. Alteraciones en el pulmón tras tratamiento con LPS 208

2.1.1.2. Alteraciones en la piel tras el tratamiento con carragenina. 209

2.1.1.3. Alteraciones en el riñón tras la isquemia-reperfusión 211

2.1.2. Infiltrado leucocitario. 214

2.1.3. Índice de Mieloperoxidasa (MPO)

2.1.4. Expresión y concentración de citoquinas quimiotácticas e inflamatorias 223

2.1.4.1. Análisis de la expresión de CXCL12 223

2.1.4.2. Análisis de la expresión de IL1ß e IL6 225

2.1.4.3. Análisis de la concentración de IL1ß, IL6 y TNFa 226

2.2. Estudio del efecto de la sobreexpresión de endoglina soluble en la permeabilidad vascular. 235

2.2.1. Concentración de proteínas 235

2.2.2. Edema pulmonar 237

2.2.3. Evaluación de la permeabilidad vascular pulmonar al FITC-Dextrano.....237

2.2.4. Ensayo de permeabilidad endotelial in vitro 238 
2.3. Análisis de las moléculas de adhesión

2.3.1. Expresión de moléculas de adhesión.

2.3.2. Niveles de las moléculas de adhesión .

DISCUSIÓN GENERAL 


\section{1. ÍNDICE DE FIGURAS}

Figura 1. Condiciones fisiológicas en la inflamación aguda vs inflamación crónica.

Figura 2. Representación simplificada de la respuesta inflamatoria ante lesión. .50

Figura 3. Representación de las interacciones leucocito-endotelio, y las principales moléculas implicadas.

Figura 4. Representación de la migración leucocitaria transendotelial, a través de los espacios entre pericitos.

Figura 5. Diferencias entre la permeabilidad vascular en condiciones fisiológicas y en condiciones inflamatorias.

Figura 6. Estructura de las distintas isoformas de endoglina: L-endoglina, S-endoglina y endoglina soluble.

Figura 7. La señalización intracelular de las isoformas de endoglina .84

Figura 8. Representación de un posible papel de endoglina de membrana en la extravasación leucocitaria.

Figura 9. Construcción genética para la generación de los ratones L-ENG+, S-ENG+ y sEng+. Adaptado de Oujo et al, 2014

Figura 10. Ratones transgénicos utilizados. Líneas de ratones utilizados, en el código de colores empleado en este estudio

Figura 11. Expresión de endoglina humana en tejido. A, B. Análisis de la expresión del ARNm de endoglina total (A) y S-endoglina humanas (B) en tejido de ratones WT, 
L-ENG+, S-ENG+, analizada mediante qPCR. C, niveles de endoglina humana en tejido de ratones WT, L-ENG+, S-ENG+, analizados mediante Western blot.

Figura 12. Concentración de endoglina humana en plasma. Análisis de la concentración de endoglina humana en el plasma de ratones WT y sEng+, analizado mediante ELISA y expresado en $\mathrm{ng} / \mathrm{ml}$.

Figura 13. Inyección en el seno venoso retroorbital.

Figura 14. Cámara de nebulización empleada. 120

Figura 15. Procedimiento y material utilizados para el lavado broncoalveolar por intubación traqueal. 122

Figura 16. Cronograma del modelo de daño pulmonar inducido por LPS 123

Figura 17. Cronograma del modelo de Inyección intravenosa de FITC-Dextrano tras daño pulmonar agudo inducido por LPS 126

Figura 18. Air pouch tras inyección subcutánea de $3 \mathrm{ml}$ de aire estéril 128

Figura 19. Cronograma del modelo de inflamación inducida por carragenina en air pouch. 130

Figura 21. Tejido correspondiente al air pouch, recogido para análisis histológicos... 130

Figura 21. Procedimiento para la isquemia-reperfusión renal. 132

Figura 22. Cronograma del modelo de isquemia-reperfusión renal..... 133

Figura 23. Esquema del experimento de permeabilidad endotelial con transwell 139

Figura 24. Estudio histológico del pulmón de ratones WT, L-ENG+ y S-ENG+. Imágenes representativas de la tinción H\&E correspondiente a pulmones de ratones WT, L- 
ENG+ y S-ENG+, control y tratados con LPS. Micrografías obtenidas mediante cámara acoplada a un microscopio óptico con 200 y 400 aumentos, respectivamente. WT $(n=6)$, L-ENG+ $(n=6)$ y $S-E N G+(n=6)$. El círculo amarillo marca una zona de infiltrado leucocitario.

Figura 25. Índice de infiltrado pulmonar en ratones WT, L-ENG+ y S-ENG+. Valoración histológica cuantitativa del infiltrado pulmonar en ratones WT, L-ENG+ y S-ENG+, control y tratados con LPS. Cada barra representa la media \pm EEM. WT $(n=6), L-$ ENG $+(n=6)$ y S-ENG $+(n=6)$. Test estadístico ANOVA de doble vía, $+p<0,0001$ vs control, *p<0,005 vs LPS WT.

Figura 26. Estudio histológico de la piel del air pouch, de ratones WT, L-ENG+ y SENG+. Imágenes representativas de la tinción H\&E correspondiente a la piel de la zona del air pouch de ratones WT, L-ENG+ y S-ENG+, control y tratados con carragenina. Micrografías obtenidas mediante cámara acoplada a un microscopio óptico con 200 y 400 aumentos, respectivamente. WT $(n=6), L-E N G+(n=5)$ y SENG+ $(n=6)$. El círculo amarillo marca una zona de infiltrado leucocitario. 168

Figura 27. Índice de infiltrado en la piel del air pouch en ratones WT, L-ENG+ y SENG+. Valoración histológica cuantitativa del infiltrado pulmonar en ratones WT, LENG+ y S-ENG+, control y tratados con carragenina. Cada barra representa la media \pm EEM. WT $(n=6), L-E N G+(n=5)$ y S-ENG $+(n=6)$. Test estadístico ANOVA de doble vía, $+p<0,0001$ vs control 169

Figura 28. Estudio histológico del riñón de ratones WT, L-ENG+ y S-ENG+. Imágenes representativas de la tinción H\&E correspondiente al riñón de ratones WT, L-ENG+ y S-ENG+, control y sometidos a isquemia-reperfusión. Micrografías obtenidas mediante cámara acoplada a un microscopio óptico con 200 y 400 aumentos, respectivamente. WT $(n=6), L-E N G+(n=5)$ y S-ENG+ $(n=6)$. El círculo azul marca una zona de necrosis tubular.

Figura 29. Índice de necrosis tubular en el riñón de ratones WT, L-ENG+ y S-ENG+. Valoración histológica cuantitativa del infiltrado pulmonar en ratones WT, L-ENG+ 
y S-ENG+, control y sometidos a isquemia-reperfusión. Cada barra representa la media \pm EEM. WT $(n=6), L-E N G+(n=5)$ y S-ENG+ $(n=6)$. Test estadístico ANOVA de doble vía, $+p<0,0001$ vs control, * $p<0,05$ vs isquemia WT.

Figura 30. Concentración de leucocitos en el lavado broncoalveolar en ratones WT, LENG+ y S-ENG+. Análisis de la concentración de leucocitos en el BAL de ratones WT, L-ENG+ y S-ENG+, control y tratados con LPS. Los datos se expresan por $10 \mathrm{e}^{5} / \mathrm{ml}$. Cada barra representa la media \pm EEM. WT $(n=10), \mathrm{L}-\mathrm{ENG}+(\mathrm{n}=10)$ y SENG $+(n=10)$. Test estadístico ANOVA de doble vía: $+p<0,0001$ vs control, ${ }^{*} p<0,01$ vs LPS WT.

Figura 31. Concentración de leucocitos en el lavado del air pouch en ratones WT, LENG+ y S-ENG+. Análisis de la concentración de leucocitos en el lavado del air pouch de ratones WT, L-ENG+ y S-ENG+, tratados con carragenina. Los valores se expresan en porcentaje, normalizados respecto a los WT. Cada barra representa la media \pm EEM. WT $(n=6), L-E N G+(n=8)$ y S-ENG $+(n=7)$.

Figura 32. Análisis de la expresión de CD45 en ratones WT, L-ENG+ y S-ENG+. Análisis mediante qPCR de los niveles de expresión de CD45 en pulmón $(A, B)$ y en riñón $(C, D)$ de ratones WT, L-ENG+ y S-ENG+, control, tratados con LPS o isquemiareperfusión renal, respectivamente. Los valores se representan como el logaritmo en base dos de la expresión relativa de cada muestra con respecto de las muestras WT. Se representa un box plot 10-90 percentil. WT $(n=5), L-E N G+(n=5)$ y S-ENG+ $(n=5)$. Test estadístico ANOVA de doble vía: $(A, B)+p<0,0001$ vs control, $(C)$ $* p<0,05$ vs control WT, $\# p<0,0001$ vs control L-ENG+, $(D)+p<0,05$ vs control, $* p<0,01$ vs control WT, $\# p<0,0001$ vs control S-ENG+.

Figura 33. Análisis de la expresión de CXCL12 en ratones WT, L-ENG+ y S-ENG+. Análisis mediante qPCR de los niveles de expresión de CXCL12 en pulmón $(A, B)$ y en riñón $(C, D)$ de ratones WT, L-ENG+ y S-ENG+, control, tratados con LPS o isquemia-reperfusión renal, respectivamente. Los valores se representan como el logaritmo en base dos de la expresión relativa de cada muestra con respecto de las muestras WT. Se representa un box plot 10-90 percentil. En pulmón: WT $(n=5)$, 
L-ENG+ $(n=5)$ y S-ENG+ $(n=5)$, en riñón: WT $(n=5), L-E N G+(n=4)$ y S-ENG+ $(n=5)$. Test estadístico ANOVA de doble vía: $+p<0,005$ vs control. ${ }^{*} p<0,01$ vs WT, respectivamente.

Figura 34. Análisis de la expresión de IL1ß en ratones WT, L-ENG+ y S-ENG+. Análisis mediante qPCR de los niveles de expresión de IL1 $\beta$ en pulmón $(A, B)$ y en riñón $(C$, D) de ratones WT, L-ENG+ y S-ENG+, control, tratados con LPS o isquemiareperfusión renal, respectivamente. Los valores se representan como el logaritmo en base dos de la expresión relativa de cada muestra con respecto de las muestras WT. Se representa un box plot 10-90 percentil. En pulmón: WT ( $n=5)$, L-ENG+ $(n=5)$ y $S-E N G+(n=5)$, en riñón: WT $(n=5), L-E N G+(n=4)$ y $S-E N G+(n=4)$. Test estadístico ANOVA de doble vía, $+p<0,005$ vs control. $(B) * p<0,05$ vs LPS WT, $\# p<0,0001$ vs control S-ENG+. (C)*p<0,0001 vs control WT, $\# p<0,0001$ vs control L-ENG+. (D)*p<0,0005 vs control WT

Figura 35. Análisis de la expresión de IL6 en ratones WT, L-ENG+ y S-ENG+. Análisis mediante qPCR de los niveles de expresión de IL6 en pulmón $(A, B)$ y en riñón $(C$, D) de ratones WT, L-ENG+ y S-ENG+, control, tratados con LPS o isquemiareperfusión renal, respectivamente. Los valores se representan como el logaritmo en base dos de la expresión relativa de cada muestra con respecto de las muestras WT. Se representa un box plot 10-90 percentil. En pulmón: WT ( $n=5)$, L-ENG+ $(n=5)$ y S-ENG+ $(n=5)$, en riñón: WT $(n=4), L-E N G+(n=5)$ y S-ENG+ $(n=4)$. Test estadístico ANOVA de doble vía, $(A)+p<0,0001$ vs control, $(B)+p<0,0001$ vs control, ${ }^{*} p<0,05$ vs LPS WT, $\# p<0,000$, vs control S-ENG+, $(C)+p<0,05$ vs control, $* p<0,05$ vs isquemia WT, (D) ${ }^{*} p<0,01$ vs isquemia WT, $\# p<0,0001$ vs control SENG+. 183

Figura 36. Concentración de IL6 en el lavado broncoalveolar y en plasma de ratones WT, L-ENG+ y S-ENG+. Análisis de la concentración de IL6 en el BAL ( $A, B$ ) y en el plasma $(C, D)$ de ratones WT, L-ENG+ y S-ENG+, control y tratados con LPS, analizado mediante ELISA. Los valores se expresan como pg/ml. Cada barra representa la media \pm EEM. En BAL: WT $(n=4), L-E N G+(n=5)$ y S-ENG+ $(n=6)$, en plasma: WT $(n=4), L-E N G+(n=7)$ y S-ENG $+(n=6)$. Test estadístico ANOVA de 
doble vía, $(A)+p<0,0001$ vs control, $(B)+p<0,0005$ vs control, * $p<0,005$ vs LPS WT $(C)+p<0,0005$ vs control, (D) $+p<0,001$ vs control, ${ }^{*} p<0,005$ vs control S-ENG+.

Figura 37. Concentración de TNFa en el lavado broncoalveolar y en plasma en ratones WT, L-ENG+ y S-ENG+. Análisis de la concentración de TNFa en el BAL $(A, B)$ y en el plasma (C, D) de ratones WT, L-ENG+ y S-ENG+, control y tratados con LPS, analizado mediante ELISA. Los valores se expresan como pg/ml. Cada barra representa la media \pm EEM. En BAL: WT $(n=4), L-E N G+(n=5)$ y S-ENG+ $(n=5)$, en plasma: WT $(n=7), L-E N G+(n=5)$ y S-ENG $+(n=7)$. Test estadístico ANOVA de doble vía, $(A)+p<0,0001$ vs control, $(B)+p<0,0001$ vs control, ${ }^{*} p<0,005$ vs LPS WT $(C)+p<0,001$ vs control, (D) $+p<0,005$ vs control. 186

Figura 38. Concentración de IL10 en el lavado broncoalveolar y en plasma en ratones WT, L-ENG+ y S-ENG+. Análisis de la concentración de IL10 en el BAL ( $A, B)$ y en el plasma (C, D) de ratones WT, L-ENG+ y S-ENG+, control y tratados con LPS, analizado mediante ELISA. Los valores se expresan como pg/ml. Cada barra representa la media \pm EEM. En BAL y plasma: WT $(n=5), L-E N G+(n=5)$ y S-ENG+ $(n=5)$. Test estadístico ANOVA de doble vía, $+p<0,0001$ vs control.

Figura 39. Figura resumen comparativa. Se muestran algunos de los resultados obtenidos al valorar los efectos de la sobreexpresión de la isoforma larga de endoglina de membrana, tanto en condiciones control como tras inducción inflamatoria, no observándose diferencias significativas. Para comprobar si el papel de endoglina de membrana se debe al dominio intracelular o al extracelular, se realizaron los mismos experimentos en ratones que sobreexpresan la isoforma corta de endoglina de membrana, por lo que las diferencias se deben a la ausencia de dominio intracelular. (A), Imágenes representativas de la tinción H\&E correspondiente a pulmones de ratones L-ENG+ y S-ENG+, control y tratados con LPS. Micrografías obtenidas mediante cámara acoplada a un microscopio óptico con 400 aumentos. L-ENG+ $(n=6)$ y S-ENG+ $(n=6)$. (B), Concentración de leucocitos en el lavado broncoalveolar en ratones, WT, L-ENG+ y S-ENG+, control y tratados con LPS. Los datos se expresan por $10 \mathrm{e}^{5} / \mathrm{ml}$. Cada barra representa la 
media \pm EEM. WT $(n=10), L-E N G+(n=10)$ y S-ENG+ $(n=10)$. Test estadístico ANOVA de doble vía: $+p<0,0001$ vs control, ${ }^{*} p<0,01$ vs LPS WT. (C), Concentración de IL6 en el lavado broncoalveolar de ratones WT, L-ENG+ y SENG+ control y tratados con LPS, analizado mediante ELISA. Los valores se expresan como pg/ml. Cada barra representa la media \pm EEM. WT $(n=4), L-E N G+$ $(n=5)$ y S-ENG+ $(n=6)$. Test estadístico ANOVA de doble vía, $(A)+p<0,0001$ vs control, (B) $+p<0,0005$ vs control, *p<0,005 vs LPS WT. (D), Concentración de TNFa en el lavado broncoalveolar en ratones WT, L-ENG+ y S-ENG+, control y tratados con LPS, analizado mediante ELISA. Los valores se expresan como pg/ml. Cada barra representa la media \pm EEM. WT $(n=4), L-E N G+(n=5)$ y S-ENG $+(n=5)$. Test estadístico ANOVA de doble vía, $(A)+p<0,0001$ vs control, $(B)+p<0,0001$ vs control, ${ }^{*} p<0,005$ vs LPS WT. 189

Figura 40. Concentración de proteínas en el lavado broncoalveolar en ratones WT, LENG+ y S-ENG+. Determinación de la concentración de proteínas en el BAL de ratones WT, L-ENG+ y S-ENG+, control y tratados con LPS. Los valores se expresan como $\mathrm{mg} / \mathrm{ml}$. Cada barra representa la media \pm EEM. WT ( $\mathrm{n=10}), \mathrm{L}-\mathrm{ENG}+$ $(n=10)$ y S-ENG $+(n=10)$. Test estadístico ANOVA de doble vía, $+p<0,0001$ vs control.

Figura 41. Concentración de proteínas en el lavado del air pouch en ratones WT, LENG+ y S-ENG+. Determinación de la concentración de proteínas en el lavado del air pouch de ratones WT, L-ENG+ y S-ENG+, control y tratados con carragenina. Los valores se expresan como $\mathrm{mg} / \mathrm{ml}$. Cada barra representa la media \pm EEM. WT $(n=6), L-E N G+(n=5)$ y S-ENG+ $(n=4)$. Test estadístico ANOVA de doble vía, $+p<0,0001$ vs control.

Figura 42. Análisis del edema pulmonar en ratones WT, L-ENG+ y S-ENG+. Análisis del edema pulmonar mediante el ratio peso húmedo/peso seco, en pulmones de ratones WT, L-ENG+ y S-ENG+, tratados con LPS. Cada barra representa la media \pm EEM. WT $(n=6), L-E N G+(n=5)$ y S-ENG+ $(n=5)$ 194 
Figura 43. Concentración de FITC-Dextrano en el lavado broncoalveolar en ratones WT, L-ENG+ y S-ENG+. Determinación de la concentración de FITC-Dextrano en el BAL de ratones WT, L-ENG+ y S-ENG+, tratados con LPS y a los que se les ha inoculado FITC-Dextrano retroorbital. Los valores se expresan como el ratio fluorescencia en el lavado broncoalveolar/fluorescencia en plasma. Cada barra representa la media \pm EEM. WT $(n=6), L-E N G+(n=5)$ y S-ENG+ $(n=5)$

Figura 44. Análisis de la expresión de CDH5 en ratones WT, L-ENG+ y S-ENG+.

Análisis mediante qPCR de los niveles de expresión de CDH5 en pulmón $(A, B)$ y en riñón $(C, D)$ de ratones WT, L-ENG+ y S-ENG+, control, tratados con LPS o isquemia-reperfusión renal, respectivamente. Los valores se representan como el logaritmo en base dos de la expresión relativa de cada muestra con respecto de las muestras WT. Se representa un box plot 10-90 percentil. WT $(n=5), L-E N G+$ $(n=5)$ y S-ENG $+(n=5)$. Test estadístico ANOVA de doble vía, $(A) * p<0,005$ vs WT, (C) $+p<0,0001$ vs control, ${ }^{*} p<0,05$ vs $W T,(D)+p<0,0001$ vs control, ${ }^{*} p<0,005$ vs WT. 196

Figura 45. Análisis de la expresión de SELE en ratones WT, L-ENG+ y S-ENG+. Análisis mediante qPCR de los niveles de expresión de SELE en pulmón $(A, B)$ y en riñón $(C$, D) de ratones WT, L-ENG+ y S-ENG+, control, tratados con LPS o isquemiareperfusión renal, respectivamente. Los valores se representan como el logaritmo en base dos de la expresión relativa de cada muestra con respecto de las muestras WT. Se representa un box plot 10-90 percentil. En pulmón: WT ( $n=5)$, L-ENG+ $(n=5)$ y S-ENG+ $(n=5)$, en riñón: WT $(n=5), L-E N G+(n=4)$ y S-ENG+ $(n=4)$. Test estadístico ANOVA de doble vía, $(A)+p<0,01$ vs control, $(C)+p<0,005$ vs control, ${ }^{*} p<0,05$ vs control WT, $\# p<0,0001$ vs control $S-E N G+,(D)+p<0,001$ vs control, ${ }^{*} p<0,05$ vs control WT, $\# p<0,0001$ vs control S-ENG+....

Figura 46. Análisis de la expresión de VCAM-1 en ratones WT, L-ENG+ y S-ENG+. Análisis mediante qPCR de los niveles de expresión de VCAM-1 en pulmón ( $A, B)$ y en riñón $(C, D)$ de ratones WT, L-ENG+ y S-ENG+, control, tratados con LPS o isquemia-reperfusión renal, respectivamente. Los valores se representan como el logaritmo en base dos de la expresión relativa de cada muestra con respecto de 
las muestras WT. Se representa un box plot 10-90 percentil. En pulmón: WT $(n=5)$, L-ENG+ $(n=5)$ y S-ENG+ $(n=5)$, en riñón: WT $(n=4), L-E N G+(n=5)$ y S-ENG+ $(n=5)$. Test estadístico ANOVA de doble vía, $(A)+p<0,0005$ vs control, $(B)+p<0,001$ vs control, $(C)+p<0,0001$ vs control, $\# p<0,05$ vs control L-ENG+, (D) $+p<0,0001$ vs control, $* p<0,001$ vs WT, $\# p<0,0001$ vs control S-ENG+ 200

Figura 47. Análisis de la expresión de ICAM-1 en ratones WT, L-ENG+ y S-ENG+. Análisis mediante qPCR de los niveles de expresión de ICAM-1 en pulmón $(A, B)$ y en riñón $(C, D)$ de ratones WT, L-ENG+ y S-ENG+, control, tratados con LPS o isquemia-reperfusión renal, respectivamente. Los valores se representan como el logaritmo en base dos de la expresión relativa de cada muestra con respecto de las muestras WT. Se representa un box plot 10-90 percentil. WT $(n=5), L-E N G+$ $(n=5)$ y $S-E N G+(n=5)$. Test estadístico ANOVA de doble vía, $(A)+p<0,005$ vs control, $(B)+p<0,005$ vs control, $* p<0,01$ vs LPS $W T,(D) * p<0,05$ vs WT.

Figura 48. Análisis de la expresión de CD31 en ratones WT, L-ENG+ y S-ENG+. Análisis mediante qPCR de los niveles de expresión de CD31 en pulmón $(A, B)$ y en riñón (C, D) de ratones WT, L-ENG+ y S-ENG+, control, tratados con LPS o isquemiareperfusión renal, respectivamente. Los valores se representan como el logaritmo en base dos de la expresión relativa de cada muestra con respecto de las muestras WT. Se representa un box plot 10-90 percentil. En pulmón: WT ( $n=5)$, L-ENG+ $(n=5)$ y S-ENG+ $(n=5)$, en riñón: WT $(n=5), L-E N G+(n=5)$ y S-ENG+ $(n=4)$. Test estadístico ANOVA de doble vía, (A)*p<0,01 vs WT, $(C)+p<0,005$ vs control, (D) $+p<0,001$ vs control.

Figura 49. Estudio histológico del pulmón de ratones WT y sEng+. Imágenes representativas de la tinción H\&E correspondiente a pulmones de ratones WT y sEng+, control y tratados con LPS. Micrografías obtenidas mediante cámara acoplada a un microscopio óptico con 200 y 400 aumentos, respectivamente. WT $(n=5)$ y sEng $+(n=5)$. El círculo amarillo marca una zona de infiltrado leucocitario. 
Figura 50. Índice de infiltrado pulmonar en ratones WT y sEng+. Valoración histológica cuantitativa del infiltrado pulmonar en ratones WT y sEng+, control y tratados con LPS. Cada barra representa la media \pm EEM. WT $(n=5)$ y $s E n g+(n=5)$. Test estadístico ANOVA de doble vía, $+p<0,0001$ vs control 209

Figura 51. Estudio histológico de la piel del air pouch, de ratones WT y sEng+. Imágenes representativas de la tinción H\&E correspondiente a la piel de la zona del air pouch de ratones WT y sEng+, control y tratados con carragenina. Micrografías obtenidas mediante cámara acoplada a un microscopio óptico con 200 y 400 aumentos, respectivamente. WT $(n=5)$ y sEng+ $(n=5)$. El círculo amarillo marca una zona de infiltrado leucocitario. 210

Figura 52. Índice de infiltrado en la piel del air pouch en ratones WT y sEng+.

Valoración histológica cuantitativa del infiltrado pulmonar en ratones WT y sEng+, control y tratados con carragenina. Cada barra representa la media \pm EEM. WT $(n=5)$ y sEng $+(n=5)$. Test estadístico ANOVA de doble vía, $+p<0,0001$ vs control, $* p<0,05$ vs carragenina WT.

Figura 53. Estudio histológico del riñón de ratones WT y sEng+. Imágenes representativas de la tinción H\&E correspondiente al riñón de ratones WT y sEng+, control y sometidos a isquemia-reperfusión. Micrografías obtenidas mediante cámara acoplada a un microscopio óptico con 200 y 400 aumentos, respectivamente. WT $(n=6)$ y sEng+ $(n=6)$. El círculo amarillo marca una zona de infiltrado leucocitario y el azul necrosis tubular.

Figura 54. Índice de necrosis tubular e infiltrado en el riñón de ratones WT y sEng+. Valoración histológica cuantitativa, de la necrosis tubular $(A)$ y el infiltrado renal (B) en ratones WT y sEng+, control y sometidos a isquemia-reperfusión. Cada barra representa la media \pm EEM. WT $(n=6)$ y sEng+ $(n=6)$. Test estadístico ANOVA de doble vía: $(A)+p<0,0001$ vs control, $(B)+p<0,005$ vs control, ${ }^{*} p<0,01$ vs isquemia WT. 
Figura 55. Concentración de leucocitos en el lavado broncoalveolar en ratones WT y sEng+. Análisis de la concentración de leucocitos en el BAL de ratones WT y sEng+, control y tratados con LPS. Los datos se expresan por $10 e^{5} / \mathrm{ml}$. Cada barra representa la media \pm EEM. WT $(n=6)$ y sEng $+(n=6)$. Test estadístico ANOVA de doble vía: $+p<0,0001$ vs control, * $p<0,005$ vs LPS WT, $\# p<0,005$ vs control sEng+.

Figura 56. Concentración de leucocitos en el lavado del air pouch en ratones WT y sEng+. Análisis de la concentración de leucocitos en el lavado del air pouch de ratones WT y sEng+, tratados con carragenina. Los valores se expresan en porcentaje, normalizados respecto a los WT. Cada barra representa la media \pm EEM. WT $(n=10)$ y sEng+ $(n=10)$. Test estadístico t de student: *p<0,0005 vs WT.

Figura 57. Concentración de linfocitos y neutrófilos en el lavado del air pouch en ratones WT y sEng+. Análisis de la concentración de linfocitos $(A, B)$ y neutrófilos $(C, D)$ en el lavado del air pouch de ratones WT y sEng+, tratados con carragenina. Los valores se expresan en porcentaje, normalizados respecto a los WT. Cada barra representa la media \pm EEM. WT $(n=10)$ y sEng $+(n=10)$. Test estadístico t de student: $(A) * p<0,005$ vs WT, $(B) * p<0,01$ vs WT.

Figura 58. Análisis de la expresión de CD45 en ratones WT y sEng+. Análisis mediante qPCR de los niveles de expresión de CD45 en pulmón (A) y en riñón (B) de ratones WT y sEng+, control, tratados con LPS o isquemia-reperfusión renal, respectivamente. Los valores se representan como el logaritmo en base dos de la expresión relativa de cada muestra con respecto de las muestras WT. Se representa un box plot 10-90 percentil. WT $(n=5)$ y sEng+ $(n=5)$

Figura 59. Actividad mieloperoxidasa ratones WT y sEng+. Determinación de la actividad mieloperoxidasa en ratones WT y sEng+, en pulmón $(A)$ y riñón $(B)$ de ratones WT y sEng+, control, tratados con LPS o isquemia-reperfusión renal, analizado mediante ELISA. Los valores se expresan como U/mg tejido. Cada barra representa la media \pm EEM. En pulmón: WT $(n=5)$ y sEng+ $(n=4)$, en riñón: WT 
$(n=6)$ y sEng+ $(n=5)$. Test estadístico ANOVA de doble vía: $(A)+p<0,01$ vs control, $(B)+p<0,0001$ vs control, ${ }^{*} p<0,05$ vs isquemia $W T, \# p<0,05$ vs control sEng +.218

Figura 60. Análisis de la expresión de CXCL12 en ratones WT y sEng+. Análisis mediante qPCR de los niveles de expresión de CXCL12 en pulmón ( $A$ ) y en riñón (B) de ratones WT y sEng+, control, tratados con LPS o isquemia-reperfusión renal, respectivamente. Los valores se representan como el logaritmo en base dos de la expresión relativa de cada muestra con respecto de las muestras WT. Se representa un box plot 10-90 percentil. WT $(n=5)$ y sEng+ $(n=5)$. Test estadístico ANOVA de doble vía: $(B)+p<0,0001$ vs control, $* p<0,05$ vs WT. 224

Figura 61. Análisis de la expresión de IL1 $\beta$ e IL6 en ratones WT y sEng+. Análisis mediante qPCR de los niveles de expresión de IL1 $\beta$ ( $A, B)$ e IL6 (C, D) en pulmón y en riñón de ratones WT y sEng+, control, tratados con LPS o isquemia-reperfusión renal, respectivamente. Los valores se representan como el logaritmo en base dos de la expresión relativa de cada muestra con respecto de las muestras WT. Se representa un box plot 10-90 percentil. WT $(n=5)$ y sEng+ $(n=5)$. Test estadístico ANOVA de doble vía: $+p<0,0001$ vs control. 225

Figura 62. Concentración de IL1 $\beta$, IL6 y TNFa en pulmón y riñón en ratones WT y sEng+. Análisis de la concentración de IL1 $\beta$, IL 6 y TNFa en pulmón ( $A-C)$ y en riñón (D-E) de ratones WT y sEng+, control, tratados con LPS o isquemia-reperfusión renal, analizado mediante ELISA. Los valores se expresan como pg/mg tejido. Cada barra representa la media \pm EEM. WT $(n=5), L-E N G+(n=5)$ y S-ENG $+(n=5)$. Test estadístico ANOVA de doble vía: $(A, C, E)+p<0,005$ vs control, $(B, D, F)+p<0,01$ vs control.

Figura 63. Concentración de IL1 $\beta$, IL6 y TNFa en el lavado broncoalveolar y en el lavado del pouch de ratones WT y sEng+. Análisis de la concentración de IL1ß, IL6 y TNFa en el BAL $(A, C, E)$ y en el lavado del pouch $(B, D, F)$ de ratones WT y sEng+, control, tratados con LPS o carragenina, analizado mediante ELISA. Los valores se expresan como $\mathrm{pg} / \mathrm{ml}$. Cada barra representa la media \pm EEM. WT $(n=5)$, L-ENG+ $(n=5)$ y S-ENG+ $(n=5)$. Test estadístico ANOVA de doble vía: $(A)+p<$ 
0,0001 vs control, $* p<0,05$ vs LPS WT, $(B)+p<0,01$ vs control, $(C)+p<0,0001$ vs control, ${ }^{*} p<0,05$ vs LPS WT, $\# p<0,001$ vs control sEng $+,(D)+p<0,01$ vs control, ${ }^{*} p<0,05$ vs LPS WT, $(E)+p<0,0001$ vs control, $(F)+p<0,05$ vs control.

Figura 64. Concentración de IL1 $\beta$, IL6 y TNFa en el plasma de ratones WT y sEng+. Análisis de la concentración de IL1 $\beta$ (A), IL6 (B) y TNFa (C) en el plasma de ratones WT y sEng+, control, tratados con LPS o carragenina, analizado mediante ELISA. Los valores se expresan como $\mathrm{pg} / \mathrm{ml}$. Cada barra representa la media \pm EEM. WT $(n=4), L-E N G+(n=4)$ y S-ENG+ $(n=4)$. Test estadístico ANOVA de doble vía: $(A)+p<0,005$ vs control, $(B)+p<0,0001$ vs control.

Figura 65. Concentración de proteínas en el lavado broncoalveolar y en el lavado del air pouch en ratones WT y sEng+. Determinación de la concentración de proteínas en el BAL ( $A$ ) y en el lavado del air pouch (B) de ratones WT y sEng+, control y tratados con LPS o carragenina, respectivamente. Los valores se expresan como $\mathrm{mg} / \mathrm{ml}$. Cada barra representa la media \pm EEM. En el BAL: WT $(n=5)$ y sEng $+(n=4)$, en el lavado del air pouch: WT $(n=10)$ y sEng+ $(n=10)$. Test estadístico ANOVA de doble vía: $(A)+p<0,0001$ vs control, ${ }^{*} p<0,01$ vs LPS WT, $\# p<0,05$ vs control sEng+, (B) $+p<0,0001$ vs control.

Figura 66. Análisis del edema pulmonar en ratones WT y sEng+. Análisis del edema pulmonar mediante el ratio peso húmedo/peso seco, en pulmones de ratones WT y $s E n g+$, tratados con LPS. Cada barra representa la media \pm EEM. WT $(n=5)$ y $\mathrm{sEng}+(\mathrm{n}=5)$. Test estadístico t de student: ${ }^{*} \mathrm{p}<0,0005$ vs WT.

Figura 67. Concentración de FITC-Dextrano en el lavado broncoalveolar en ratones WT y sEng+. Determinación de la concentración de FITC-Dextrano en el BAL de ratones WT y sEng+, tratados con LPS y a los que se les ha inoculado FITCDextrano retroorbital. Los valores se expresan como el ratio fluorescencia en el lavado broncoalveolar/fluorescencia en plasma. Cada barra representa la media \pm EEM. WT $(n=5)$ y sEng+ $(n=5)$. Test estadístico t de student: ${ }^{*} p<0,05$ vs WT...238 
Figura 68. Ensayo de permeabilidad endotelial in vitro. Estudio de la permeabilidad de FITC-Dextrano a una monocapa endotelial in vitro. Se representa el tanto por ciento de fluorescencia, proveniente del FITC-Dextrano que atraviesa la monocapa endotelial y llega al compartimento inferior del transwell en presencia de sEng, con respecto a las células control. Se ha medido fluorescencia a las 0, 4, 16, 20 y 24 horas. Los resultados representan la media de 3 experimentos en cada caso. ...239

Figura 69. Análisis de la expresión de CDH5 en ratones WT y sEng+. Análisis mediante qPCR de los niveles de expresión de $\mathrm{CDH} 5$ en pulmón $(A)$ y en riñón $(B)$ de ratones WT y sEng+, control, tratados con LPS o isquemia-reperfusión renal, respectivamente. Los valores se representan como el logaritmo en base dos de la expresión relativa de cada muestra con respecto de las muestras WT. Se representa un box plot 10-90 percentil. WT $(n=5)$ y sEng $(n=6)$. Test estadístico ANOVA de doble vía: $(A)+p<0,0001$ vs control, ${ }^{*} p<0,01$ vs $W T,(B)+p<0,05$ vs control.

Figura 70. Análisis de los niveles de VE-cadherina en ratones WT y sEng+. Análisis de los niveles de VE-cadherina en el pulmón de ratones WT y sEng+, control y tratados con LPS, analizados por Western blot. Cada barra representa la media \pm EEM. WT $(n=5)$ y sEng+ $(n=5)$. Test estadístico ANOVA de doble vía: $+p<0,0001$ vs control.

Figura 71. Análisis de la expresión de SELE en ratones WT y sEng+. Análisis mediante qPCR de los niveles de expresión de SELE en pulmón $(A)$ y en riñón (B) de ratones WT y sEng+, control, tratados con LPS o isquemia-reperfusión renal, respectivamente. Los valores se representan como el logaritmo en base dos de la expresión relativa de cada muestra con respecto de las muestras WT. Se representa un box plot 10-90 percentil. WT $(n=5)$ y $s E n g+(n=5)$, en riñón: WT $(n=5)$ y sEng $+(n=6)$. Test estadístico ANOVA de doble vía: $(A) * p<0,001$ vs control WT, $\# p<0,05$ vs control sEng $+,(B)+p<0,0001$ vs control, $* p<0,001$ vs control WT, $\# p<0,05$ vs control sEng+. 
Figura 72. Análisis de la expresión de VCAM-1 en ratones WT y sEng+. Análisis mediante qPCR de los niveles de expresión de VCAM-1 en pulmón (A) y en riñón (B) de ratones WT y sEng+, control, tratados con LPS o isquemia-reperfusión renal, respectivamente. Los valores se representan como el logaritmo en base dos de la expresión relativa de cada muestra con respecto de las muestras WT. Se representa un box plot 10-90 percentil. WT $(n=5)$ y sEng $(n=5)$. Test estadístico ANOVA de doble vía: $(B)+p<0,0001$ vs control, $* p<0,01$ vs isquemia WT, $\# p<0,005$ vs control sEng+.....

Figura 73. Análisis de la expresión de ICAM-1 en ratones WT y sEng+. Análisis mediante qPCR de los niveles de expresión de ICAM-1 en pulmón (A) y en riñón (B) de ratones WT y sEng+, control, tratados con LPS o isquemia-reperfusión renal, respectivamente. Los valores se representan como el logaritmo en base dos de la expresión relativa de cada muestra con respecto de las muestras WT. Se representa un box plot 10-90 percentil. WT $(n=5)$ y sEng+ $(n=5)$. Test estadístico ANOVA de doble vía: $(B)+p<0,0001$ vs control.

Figura 74. Análisis de la expresión de CD31 en ratones WT y sEng+. Análisis mediante qPCR de los niveles de expresión de CD31 en pulmón $(A)$ y en riñón $(B)$ de ratones WT y sEng+, control, tratados con LPS o isquemia-reperfusión renal, respectivamente. Los valores se representan como el logaritmo en base dos de la expresión relativa de cada muestra con respecto de las muestras WT. Se representa un box plot 10-90 percentil. En pulmón: WT $(n=5)$ y sEng+ $(n=5)$, en riñón: WT $(n=4)$ y sEng+ $(n=6)$. Test estadístico ANOVA de doble vía: $(A)+p<0,0001$ vs control, $(B) * p<0,05$ vs isquemia $W T, \# p<0,05$ vs control sEng+.

Figura 75. Análisis de los niveles de las VCAM-1 e ICAM-1 en ratones WT y sEng+. Análisis de los niveles de las VCAM-1 (A) e ICAM-1 (B) en el pulmón de ratones WT y sEng+, control y tratados con LPS, analizados por Western blot. Cada barra representa la media \pm EEM. WT $(n=5)$ y sEng $+(n=5)$. Test estadístico ANOVA de doble vía: $(A)+p<0,05$ vs control. 


\section{2. ÍNDICE DE TABLAS}

Tabla 1. Cebador de endoglina para genotipado y condiciones de PCR.

Tabla 2. Anticuerpos y condiciones de Western blot. 145

Tabla 3. Cebadores y condiciones de PCR .151

Tabla 4. ELISAs utilizados 153

Tabla 5. Reactivos y productos utilizados 158

Tabla 6. Equipos y aparatos utilizados. 159

Tabla 7. Sistema cuantitativo utilizado en la histología para medir el grado de infiltrado leucocitario 166

Tabla 8. Sistema cuantitativo utilizado para medir el grado de necrosis tubular 170 
ABREVIATURAS Y GLOSARIO 


\section{ABREVIATURAS}

AcP Anticuerpo policlonal

ADN Ácido desoxirribonucleico

ADNc Ácido desoxirribonucleico complementario o copia

Akt Proteína serina/treonina kinasa (Alpha serina/threonina-protein kinasa)

ALK Receptor de tipo I de TGF- $\beta$ (Activin receptor-Like Kinase)

ANOVA Análisis de la varianza (Analysis Of Variance)

$\boldsymbol{A R N m}$ Ácido ribonucleico mensajero

AVMA Asociación de Medicina Veterinaria Americana (American Veterinary Medical Association)

BAL Lavado broncoalveolar (BronchoAlveolar Lavage)

BEOCYL Biobanco en Red de Enfermedades Oncológicas de Castilla y León

BMP Proteínas morfogénicas del hueso (Bone Morphogenetic Proteins)

BMPER Precursor endotelial de proteínas morfogenéticas óseas (Bone Morphogenetic Proteins Endothelial Precursor)

BSA Albúmina de suero bovino (Bovine Serum Albumina)

CBLR Compartimento de borde lateral reciclable

CD Cluster de diferenciación

CMV (Cauliflower Mosaic Virus)

cox Ciclooxigenasa

Proteína tirosina kinasa derivada del protooncogén activador de tirosin

c-Src quinasas (Proto-oncogene tyrosine-proteun kinasa Stored Response Chain) 
CXCL12 Quimiocina 12 de motivo C-X-C (C-X-C motif chemokine 12)

DMEM (Dulbecco Modified Eagle Medium)

dNTP Desoxirribonucleótidos trifosfato

$\boldsymbol{D P X}$ (Distyrene Plastiicizer Xylene)

DSS Sodio Dextran sulfato (Dextrane Sulfate Sodium)

DTT Ditiotritol

DMSO Dimetil sulfóxido

EDTA Ácido etilendiaminotetraacético

EEM Error estándar de la media

EII Enfermedad Inflamatoria Intestinal

ELISA Ensayo de inmunoadsorción enzimática (Enzyme Linked ImmunoSorbent Assay)

ENG Endoglina

Eng $^{+/-} \quad$ Genotipo de ratón haploinsuficiente en endoglina

eNOS Óxido nítrico sintasa endotelial (endothelial Nitric Oxide Synthase)

FBS Suero bovino fetal (Foetal Bovine Serum)

FITC Isotiocianato de fluoresceína (Fluorescein IsoThioCyanate)

FRA Fallo Renal Agudo

GAPDH Gliceraldehído-3-fosfato deshidrogenasa (GlycerAldehyde 3-Phosphate DeHydrogenase)

G-CSF Factor estimulante de colonias de granulocitos (Granulocyte-colony stimulating factor)

GTP Guanosín Trifosfato

HA Hemaglutinina de Influenzza

HELLP (Hemolysis, elevated liver enzymes, low platelet count) 
H\&E Hematoxilina-eosina

HHT Telangiectasia Hemorrágica Hereditaria (Haemorragic Hereditary Telangectasia)

HIF Factor inducible por hipoxia (Hypoxia-Inducible Factor)

HRP Peroxidasa de rábano picante (HorseRadish Peroxidase)

HUVES Células endoteliales de vena umbilical humana (Human Umbilical Vein Endothelial Cells)

ICAM Molécula de adhesión intercelular (Intercellular Adhesion Molecule)

IL Interleucina

iNOS Óxido nítrico sintasa inducible (inducible Nitric Oxide Synthase)

IR Isquemia-reperfusión

JAM Molécula de adhesión de uniones (Junctional Adhesion Molecule)

L-endoglina Isoforma larga de endoglina (Long Endoglin)

L-ENG+ Genotipo de ratón empleado en este trabajo, que sobreexpresa Lendoglina humana

LFA-1 Antígeno 1 asociado a la función linfocitaria (Lymphocyte functionassociated antigen 1)

LPMs Macrófagos grandes peritoneales residentes en el tejido a largo plazo (Long-Term large Peritoneal Macrophages)

LPS Lipopolisacárido

Mac-1 Integrina de macrófagos 1 (Macrophage-1 integrin)

MAPK Proteínas kinasas activadas por mitógeno (Mitogen Activated Protein Kinases)

MMPs Metaloproteinasas de matriz extracelular (Matrix metalloproteinases)

MPO Mieloperoxidasa

MTE Migración Transendotelial 
NADPH Nicotinamida adenina dinucleótido fosfato

NCBI (National Center for Biotechnology Information)

Factor nuclear potenciador de las cadenas ligeras kappa de las células $B$

NFKB activadas (Nuclear Factor Kappa-light-chain-enhancer of activated B cell)

No Óxido nítrico (Nitric oxide)

Nox-2 NADPH oxidasa 2

$\mathbf{O}_{2}^{-} \quad$ Anión superóxido

OUU Obstrucción ureteral unilateral

PAGE Electroforesis en gel de poliacrilamida (PolyAcrilamide Gel Electrophoresis)

PBS Salino con tampón fosfato (Phosphate-Buffered Saline)

PCR Reacción en cadena de la polimerasa (Polimerase Chain Reaction)

PECAM Molécula endotelial de adhesión a plaquetas (Platelet Endothelial Cell Adhesion Molecule)

PIGF Factor de crecimiento placentario (Placental Growth Factor)

PRS13 Proteína Ribosomal S13

PSGL-1 Ligando 1 de la glicoproteína P-selectina ( $P$-selectin glycoprotein ligand 1)

PVDF Difluoruro de polivinilideno (PolyVinyliDene Fluoride)

qPCR PCR cuantitativa

RBE Regiones de baja expresión

$\boldsymbol{R G D}$ Tripéptido arginina - glicina - aspartato

RhoA (Ras homolog gene family, member A)

rhEng Endoglina humana recombinante (Recombinant Human Endoglin)

ROS Especies reactivas de oxígeno (Reactive Oxygen Species) 
SDRA Síndrome de Dificultad Respiratoria Aguda

SDS Dodecil sulfato sódico (Sodium Dodecyl Sulphate)

SEA Servicio de Experimentación Animal

SEDISA Sociedad Española de Directivos de la Salud

sEng Endoglina soluble

sEng+ Genotipo de ratón empleado en este trabajo que sobreexpresa endoglina soluble humana

S-endoglina Isoforma corta de endoglina (Short Endoglin)

S-ENG+ Genotipo de ratón empleado en este trabajo que sobreexpresa Sendoglina humana

sFlt1 Forma soluble del receptor 1 de VEGF (fms related tyrosine kinase 1)

SL Secuencia Líder

Smad Small protein Mothers Against Decapentaplegic

SPF Barrera libre de patógenos (Specific-pathogen-free)

SPMs Macrófagos peritoneales pequeños (Small Peritoneal Macrophage)

Ta Temperatura

TEMED Tetrametiletilendiamina (TEtraMEthylEthyleneDiamine)

TGF-6 Factor de crecimiento transformante 8 (Transforming Growth Factor $\beta$ )

T6RI Receptor de tipo I de TGF- $\beta$

T6RII Receptor de tipo II de TGF- $\beta$

TLR Toll-Like Receptor

TNFa Factor de necrosis tumoral (Tumor Necrosis Factor)

TSP-1 Trombospondina-1 (Thrombospondin-1)

VCAM Molécula de adhesión vascular (Vascular Adhesion Molecule) 
VE-PTP Receptor de tipo tirosina fosfatasa beta (Receptor-type tyrosune-protein phosphatase beta)

VE-cadherina Cadherina vascular endotelial (Vascular endothelial Cadherin)

\begin{aligned} \hline VEGF & $\begin{array}{l}\text { Factor endotelial de crecimiento vascular (Vascular Endothelial Growth } \\ \text { Factor) }\end{array} \\$\hline VEGFR & Receptor de VEGF \\ \hline VLA-4 & Integrina a4ß1 (Integrin a4ß1, Very Late Antigen-4) \\ \hline WT & Genotipo wild type o salvaje, control utilizado en este trabajo. \\ \hline ZO-1 & Proteína de las uniones ocluyentes 1 (Zonula Occludens 1) \\ \hline ZP & Zona pelúcida \end{aligned}

aSMA Actina a de músculo liso vascular (a Smooth Muscle Actin) 


\title{
4. GLOSARIO DE TÉRMINOS EN INGLÉS
}

\author{
Curva de melting Curva de disociación de la doble hebra de ADN al someterla a un \\ incremento gradual de la temperatura.
}

Outlier Observación o dato que dista del resto de observaciones del experimento.

Splicing alternativo

Modificación postranscripcional de ayuste o eliminación alternativa de intrones para dar lugar a diferentes ARNm

Housekeeping exp

Genes cuya expresión se utiliza como control interno en los experimentos de qPCR por ser constitutiva o no regulada y, por tanto, constante en todas las condiciones del experimento.

Tag Etiqueta, que en este caso se le pone al gen de una proteína en la generación de transgénicos, para facilitar la detección de la misma.

Línea horizontal que se establece sobre la gráfica de una reacción de qPCR y que corta a cada curva de amplificación, de cada una de las muestras, en su fase exponencial. Permite establecer el Ct (ciclo

Threshold threshold), que es el ciclo de PCR al que la curva de amplificación de una determinada muestra corta la línea de threshold; el Ct será tanto menor cuanto mayor sea la cantidad del ADN sustrato de PCR en esa muestra.

Transwell

Inserto con el fondo de membrana porosa, para estudiar el paso o migración de las células in vitro.

Wild type Genotipo salvaje. 
INTRODUCCIÓN 


\section{INFLAMACIÓN}

Doce de las quince principales causas de muerte en el mundo cursan con un proceso inflamatorio: enfermedad coronaria, cáncer, enfermedades respiratorias y pulmonares, derrame cerebral, diabetes mellitus, gripe, enfermedad renal, septicemia, enfermedad hepática crónica, cirrosis, Alzheimer, hipertensión y Parkinson (Okin \& Medzhitov, 2012). Estas enfermedades suponen una reducción de la calidad de la vida en estos enfermos, además de un gran coste desde el punto de vista social y sanitario. La inflamación es un promotor clave de las enfermedades degenerativas, que matan a millones de personas cada año, afectando por ello al desarrollo socioeconómico de los países. En España, el $80 \%$ del gasto sanitario se dedica a atender enfermedades crónicas en las cuales el componente inflamatorio tiene un papel fundamental. La mitad de la población, es decir, más de 20 millones de personas, sufre una enfermedad crónica, y se estima que después de los 65 años, padecerán una media de cuatro (SEDISA. Sociedad Española de Directivos de la Salud).

Las enfermedades inflamatorias sistémicas se encuentran distribuidas globalmente. Se estima que el 30-70\% de la población desarrollará alguna de estas enfermedades en algún período de la vida. Además, se espera que su prevalencia vaya aumentando en los próximos años debido, entre otros factores, a la industrialización y el cambio climático (Pulido et al, 2014). Esto supone una alta carga económica para los servicios de salud, tanto en recursos sanitarios utilizados como por los costes directos generados en su tratamiento. En particular, la prevalencia de soriasis en España ha aumentado un 1\% en los últimos años (Pulido et al, 2014). Afectando a un 2,3\% de la población, lo cual supone más de 1 millón de casos en España. Además, el coste asociado a la pérdida de productividad por enfermedades dermatológicas es considerable, estimándose que en Europa podría llegar a alcanzar los 5 billones de euros anuales (Pulido et al, 2014).

La inflamación es la respuesta fisiopatológica del sistema inmunológico al daño causado a las células y tejidos vascularizados frente a una infección o cualquier otro agresor de naturaleza biológica, química, física o mecánica (Abbas \& Lichtman, 2010). Se trata de una respuesta inmune inespecífica que aísla y destruye el agente dañino, y repara el 
tejido u órgano dañado (Abbas \& Lichtman, 2010). La respuesta coordinada y colectiva frente a sustancias extrañas es la respuesta inmunitaria. Tanto la inflamación como la respuesta inmunitaria son en la actualidad un objetivo principal en el tratamiento de las enfermedades inflamatorias (Preshaw, 2017).

En el proceso inflamatorio, la defensa frente a microorganismos está mediada por una respuesta temprana por parte de la inmunidad innata y una respuesta tardía por parte de la inmunidad adaptativa. La inmunidad innata o inespecífica es una respuesta extremadamente rápida, que carece de memoria inmunológica, cuyos principales componentes son: las barreras físicas, como el epitelio; las células fagocíticas (neutrófilos y macrófagos), células dendríticas y células natural killer; proteínas sanguíneas mediadoras de la inflamación (sistema del complemento) y citoquinas, que regulan y coordinan la mayoría de los procesos inflamatorios (Abbas \& Lichtman, 2010).

La inflamación aguda es parte de la inmunidad innata. Comienza de forma muy rápida: unos minutos después del contacto con el agente inflamatorio, y su duración es breve: unas horas o pocos días. Se caracteriza por tres aspectos fundamentales: cambios hemodinámicos, migración leucocitaria y permeabilidad vascular. Por su parte, la inflamación crónica aparece cuando la inflamación aguda no se resuelve, y persiste durante meses e incluso años, coexistiendo el daño tisular y los intentos de reparación, ocasionando fibrosis (Abbas \& Lichtman, 2010) (Figura 1). Es el caso de enfermedades como artritis reumatoide, la arterioesclerosis, la tuberculosis o la fibrosis pulmonar. Además, es importante en el desarrollo del cáncer y en enfermedades que anteriormente se consideraban exclusivamente degenerativas, como el Alzheimer (Cain et al, 2009). 


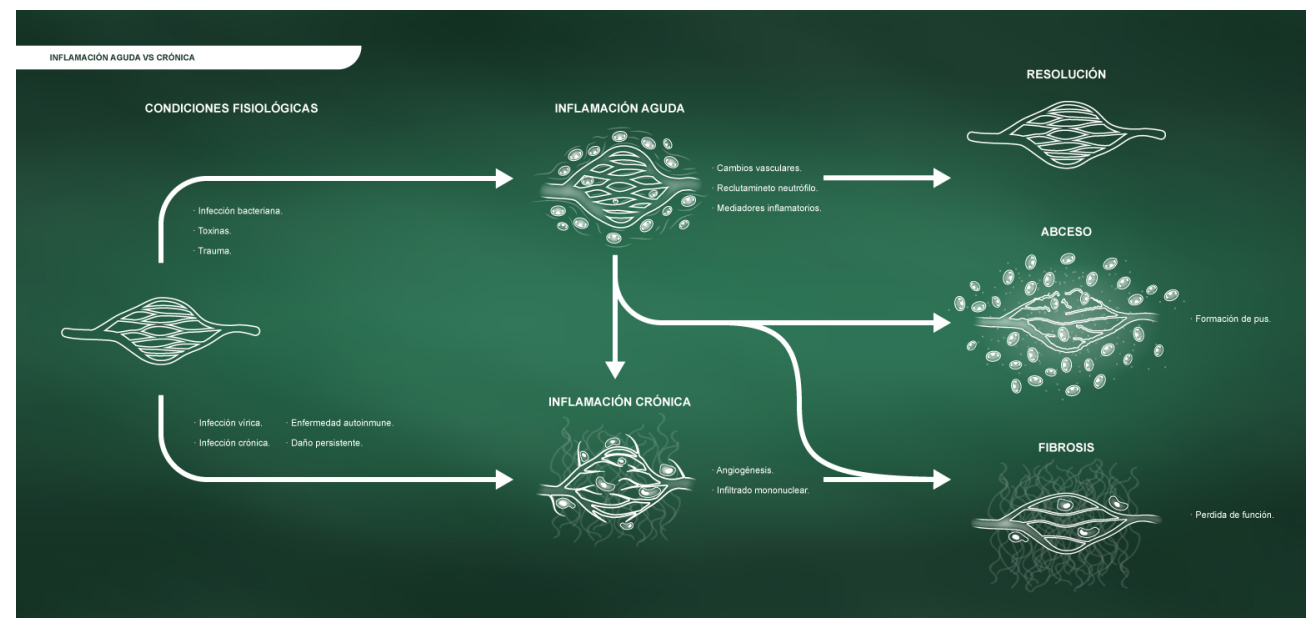

Figura 1. Condiciones fisiológicas en la inflamación aguda vs inflamación crónica.

Tras una inducción inflamatoria de distinta naturaleza (mecánica, por infección, por hipoxia...) comienza la liberación de mediadores inflamatorios por los leucocitos tisulares, entre los que se encuentran las citoquinas inflamatorias, y suponiendo el inicio del proceso inflamatorio. La liberación de las citoquinas inflamatorias produce alteraciones vasculares y quimiotaxis, favoreciendo la llegada de moléculas inflamatorias y leucocitos al foco inflamatorio. Esto constituye en sí mismo la fase aguda de la inflamación (Ley 2006). El conjunto de citoquinas inflamatorias varía en función de la naturaleza de la inducción y de la intensidad, siendo un proceso estrechamente regulado por mecanismos inhibidores, que equilibran el proceso.

Este inicio del proceso inflamatorio ha sido ampliamente estudiado para el desarrollo de terapias antiinflamatorias (Preshaw, 2017), permitiendo reducir el daño ocasionado por las células inflamatorias al foco inflamatorio y a los tejidos circundantes.

Actualmente se están estudiando también de manera extensiva los mecanismos involucrados en la resolución de la inflamación, siendo los mejores caracterizados la resolución local por derivados del ácido araquidónico, la resolución por las descargas del sistema nervioso autónomo y la resolución por citoquinas antiinflamatorias (Villagrana 
et al, 2014). La regulación de estas vías permite disminuir la proliferación y maduración de células inmunes, la inducción de la apoptosis y fagocitosis de leucocitos activos y la inhibición y depuración de mediadores inflamatorios (Villagrana et al, 2014). Sin embargo, los tratamientos basados en la resolución de la inflamación solamente tienen aplicabilidad en enfermedades crónico-degenerativas. Por ello, para enfermedades que cursan con un proceso inflamatorio no degenerativo, sería interesante controlar la inflamación en estadios más tempranos. A pesar de ello, la terapéutica convencional orientada a la inhibición de mediadores proinflamatorios presenta desventajas a causa de la interacción con otros procesos fisiológicos que cursan con inflamación (Villagrana et al, 2014).

Muchas de las patologías existentes cursan con un proceso inflamatorio. Por ejemplo, las enfermedades cardiovasculares, la diabetes, la preeclampsia y el cáncer son enfermedades con una gran prevalencia en la población, y, aunque se ha demostrado que cursan con un proceso inflamatorio, se desconoce si la inflamación constituye en sí misma la base patológica de la enfermedad (Zhang et al, 2013).

A pesar de la gran cantidad de recursos empleados en la investigación y caracterización de los componentes celulares y moleculares de la inflamación (Serhan et al, 2010), las estrategias terapéuticas empleadas en la actualidad son insuficientes. Esto es especialmente grave si tenemos en cuenta que se estima que más de la mitad de la población mundial desarrollará algún tipo de enfermedad inflamatoria a lo largo de su vida, aumentando la prevalencia cada año (SEDISA. Sociedad Española de Directivos de la Salud).

En este estudio, exploramos el papel de endoglina, un co-receptor de la superfamilia de TGF- $\beta$, como potencial regulador de las respuestas inflamatorias involucradas en las primeras etapas del proceso inflamatorio. Esta tesis se centra en el papel de la endoglina en la respuesta inflamatoria aguda.

Se ha demostrado que la proteína endoglina está aumentada en patologías inflamatorias especialmente en enfermedades cardiovasculares, preeclampsia y cáncer, considerándose un marcador de mal pronóstico. Sin embargo, desconocemos si 
endoglina podría estar teniendo un papel en la inducción del componente inflamatorio, o incluso en la base patológica de estas enfermedades. Esto hace muy atractivo cualquier estudio que vislumbrara información acerca de la relación de endoglina e inflamación, ya que podría constituir, en sí misma, una molécula reguladora de la respuesta inflamatoria.

\subsection{INFLAMACIÓN AGUDA}

Clínicamente, la inflamación aguda se caracteriza por 5 signos: rubor (enrojecimiento), calor (aumento de la temperatura), tumor (hinchazón), dolor y pérdida de función. El enrojecimiento y el calor se deben al aumento del flujo sanguíneo al área inflamada, la hinchazón se ocasiona por la acumulación de líquido (edema), el dolor se origina por la liberación de moléculas que estimulan las terminaciones nerviosas, como las citoquinas, y la pérdida de la función se produce por una combinación de factores, consecuencia de los anteriores (CHANDRASOMA, 2013).

La inflamación aguda es una respuesta inmediata e inespecífica frente a una lesión o infección. Consiste en la extravasación e infiltración de leucocitos, proteínas del plasma y fluidos provenientes de la sangre, al foco inflamatorio (Figura 2). Los principales leucocitos polimorfonucleares reclutados son los neutrófilos y los monocitos, que una vez fuera del torrente sanguíneo se diferencian a macrófagos. La liberación de estas células sanguíneas a los sitios de inflamación depende de cambios reversibles que se dan en las células endoteliales en lugares de infección o daño tisular. Estos cambios incluyen una dilatación arterial, lo que ocasiona un incremento en el flujo sanguíneo, una intensificación en la transmigración endotelial leucocitaria, así como un aumento en la permeabilidad de los capilares y vénulas a proteínas del plasma. Estos cambios están estrechamente coordinados por citoquinas y moléculas procedentes de células residentes en el tejido afectado, tales como mastocitos, macrófagos y células endoteliales (Serhan et al, 2010). 


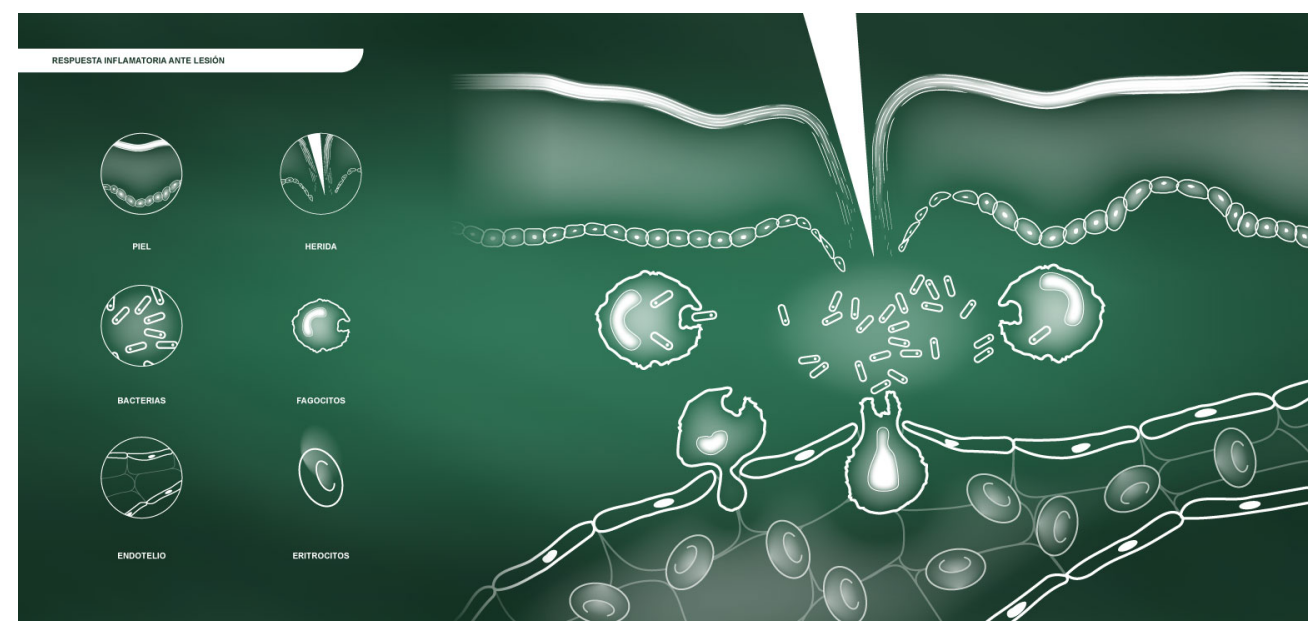

Figura 2. Representación simplificada de la respuesta inflamatoria ante lesión.

Cuando la inflamación se mantiene de manera continuada (semanas o meses), los intentos fallidos de reparación comienzan a ocasionar daño tisular, denominándose inflamación crónica. Esto puede producirse si no se resuelve la causa inflamatoria, o empezar de manera progresiva y ocasionar daño tisular crónico, siendo este el caso de la artritis reumatoide, la ateroesclerosis y la tuberculosis, las cuales están entre las enfermedades más invalidantes en la actualidad (Abbas \& Lichtman, 2010). También es importante en el desarrollo del cáncer y de enfermedades, como el Alzheimer, que se consideraron en un principio exclusivamente degenerativas. Cuando la respuesta inmunitaria se produce de manera exagerada y descontrolada, la respuesta inmune, en lugar de ser beneficiosa, es dañina, como es el caso del asma bronquial. Estas enfermedades suelen cursar con brotes repetidos de inflamación, presentando características mixtas de inflamación aguda y crónica, lo cual complica considerablemente sus tratamientos (Abbas \& Lichtman, 2010). 


\subsubsection{PRINCIPALES CITOQUINAS IMPLICADAS EN LA INFLAMACIÓN}

El balance de las citoquinas inflamatorias, tanto quimiotácticas, proinflamatorias y antiinflamatorias, son esenciales tanto en la inducción inflamatoria como en la regulación y resolución del proceso inflamatorio (Serhan et al, 2010).

Su papel fundamental en el avance del proceso inflamatorio las ha situado como un objetivo principal en el campo de la inmunoterapia (Anestakis et al, 2015). Dada la heterogeneidad de las enfermedades inflamatorias, los estudios se centran en analizar las principales citoquinas implicadas en cada enfermedad, y valorar sus posibles aplicaciones clínicas.

Como consecuencia de la respuesta inflamatoria, las citoquinas promueven la activación leucocitaria, que cuando es excesiva, ocasiona el síndrome de disfunción múltiple de órganos y numerosos fallos en los órganos vitales (Bhatia et al, 2000; Bhatia, 2002). Existen cientos de citoquinas implicadas en el proceso inflamatorio, pero algunas de las principales citoquinas mediadoras son TNFa, IL1 $\beta$, IL6 e IL10 (Cohen, 2002).

En el foco inflamatorio, los macrófagos con fenotipo proinflamatorio liberan el factor de necrosis tumoral a (TNFa) y la interleucina $1 \beta$ (IL1 $\beta$ ), que son citoquinas proinflamatorias que actúan a nivel de receptores de membrana (Cohen, 2002; Norman et al, 1995; Putensen \& Wrigge, 2000).

Los niveles de TNFa están elevados en el torrente sanguíneo en enfermedades que cursan con inflamación sistémica, siendo TNFa uno de los principales mediadores (Cohen, 2002; Norman et al, 1995; Putensen \& Wrigge, 2000). De manera similar, IL1 $\beta$ activa neutrófilos y provoca un aumento de expresión de moléculas de adhesión, tanto leucocitarias como endoteliales (Cohen, 2002; Norman et al, 1995; Putensen \& Wrigge, 2000).

Durante la inducción de un proceso inflamatorio agudo, TNFa e IL1 $\beta$ se liberan al torrente sanguíneo 30-90 minutos después de la exposición a lipopolisacárido (LPS), activando 
cascadas inflamatorias secundarias que incluyen a otras citoquinas, mediadores lipídicos, especies reactivas de oxígeno (ROS) y aumentando la expresión de moléculas de adhesión, lo que desencadena el inicio de la migración leucocitaria a los tejidos (Cohen, 2002; Norman et al, 1995; Putensen \& Wrigge, 2000).

La interleucina 6 (IL6) es producida por distintos tipos celulares, entre los que se incluyen monocitos-macrófagos, células endoteliales activadas, fibroblastos y células del músculo liso en respuesta a endotoxinas o a las propias citoquinas TNFa e IL1 $\beta$ (Cohen, 2002). Elevados niveles de IL6 se han descrito en distintos casos de inflamación aguda, como quemaduras, cirugías y shock séptico (Nijsten et al, 1991). El nivel de IL6 circulante se utiliza como marcador para el pronóstico de la severidad del síndrome de dificultad respiratoria aguda (SDRA) de distinto origen, como la sepsis (Leser et al, 1991) y la pancreatitis aguda (Remick et al, 2002).

Por su parte, la interleucina 10 (IL10) es una citoquina antiinflamatoria (Kasama et al, 1994; Fiorentino et al, 1991). Sus niveles plasmáticos están elevados en modelos animales de endotoxemia, e inhibe la liberación de citoquinas proinflamatorias, como TNFa, IL1ß e IL6, por parte de los macrófagos, por lo que previene el daño tisular. Además, IL10 inhibe la producción de mediadores proinflamatorios por parte de los macrófagos alveolares en el síndrome de dificultad respiratoria aguda (Lo et al, 1998). Pacientes con dicho síndrome, de distinta etiología, presentan menor cantidad de IL10 en el BAL y plasma (y mayores niveles de TNFa) que pacientes en riesgo de SDRA pero que no padecen la enfermedad (Armstrong \& Millar, 1997).

Entre los pacientes del síndrome de dificultad respiratoria aguda, una de las principales causas de morbilidad y mortalidad a nivel mundial es la septicemia por neumonía bacteriana (Mizgerd, 2006; Wheeler \& Bernard, 1999). Las bacterias de neumonía invasoras del tracto respiratorio son detectadas por macrófagos alveolares, que residen en el tejido pulmonar (Mizgerd, 2008). Una vez que los macrófagos alveolares identifican la bacteria se inicia la respuesta inflamatoria, liberándose las citoquinas inflamatorias TNFa, IL1ß e IL6. Estos mediadores activan a las células epiteliales del tracto respiratorio produciéndose la liberación de quimiocinas, lo cual provoca la migración de neutrófilos 
al espacio alveolar. Los neutrófilos infiltrados en el tejido tienen un papel clave, fagocitando y eliminando a las bacterias invasoras (Knapp, 2009; Fadok et al, 1998).

Aunque se han descrito ampliamente las principales citoquinas implicadas en las distintas enfermedades inflamatorias (Preedy \& Hunter, 2011), los conocimientos actuales son insuficientes para desarrollar terapias efectivas. En esta tesis, exploramos el papel del co-receptor de TGF- $\beta$, endoglina, como potencial regulador del inicio de la respuesta inflamatoria, lo cual está estrechamente regulado por el balance de citoquinas inflamatorias.

\subsubsection{INDUCCIÓN DE LA INFLAMACIÓN AGUDA}

La inflamación aguda se induce ante cualquier lesión tisular o infección por parte de componentes de la inmunidad innata, constituyendo una primera línea de defensa. Por ello, los elementos que inducen inflamación aguda son muchos y muy diversos (Abbas \& Lichtman, 2010).

Los modelos animales son esenciales para el estudio de las bases fisiopatológicas de las enfermedades, entre las que se encuentran las enfermedades inflamatorias. Dada la complejidad de la respuesta inflamatoria, durante esta tesis se han desarrollado tres modelos animales muy diferentes, que nos permiten simular y estudiar dicha respuesta.

El primer objetivo al diseñar los modelos inflamatorios era que nos aportaran información diversa, lo cual nos permitiría hacer un estudio mucho más completo. Por ello, se optimizaron tres modelos inflamatorios muy distintos, en los cuales las inducciones inflamatorias son de naturaleza diferente, y se dan a su vez en tres tejidos distintos. Esto nos permite evaluar el proceso inflamatorio de manera mucho más amplia y eficaz.

En esta tesis nos centramos en el estudio de tres agentes inductores de inflamación: la inflamación pulmonar por nebulización de lipopolisacárido, la inflamación aguda renal 
ante daño por isquemia-reperfusión y la inducción de la inflamación aguda por tratamiento con carragenina en el air pouch.

\subsubsection{INFLAMACIÓN AGUDA PULMONAR}

El síndrome de dificultad respiratoria aguda es un síndrome que cursa con inflamación, aumento de la permeabilidad vascular y diversas respuestas patológicas ante lesión en el parénquima pulmonar, ocasionando daño agudo pulmonar (Weinacker \& Vaszar, 2001; Tasaka et al, 2002). En concreto el SDRA se caracteriza por una respuesta inflamatoria local, la cual conlleva la distribución de mediadores inflamatorios por el torrente sanguíneo. Los mediadores inflamatorios tienen un papel clave en la patogénesis del SDRA, siendo la principal causa de muerte de los pacientes que sufren dicho síndrome (Bhatia \& Moochhala, 2004). La gravedad del SDRA se relaciona directamente con la magnitud de la respuesta inflamatoria sistémica, pudiendo ocasionarse por infecciones (bacterianas, víricas, por hongos o parásitos) o por lesiones no infecciosas (shock hemorrágico, pancreatitis aguda y quemaduras). En nuestro modelo, inducimos inflamación por nebulización pulmonar de lipopolisacárido.

Dada la implicación del proceso inflamatorio en la patogénesis del SDRA, se consideró muy interesante desarrollar un modelo animal que mimificara sus características, para lo cual se optó por inducir la respuesta inflamatoria por administración por nebulización de LPS en el pulmón, un modelo ampliamente descrito (Matute-Bello et al, 2008). Este modelo nos permite valorar la respuesta inflamatoria pulmonar ante infección, asegurando, gracias a la nebulización, una afectación similar en ambos pulmones.

Se diseñó este modelo inflamatorio porque el pulmón constituye un tejido muy interesante para este tipo de valoraciones. Por un lado, es un órgano de gran tamaño, lo cual evita las posibles limitaciones causadas por falta de tejido. Además, como es el órgano en el que se da el intercambio gaseoso, presenta una enorme densidad endotelial, haciendo posibles los estudios de expresión de moléculas de adhesión endotelial y en especial, la valoración de la permeabilidad vascular. 
EI LPS, o endotoxina, es un componente mayoritario de la membrana externa de las bacterias Gram negativas, siendo el principal responsable de la estimulación del sistema inmune ante infección bacteriana. Una endotoxina es una fracción de lipopolisacárido que al solubilizarse actúa como una toxina. Se libera de la bacteria estimulando varias respuestas de inmunidad innata, como la secreción de citoquinas proinflamatorias, aumento de la expresión endotelial de moléculas de adhesión vascular y activación de la capacidad fagocítica del macrófago. El lipopolisacárido consta principalmente de dos partes: un glucolípido denominado lípido A, y un heteropolisacárido denominado núcleo, unidos entre sí por el azúcar ácido 2-keto-3-deoxioctanato (Romero Hurtado \& Iregui, 2010). El lípido A está compuesto por un disacárido de dos unidades de glucosamina fosforilada y constituye en sí la endotoxina bacteriana, la cual desencadena la respuesta inmune.

La exposición aguda a LPS da lugar a inflamación aguda pulmonar, desencadenando por ello la cascada inflamatoria, con migración leucocitaria, aumento de la liberación de citoquinas y permeabilidad en los capilares pulmonares, generando edema pulmonar (Kabir et al, 2002; Matute-Bello et al, 2008).

\subsubsection{INFLAMACIÓN AGUDA RENAL}

El fallo renal agudo (FRA) empeora severamente el pronóstico de los pacientes hospitalizados: el 1-5\% de los pacientes terminan padeciendo FRA (Kribben et al, 2003), con una mortalidad muy elevada, de hasta el 70\% (Kellum, 2008). La causa principal de FRA en pacientes hospitalizados es la hipoperfusión renal: daño por isquemiareperfusión (Lameire et al, 2005; Chertow et al, 2005; Kribben et al, 2003). El daño por isquemiareperfusión en el riñón es muy común en los transplantes renales (Boros \& Bromberg, 2006). Además, patologías asociadas a la isquemia, como infarto de miocardio, infarto cerebral o septicemia, tienen un gran impacto tanto en la mortalidad como en la morbilidad de los pacientes.

La isquemia afecta tanto la función como a la estructura de las células tubulares epiteliales, llegando a necrosis en los casos más severos (Zappitelli, 2008). Además de 
la necrosis tubular, la isquemia-reperfusión provoca inflamación y microvasculopatías intersticiales, lo cual retrasa la restauración de la función renal, empeorando gravemente el pronóstico de los pacientes con FRA isquémico (Devarajan, 2006). La microvasculopatía post-isquémica se caracteriza por engrosamiento de las células endoteliales, ocasionando que, aunque la reperfusión sea efectiva, algunos capilares permanecen isquémicos (Lehr et al, 1993). Esto prolonga la isquemia pese a que la causa primaria de hipoperfusión haya cesado (Patschan et al, 2011, 2006). La causa principal suele ser trombosis, vasoconstricción y el engrosamiento edematoso de las células endoteliales.

Se eligió el modelo inflamatorio de isquemia-reperfusión renal, en el cual se practican 30 minutos de isquemia en uno de los riñones, seguidos de 48 horas de reperfusión. La isquemia induce una rápida liberación de moléculas inflamatorias al torrente sanguíneo, que llegan al foco inflamatorio durante la reperfusión. El hecho de practicar una isquemia renal, nos permite, por un lado, que el ratón se mantenga con vida durante los 30 minutos de la isquemia, ya que tiene el otro riñón en funcionamiento mientras tanto, siendo un modelo mucho menos agresivo.

El proceso inflamatorio intersticial tras isquemia-reperfusión comienza con disfunción de las células endoteliales y tubulares. Esto ocasiona una liberación de citoquinas proinflamatorias tanto al riñón como al torrente sanguíneo, destacando TNFa, IL1ß e IL6, entre otras (Kielar et al, 2005; Ramesh \& Reeves, 2004). Niveles elevados en plasma de IL6 se correlacionan con un mayor riesgo de muerte en pacientes con FRA (Simmons et al, 2004). Tras la liberación de citoquinas proinflamatorias, aumenta la infiltración al intersticio renal de neutrófilos, macrófagos, células natural killer y células $T$, donde modulan la respuesta inflamatoria (Devarajan, 2006; Bonventre \& Weinberg, 2003; Friedewald \& Rabb, 2004). La primera población leucocitaria que comienza a acumularse en los capilares peritubulares, en el intersticio y en los mismos túbulos son los neutrófilos (Devarajan, 2006). Aun así, la isquemia-reperfusión no siempre cursa con infiltración neutrófila, aunque el bloqueo de la función de los neutrófilos (Friedewald \& Rabb, 2004) y la depleción de macrófagos (Day et al, 2005) en distintos modelos animales protege del FRA. 
Por su parte, la concentración del vasodilatador óxido nítrico (NO) está reducida en los capilares tras IR. La falta de NO disminuye la vasodilatación del capilar, ocasionando una vasoconstricción que aumenta la adhesión de leucocitos a la cara luminal del endotelio (Webb et al, 2004).

\subsubsection{INFLAMACIÓN AGUDA SINOVIAL}

Las articulaciones están rodeadas de una cápsula recubierta por una membrana llamada sinovia. Cuando la sinovia se irrita por abrasión continuada, causado por infecciones, traumatismos o enfermedades autoinmunes directas, como la artritis reumatoide, aumenta la producción del líquido sinovial, ocasionando edema, rigidez y dolor articular agudo (SER - Sociedad Española de Reumatología).

La inyección de carragenina se utiliza para inducir sinovitis en distintos modelos (Wang et al, 2017). La carragenina es un co-polisacárido sulfatado lineal de origen natural, que se extrae de las algas rojas de la familia Rhodophyceae, particularmente de chondrus crispus (Torres et al, 2016). Está formada por una estructura lineal de $\beta$-D-galactosa y 3,6anhidro-a-D-galactosa. Las unidades de disacárido presentan variabilidad en sus grupos sulfatados, presentando un contenido de sulfato de entre el 22-38\% del peso de la carragenina comercial (van de Velde et al, 2002). Hay distintas variedades de carragenina, presentando cierta variabilidad en su estructura química y propiedades. Las de mayor importancia comercial son las carrageninas iota, kappa y lambda. Las carrageninas son empleadas de manera industrial en el sector alimenticio, como espesantes y gelificantes (van de Velde et al, 2002), así como en la industria farmacéutica como excipientes. Por su parte, en medicina experimental, la carragenina se utiliza desde hace décadas para probar el efecto de agentes antiinflamatorios (Zacharopoulos \& Phillips, 1997).

Las carrageninas pueden tener distintas actividades biológicas, incluyendo la inmunomodulatoria, anticoagulante, antitrombótica, antiviral y antitumoral. El edema en la pata inducido por carragenina es uno de los modelos más comunes en el estudio de fármacos antiinflamatorios y analgésicos, existiendo en la literatura unos 400 artículos 
sobre el uso de este modelo (Posadas et al, 2004). Para generar edema, se utiliza de manera local una solución de carragenina al 1-3\% en salino, inyectada de manera local (Estakhr et al, 2011). Sin embargo, en el caso de modelos de condiciones fisiopatológicas específicas se utilizan soluciones más concentradas (Estakhr et al, 2011).

En la fase temprana de la inflamación inducida por carragenina se detectan histamina, bradiquinina y serotonina, mientras que en fases más tardías se detectan las prostaglandinas, las cuales se relacionan con el aumento de la permeabilidad vascular. Además, se da el aumento en los niveles de citoquinas proinflamatorias TNFa, IL1ß e IL6 (Cuzzocrea et al, 1999). La fase inicial del edema se atribuye a la liberación de histamina, 5hidroxitriptamina y bradiquinina, mientras que la segunda fase de inflamación se asocia tanto con el aumento de prostaglandinas como con la inducción de COX-2. La respuesta inflamatoria a carrageninas también se asocia con infiltración neutrófila, la cual contribuye a la inflamación mediante mediadores inflamatorios como ROS, anión superóxido $\left(\mathrm{O}_{2}^{-}\right)$y radicales hidroxilos (Posadas et al, 2004). Además, la carragenina causa la producción y liberación de NO en el foco inflamatorio, lo cual contribuye al daño tisular y sinovial, edema e hiperalgesia (Omote et al, 2001).

La inyección de aire en el dorso de roedores permite la formación de una cavidad (pouch) que nos permite estudiar la respuesta inflamatoria (Romano et al, 1997). Se ha demostrado que el mantenimiento de dicho pouch durante 7 días da lugar al desarrollo de tejido granuloso en el tejido conjuntivo del ratón, conteniendo gran cantidad de fibroblastos, macrófagos y granulocitos (Colville-Nash \& Lawrence, 2003). La formación de este tejido permite estudiar la respuesta ante estímulos inflamatorios e irritantes mediante la cuantificación de exudado inflamatorio y la medida de la concentración leucocitaria (Colville-Nash \& Lawrence, 2003), razón por la cual elegimos el modelo del air pouch como nuestro tercer modelo inflamatorio para estudiar el comienzo de la inflamación aguda. Al combinar la formación del air pouch con la inyección de carragenina, es posible estudiar la respuesta inflamatoria aguda de manera reproducible en el exudado inflamatorio presente en la cavidad del pouch y el infiltrado en el tejido. Esto hace que este modelo sea muy adecuado para nuestro proyecto, ya que nos permite valorar la 
permeabilidad vascular analizando el exudado inflamatorio en la cavidad del pouch y el infiltrado leucocitario presente en la piel del dorso del ratón.

\subsection{CASCADA DE ADHESIÓN LEUCOCITARIA}

El proceso de extravasación leucocitaria es un paso clave en la respuesta inflamatoria. Implica la migración de los leucocitos del torrente sanguíneo a los tejidos diana, donde ejercen su función efectora. La extravasación leucocitaria está mediada por la acción cooperativa de receptores de adhesión celular y factores quimiotácticos, ocasionando cambios morfológicos drásticos tanto en leucocitos como en las propias células endoteliales. Es un proceso activo que permite la rápida y eficiente llegada de leucocitos a los focos inflamatorios, sin comprometer la integridad endotelial (Barreiro \& SánchezMadrid, 2009).

Ante un daño tisular o infección, los leucocitos circulantes migran al foco inflamatorio para eliminar el desencadenante primario de la inflamación y reparar los tejidos dañados. En la inmunidad innata, este proceso comienza una vez que el sistema inmune reconoce las moléculas asociadas a patógenos (liberadas por microorganismos durante una infección) o moléculas asociadas a daño (que derivan de células muertas) (Medzhitov, 2008). Además, los antígenos también pueden desencadenar la inflamación al ser reconocidos por células $\mathrm{T}$ de memoria, dando lugar al reclutamiento de leucocitos mediante la secreción de citoquinas inflamatorias. Las células tisulares centinelas, entre las que se incluyen mastocitos, macrófagos y células dendríticas, tienen un papel clave en la detección de estas señales, pudiendo liberar gran variedad de mediadores proinflamatorios que conllevan reclutamiento leucocitario (Medzhitov, 2008).

El primer paso en la cascada de migración leucocitaria es la creación de interacciones de adhesión débil entre los leucocitos y las células endoteliales de las vénulas postcapilares de las zonas cercanas al foco inflamatorio. Esto permite la estimulación in situ de los leucocitos por quimioatractantes presentes en la superficie luminal de las células endoteliales, ocasionando el arresto leucocitario, la adhesión firme, el gateo y la 
subsecuente transmigración a través del endotelio (Ley et al, 2007). Como estas etapas son previas a la transmigración celular, la modificación de cualquiera de ellas resultaría en cambios en el infiltrado leucocitario, y por ello, reduciría el daño originado en el foco inflamatorio por la liberación continuada de citoquinas inflamatorias.

Como en esta tesis vamos a valorar el papel de endoglina como potencial regulador de las etapas iniciales de la respuesta inflamatoria aguda, el entendimiento de las etapas previas a la transmigración leucocitaria en condiciones control, así como la propia transmigración leucocitaria, son de gran interés. Su comprensión nos permitirá interpretar los posibles cambios originados por la presencia de endoglina.

La cascada de adhesión leucocitaria está principalmente controlada por dos familias de receptores de adhesión: las selectinas, expresadas en los leucocitos y células endoteliales, y las integrinas, expresadas únicamente en los leucocitos (Ley et al, 2007). La activación de las células endoteliales es un paso decisivo para que se desencadene la cascada de adhesión leucocitaria, y puede suceder de manera rápida o lenta. La manera rápida ocurre en cuestión de minutos, ya sea tras la inducción de la síntesis de proteínas o aumentando la expresión de moléculas de adhesión en la membrana celular (como la P-selectina), lo cual permite la unión de leucocitos y células endoteliales. Las células endoteliales también pueden activarse de manera más lenta, dándose en cuestión de horas la inducción de la transcripción de moléculas asociadas al tráfico leucocitario: selectinas, ligandos de integrinas y algunos quimioatractantes (Pober \& Sessa, 2007). Esta activación lenta de las células endoteliales se desencadena por la presencia de citoquinas inflamatorias, como TNFa e IL1 $\beta$.

Minutos después del arresto leucocitario en las células endoteliales, los leucocitos integran señales quimiotácticas adicionales (Alon \& Shulman, 2011; Rot \& von Andrian, 2004). La presencia y gradiente de citoquinas será clave en la determinación del sitio y ruta de migración: entre células endoteliales (paracelular) o a través de una célula endotelial (transcelular). El gateo del leucocito en la cara luminal del endotelio, inspeccionando posibles sitios para migrar al foco inflamatorio, permite el encuentro del leucocito con distintas citoquinas. Este gateo se hace posible gracias a protrusiones 
leucocitarias que se extienden a través de las uniones adherentes entre células endoteliales o que atraviesan el propio cuerpo endotelial, siendo un mecanismo de detección de gradientes quimiotácticos que permite además al leucocito elegir un lugar apropiado para cruzar el endotelio (Alon \& Shulman, 2011).

Una vez que se traspasa el endotelio, los leucocitos tienen que atravesar la capa de pericitos y la membrana basal, siendo un proceso en el que tanto el leucocito como componentes celulares y de la matriz sufren modificaciones espaciales y en su señalización (Nourshargh et al, 2010). Además, tras la transmigración los leucocitos presentan un fenotipo alterado, proactivo, con mayor supervivencia y capacidad destructora de patógenos y células tumorales.

\subsubsection{INTERACCIONES LEUCOCITO-ENDOTELIALES EN VÉNULAS POSTCAPILARES}

En la cascada de adhesión leucocitaria, cada paso condiciona al siguiente, dándose además un continuo solapamiento (Figura 3). Las opciones moleculares en cada paso son de gran diversidad, pudiendo darse distintas combinaciones de alta especificidad en función del antígeno, del tejido y del contexto inflamatorio (Ley et al, 2007).

Tanto la naturaleza de la inducción inflamatoria, como el tejido en el que se sitúa el foco de la inflamación, darán lugar a cambios en la cascada de adhesión leucocitaria y, consecuentemente, en la cantidad de infiltrado leucocitario. Así, una inducción inflamatoria por infección, como es el caso del LPS, inducirá un mayor infiltrado leucocitario que una inducción isquémica (Knapp, 2009).

Las características anatómicas de los distintos tejidos permitirán que el reclutamiento leucocitario sea más o menos eficiente (Block et al, 2012). De hecho, la cascada de adhesión leucocitaria varía en función del tejido en el que se encuentre el foco inflamatorio, dándose en vénulas postcapilares en el riñón, mientras que se da en capilares en el tejido pulmonar (Block et al, 2012). Esto facilita las interacciones de las 
integrinas leucocitarias con las endoteliales debido a la reducida luz del endotelio capilar, siendo un tejido en el que podemos observar gran cantidad de acúmulos de infiltrado leucocitario en condiciones inflamatorias (Herter \& Zarbock, 2013).

Las integrinas son una familia de 30 heterodímeros que participan en una gran variedad de funciones celulares. La unión de las integrinas a sus ligandos conlleva un cambio de conformación del citoesqueleto, así como redistribución intracelular (Herter \& Zarbock, 2013). En general, los leucocitos tienen sus integrinas en estado de reposo. Las integrinas leucocitarias desarrollan afinidad por sus ligandos endoteliales específicos, dándose adhesiones fuertes que resisten el empuje del flujo sanguíneo (Alon \& Shulman, 2011; Carman \& Springer, 2003; Ley et al, 2007).

Para que se de esta transición, es necesario que leucocitos que circulan de manera libre por el torrente sanguíneo queden capturados en el endotelio, proceso mediado por la interacción de glicoproteínas leucocitarias (como PSGL-1) con selectinas. La expresión de las selectinas se induce tanto en vénulas postcapilares activadas de manera aguda o crónica (P y E-selectina) como en plaquetas (Ley et al, 2007; Zarbock et al, 2011). Además, los leucocitos circulantes pueden unirse a su vez a leucocitos unidos al endotelio mediante la unión entre L-selectina y PSGL-1 (Walcheck et al, 1996).

El rodamiento leucocitario mediado por selectinas se estabiliza generalmente por microvellosidades leucocitarias, que ralentizan el rodamiento permitiendo que se den interacciones con citoquinas e integrinas endoteliales (Chen \& Springer, 1999). En los neutrófilos en rodamiento se da la unión de E-selectina endotelial con ña PSGL-1 leucocitaria, desencadenándose uniones débiles entre integrinas leucocitarias clave, como LFA-1 y VLA-4, con sus ligandos endoteliales: la molécula de adhesión intercelular (ICAM-1) y la molécula de adhesión vascular (VCAM-1), dándose una ralentización del rodamiento mediado por selectinas. Aunque ICAM-1 y VCAM-1 no se localizan en los bordes endoteliales ni intervienen directamente en la transmigración, participan en eventos que ocurren justo antes de la diapédesis, reclutándose en los bordes endoteliales durante la transmigración. ICAM-1 y VCAM-1 intervienen de manera directa 
en la adhesión firme de los leucocitos a la superficie apical de las células endoteliales (Barreiro et al, 2008; Carman \& Springer, 2004).

El arresto leucocitario requiere la activación de al menos una de las principales integrinas leucocitarias: LFA-1 (presente en leucocitos efectores), Mac-1 (presente en neutrófilos y monocitos) o VLA-4 (presente en monocitos, eosinófilos y células B y T efectoras). Una vez que el leucocito esta adherido de manera firme al endotelio, ICAM-1 se agrupa en los bordes endoteliales de justo debajo del leucocito y continúa rodeándole, desplazándose los agrupamientos de ICAM-1 a la vez que se va desplazando el leucocito.

Tras el arresto, los leucocitos efectores pueden o translocarse a través de la capa endotelial, generalmente en uniones endoteliales paracelulares, o gatear, mediante uniones de sus integrinas, por la cara luminal endotelial, buscando sitios óptimos para la transmigración (Phillipson et al, 2009). In vivo, se ha demostrado que el gateo permite la detección de gradientes de quimiocinas que dirigen a los leucocitos de tejidos sanos al foco inflamatorio, reduciéndose así posibles daños colaterales causados por el infiltrado inflamatorio (McDonald et al, 2010).

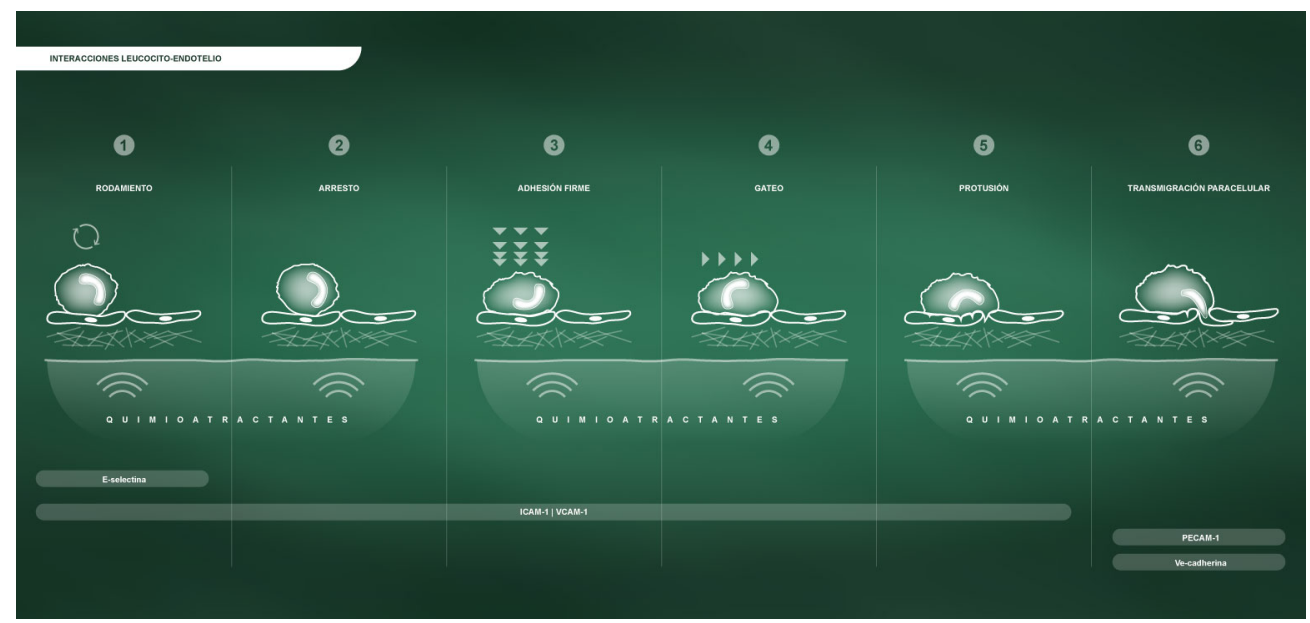

Figura 3. Representación de las interacciones leucocito-endotelio, y las principales moléculas implicadas. 
Como ocurre en otros procesos migratorios, los leucocitos reorganizan su citoesqueleto de actina, generando un borde delantero protrusivo y un urópodo contráctil (Hyun et al, 2012). El reciclaje de integrinas en el borde protrusivo contribuye al gateo leucocitario hacia sitios óptimos para transmigrar (Katagiri et al, 2006). Durante el gateo, los leucocitos generan numerosos contactos de tipo integrina con la cara luminal endotelial (Shulman et $a l, 2009)$. Esto hace posible que el gateo leucocitario pueda darse en dirección contraria o perpendicular al flujo sanguíneo, permitiendo una exploración total de la superficie luminal vascular (Carlin et al, 2013; Phillipson et al, 2009; Sumagin et al, 2010).

\subsubsection{MIGRACIÓN CELULAR TRANSENDOTELIAL}

El paso de gateo leucocitario a la rotura del endotelio y consecuente migración transendotelial (MTE) está orquestado por múltiples eventos moleculares y celulares. Entre ellos destacan la detección de sitios óptimos de transmigración que proporcionen una guía quimiotáctica a través del lumen, interacciones reversibles con la cara luminal endotelial y cambios en la morfología del leucocito que permitan al gran núcleo leucocitario atravesar las uniones estrechas interendoteliales (Nourshargh et al, 2010).

En un 70-90\% de los casos, la transmigración es por la vía paracelular (entre células endoteliales adyacentes), dándose la MTE por vía transcelular en casos aislados (Ley et al, 2007; Muller, 2011; Woodfin et al, 2011). Sin embargo, en las células endoteliales del cerebro la proporción es la contraria, siendo la vía transcelular la más común. Esto se ha atribuido a que las uniones adherentes entre células endoteliales cerebrales son más estrechas, restringiéndose la vía transcelular (Engelhardt \& Ransohoff, 2012).

Tanto la vía paracelular como la transcelular conllevan cambios endoteliales causados por el leucocito. Por ejemplo, la adhesión leucocitaria mediada por integrinas desencadena la agrupación del ICAM-1 endotelial, y el consecuente reclutamiento de VCAM-1 en estructuras membranosas que actúan como plataformas para el arresto leucocitario firme y la posterior MTE (Barreiro et al, 2008; Carman \& Springer, 2004). La unión de ICAM-1 y VCAM-1 a ligandos como CD9, CD151 y CD147 en leucocitos en la fase de 
gateo desencadena eventos que incrementan la permeabilidad de la barrera endotelial: aumento del calcio intracelular (Huang et al, 1993; Pfau et al, 1995), generación de ROS (Deem et al, 2007; Martinelli et al, 2009) y activación de la proteína quinasa activada por mitógeno p38 (MAPK) (Hu et al, 2000). Además, en la MTE por la vía paracelular, la unión de ICAM-1 da lugar a la fosforilación en las tirosinas de moléculas clave en el mantenimiento de las uniones adherentes endoteliales, facilitándose así indirectamente la diapédesis. En la vía transcelular, agrupaciones de ICAM-1 se pueden translocar a dominios de caveola ricos en actina, formando canales intracelulares a través de los cuales los leucocitos atraviesan el endotelio (Carman et al, 2007; Millán et al, 2006).

Una vez que los leucocitos se han unido a las zonas de uniones endoteliales, la rotura del endotelio está finamente regulada por moléculas de adhesión expresadas de manera selectiva, o que presentan mayor expresión, entre células endoteliales adyacentes. En las uniones adherentes destaca VE-cadherina y la familia de moléculas de adhesión de uniones (JAM). En los bordes de células endoteliales adyacentes también aumentan los niveles de PECAM-1, CD99 e ICAM-2 (Muller, 2011; Nourshargh et al, 2010).

El paso clave para la MTE es la unión homofílica del PECAM-1 leucocitario con el PECAM1 del borde de la célula endotelial (Muller, 2011; Mamdouh et al, 2003). Es además el punto de no retorno para el leucocito. In vivo, los pasos anteriores de arresto, rodamiento y adhesión firme son reversibles. La mayoría de los leucocitos que pasan por una vénula postcapilar cercana al foco inflamatorio no son capturados, muchos se llegan a unir al endotelio y se sueltan, volviendo a la circulación. Pero una vez que se da la diapédesis, continúa la migración al foco inflamatorio y no vuelve al torrente sanguíneo(Muller, 2015). De hecho, el bloqueo de PECAM con anticuerpos impide la MTE por completo, quedando los leucocitos en la etapa de gateo en superficie apical endotelial. Siguen activados y continúan con el gateo, pero mientras se mantiene PECAM bloqueado no inician la diapédesis (Schenkel et al, 2004).

Uniones homofílicas entre el PECAM leucocitario y el endotelial dan lugar a señales de reclutamiento del compartimento de borde lateral reciclable (CBLR). Durante la MTE, hay gran cantidad de moléculas que se reciclan en compartimentos intracelulares o 
vesículas, como CBLR, caveolas y endosomas (Ley et al, 2007; Muller, 2011; Vestweber, 2012). Su función parece ser el mantenimiento de la integridad endotelial y aportar compartimentos membranosos que rodeen al leucocito a su paso por la célula endotelial (Mamdouh et al, 2003). Así el CBLR es un depósito de moléculas necesarias para la MTE, como son PECAM-1, CD99 y JAM-A, permitiendo el reclutamiento de moléculas clave al sitio de diapédesis (Muller, 2011).

Además, para que la MTE sea eficiente es necesario que se dé la pérdida transitoria de VE-cadherina de la superficie celular (Weber et al, 2007). VE-cadherina tiene un papel crucial en la integridad endotelial, manteniendo adhesiones estrechas homofílicas entre células endoteliales adyacentes. Esto la convierte en una de las moléculas responsables de la permeabilidad endotelial, manteniendo en condiciones fisiológicas la barrera endotelial ante macromoléculas y leucocitos (Vestweber, 2012). Las funciones de VEcadherina están reguladas de manera directa por cateninas citoplasmáticas, que controlan las interacciones de VE-cadherina con la actina cortical del citoesqueleto. Además, en condiciones fisiológicas, VE-cadherina está asociada a una fosfatasa específica (VE-PTP), que se disocia del complejo VE-cadherina ante la presencia leucocitaria (Vockel \& Vestweber, 2013). VE-PTP provoca la fosforilación en residuos de tirosina tanto en VE-cadherina como en las cateninas asociadas, permitiéndose el reclutamiento del adaptador endocítico a-adaptina, dándose la endocitosis reversible de VE-cadherina en los lugares cercanos a la diapédesis (Wessel et al, 2014).

\subsubsection{ROTURA DE LA PARED VENULAR TRAS LA MIGRACIÓN TRANSENDOTELIAL}

Para salir por completo de la pared de la vénula, los leucocitos que están atravesando la barrera endotelial tienen que pasar la cubierta de pericitos y la membrana basal (Nourshargh et al, 2010) (Figura 4). Los pericitos son células murales que se encuentran embebidas en la membrana basal, envolviendo a las células endoteliales de manera discontinua. Los pericitos pueden expresar de manera inducible tanto moléculas de adhesión clave, como ICAM-1 y VCAM-1, como quimiocinas y receptores de citoquinas proinflamatorias (Pober \& Sessa, 2007; Stark et al, 2013; Voisin \& Nourshargh, 2013). Se ha 
demostrado que los pericitos aportan un sustrato adhesivo, mediado por la interacción del ICAM-1 expresado por los pericitos con Mac-1 o LFA-1 de neutrófilos, participando activamente en la transmigración y permitiendo que el neutrófilo localice lugares óptimos para infiltrarse en el tejido (Proebstl et al, 2012).

Al igual que las células endoteliales, los pericitos contribuyen en las propiedades de barrera propias de la membrana basal. La membrana basal es una compleja red proteica, principalmente constituida por laminina y colágeno IV, formando una barrera muy poco permeable para los leucocitos (Rowe \& Weiss, 2008). A día de hoy, se piensa que existen zonas de la membrana basal que son menos densas, conocidas como regiones de baja expresión (RBE), que además coinciden espacialmente con huecos entre pericitos adyacentes. Por ello, las RBE se comportan como salidas elegidas para atravesar la membrana basal (Voisin \& Nourshargh, 2013). De hecho, se ha demostrado que su tamaño aumenta considerablemente durante la transmigración leucocitaria (Voisin et al, 2010).

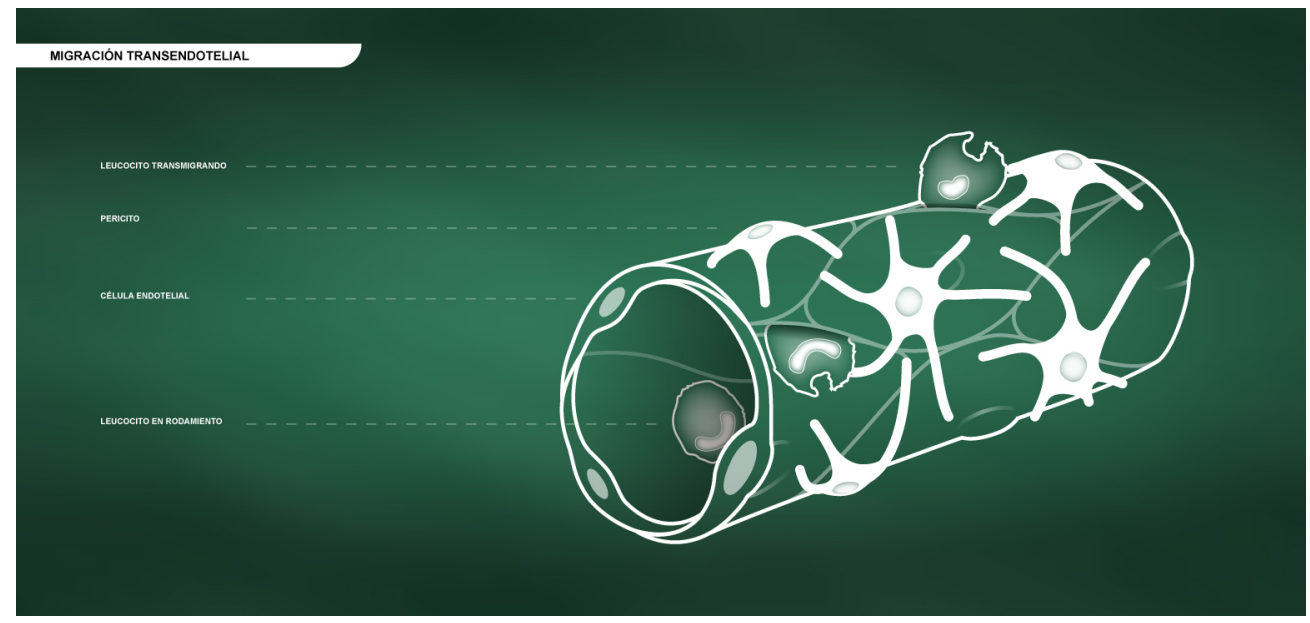

Figura 4. Representación de la migración leucocitaria transendotelial, a través de los espacios entre pericitos. 
Aunque las células endoteliales son la fuente principal de moléculas quimiotácticas para leucocitos efectores, los pericitos, fragmentos de la membrana basal, macrófagos perivasculares, mastocitos, señales antigénicas y leucocitos recién extravasados liberan también factores quimiotácticos, enviando señales de corto alcance que dirigen a los leucocitos durante la diapédesis (Nourshargh \& Alon, 2014). Por ello, los mecanismos que guían al leucocito en la migración desde el lumen vascular hasta el tejido extravascular, donde ejercerá sus funciones efectoras, son múltiples y cooperativos, y están estrechamente relacionados.

Más adelante en el proceso inflamatorio, los neutrófilos extravasados que han sido fagocitados por macrófagos perivasculares regulan de manera negativa la extravasación leucocitaria, mediante la secreción de mediadores de la resolución de la inflamación como resolvinas, lipoxinas (Wolf et al, 2008) y citoquinas antiinflamatorias como IL10. Estos mediadores reducen la extravasación leucocitaria, la respuesta ante quimioatractantes y la expresión de moléculas de adhesión endotelial (Soehnlein et al, 2009). Esta retroalimentación negativa es crítica, ya que, aunque la extravasación leucocitaria es necesaria para mantener las funciones vitales y proteger al organismo de agentes infecciosos o lesiones, ocasiona daño tisular cuando se descontrola. Un reclutamiento leucocitario excesivo contribuye al desarrollo de enfermedades inflamatorias crónicas, entre las que se encuentran ateroesclerosis, diabetes mellitus y artritis reumatoide entre otras (Ley \& Reutershan, 2006). 


\section{PERMEABILIDAD VASCULAR}

La función principal de la vasculatura es asegurar el aporte de sangre oxigenada a los tejidos, para posteriormente recoger la sangre sin oxígeno y llevarla de nuevo a los pulmones. Además, la vasculatura controla distintas funciones homeostáticas, como la hemostasia, el transporte de lípidos y la respuesta inmune (Lanitis et al, 2015). En un individuo sano, la vasculatura es estable, permitiendo la supervivencia de las células endoteliales (Lee et al, 2007).

En condiciones control, la vasculatura es permeable a solutos y pequeñas moléculas, restringiendo la extravasación de células y moléculas de mayor tamaño. En muchas patologías, como el cáncer y enfermedades que cursan con inflamación, la barrera vascular pierde su estructura y la permeabilidad aumenta extremadamente (Figura 5). La fuga de células y moléculas de gran tamaño ocasiona edema e inflamación, llegando a hacerse crónica en ciertas patologías (Lee et al, 2007).

\subsection{IMPORTANCIA FISIOPATOLÓGICA}

El edema se define como la acumulación de líquido en el espacio intersticial, y en la actualidad se considera un signo clínico, propio de patologías como las enfermedades cardiovasculares. La mayor parte de la circulación de líquido y proteínas a la cavidad intersticial ocurre en los capilares o en las vénulas postcapilares pulmonar (Siddall et al, 2017), coincidiendo con los lugares óptimos para la migración transendotelial.

La permeabilidad vascular puede incrementarse de manera patológica y generar edema por distintas causas, entre las que se encuentra la insuficiencia renal, la cirrosis hepática, la insuficiencia cardíaca y la inflamación (Cho \& Atwood, 2002).

El edema puede ser sistémico, provocando una tumefacción de todos los tejidos y órganos, o puede ser localizado, entre los que destaca el edema pulmonar (Siddall et al, 2017; Akdemir et al, 2014). En esta manifestación clínica, se acumula líquido en los 
pulmones por un aumento de presión en los capilares pulmonares, edematizándose tanto el espacio intersticial del parénquima pulmonar como el propio espacio alveolar (Akdemir et al, 2014). Una de las causas que provocan el edema pulmonar es la inhalación de productos tóxicos o las infecciones, causando insuficiencia respiratoria (Assaad et al, 2017).

También destacan los edemas cutáneos, generándose por las picaduras de insectos, daño mecánico, las quemaduras, o el contacto de la piel con irritantes como las carrageninas (Posadas et al, 2004).

Dada la repercusión fisiopatológica y la extensión en la población de los edemas pulmonares y cutáneos, nos propusimos estudiar el papel de endoglina en la permeabilidad vascular en condiciones inflamatorias en dos modelos animales que mimificaran dichas patologías. Por un lado, el modelo de nebulización pulmonar de LPS nos permite valorar el edema pulmonar ante infección aguda en presencia de endoglina, mientras que mediante el tratamiento con carragenina en el modelo del air pouch podemos valorar el edema cutáneo. 
PERMEABILIDAD VASCULAR EN CONDICIONES FISIOLÓGICAS
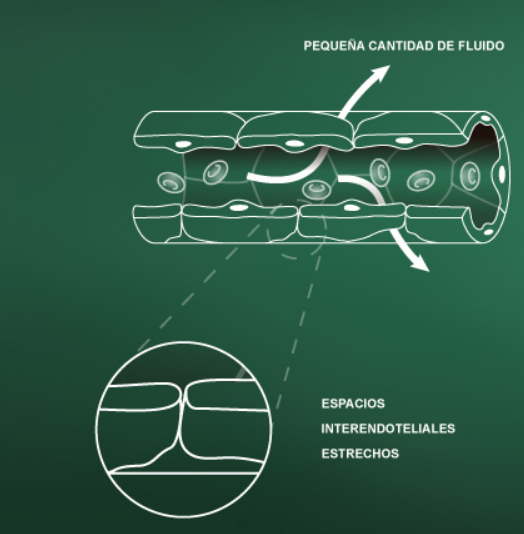

ESPACIOS

INTERENDOTELIALES ESTRECHOS
PERMEABILIDAD VASCULAR

DURANTE INFLAMACIÓN
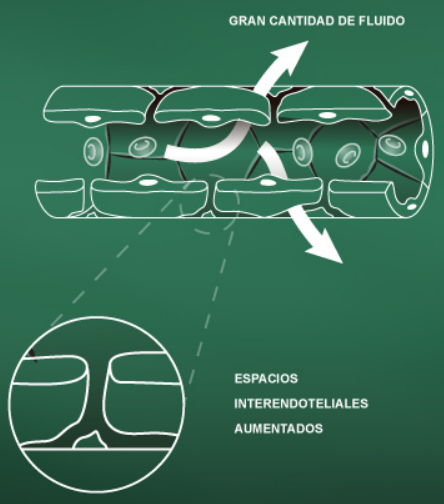

ESPACIOS

INTERENDOTELIALES

AUMENTADOS

Figura 5. Diferencias entre la permeabilidad vascular en condiciones fisiológicas y en condiciones inflamatorias.

\subsection{MECANISMOS EN LA PERMEABILIDAD VASCULAR}

En condiciones fisiológicas, las moléculas menores a $40 \mathrm{kDa}$ pueden extravasarse de manera espontánea (Egawa et al, 2013), mientras que moléculas de mayor tamaño necesitan la ruptura de la barrera vascular para extravasarse al tejido. Como ya hemos explicado, aunque este proceso ocurre generalmente en las vénulas postcapilares, los capilares y vénulas de mayor tamaño también pueden aumentar su permeabilidad.

El mecanismo de la permeabilidad vascular puede variar dependiendo del órgano y del tipo de vaso. A día de hoy, se consideran dos modelos principales. El primero requiere 
la formación de poros transendoteliales por vesículas o vacuolas: el orgánulo vesículovacuolar. El segundo modelo, requiere la disociación reversible de uniones paracelulares entre células endoteliales.

\subsubsection{EL ORGÁNULO VESÍCULO-VACUOLAR}

El orgánulo vesículo vacuolar está implicado principalmente en la extravasación de macromoléculas. El transporte vesicular a través del endotelio (transcitosis) es un importante mecanismo para la liberación de macromoléculas al tejido. Durante la transcitosis, regiones de la membrana plasmática llamadas caveolas se separan, funcionando como transportadores vesiculares, y se fusionan con la membrana plasmática abluminal, liberando su contenido en el espacio perivascular. La transcitosis endotelial ocurre en ciertos vasos, bajo ciertas condiciones fisiológicas. Por ejemplo, la transcitosis es común en la vasculatura cerebral, aumentando considerablemente ante alteraciones de la barrera hematoencefálica (Armulik et al, 2010).

\subsubsection{UNIONES PARACELULARES}

Las uniones entre células endoteliales pueden ser adherentes u oclusivas. El principal componente de las uniones adherentes es VE-cadherina, la cual forma uniones homofílicas entre célula endoteliales adyacentes (Dejana et al, 1999). Las uniones adherentes se separan en respuesta a distintos estímulos, como el factor de crecimiento endotelial vascular (VEGF) y citoquinas proinflamatorias como la histamina y la bradiquinina. Estos estímulos causan la hiperfosforilación de VE-cadherina y por ello, su disociación. VE-cadherina está también fosforilada en el estado basal, a través de la activación de c-Src. El evento que desencadena la internalización de VE-cadherina sigue sin identificar (Gavard \& Gutkind, 2006).

En condiciones fisiológicas, la disociación de las uniones adherentes es transitoria, y vuelven a cerrarse debido al reciclaje de VE-cadherina, situándose de nuevo en la superficie celular (Fukuhra et al, 2006). Hay distintos artículos que muestran las uniones 
adherentes abiertas, o incluso se ha observado la dinámica de apertura y cierre in vivo (Baluk et al, 1997). En enfermedades caracterizadas por una permeabilidad vascular excesiva, la regulación de la apertura y cierre de las uniones está descontrolada, manteniéndose abiertas de manera continua, ocasionado permeabilidad vascular crónica (Nagy et al, 2008).

Se ha hipotetizado que la retracción del citoesqueleto de actina, que provoca la contracción de las células endoteliales, podría facilitar la apertura de las uniones adherentes, por lo que también podría estar implicada en el aumento de permeabilidad vascular. Sin embargo, esta hipótesis no es clara, ya que los cambios celulares observados podrían deberse al mismo desensamblaje de las uniones adherentes. Por ello, sería necesario estudiar más a fondo el posible papel del citoesqueleto de actina en la permeabilidad vascular.

\subsection{REGULACIÓN DE LA PERMEABILIDAD VASCULAR}

La permeabilidad vascular puede regularse de manera directa por moléculas que provoquen desestabilización de la barrera endotelial, ya sea por la formación de vesículas o por la apertura de uniones intercelulares. La magnitud de la permeabilidad vascular también se puede regular indirectamente por la presión y el flujo sanguíneo. Así, un incremento en el flujo sanguíneo supondría un aumento en la permeabilidad vascular (Baskurt et al, 2004; Meininger \& Davis, 1992). Entre los factores que regulan la permeabilidad destacan los factores de crecimiento, como VEGF (Ferrara, 2005) y citoquinas inflamatorias.

Las citoquinas inflamatorias que destacan en la regulación de la permeabilidad vascular son la histamina y la bradiquinina. Ambas median la activación de la serina/treonina quinasa Akt, que fosforila y activa eNOS. Una vez fosforilado, eNOS cataliza la generación de NO, el cual es un potente vasodilatador. Además, NO nitrosila la $\beta$ catenina que está fisiológicamente unida a VE-cadherina, provocando su disociación y 
la consecuente ruptura de las uniones adherentes entre células endoteliales (Thibeault et al, 2010).

\subsection{PERMEABILIDAD VASCULAR Y MIGRACIÓN TRANSENDOTELIAL}

Durante muchos años, se ha asumido que el proceso de permeabilidad vascular y la MTE estaban directamente relacionados: a mayor permeabilidad, mayor facilidad para que se dé la extravasación leucocitaria. Por ello, tradicionalmente se ha entendido la permeabilidad vascular como un requisito para que se diera la MTE. Esto parecía evidente porque moléculas relacionadas con la adhesión leucocitaria y transmigración se relacionaban a su vez con la ruptura de uniones endoteliales, como trombina, histamina y bradiquinina (Mehta \& Malik, 2006).

Sin embargo, se ha demostrado que una MTE eficiente no requiere de un aumento en la permeabilidad de las uniones endoteliales (Weber et al, 2015; Winger et al, 2014). En estudios de inflamación en la vasculatura de la tráquea in vivo, se demostró que la permeabilidad vascular se da principalmente en las vénulas postcapilares de menor diámetro (20-40 $\mu \mathrm{m})$, mientras que la mayoría de los leucocitos transmigran en vénulas más distales, de mayor tamaño (40-60 m) (Baluk et al, 1997; McDonald, 1994). Por ello, permeabilidad y MTE no tienen por qué ocurrir simultáneamente.

De hecho, la permeabilidad vascular y la MTE se controlan mediante residuos de tirosina del dominio citoplasmático de VE-cadherina distintos. Esto se estudió con ratones mutantes para distintos residuos de tirosina, demostrándose que los que presentaban una mutación tenían defectos en la inducción de la permeabilidad vascular, pero presentaban una extravasación leucocitaria normal, mientras que los ratones mutantes para otro residuo de tirosina presentaban una MTE neutrófila defectuosa, pero respondían con normalidad a agentes inductores de la permeabilidad (Wessel et al, 2014). 
Los mecanismos de ruptura de las uniones adherentes y modulación de VE-cadherina que permiten la permeabilidad vascular y MTE son distintos, aunque algunas de las moléculas que participan en ambos fenómenos sean comunes. Asimismo, la MTE es un fenómeno local que requiere de múltiples señales entre el leucocito y el endotelio (Muller, 2011, 2015), mientras que la permeabilidad vascular es una respuesta global. 


\section{ENDOGLINA}

Se ha demostrado que la proteína endoglina está aumentada en patologías que cursan con un proceso inflamatorio, entre las que se encuentran las enfermedades cardiovasculares, la preeclampsia y el cáncer (Bernabeu et al, 2009; López-Novoa \& Bernabeu, 2010). Sin embargo, se desconoce si endoglina podría estar teniendo un papel en la inducción del componente inflamatorio, o incluso en la base patológica de estas enfermedades.

A pesar de que se han empleado gran cantidad de recursos en la caracterización de los componentes celulares y moleculares de la inflamación, a día de hoy las terapias relacionadas con las enfermedades inflamatorias siguen siendo paliativas, estando lejos aún quedan lejos de estrategias terapéuticas que aborden las enfermedades inflamatorias de manera efectiva.

En esta tesis, exploramos el papel de endoglina como potencial regulador de las respuestas inflamatorias involucradas en el comienzo de inflamación, centrándonos en concreto en el papel de la endoglina en la respuesta inflamatoria aguda.

\subsection{EXPRESIÓN Y DISTRIBUCIÓN CELULAR}

Endoglina (CD105), es una glicoproteína de membrana homodimérica, de 180 kDa, formada por dos subunidades de $90 \mathrm{kDa}$ unidas por puentes disulfuro (Gougos \& Letarte, 1990).

Se expresa fundamentalmente en células endoteliales, especialmente en venas y capilares (Mahmoud et al, 2009), y tanto en adultos como en la vasculatura embrionaria (Arthur et al, 2000), por lo que es considerada como uno de los principales marcadores endoteliales. Además, endoglina se expresa en menores niveles en el músculo liso vascular y en pericitos (Conley et al, 2000; Rivera \& Brekken, 2011). También se ha descrito la expresión de endoglina en células de origen hematopoyético, como precursores de 
células B (Zhang et al, 1996), proeritroblastos (Buhring et al, 1991), macrófagos (Lastres et al, 1992; O'Connell et al, 1992), y células estromales de la médula ósea (St-Jacques et al, 1994a; Rokhlin et al, 1995), en los sincitiotrofoblastos de la placenta (Gougos et al, 1992; St-Jacques et al, 1994b), en fibroblastos (Gougos and Letarte, 1988), condrocitos del cartílago (Parker et al, 2003), células mesangiales de riñón (Rodriguez-Barbero et al, 2001; Diez-Marques et al, 2002) y en las células estrelladas del hígado (Meurer et al, 2005).

\subsection{ENDOGLINA COMO RECEPTOR AUXILIAR DE TGF-B}

El factor de crecimiento transformante beta (TGF- $\beta$ ) pertenece a una superfamilia de moléculas pleiotrópicas entre las que se encuentran las proteínas morfogenéticas óseas (BMPs), las activinas, inhibinas, factores de crecimiento y diferenciación y factores neurotróficos derivados de la glía (Massagué, 2000). Controlan tanto el desarrollo como la homeostasis del organismo, y están implicados en la regulación de la proliferación, diferenciación y apoptosis celular, procesos involucrados en la reparación tisular, en la angiogénesis y en la respuesta inmune (Massagué, 1998).

TGF $\beta$-1 es la isoforma más abundante de la superfamilia de TGF- $\beta$, y participa en distintos efectos biológicos: regula la proliferación celular, la apoptosis y procesos de desarrollo, la diferenciación celular y migración, además de modular la respuesta inmune (Shi \& Massagué, 2003; ten Dijke \& Arthur, 2007).

La señalización intracelular de TGF $\beta$-1 está mediada por receptores heterotriméricos con actividad serina/treonina quinasa y por proteínas citoplasmáticas denominadas Smads. EI TGF $\beta-1$ se une a su receptor tipo II, T $\beta$ RII para activar el receptor tipo I, T $\beta R I$, y fosforilar a las proteínas Smads. Existen dos receptores tipo I principales para TGF $\beta$ 1: las quinasas similares al receptor de activina: ALK5 y ALK1. ALK5 fosforila las proteínas Smad2 y Smad3, mientras que ALK1 fosforila a Smad1 y Smad5 (Goumans et al, 2002; Lebrin et al, 2005; Bertolino et al, 2005). Una vez activadas, las Smads forman un complejo que viaja al núcleo, donde actúa como factor de transcripción. 
Endoglina actúa como receptor auxiliar (receptor de tipo III) de la superfamilia de TGFß. A través de una secuencia de unión proteína-proteína presente en el dominio extracelular de endoglina, se favorece la estabilización del complejo de receptores que se forma tras la llegada del ligando, formado por los receptores de tipo I y tipo II. La formación de este complejo permite la fosforilación de los residuos intracelulares específicos, y, por tanto, la activación de la cascada de señalización de las Smads al interior celular. Endoglina carece de actividad enzimática, por lo que, aunque no activa por sí sola ninguna vía de señalización, modula la señal, ya que en su dominio intracelular existen residuos susceptibles de ser fosforilados, así como regiones claves de interacción con otras proteínas que pueden estar participando o interfiriendo en la cascada de señalización (Bernabeu et al, 2009; López-Novoa \& Bernabeu, 2010; Núñez-Gómez et al, 2017).

\subsection{ESTRUCTURA}

Endoglina es una glicoproteína de membrana homodimérica, de 180 kDa, formada por dos subunidades de $90 \mathrm{kDa}$ cada una, unidas por dos puentes disulfuro. Su dominio extracelular se encuentra altamente glicosilado por oligosacáridos unidos a las cadenas peptídicas mediante enlaces $\mathrm{N}$-Asn y O-Ser/Thr, que suponen aproximadamente el $20 \%$ del total del peso de la proteína. De los 658 aminoácidos que tiene endoglina, 561 corresponden a su dominio extracelular y 47 a la cola citoplasmática (Gougos \& Letarte, 1990; Llorca et al, 2007). Existe una segunda isoforma de endoglina, S-endoglina, minoritaria y más corta, que consta de 625 aminoácidos, puesto que carece de gran parte del dominio intracelular (Bellon et al, 1993). Además, endoglina presenta una forma soluble que circula en plasma (endoglina soluble), que se corresponde con la región extracelular de endoglina de membrana.

\subsubsection{EL DOMINIO EXTRACELULAR DE ENDOGLINA}

El dominio extracelular de endoglina consta de dos regiones diferenciadas: un dominio $\mathrm{N}$-terminal, y el dominio ZP (zona pelúcida), muy conservado entre las diferentes 
especies. Los primeros 25 aminoácidos corresponden al péptido señal o secuencia líder, que dirige endoglina a la membrana citoplasmática, donde este fragmento es eliminado (Gougos \& Letarte, 1990).

El dominio N-terminal es portador de la secuencia de unión de TGF- $\beta$ en su papel de receptor auxiliar (López-Casillas et al, 1994; Llorca et al, 2007; Castonguay et al, 2011; Alt et al, 2012).

El dominio ZP, por su parte, consta de 260 aminoácidos y está implicado en las interacciones proteína-proteína (Jovine et al, 2005). Participa en la oligomerización de endoglina y en su interacción con los receptores TßRII y ALK5 (Guerrero-Esteo et al, 2002). Además, presenta el tripéptido RGD (arginina-glicina-aspartato), comprendido entre los aminoácidos 374 y 376, implicado en adhesión celular (Gougos \& Letarte, 1990; Cheifetz et al, 1992; Llorca et al, 2007).

\subsubsection{EL DOMINIO INTRACELULAR DE ENDOGLINA}

Tras el dominio extracelular, endoglina posee una única región transmembrana y un corto dominio citoplasmático, que consta de 47 aminoácidos y se encuentra constitutivamente fosforilado en las células endoteliales (Lastres et al, 1994; Yamashita et al, 1994). En este dominio citosólico endoglina presenta numerosos residuos serina, treonina y tirosina susceptibles de ser fosforilados (Lastres et al, 1994; Koleva et al, 2006; Pan et al, 2014). Los tres últimos residuos C-terminales constituyen una secuencia de unión a motivos PDZ tipo I de otras proteínas (Guerrero-Esteo et al, 2002).

\subsubsection{LAS ISOFORMAS DE ENDOGLINA}

El gen de endoglina consta de 15 exones, pero en ocasiones, el ARNm resultante de su transcripción puede sufrir splicing alternativo, dando lugar a dos isoformas diferentes de la proteína: la isoforma larga, L-endoglina, y la isoforma corta, S-endoglina. 
La isoforma predominante es L-endoglina, a la que corresponde la estructura proteica anteriormente descrita. Pero si durante la transcripción génica no se elimina el último intrón, localizado entre los exones 13 y 14, el ARNm maduro resultante da lugar a la traducción de una proteína más corta, S-endoglina, que carece de gran parte del dominio intracelular ya que el intrón introduce un codón de parada prematuro (Bellon et al, 1993; Perez-Gomez et al, 2005).

S-endoglina humana consta de 625 aminoácidos, con una cola citoplasmática de 14 aminoácidos, de los cuales solo 7 son comunes a la isoforma larga (del 612 al 618), puesto que los 7 aminoácidos terminales corresponden a la región del intrón que se traduce, hasta el codón de paro (del 619 al 625). Este dominio intracelular, por tanto, carece del tripéptido PDZ, así como de sitios clave de fosforilación como son la Ser ${ }^{621}$ y todos los residuos fosforilables por miembros del complejo de receptores de TGF- $\beta$, pero conserva los sitios de fosforilación por Src.

S-endoglina se expresa significativamente en hígado y pulmón en ratón (Perez-Gomez et al, 2005), y su expresión aumenta durante la senescencia de las células endoteliales (Blanco et al, 2008) y en situaciones de estrés oxidativo y envejecimiento en macrófagos (Aristorena et al, 2014a).

La mayoría de estudios se han realizado atendiendo a la isoforma mayoritaria, Lendoglina. Se cree que ambas isoformas, L y S-endoglina, modulan de manera distinta la señalización de las vías ALK1 y ALK5. En distintos modelos celulares se ha demostrado que la sobreexpresión de S-endoglina favorece la señalización a través de ALK5/Smad2/3, mientras que L-endoglina lo hace a través de ALK1/Smad1/5/8 (Blanco et al, 2008; Velasco et al, 2008).

Por su parte, la forma soluble de endoglina, endoglina soluble, es una proteína circulante que se corresponde con la región extracelular, N-terminal, de endoglina de membrana. La endoglina soluble se genera mediante el corte proteolítico de la endoglina de membrana por la metaloproteinasa MMP14 en la posición 586-587, próximo al dominio transmembrana, liberando al medio el fragmento correspondiente a casi todo el dominio 
extracelular, de aproximadamente 80 kDa (Hawinkels et al, 2010; Kaitu'u-Lino et al, 2012) (Figura 6).

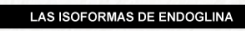

L-ENDOGLINA

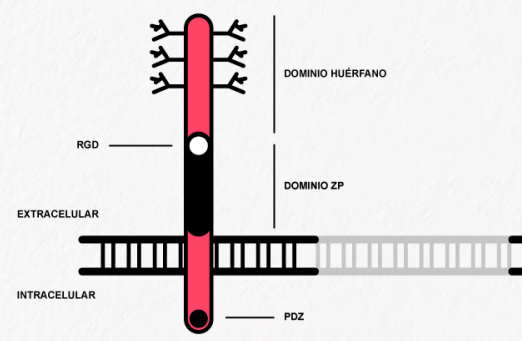

S-ENDOGLINA

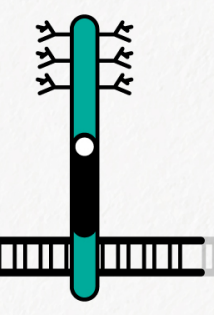

ENDOGLINA SOLUBLE

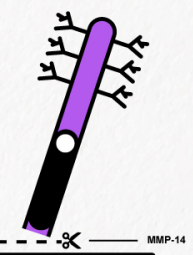

IIIIII IIIIIII

Figura 6. Estructura de las distintas isoformas de endoglina: L-endoglina, S-endoglina y endoglina soluble.

En condiciones fisiológicas aparece en plasma en bajas concentraciones y aumentada en diversas patologías como la preeclampsia, leucemia mieloide aguda, distintos tipos de tumores sólidos y cardiomiopatía dilatada, donde los niveles elevados de endoglina soluble están asociados a un peor pronóstico (Bernabeu et al, 2009; Cruz-Gonzalez et al, 2008; Pérez-Gómez et al, 2007). Además, en pacientes con diabetes e hipertensión, la presencia de altas concentraciones de endoglina soluble se ha relacionado con alteraciones cardiovasculares (Blázquez-Medela et al, 2010).

\subsubsection{FUNCIONES DIFERENCIALES DE LAS ISOFORMAS DE ENDOGLINA}

\subsection{Y S-ENDOGLINA}

Apenas se conoce el papel que desempeña S-endoglina in vivo. Aunque hay muy pocas investigaciones como para sacar conclusiones sólidas, estudios en ratón sugieren que 
puede comportarse como una molécula antiangiogénica, de manera contraria a la función proangiogénica que se le atribuye a la L-endoglina. Ratones que sobreexpresan S-endoglina presentan un retraso en el crecimiento tumoral, similar a aquel observado en ratones deficientes de endoglina (Quintanilla et al, 2003; Perez-Gomez et al, 2005; Duwel et al, 2007). También se le ha atribuido un papel en senescencia (Blanco et al, 2008), y se ha sugerido que el ratio L-endoglina / S-endoglina puede verse reducido con el envejecimiento.

Se han descrito diferentes respuestas celulares a la sobreexpresión de L-endoglina o de S-endoglina, sugiriendo un papel esencial del dominio intracelular de la proteína en la modulación de numerosos procesos (Figura 7). Así, en un modelo celular de mioblastos de rata, la sobreexpresión de L-endoglina promueve la activación de la vía de Smad1/5/8, inhibe la vía de $S m a d 2 / 3$ y estimula la proliferación celular. Por el contrario, la sobreexpresión de S-endoglina induce la señalización a través de Smad2/3 y la producción de componentes de la matriz extracelular (Velasco et al, 2008). 
L-ENDOGLINA

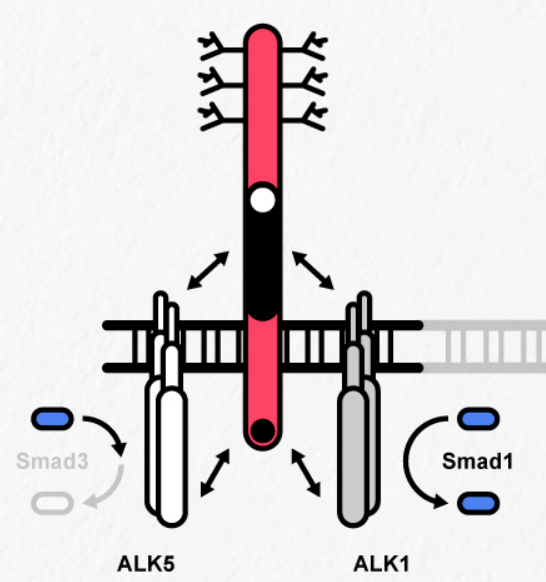

S-ENDOGLINA

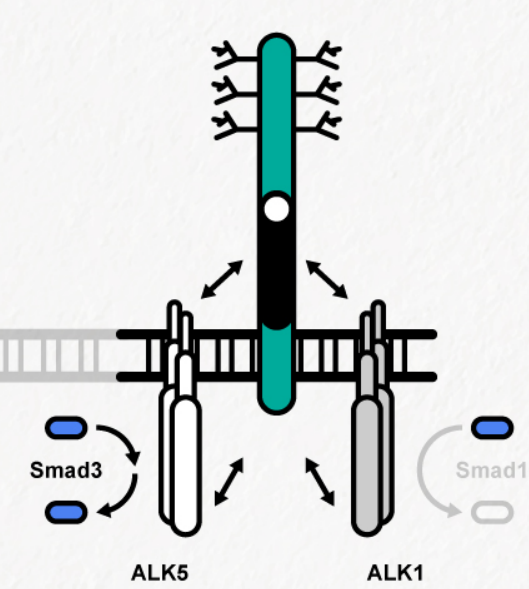

Figura 7. La señalización intracelular de las isoformas de endoglina

Una posible hipótesis es que, al carecer de la mayor parte del dominio intracelular, Sendoglina esté actuando como un dominante negativo del efecto de L-endoglina, al competir con ella por la unión al complejo de receptores de TGF- $\beta$. De esta forma, Sendoglina ejercería el mismo papel que L-endoglina en aquellos procesos mediados exclusivamente por el dominio extracelular, pero antagonizaría el efecto de la isoforma principal cuando es el dominio intracelular quien modula el proceso en cuestión.

\subsection{ENDOGLINA SOLUBLE}

El mecanismo de acción de endoglina soluble aún no ha sido bien definido. Una de las teorías comúnmente aceptada es que endoglina soluble ejerce su acción mediante la inhibición de la ruta de señalización de TGF- $\beta$. 
Como se ha explicado anteriormente, endoglina de membrana actúa como modulador de esta vía de señalización, interaccionando con el ligando y con el resto de receptores mediante su dominio extracelular. Por lo tanto, se sugiere que el exceso de endoglina soluble podría interaccionar con el ligando TGF- $\beta$ y antagonizar su unión a los receptores de membrana (Venkatesha et al, 2006). Sin embargo, se ha demostrado que endoglina por sí sola, no puede unirse a TGF- $\beta$, si no que requiere de la interacción con los otros

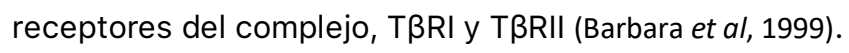

Podría ser cierto que endoglina soluble estuviera modificando la señalización a través de TGF- $\beta$, pero interaccionando con el complejo de receptores formado tras la unión del ligando, y no mediante unión directa al mismo. En este caso, al carecer del dominio citoplasmático, endoglina soluble actuaría de manera similar a la S-endoglina, modificando la señal al interior celular. Otra posibilidad es que se forme un complejo entre endoglina soluble y el receptor soluble de tipo I o II de TGF- $\beta$ (endoglina solublesT $\beta R I$ o endoglina soluble-sT $\beta R I I)$, bloquee la interacción con los receptores de membrana e inhiba su señalización. A pesar de estas hipótesis, se hacen necesarias más investigaciones antes de poder hacer conclusiones al respecto. 


\section{ENDOGLINA E INFLAMACIÓN}

La expresión y función de endoglina se ha estudiado profundamente en relación con células endoteliales y fisiología vascular en general (López-Novoa \& Bernabeu, 2010). La endoglina se ha asociado con distintas patologías, entre las que se encuentran la Telangiectasia Hemorrágica Hereditaria $(\mathrm{HHT})$, cáncer, preeclampsia o hipertensión (Bernabeu et al, 2009; Shovlin, 2010; Kapur et al, 2012; Rana et al, 2012; Valbuena-Diez et al, 2012).

A pesar de que se ha demostrado la relación de endoglina con distintas patologías, actualmente no se ha descrito su papel en la inflamación. El hecho de que la expresión de endoglina aumente, tanto en condiciones inflamatorias como en distintas patologías que cursan con inflamación, sitúa a endoglina como una molécula extremadamente interesante, lo cual hace necesaria la profundización en el estudio de los efectos de endoglina en inflamación.

\subsection{ENDOGLINA EN PATOLOGÍAS}

Se han relacionado niveles elevados de endoglina de membrana con distintos procesos inflamatorios. La expresión de endoglina de membrana en células endoteliales aumenta en la piel, el hígado, el intestino y el pulmón durante los procesos inflamatorios, siendo mayor la expresión en zonas de infiltrado inflamatorio (Torsney et al, 2002). Particularmente, la expresión de endoglina se triplica durante la cicatrización de heridas. Además, se ha demostrado que la expresión máxima de endoglina coincide con el pico de extravasación leucocitaria (Torsney et al, 2002).

La expresión de endoglina se valoró en arteroesclerosis, demostrándose que en las placas arteroescleróticas humanas la mayoría de las células de músculo liso vascular expresan elevados niveles de endoglina, mientras que no se detecta en paredes arteriales normales (Conley et al, 2000). Además, se ha observado una mayor expresión de endoglina en las muestras de piel con soriasis que en piel normal (Rulo et al, 1995). En artritis reumatoide, se valoró la expresión de endoglina en tejido sinovial, siendo muy 
superior en las células mieloides y en los macrófagos del tejido sinovial de artritis reumatoide que en los casos control (Szekanecz et al, 1995). Además, se ha demostrado que endoglina aumenta su expresión tras un daño vascular (Ma et al, 2000).

Muchas de las patologías en las que se observa una sobreexpresión de endoglina cursan con microambientes hipóxicos, como es el caso de la isquemia (Núñez-Gómez et al, 2017). Los mecanismos que causan este aumento de los niveles de endoglina son probablemente multifactoriales, pudiendo tener especial importancia la hipoxia causada por la isquemia del tejido (López-Novoa \& Bernabeu, 2010).

Se ha observado aumento en la expresión de endoglina tras isquemia-reperfusión en riñón. La expresión de endoglina en animales control es endotelial, mientras que tras la isquemia empieza a expresarse también en zonas de fibrosis e inflamación en el intersticio renal (Docherty et al, 2006).

Los mismos resultados se han obtenido al practicar isquemia en la pata trasera (Jerkic et al, 2006) y tras inducción de infarto de miocardio por ligadura de la arteria coronaria en ratón, expresándose endoglina intensamente en las células endoteliales de la zona infartada (van Laake et al, 2006).

Dado el elevado aumento de endoglina observado tras isquemia en riñón, se ha considerado el modelo de isquemia-reperfusión renal como un modelo óptimo para valorar el posible papel de endoglina en la inflamación.

Como el riñón es uno de los tejidos en el que se observa un mayor aumento de la expresión de endoglina tras una inducción inflamatoria, se eligió dicho modelo porque nos permite observar, con mayor facilidad, un potencial efecto de endoglina en comparación con tejidos donde la expresión sea menor.

Otro proceso patológico que cursa con hipoxia y sobreexpresión de endoglina de membrana es la angiogénesis tumoral (Bernabeu et al, 2009). Se ha observado aumento en 
la expresión de endoglina durante la proliferación de células endoteliales tumorales (Miller et al, 1999) y en la vasculatura de tumores sólidos en glándula mamaria (Li et al, 2001), próstata (Kassouf et al, 2004), cérvix (Brewer et al, 2000), cólon y recto (Takahashi et al, 2001; Akagi et al, 2002), pulmón (Tanaka et al, 2001), cabeza y cuello (Kyzas et al, 2006), riñón (Sandlund et al, 2006), esófago (Saad et al, 2005) y útero (Saad et al, 2003).

En patologías que cursan con inflamación se hace patente, como hemos explicado, un aumento en la expresión de endoglina de membrana. Sin embargo, también se observa un aumento en los niveles circulantes de endoglina soluble en distintas patologías, encontrándose elevada en el plasma y la orina de pacientes con cáncer, arterioesclerosis, diabetes y preeclampsia (Li et al, 2000, Blázquez-Medela et al, 2010, Cruz-Gonzalez et al, 2008, Venkatesha et al, 2006).

Al analizar los niveles de endoglina soluble en el plasma de pacientes sanos y en pacientes con cáncer de pecho, el $86 \%$ de los pacientes con cáncer tenían valores detectables de endoglina soluble, mientras que en los pacientes control solo fue detectable en el $73 \%$ de los pacientes. Los pacientes con metástasis tenían una concentración de endoglina soluble en plasma aún mayor, y, de hecho, los pacientes con metástasis en órganos distantes presentaron concentraciones de endoglina soluble incluso mayores (Li et al, 2000). Estos mismos resultados también se observan en pacientes con tumores sólidos colorrectales y de pecho (Takahashi et al, 2001), en cáncer de próstata (Fujita et al, 2009), en leucemia mieloide aguda y en desórdenes crónicos mieloproliferativos (Calabrò et al, 2003).

Estos datos sugieren que los niveles de endoglina soluble en plasma podrían utilizarse como un biomarcador para monitorizar de manera temprana síntomas de metástasis, gravedad y recaída en tumores sólidos y leucemias. Sin embargo, los valores de endoglina soluble en plasma disminuyen tras la quimioterapia (Takahashi et al, 2001), lo que limita la utilidad de endoglina soluble como marcador de metástasis y recurrencia (Bernabeu et al, 2009). 
También se han detectado elevados niveles de endoglina soluble en el plasma de pacientes con arterioesclerosis en comparación con controles sanos (Blann et al, 1996). Asimismo, la endoglina soluble aumenta en el plasma de pacientes con diabetes, siendo mayor en los pacientes con diabetes más severas (Blázquez-Medela et al, 2010). Por otro lado, un estudio observacional reveló que los niveles de endoglina soluble en plasma en pacientes que habían sufrido infarto agudo de miocardio son mayores que los de pacientes sanos, y que, de hecho, la concentración de endoglina soluble disminuye 48 horas tras el infarto (Cruz-Gonzalez et al, 2008).

Sin embargo, aunque actualmente la presencia de endoglina soluble se asocie a un peor pronóstico, no está claro por qué endoglina soluble se encuentra elevada en estas enfermedades.

El hecho de que aparezca en mayores concentraciones en el plasma de pacientes con las patologías descritas anteriormente nos haría pensar que tenga efectos perjudiciales, pero esto no está demostrado científicamente. No hay estudios que analicen de qué magnitud sería la enfermedad de dichos pacientes si endoglina soluble no aumentara su concentración en plasma. Por ello, antes de hacer conclusiones que sitúen a endoglina soluble como una molécula dañina, es necesario obtener más información al respecto.

Se ha demostrado en gran cantidad de publicaciones que hay niveles elevados de endoglina soluble en el plasma de pacientes con preeclampsia, una enfermedad que afecta a las embarazadas, y se caracteriza por hipertensión sistémica, proteinuria y edema en el tercer trimestre de embarazo (Sibai et al, 2005; Young et al, 2010). Este síndrome afecta tanto al feto como a la madre y se da aproximadamente en el $5 \%$ de las gestaciones. La preeclampsia severa se caracteriza por la apariencia del síndrome de HELLP (hemólisis, aumento de enzimas del hígado y bajo recuento plaquetario), convulsiones y reducción del tamaño fetal, ocasionando en muchos casos abortos (Sibai et al, 2005; Young et al, 2010). Se piensa que la preeclampsia es consecuencia de una invasión trofoblástica pobre a las arterias espirales, dando lugar a defectos en la placentación (Khong et al, 1986). 
La hipoxia y el estrés oxidativo se consideran responsables de la patogénesis de la preeclampsia (Soleymanlou et al, 2005; Al-Gubory et al, 2010). Asimismo, tanto la hipoxia como señales inflamatorias extracelulares pueden inducir la acumulación intracelular de ROS (Duranteau et al, 1998; Nakagawara et al, 1982).

Durante el embarazo, se induce un proceso inflamatorio que está incrementado en preeclampsia (Redman \& Sargent, 2003; Redman et al, 1999). En esta enfermedad se ha descrito un aumento de citoquinas proinflamatorias como TNFa, IL6 e IL1 $\beta$, mientras que se da una disminución de citoquinas antiinflamatorias, como IL10 e IL4 (Conrad et al, 1998; Hennessy et al, 1999; Szarka et al, 2010).

Este incremento en los factores proinflamatorios en placenta puede inducir la muerte de trofoblastos y la activación de células endoteliales, lo que da lugar a la disfunción endotelial observada en preeclampsia (Chen et al, 2010). Las citoquinas proinflamatorias TNFa, IL6 e IL1 $\beta$ incrementan la permeabilidad vascular, aumentan la expresión de moléculas de adhesión en células endoteliales y activan los leucocitos (Bamforth et al, 1996; Hofmann et al, 2002; Puhlmann et al, 2005), aumentando tanto la infiltración leucocitaria como el daño endotelial.

Además, la disminución de citoquinas antiinflamatorias está relacionada con una desregulación de la respuesta inmune, que también juega un papel muy importante en el correcto desarrollo del embarazo (Wegmann et al, 1993). Por ello, el aumento de citoquinas proinflamatorias y la disminución de antiinflamatorias contribuye al desarrollo de las alteraciones presentes en esta enfermedad.

Se cree que el estrés oxidativo generado es uno de los principales responsables del aumento de la respuesta inflamatoria en preeclampsia. Oxisteroles como 25hydroxicolesterol y 7-ketocolesterol, promueven la liberación de IL6 y TNFa (Aye et al, 2012). A su vez, la respuesta inflamatoria puede incrementar el estrés oxidativo y las ROS son consideradas como segundos mensajeros en la propagación del estímulo inflamatorio (Hensley et al, 2000). Además, se ha descrito que citoquinas inflamatorias como NFkB y TNFa, favorecen el aumento de HIF-1a (Görlach \& Bonello, 2008; Taylor, 2008). 
Por todo ello, tanto las citoquinas proinflamatorias como el incremento de ROS contribuyen a la disfunción endotelial mediante alteraciones estructurales de células endoteliales, cambios en la permeabilidad vascular y aumento de infiltración leucocitaria.

Dado que en preeclampsia existe un aumento de los niveles de endoglina soluble circulante, así como condiciones inflamatorias, podríamos pensar que existe una relación. Por ello, nos proponemos 3 modelos animales que presentan elevados niveles de endoglina soluble circulantes en los cuales inducimos 3 respuestas inflamatorias de distinta naturaleza. Los resultados que obtengamos sobre la potencial relación de endoglina soluble y la inflamación, podrían servir para explicar, al menos en parte, el papel de endoglina soluble en la inflamación presente en los casos de preeclampsia.

El hecho de que endoglina aumente su expresión en condiciones inflamatorias la convierte en una molécula de gran interés biomédico. A pesar de ser una proteína que se expresa de manera constitutiva en las células endoteliales, las cuales presentan un papel muy activo en la inflamación, la mayoría de las publicaciones que estudian endoglina se centran en su función en la fisiología vascular en general (Bernabeu et al, 2009; López-Novoa \& Bernabeu, 2010), y no analizan en detalle qué papel tiene en la respuesta inflamatoria, y, por ello, en las patologías en las que endoglina aumenta su expresión.

Si se definiera más profundamente si la endoglina tiene algún papel en la inflamación, podría constituir en sí misma una diana terapéutica muy atractiva. Actualmente, la información que se conoce sobre el papel de endoglina en inflamación es mínima, y dada la creciente morbilidad de las enfermedades inflamatorias a nivel mundial, tenemos la necesidad de encontrar tratamientos alternativos, lo cual significa, vislumbrar toda la información posible sobre moléculas que regulen la respuesta inflamatoria.

Además, distintos estudios han valorado la respuesta inflamatoria en ausencia de endoglina o cuando su expresión se encuentra reducida a la mitad (haploinsuficiencia de endoglina). Mediante este tipo de estudios se ha observado que la presencia de endoglina interfiere con la respuesta inflamatoria (Docherty et al, 2006, Scharpfenecker et al, 
2012, Jerkic et al, 2010, Shen et al, 2014), lo que la convierte en una molécula de enorme interés biomédico. A pesar de ello, los estudios que relacionan endoglina e inflamación son pocos, y en todos los casos valoran únicamente los efectos en la inflamación de una mayor o menor presencia de endoglina de membrana, sin valorar en ningún momento si se trata del dominio extracelular o el dominio intracelular de endoglina el responsable de dichos efectos, lo cual sería totalmente necesario para futuras aplicaciones biomédicas.

Se ha demostrado que, en haploinsuficiencia de endoglina, los riñones sometidos a isquemia-reperfusión muestran una histología prácticamente normal, sin observarse las alteraciones típicas provocados por la reperfusión, mostrando, de hecho, una infiltración leucocitaria mínima. Además, en haploinsuficiencia de endoglina no se observa el aumento en la expresión de iNOS y VCAM-1 ni la infiltración tisular de macrófagos propios de la isquemia, así como una menor actividad mieloperoxidasa en comparación con los WT isquémicos (Docherty et al, 2006).

De hecho, tras irradiar tejido de ratones haploinsuficientes de endoglina, se observa menos infiltración de macrófagos y una consecuente menor producción de citoquinas proinflamatorias IL1 $\beta$ e IL6y menor marcaje de CD45 que los ratones WT(Scharpfenecker et al, 2012). De hecho, la haploinsuficiencia de endoglina da lugar a una menor transmigración leucocitaria, tanto en el peritoneo como en sangre, observándose tras inducción inflamatoria con carragenina, así como tras LPS (Rossi et al, 2013). Por otro lado, se ha estudiado el efecto de endoglina en la migración leucocitaria in vitro. Observándose que tras añadir el quimioatractante CXCL12, la transmigración leucocitaria es mayor a través de los mioblastos que expresan endoglina que a través de los mock (Rossi et al, 2013).

Todos estos estudios concluyen que la haploinsuficiencia de endoglina da lugar a una respuesta inflamatoria reducida, tanto a nivel de expresión de moléculas de adhesión y citoquinas inflamatorias, así como actividad MPO e infiltrado inflamatorio (Docherty et al, 2006, Scharpfenecker et al, 2012, Rossi et al, 2013). 
Desde otro punto de vista, distintos estudios deducen que, la menor respuesta inflamatoria en haploinsuficiencia de endoglina se asocia con una peor resolución de la inflamación, dando lugar a la cronicidad del proceso inflamatorio. La haploinsuficiencia de endoglina se asocia a una menor supervivencia a la colitis, pasando los ratones haploinsuficientes por una colitis en general más severa que los WT (Jerkic et al, 2010). Mientras que los ratones $W T$ se recuperan de la fase aguda, observándose una disminución del infiltrado inflamatorio y regeneración de la mucosa, los ratones haploinsuficientes de endoglina continúan con inflamación persistente y daño en la submucosa, sin signos de resolución, y con síntomas de inflamación crónica, como son la presencia de infiltrado inflamatorio residual, daño en la submucosa y ensanchamiento de la capa serosa (Jerkic et al, 2010). Resultados similares se observaron al inducir un infarto cerebral, asociándose la haploinsuficiencia de endoglina con un mayor volumen cerebral infartado y peor recuperación (Shen et al, 2014).

El estudio del papel de endoglina en inflamación, así como la haploinsuficiencia de endoglina, se relaciona directamente con el síndrome de Rendu-Osler-Weber o HHT1, el cual es una enfermedad vascular causada por mutaciones en el gen de endoglina (McAllister et al, 1994). Como en esta patología la expresión de endoglina se reduce a la mitad, se han utilizado los modelos animales haploinsuficientes para su estudio.

La HHT es una enfermedad hereditaria autosómica dominante que se caracteriza por displasias vasculares, epistaxias frecuentes, telangiectasias mucocutáneas y malformaciones arteriovenosas en pulmón, cerebro, hígado y tracto gastrointestinal (Govani \& Shovlin, 2009). Como la expresión de endoglina es muy elevada en las células endoteliales, se ha especulado que la pérdida de función de uno de los alelos de endoglina pueda ser la causa de las lesiones vasculares típicas en HHT. Sin embargo, dado que dichas lesiones aparecen únicamente en distintas zonas en ciertos órganos, se considera que es necesario un segundo evento, como inflamación, infección, daño vascular, isquemia o trauma, que junto con la haploinsuficiencia de endoglina genere la lesión. De hecho, ratones con haploinsuficiencia de endoglina criados en zonas libres de patógenos no suelen mostrar síntomas de HHT. 
Como en lesiones vasculares se observa una sobreexpresión de endoglina, se ha propuesto que, quizás, en dichas condiciones se hace especialmente necesaria la función de endoglina, y al estar reducida la expresión, se podrían ocasionan las malformaciones vasculares (López-Novoa \& Bernabeu, 2010).

Un hecho interesante es que endoglina también esté presente en monocitos activados y precursores hematopoyéticos y mesenquimales, lo que sugiere un papel en la respuesta inmune (Lastres et al, 1994; Rokhlin et al, 1995; St-Jacques et al, 1994b). De hecho, algunos estudios muestran una mayor incidencia de infecciones severas en pacientes con HHT (Dupuis-Girod et al, 2007; Mathis et al, 2012) lo cual sugiere que esta patología cursa con alteraciones en la respuesta inmune. Además, se han observado defectos en la mielopoyesis y eritropoyesis en células madre embrionarias de ratones que carecen de endoglina (Cho et al, 2001) observándose que, en zonas isquémicas, las células mononucleares derivadas de pacientes con HHT1 son menos abundantes (van Laake et al, 2006).

Otro estudio relacionado, utiliza un ratón transgénico que no expresa endoglina en la línea mieloide (Eng $\left.{ }^{f / f t} L y s M C r e\right)$, que, además, muestra una gran predisposición a desarrollar infecciones espontáneas por bacterias oportunistas. De hecho, este ratón muestra mayor supervivencia tras peritonitis inducida por LPS, lo que indica que tiene una respuesta inmune tardía. Los macrófagos del peritoneo muestran actividad fagocítica defectuosa, lo cual es un defecto en uno de los pasos principales que contribuye al inicio de la respuesta inmune (Ojeda-Fernández et al, 2016). Esto podría guardar relación con la gran cantidad de enfermedades infecciosas que sufren los pacientes con HHT.

A pesar de ello, los estudios realizados en haploinsuficiencia de endoglina no dejan de ser un modelo que imita las condiciones de los pacientes de HHT, y que son difícilmente extrapolables al resto de la población, y especialmente, a personas con enfermedades inflamatorias. Por ello, se hace necesario ahondar en el estudio del papel concreto de endoglina en inflamación. 
Como se ha comentado, la endoglina de membrana tiene un papel en la inflamación, observándose una reducción en la respuesta inflamatoria cuando la cantidad de endoglina se reduce a la mitad. Sin embargo, también se ha observado que la presencia de endoglina soluble modifica la respuesta inflamatoria. Actualmente, el papel de endoglina soluble en el proceso inflamatorio no está definido.

En un estudio reciente, se ha concluido que la combinación de elevadas concentraciones de endoglina soluble en plasma y dieta hipercalórica en ratón induce la activación de mecanismos proinflamatorios, pro-oxidativos y vasoprotectores en la aorta (Jezkova et al, 2016). En este estudio, tras alimentar a los ratones durante 3 meses con dieta hipercalórica, se observa mayor cantidad de NFKB, P-selectina, ICAM-1 y COX-2 en la aorta correspondiente a ratones con elevada concentración de endoglina soluble en plasma, que en los que tienen concentraciones bajas de endoglina soluble. Sin embargo, estas diferencias no se observan al hacer la misma comparación en ratones con dieta estándar (Jezkova et al, 2016). Por ello, los resultados indican que es necesaria la combinación de dieta hipercalórica y elevados niveles de endoglina soluble en plasma para la inducción de mecanismos proinflamatorios, y que el hecho de que la concentración de endoglina soluble en plasma sea elevada no da lugar a inflamación. Por su parte, un estudio in vitro concluye que el tratamiento con endoglina soluble en células endoteliales da lugar a la activación de algunas moléculas inflamatorias, como NFKB e IL6, que aumentan su expresión y niveles en células tratadas con endoglina soluble. Sin embargo, el tratamiento con endoglina soluble no tiene efecto en otros marcadores de disfunción endotelial e inflamación, como eNOS, VCAM, COX-1, COX-2 e ICAM-1 (Varejckova et al, 2017).

No obstante, como se ha explicado anteriormente se ha demostrado en ensayos de transwell en los que células B (Nalm6) transmigran a través de una monocapa de mioblastos transfectados con endoglina humana (L6E9), que la transmigración aumenta en presencia de endoglina de membrana (Rossi et al, 2013). Sin embargo, la transmigración se ve reducida tanto en presencia del ectodominio RGD (Arg-Gly-Asp), así como ante endoglina soluble. Al repetir el experimento utilizando monocitos U937 transmigrando por una monocapa de células endoteliales bovinas con expresión de endoglina inducible 
(GM7372-EL), se obtiene el mismo resultado: la transmigración disminuye en presencia de endoglina soluble in vitro (Rossi et al, 2013) (Figura 8).

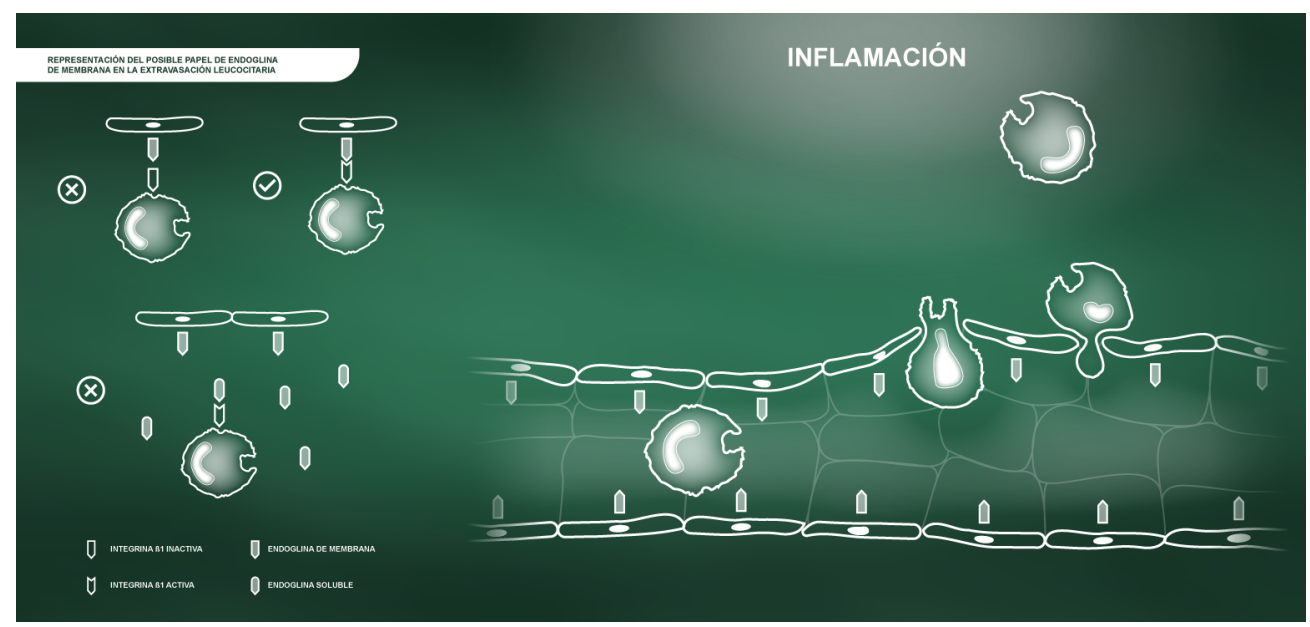

Figura 8. Representación de un posible papel de endoglina de membrana en la extravasación leucocitaria.

Además, endoglina soluble disminuye la adhesión leucocitaria. Tras estimular la adhesión de linfocitos $\mathrm{B}$ a células endoteliales con TNFa, se comprobó que la adhesión disminuye tanto en presencia de endoglina soluble como ante anticuerpos anti-Eselectina (Rossi et al, 2013). Por todo ello, los autores concluyen que la endoglina de membrana interacciona mediante su dominio RGD con la integrina leucocitaria a5 $\beta 1$. La endoglina soluble, al contener el dominio RGD compite con la endoglina de membrana por la unión a las integrinas leucocitarias, interfiriendo con la de adhesión y trasmigración características del proceso inflamatorio. Con todo ello, se hace patente la necesidad de más investigaciones que permitan definir el papel de endoglina soluble en inflamación.

Actualmente, no hay estudios que valoren el papel diferencial de las isoformas de endoglina en inflamación aguda. Los únicos estudios que hay al respecto se centran en inflamación crónica, valorándose la fibrosis tubulointersticial en modelos de daño renal agudo. Estas publicaciones han demostrado que mientras que la sobreexpresión de L- 
endoglina aumenta la fibrosis inducida por obstrucción ureteral unilateral (OUU) (Oujo et al, 2014), la sobreexpresión de S-endoglina la disminuye (Muñoz-Félix et al, 2016), lo que pone de manifiesto que el dominio citoplasmático de endoglina tiene un papel en la regulación de la fibrosis, la cual está estrechamente relacionada con la inflamación crónica.

El hecho de que las isoformas L-endoglina y S-endoglina presenten funciones antagónicas es de gran interés, ya que, dado que solo se diferencian en el dominio intracelular, cualquier diferencia que observemos se debe a que dicho proceso se controla por ese dominio. Esto, junto con que S-endoglina aumente en senescencia (Aristorena et al, 2014b), abren un campo de gran interés y enorme aplicabilidad biosanitaria. Sin embargo, es necesario investigar más acerca del papel concreto de las isoformas de endoglina en inflamación.

El papel de endoglina de membrana también ha sido estudiado en otro proceso clave de la respuesta inflamatoria: la permeabilidad vascular. Sin embargo, no existen actualmente estudios que relación el papel de endoglina soluble en la permeabilidad vascular.

\subsection{ENDOGLINA Y PERMEABILIDAD VASCULAR}

La haploinsuficiencia de endoglina, en condiciones basales, da lugar a un aumento en la permeabilidad vascular in vivo mediante inyección de Evans blue en colon (Jerkic et al, 2010). Estos mismos resultados se observaron en retina tras inyección de FITC-Dextrano, existiendo más focos de permeabilización en haploinsuficiencia de endoglina (Rossi et al, 2016).

Por otro lado, en una publicación reciente se valoró la permeabilidad vascular in vitro, utilizando para ello células endoteliales embriogénicas nulas en endoglina $\left(\mathrm{Eng}^{-/-}\right)$, haploinsuficientes en endoglina $\left(E^{+/-}\right)$y WT (Jerkic \& Letarte, 2015). Esto es muy interesante, ya que in vivo el fenotipo $\mathrm{Eng}^{-/-}$es letal, muriendo los embriones durante el 
desarrollo embrionario. Al analizar la permeabilidad al FITC-Dextrano de estos modelos celulares, se observa que las células nulas en endoglina y las haploinsuficientes son más permeables que las $W T$. Estos resultados indican que las células endoteliales deficientes en endoglina tienen la permeabilidad vascular activada de manera constitutiva (Jerkic \& Letarte, 2015).

Además, se ha observado que los niveles de VE-cadherina disminuyen considerablemente en las células nulas para endoglina respecto a las $W T$, mientras que no se observan diferencias en las haploinsuficientes (Jerkic \& Letarte, 2015). Estos resultados ponen de manifiesto el papel de endoglina de membrana en el mantenimiento de las uniones entre células endoteliales, observándose tanto in vivo como in vitro que en el modelo animal de haploinsuficiencia de endoglina, la permeabilidad vascular está aumentada, y, de hecho, está aún más aumentada en modelos celulares nulos para endoglina. Este deterioro endotelial se ha asociado directamente con procesos patológicos, como una mayor intravasación de células tumorales, demostrándose que los ratones $\mathrm{Eng}^{+/}$presentan mayor metástasis que los ratones WT (Anderberg et al, 2013b).

La disminución de la transmigración endotelial en condiciones de haploinsuficiencia de endoglina es compatible con un aumento en la permeabilidad vascular. Esto se debe a que, mientras que la permeabilidad vascular es un proceso pasivo, la transmigración leucocitaria es activo, dándose, como se ha comentado, una gran cantidad de interacciones entre moléculas de adhesión leucocitarias y endoteliales, así como una disminución de la estabilidad de las uniones entre células endoteliales.

Los hallazgos resumidos anteriormente, hacen patente la estrecha relación entre endoglina y permeabilidad vascular, lo cual sería muy interesante de cara a buscar una aplicación biomédica. Sin embargo, para ello sería necesario definir mucho más a fondo el papel de endoglina en la permeabilidad vascular. 


\subsection{RELEVANCIA Y APLICABILIDAD DEL ESTUDIO}

La información obtenida acerca del efecto que produce endoglina en la regulación de la respuesta inflamatoria tendría un impacto en el ámbito biomédico más que evidente. En este proyecto, se llevan a cabo tres modelos de inflamación en ratón, en los que el agente lesivo es distinto (abrasivo en el caso de la carragenina, por hipoxia en el caso de la isquemia, y bacteriano en el caso del lipopolisacárido) y además se centran en tejidos distintos (piel, riñón y pulmón, respectivamente). A su vez, se analizan en profundidad el papel de las distintas isoformas de endoglina en la extravasación leucocitaria y en la permeabilidad vascular, procesos clave que se ven alterados en todas y cada una de las enfermedades en las que hay un proceso inflamatorio implicado. Cualquier avance en este campo supone un avance biomédico ya que no se ha estudiado nada al respecto, y el desarrollo de nuevas terapias capaces de modular la respuesta inflamatoria es indiscutible.

Conocer el papel de las isoformas de endoglina en los procesos que cursan durante la respuesta inflamatoria nos permitiría plantear un nuevo enfoque en el estudio y el tratamiento de las enfermedades inflamatorias aplicable a distintos niveles. Por ejemplo, en el síndrome de dificultad respiratoria aguda (SDRA), que presenta una mortalidad del $30 \%$, el proceso fisiopatológico crítico es la inflamación exacerbada, ocasionando daño epitelial y endotelial, edema e infiltración masiva de neutrófilos y macrófagos, o el caso de las lesiones isquémicas que ocurren inevitablemente durante la obtención de órganos para trasplantes, empeorando por la respuesta inflamatoria tras la reperfusión, la cual genera la liberación de radicales libres de oxígeno (ROS), dando lugar a necrosis. Los resultados de este proyecto podrían ser utilizados para diseñar nuevas estrategias terapéuticas en el tratamiento de procesos inflamatorios, basadas en la endoglina, que supondrían un cambio absoluto de la calidad de vida de estos pacientes, y, por ende, una consecuente reducción del gasto sanitario.

Por otro lado, se ha asignado un papel muy importante a la endoglina soluble en la génesis de la preeclampsia (López-Novoa \& Bernabeu, 2010). Se han encontrado niveles elevados de endoglina soluble en el suero de mujeres con esta enfermedad, lo que se 
correlaciona con la gravedad de la alteración (Venkatesha et al, 2006) provocando disfunción endotelial, que conlleva a hipertensión, proteinuria y otras manifestaciones sistémicas de la preeclampsia. Hasta la fecha el único tratamiento efectivo de la preeclampsia es realizar cesárea o provocar el parto. En función de los resultados que obtuviéramos, se podría pensar en una estrategia para el control de la respuesta inflamatoria mediante el control de la expresión de endoglina. Por todo ello, conocer el papel de las isoformas de endoglina en los distintos procesos que cursan durante la respuesta inflamatoria nos permitiría plantear un nuevo enfoque en el estudio y el tratamiento de las enfermedades inflamatorias. 
OBJETIVOS 
La endoglina es una proteína que participa en el proceso inflamatorio. Los estudios relacionados han demostrado que la expresión de endoglina aumenta en patologías que cursan con una respuesta inflamatoria. Sin embargo, apenas se ha estudiado el efecto de las distintas isoformas de endoglina en la inflamación, ni cómo pueden alterar la respuesta inflamatoria.

Por ello, para conocer el papel de las isoformas de endoglina tanto en condiciones control, como tras inducción inflamatoria, nos centramos en varios mecanismos esenciales en el proceso inflamatorio. Nos hemos planteado los siguientes objetivos:

Objetivo general:

1. Analizar el papel de las isoformas de endoglina: endoglina soluble, L-endoglina y S-endoglina en el proceso inflamatorio, así como la implicación del dominio intracelular.

Objetivos específicos:

1. Investigar el efecto de endoglina soluble, L-endoglina y S-endoglina en el infiltrado leucocitario tras tres estímulos inflamatorios de distinta naturaleza, en tres tejidos diferentes, con el fin de comprobar si los resultados son similares ante distintas situaciones inflamatorias.

2. Estudiar el papel de endoglina soluble, L-endoglina y S-endoglina en la permeabilidad vascular tras estímulos inflamatorios de distinta naturaleza, en tejidos diferentes. 
MATERIALES Y MÉTODOS 


\section{MATERIALES}

Los reactivos, productos, materiales y equipos empleados para la realización de este trabajo están recogidos en las Tabla 5 y iError! No se encuentra el origen de la referencia., que se encuentran al final de este apartado de "Materiales y métodos". 


\section{RATONES QUE SOBREEXPRESAN ENDOGLINA LARGA (L-ENG+), ENDOGLINA CORTA (S-ENG+) Y ENDOGLINA SOLUBLE (SENG+)}

Los animales de experimentación utilizados en este trabajo son ratones transgénicos de fondo genético C57BL/6J que sobreexpresan de forma ubicua las proteínas humanas Lendoglina ( $L-E N G+)$, S-endoglina (S-ENG+) o endoglina soluble (sEng+).

Estos ratones se generaron mediante la microinyección de los respectivos vectores pCAGGS en un pronúcleo fecundado de CBA $x$ C57BL/6J. Estos vectores se construyeron en el laboratorio del Dr. Carmelo Bernabéu (Centro de Investigaciones Biológicas, CSIC, Madrid). El vector es portador de la secuencia de ADNc de endoglina. En el caso de los ratones $L-E N G+$, lleva la secuencia de exones del gen de endoglina, mientras que para los ratones $S-E N G+$ el vector contiene la secuencia de exones del 1 al 13, más la región del intrón que se transcribe hasta el codón de parada (Oujo et al, 2014). En los ratones sEng+, el ADNc corresponde a la secuencia de la endoglina soluble humana.

En la generación de estos vectores se utilizó un constructo formado por la secuencia líder de endoglina (SL, que comprende los aminoácidos del 1 al 25), o la secuencia truncada de endoglina (aminoácidos 26-437) en el caso de los ratones sEng+, seguida por el epítopo de la hemaglutinina de Influenzza (HA) y el ADNc maduro de endoglina de membrana o endoglina soluble respectivamente. Esta construcción fue clonada en el sitio EcoRI de un vector pcEXV. Tras la digestión con la enzima de restricción EcoRI, el fragmento se insertó en el sitio EcoRI de un plásmido pCAGGS, bajo el control del promotor de actina, de expresión ubicua. Este plásmido es además portador de la secuencia amplificadora del CMV (del inglés, Cauliflower Mosaic Virus), otro amplificador y un intrón del gen de la $\beta$-globina antes del sitio EcoRI. Después de la secuencia de endoglina, contiene un motivo de poliadenilación del gen de la $\beta$-globina (Oujo et al, 2014). Un esquema de esta construcción se representa en la Figura 9. 


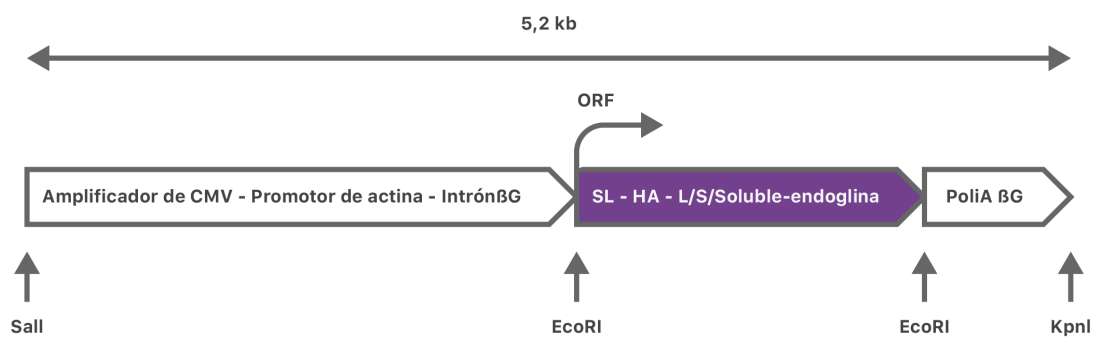

Figura 9. Construcción genética para la generación de los ratones L-ENG+, S-ENG+ y sEng+. Adaptado de Oujo et al, 2014

Con el objetivo de obtener fragmentos lineares para la microinyección, este vector fue digerido con las enzimas Sall/Kpnl. Se procedió a la separación y purificación del fragmento portador del gen de endoglina, de 5,2 kilobases (4,2 kilobases en el caso de la endoglina soluble), mediante electroforesis en gel de agarosa. Los óvulos fecundados fueron inyectados en hembras gestantes en el Servicio de Animales Transgénicos de la Universidad de Salamanca (NUCLEUS), mediante protocolos estándar. La microinyección en un estado tan inicial como es el óvulo fecundado permite que el transgen esté presente en todas las células del organismo y, por tanto, también en la línea germinal. De esta forma, los descendientes de estos ratones son portadores del transgen en todas sus células y éste, gracias al promotor del gen de actina, se expresa de forma ubicua. La descendencia fue genotipada mediante reacción en cadena de la polimerasa o PCR (del inglés, Polimerase Chain Reaction). Los animales transgénicos fundadores se retrocruzaron con ratones C57BL/6J para perpetuar la línea transgénica.

Para la realización de este trabajo se utilizaron los ratones $L-E N G+, S-E N G+$ y sEng+ mencionados. Todos los animales utilizados pertenecían a una generación de retrocruzamiento superior a ocho. Además, se han utilizado ratones $\mathrm{C57BL} / 6 \mathrm{~J}$ como línea control o wild type (WT) de los ratones $L-E N G+$ y $S-E N G+$, y los hermanos de camada (sEng-, CBAxC57BL/6J) como línea wild type de los sEng+. 
Los estudios se realizaron con ratones de 2-3 meses de edad en el caso de los L-ENG+ y los S-ENG+, y de 5-6 meses de edad en los SEng+, de un peso de unos 20-25 gramos. Los experimentos se desarrollaron con las cuatro líneas de ratones, WT, L-ENG+, SENG+ y sEng+, se diseñaron en paralelo y se llevaron a cabo siguiendo el mismo protocolo.

\subsection{CARACTERIZACIÓN DE LOS RATONES QUE SOBREEXPRESAN ENDOGLINA LARGA (L-ENG+), ENDOGLINA CORTA (S-ENG+) Y ENDOGLINA SOLUBLE (SENG+)}

Con el objetivo de estudiar el papel de las isoformas de endoglina en el proceso inflamatorio, en este trabajo se han utilizado modelos animales que sobreeexpresan de forma ubicua endoglina humana: L-endoglina en el ratón $L-E N G+$, S-endoglina en el ratón S-ENG+ y endoglina soluble en el ratón sEng+ (Figura 10).

\section{Ratones transgénicos}

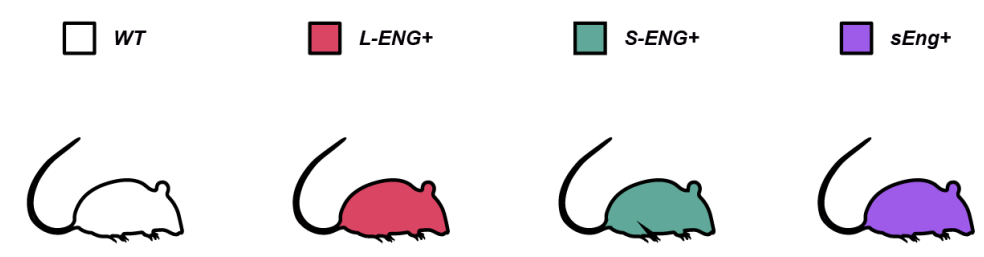

Figura 10. Ratones transgénicos utilizados. Líneas de ratones utilizados, en el código de colores empleado en este estudio.

Para comprobar que estos ratones sobreexpresan las respectivas isoformas de endoglina de membrana, se evaluaron los niveles de expresión de ARNm en lisados de corazón, pulmón, riñón e hígado de ratones $W T, L-E N G+$ y $S-E N G+$ (Figura 11). 
Además, se analizaron por Western blot los niveles de endoglina humana en las tres líneas de ratones en lisados de los mismos órganos (Figura 11). Como el epítopo se encuentra en el dominio extracelular de endoglina no existen anticuerpos que reconozcan específicamente cada una de las isoformas, por lo que se diferenciaron la isoforma larga y la isoforma corta por la altura de la banda de Western blot.

(A)

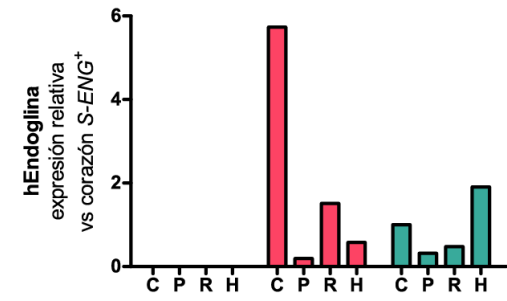

(B)

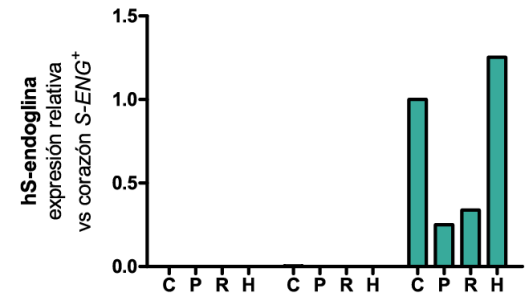

(c)

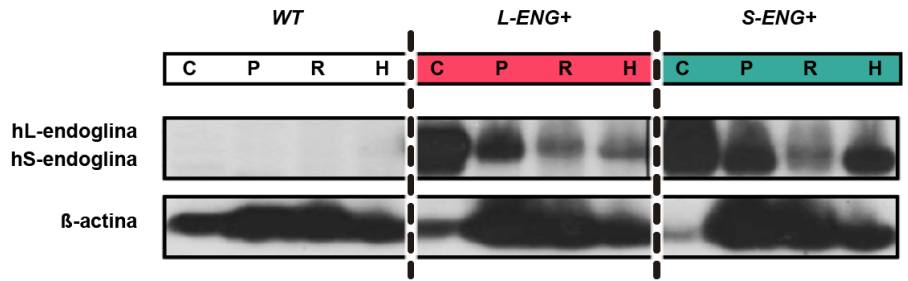

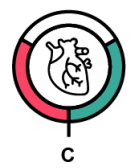

$\square w T$

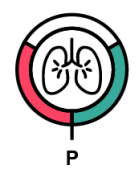

L-ENG+

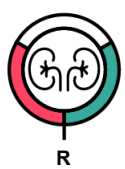

$\mathbf{R}$

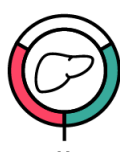

$\mathrm{H}$

S-ENG+

Figura 11. Expresión de endoglina humana en tejido. A, B. Análisis de la expresión del ARNm de endoglina total (A) y S-endoglina humanas (B) en tejido de ratones WT, L-ENG+, S-ENG+, analizada mediante qPCR. C, niveles de endoglina humana en tejido de ratones WT, L-ENG+, S-ENG+, analizados mediante Western blot. 
En la Figura 11 se observa que los ratones $L-E N G+$ sobreexpresan L-endoglina humana, los ratones S-ENG+ sobreexpresan S-endoglina humana, mientras que los ratones WT no expresan ninguna de las isoformas de endoglina de origen humano en los tejidos analizados.

Con respecto a los ratones sEng+, estos presentan elevados niveles de endoglina soluble humana circulante en la sangre, por lo que se determinó su concentración en plasma por la técnica de ELISA. En la Figura 12 se observa que los ratones sEng+ presentan endoglina humana en plasma (en torno a $1000 \mathrm{ng} / \mathrm{ml}$ ), a diferencia de los ratones $W T$, que no la presentan.

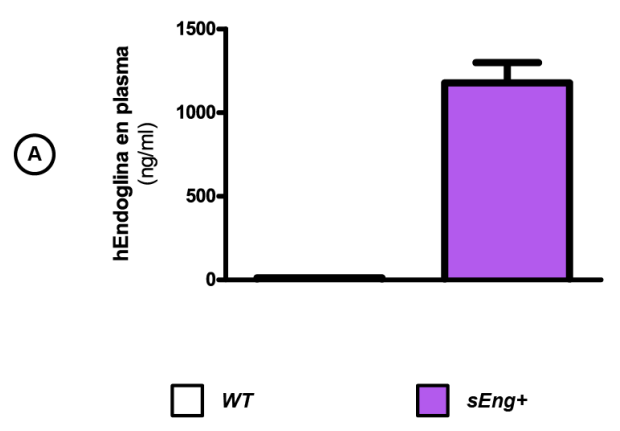

Figura 12. Concentración de endoglina humana en plasma. Análisis de la concentración de endoglina humana en el plasma de ratones WT y sEng+, analizado mediante ELISA y expresado en $\mathrm{ng} / \mathrm{ml}$.

Estos 3 ratones transgénicos constituyen por sí mismos buenos modelos para valorar el efecto de la sobreexpresión de las distintas isoformas de endoglina: L-endoglina, Sendoglina y endoglina soluble, tanto en condiciones control como tras distintos tipos de inducción inflamatoria. 


\subsection{MANTENIMIENTO Y MANIPULACIÓN DE LOS ANIMALES}

Los animales se mantuvieron en las dependencias del Servicio de Experimentación de Animal (SEA) de la Universidad de Salamanca (NUCLEUS), en un animalario bajo barrera libre de patógenos (SPF). Los animales se manipularon siguiendo las recomendaciones de la Declaración de Helsinki de la Asamblea Médica Mundial y los principios del cuidado y la utilización de los animales de experimentación estipulados en las regulaciones internacionales y en las siguientes instituciones europeas y nacionales: la Directiva Europea 2010/63/UE, la Ley del Estado Español 32/2007 de cuidado de los animales y los Reales Decretos RD1201/2005 y RD 53/2013 sobre la protección de los animales utilizados en experimentación y en otros fines científicos.

El sacrificio de los animales se llevó a cabo siguiendo estrictamente las guías para la eutanasia de los animales de experimentación detalladas en el Anexo III del RD 53/2013, basadas en el reglamento 1099/2009 del Consejo Europeo. Además, utilizamos como referencia las recomendaciones dictadas por la Asociación Médica de Veterinaria Americana (AVMA).

\subsection{DETERMINACIÓN DEL GENOTIPO DE LOS RATONES}

Como se ha indicado anteriormente, el genotipo de los ratones se determinó mediante PCR. Para ello, se digirió una pequeña porción del extremo de la cola de los ratones en tampón de lisis (Tris $50 \mathrm{nM}$, EDTA $5 \mathrm{mM}, \mathrm{NaCl} 100 \mathrm{mM}$, DTT 1mM y espermidina 0,5 mM) al que se añadieron $250 \mathrm{ng} / \mu \mathrm{L}$ de proteinasa $\mathrm{K}$, durante 24 horas a $55^{\circ} \mathrm{C}$. El sobrenadante de esta digestión contiene el ADN genómico extraído de la cola del ratón. Dicho sobrenadante se almacenó a $-20^{\circ} \mathrm{C}$. Con $0,5 \mu \mathrm{L}$ de esta muestra de ADN, se procedió a amplificar mediante PCR una región específica del fragmento extracelular del gen de endoglina humana. Para ello se utilizaron unos cebadores de PCR que amplifican 
específicamente el gen de endoglina humana (¡Error! No se encuentra el origen de la referencia.), ADN polimerasa, dNTP y el tampón de reacción.

\begin{tabular}{r|lll} 
Gen diana & Secuencia de los cebadores $\left(\mathbf{5}^{\prime}-\mathbf{3}^{\prime}\right)$ & $\begin{array}{l}\mathbf{T}^{\mathbf{a}} \text { de } \\
\text { anillamiento }\end{array}$ & $\begin{array}{l}\text { Longitud } \\
\text { amplicón }(\mathbf{p b})\end{array}$ \\
\hline \multirow{2}{*}{ ENG } & $\begin{array}{l}\text { TGAAGCCACGAATGTTTTCT } \\
\text { AGAGCATCCTCCTCCGACTGG }\end{array}$ & 59 & 375
\end{tabular}

Tabla 1. Cebador de endoglina para genotipado y condiciones de PCR

En el caso de los ratones sEng+, se procedió al fenotipado de aquellos ratones en los cuales se observó el producto de PCR correspondiente al fragmento del plásmido, para determinar los niveles de sEng humana presente en el plasma de estos ratones. En la realización de este estudio, empleamos aquellos animales que expresaban una concentración de sEng humana en plasma de más de $500 \mathrm{ng} / \mathrm{ml}$. El genotipado y fenotipado de los animales lo llevó a cabo la técnico de laboratorio. 


\section{TÉCNICAS DE EXPERIMENTACIÓN ANIMAL}

\subsection{EXTRACCIÓN DE SANGRE DEL SENO VENOSO SUBMANDIBULAR}

Esta técnica se empleó para la recogida de plasma en los ratones que no iban a ser sacrificados, obteniéndose un volumen de hasta $200 \mu \mathrm{L}$. Se realizó con el animal despierto. Inmovilizamos al ratón cogiendo un pellizco de piel lo más amplio posible de la región dorsocervical y estirando la piel del cuello para practicar estasis venosa en la región cefálica durante un corto período de tiempo. Para la extracción, se punzó con una aguja de calibre 21 junto al ángulo caudal mandibular y se recogió la sangre con un tubo eppendorf en el que previamente se añadieron unas gotas de heparina sódica $5000 \mathrm{U}$ para evitar la coagulación. Por último, se aplicó algo de presión con una gasa estéril humedecida en etanol al 70\% para cortar la hemorragia.

\subsection{EXTRACCIÓN DIRECTA DE SANGRE DEL CORAZÓN}

Esta técnica fue utilizada para la obtención de volúmenes grandes de sangre, de hasta $1.5 \mathrm{ml}$. Se realizó con el animal anestesiado vía inhalatoria: isoflurano $2 \%$ en oxígeno. El animal se situó decúbito supino. Se le realizó una incisión por la línea alba, para acceder a la caja torácica y al corazón. Para la extracción de la sangre se punzó el corazón con una aguja de calibre 21 en dirección cráneo-ventral con un ángulo de $30^{\circ}$ ejerciendo una pequeña presión negativa en la jeringa, una vez introducida, hasta que saliera sangre. Se terminó de llenar la jeringa retrayendo el émbolo lentamente.

Una vez extraída la sangre, por cualquiera de los dos procedimientos explicados, se obtuvo plasma centrifugando a $7000 \mathrm{~g}$ durante 4 minutos a $4^{\circ} \mathrm{C}$. Tras su recogida, se almacenaron las muestras a $-80^{\circ} \mathrm{C}$ para posteriores análisis bioquímicos. 


\subsection{INYECCIÓN EN EL SENO VENOSO RETROORBITAL}

Esta técnica se utilizó para inyectar FITC-Dextrano. Se anestesia al ratón con isoflurano y se le coloca decúbito lateral izquierdo, con la cabeza hacia la derecha. Se aplica una ligera presión a la piel dorsal y ventral de la cabeza, permitiendo que el globo ocular derecho del ratón sobresalga parcialmente. Es importante no aplicar en ningún momento presión a la tráquea, ya que se impediría que el ratón respirara con normalidad. Con una aguja de calibre 26 con el bisel hacia abajo, seguimos con cuidado el borde del globo ocular hasta que la punta de la aguja esté en la base del ojo (Figura 13). Se inyecta suavemente la solución y retiramos la aguja muy lentamente para que no sangre (Yardeni et al, 2011).

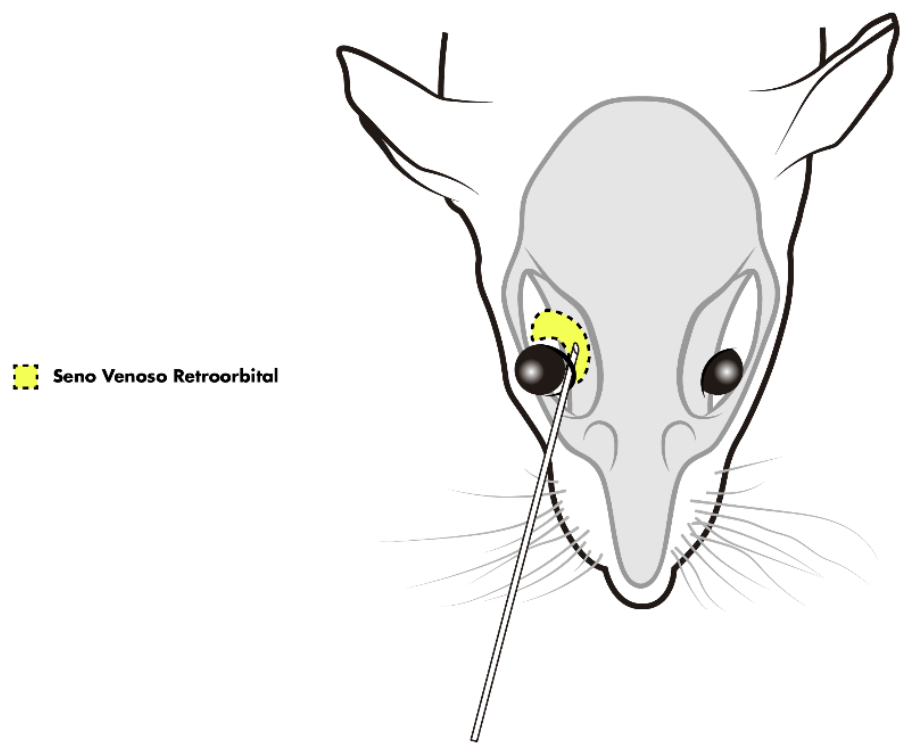




\section{DAÑO PULMONAR AGUDO INDUCIDO POR LPS}

El daño pulmonar agudo inducido por LPS nos permitió evaluar el infiltrado polimorfonuclear y la permeabilidad vascular, dada la gran cantidad de endotelio en el tejido pulmonar.

\subsection{LIPOPOLISACÁRIDO: PROPIEDADES Y ADMINISTRACIÓN}

Los lipopolisacáridos son endotoxinas estables al calor y han sido reconocidos durante mucho tiempo como un factor clave en la septicemia, induciendo la respuesta inmune aguda en mamíferos e inflamación neutrofílica en las vías respiratorias y el parénquima pulmonar (Rietschel et al, 1994; Schletter et al, 1995). Los lipopolisacáridos bacterianos, procedentes de bacterias Gram negativas, son macromoléculas de 10-20 kDa que contienen una sección lipídica hidrofóbica, el lípido A, responsable de su actividad endotóxica y por ello de la activación de la respuesta inmune (Galanos et al, 1984).

La administración pulmonar eficiente de compuestos tales como el LPS es, sin embargo, difícil de lograr. Para asegurar la distribución homogénea en ambos pulmones, se nebulizó LPS, $5 \mathrm{mg} / \mathrm{ml}$, disuelto en PBS. Para ello construimos una cámara de nebulización (Figura 14) y la conectamos a un equipo de aire comprimido, a 2 bares de presión. Los ratones se expusieron a un flujo continuo de LPS durante 30 minutos, seguido de 5 minutos de acondicionamiento sin nebulización. Los ratones control se expusieron a la nebulización de PBS durante el mismo tiempo. 


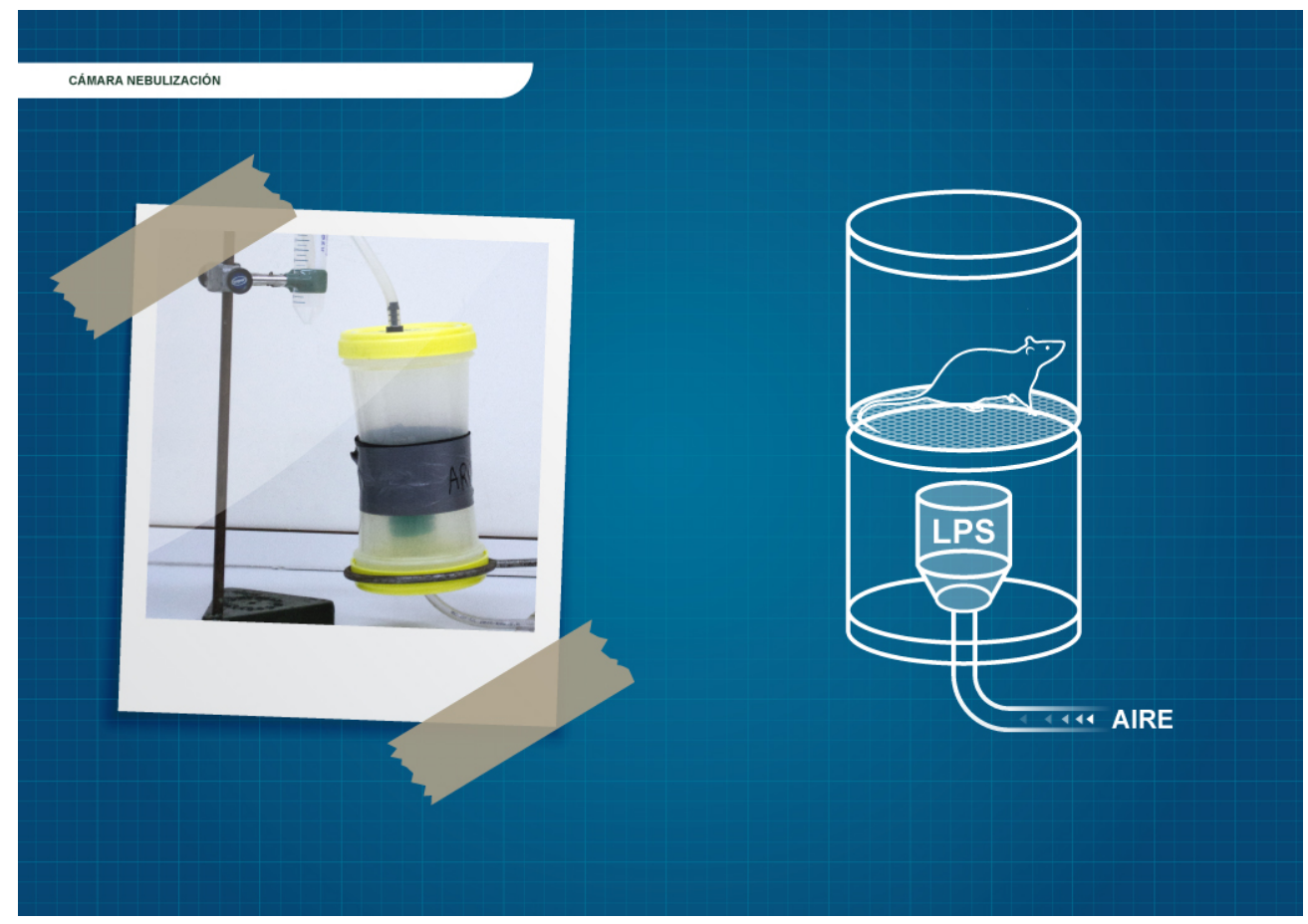

Figura 14. Cámara de nebulización empleada.

\subsection{CIRUGÍA: LAVADO BRONCOALVEOLAR (BAL)}

El primer procedimiento que se llevó a cabo para analizar el infiltrado leucocitario extravasado en la cavidad pulmonar consistió en practicar un lavado broncoalveolar $(B A L)$ por intubación traqueal.

Transcurridas 48 horas después de la nebulización de LPS, se sacrificó al ratón por desplazamiento del $\mathrm{O}_{2}$ mediante gaseado con $\mathrm{CO}_{2}$.

Los ratones se colocaron en decúbito supino y se realizó una cisura de la piel a la altura de la tráquea. Tras retirar el tejido conjuntivo más superficial, con unas pinzas de punta 
roma se separó ligeramente el músculo esternohioideo y esternotiroideo para aislar la tráquea, unos $4 \mathrm{~mm}$ por debajo de la glándula tiroidea.

Se pasó por debajo de la tráquea sutura $5 / 0$ no absorbible estéril de seda trenzada y se realizó un prenudo que no se llegó a apretar. $2 \mathrm{~mm}$ encima del prenudo, y con unas tijeras finas y muy afiladas practicamos un pequeño corte en la parte anterior de la tráquea, por el cuál introducimos la punta de una aguja de intubación de punta redonda (Figura 15). Apretamos con firmeza el prenudo y damos un segundo nudo, asegurándonos de que la tráquea y la aguja están unidas.

A continuación, con una jeringuilla de $1 \mathrm{ml}$ se inyectaron lentamente por la tráquea 500 $\mu \mathrm{l}$ de PBS heparinizado frío, y se recogió con suavidad, ya que si se ejerce demasiada presión provocaría la aparición de sangre en el lavado. Se descartaron los lavados broncoalveolares en los que se observaron restos sanguíneos. 

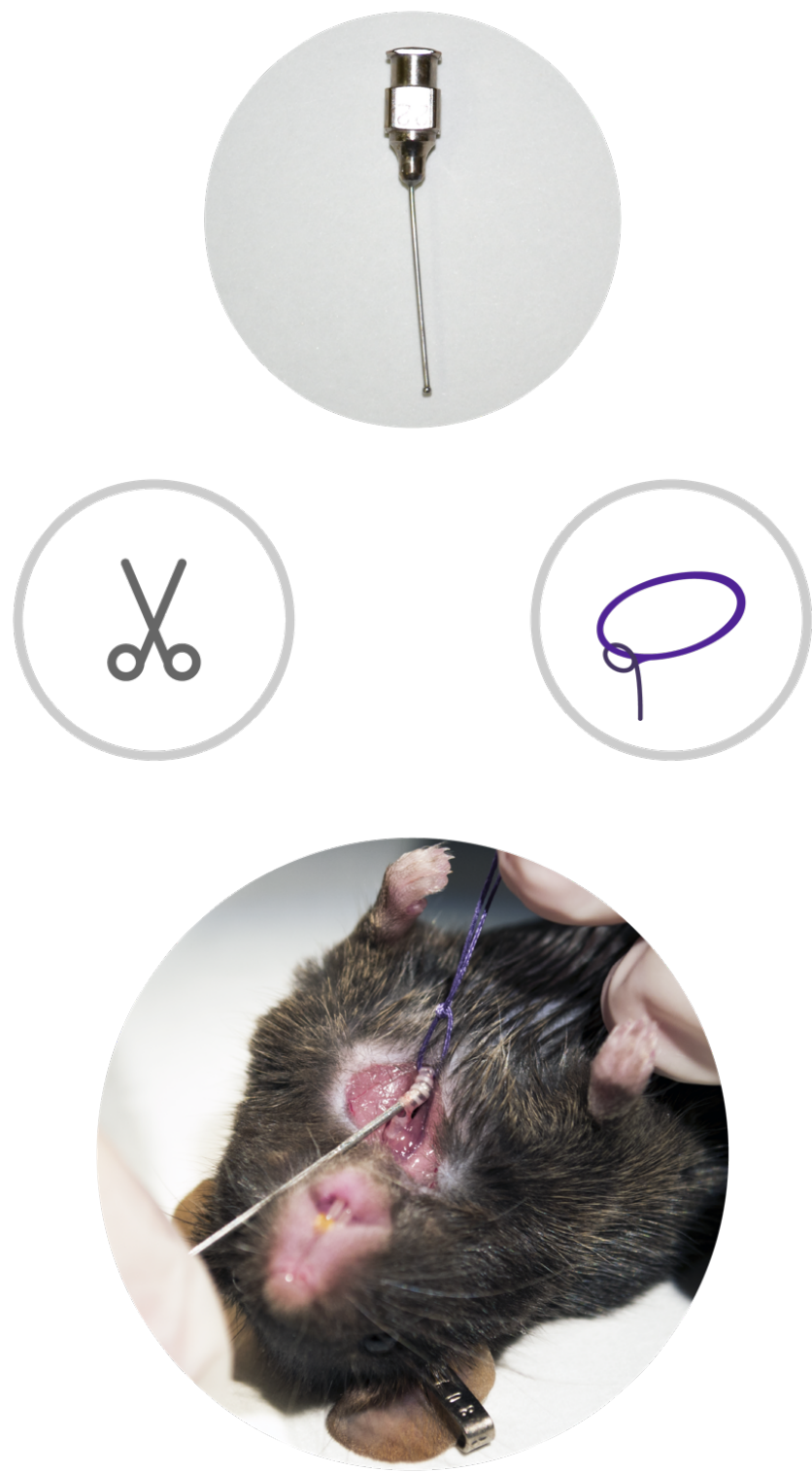

Figura 15. Procedimiento y material utilizados para el lavado broncoalveolar por intubación traqueal 
El BAL se centrifugó a $300 \mathrm{~g}$, a $4^{\circ} \mathrm{C}$ durante 10 minutos. Se guardó el sobrenadante para determinar la concentración de proteínas y realizar ELISA y se reconstituyó el pellet celular en $500 \mu \mathrm{l}$ de PBS, determinándose el número de leucocitos con una cámara de Neubauer.

En todos los casos, el lóbulo inferior izquierdo del pulmón se recogió en formol al 4\% durante al menos 24 horas a $4^{\circ} \mathrm{C}$ para su posterior análisis histológico, y el resto del tejido se congeló inmediatamente en nitrógeno líquido y se almacenó a $-80^{\circ} \mathrm{C}$ para posteriores análisis bioquímicos (Figura 16). Se recogió sangre por extracción directa del corazón y se obtuvo plasma.

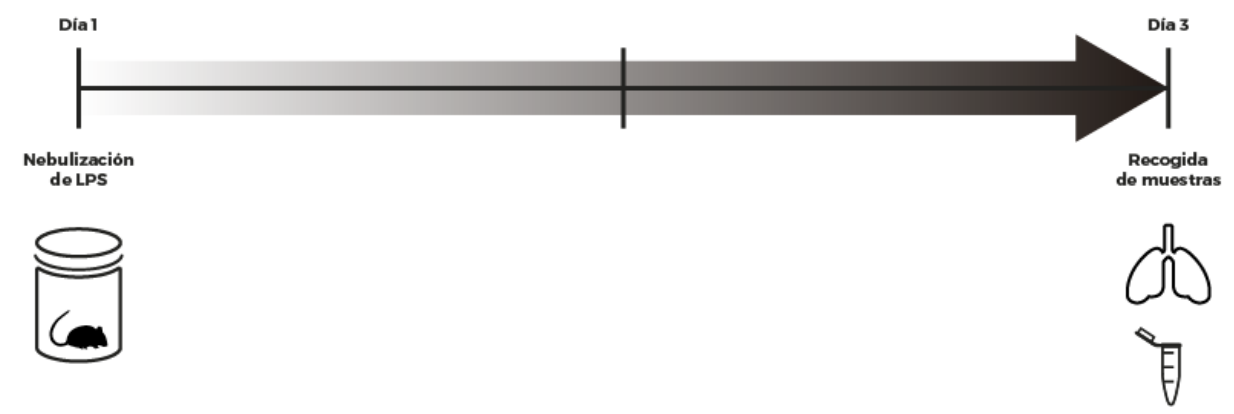

Figura 16. Cronograma del modelo de daño pulmonar inducido por LPS 


\section{INYECCIÓN INTRAVENOSA DE FITC- DEXTRANO TRAS DAÑO PULMONAR AGUDO INDUCIDO POR LPS}

El uso de dextrano unido a isotiocianato fluorescente (FITC-Dextrano) está muy extendido en estudios de permeabilidad in vivo. Mediante la inyección intravenosa de FITC-Dextrano, podemos evaluar la permeabilidad vascular estudiando la presencia en mayor o menor concentración de fluorescencia en el BAL.

Para el modelo de inyección intravenosa de FITC-Dextrano, se procedió exponiendo a los ratones a LPS nebulizado, con la diferencia de que 24 horas después se inoculó FITCDextrano.

\subsection{INYECCIÓN RETROORBITAL DE FITC- DEXTRANO}

Transcurridas 24 horas tras la nebulización de LPS, se inyectaron $100 \mu \mathrm{l}$ de FITCDextrano $(25 \mathrm{mg} / \mathrm{ml})$ en $\mathrm{NaCl} 0,9 \%$ en el seno retroorbital.

Treinta minutos después, sacrificamos al ratón por desplazamiento del $\mathrm{O}_{2}$ mediante gaseado con $\mathrm{CO}_{2}$. Practicamos un lavado broncoalveolar y se recoge sangre por extracción directa del corazón (Figura 17). 


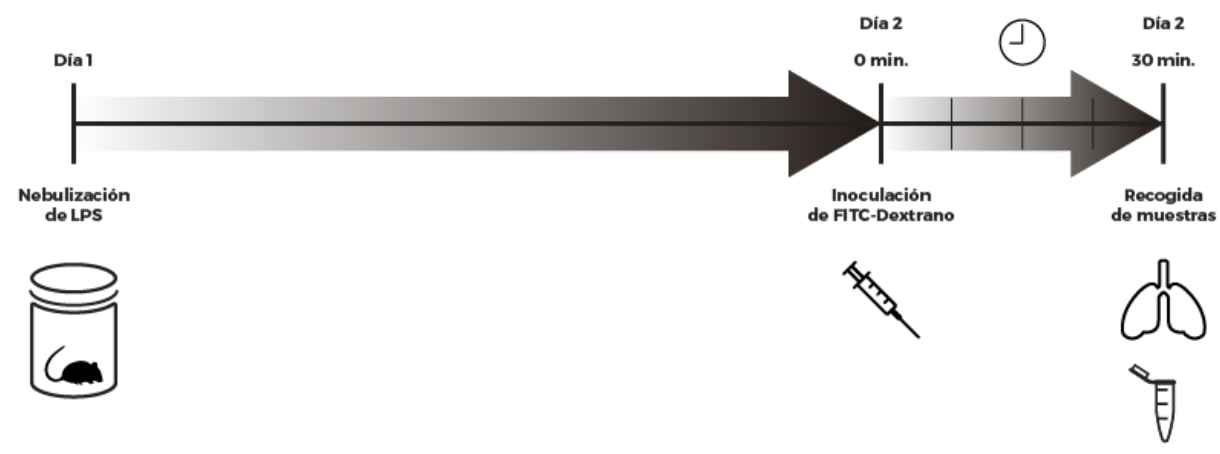

Figura 17. Cronograma del modelo de Inyección intravenosa de FITC-Dextrano tras daño pulmonar agudo inducido por LPS 


\section{INFLAMACIÓN INDUCIDA POR CARRAGENINA EN AIR POUCH}

La inflamación inducida por carragenina en air pouch nos permite evaluar de manera no invasiva los leucocitos polimorfonucleares y las proteínas extravasadas en la cavidad del pouch.

Se trata de un modelo bastante reproducible y que se mecaniza con facilidad, lo que permite un análisis muy fiable, dada la variabilidad intrínseca de los métodos in vivo. Además, no es necesario sacrificar al ratón después de realizar la técnica, por lo que pueden destinarse a otros experimentos si fuera necesario.

\subsection{CARRAGENINA: PROPIEDADES}

Las carrageninas son poligalactanos sulfatados que se obtienen de varias especies de algas rojas (Rhodophyceae). Están compuestos de unidades repetidas de disacáridos de D-galactosa (Macher 2008). Las carrageninas inducen una respuesta inflamatoria y pueden activar respuestas inmunes mediadas por linfoma de células B-10 (Bcl-10) y Toll-like receptor (TLR) (Borthakur et al, 2007; Bhattacharyya et al, 2008). En la mayoría de las publicaciones las carrageninas se usan para inducir inflamación en extremidades, en modelos de air pouch o inyectándose directamente en las articulaciones en modelos de artritis.

\subsection{MODELO DEL AIR POUCH}

El primer procedimiento que se llevó a cabo fue la creación y mantenimiento del volumen del air pouch, para posteriormente inyectar PBS o carragenina y analizar el infiltrado leucocitario extravasado. 


\subsubsection{DÍA 0: CREACIÓN DEL POUCH}

Previamente, se rasuró por completo el dorso del ratón. Se anestesió al ratón con anestesia inhalatoria: isoflurano $2 \%$ en oxígeno y se limpió la espalda del ratón con etanol al $70 \%$.

Los ratones se colocaron decúbito prono, y con una jeringa unida a un filtro de 0,45 $\mu \mathrm{m}$ y a una aguja de calibre 30 se realiza una inyección subcutánea de $3 \mathrm{ml}$ de aire estéril en la zona dorsal.

\subsubsection{DÍA 3: MANTENIMIENTO DEL POUCH}

Con el objeto de mantener constante el volumen del pouch, se realiza una segunda inyección subcutánea de $3 \mathrm{ml}$ de aire estéril en la cavidad del pouch, recuperando este su tamaño inicial (Figura 18).

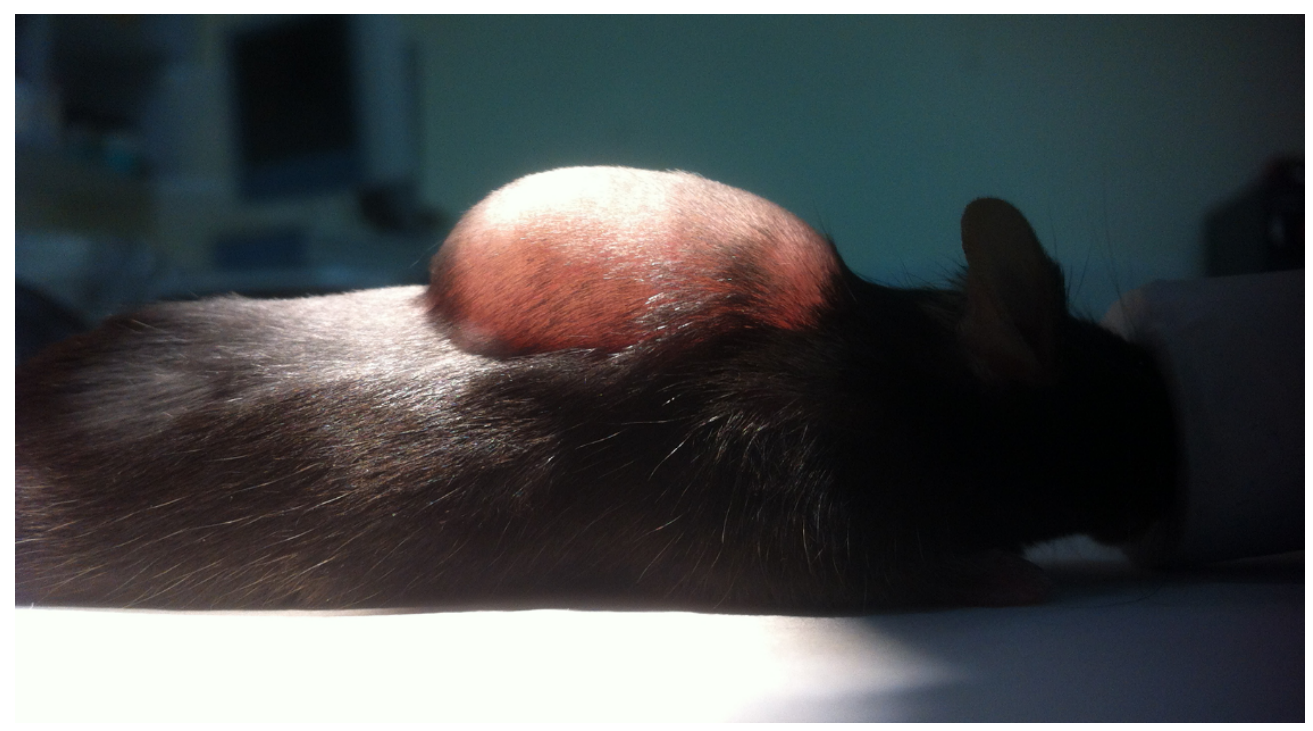

Figura 18. Air pouch tras inyección subcutánea de $3 \mathrm{ml}$ de aire estéril 


\subsubsection{DÍA 6: INYECCIÓN DE CARRAGENINA}

Se preparó una disolución al 1\% de carragenina en PBS. Con la aguja de calibre 30, inyectamos un volumen total de $0,5 \mathrm{ml}$ de carragenina en el pouch. A continuación, masajeamos con cuidado el dorso del ratón durante 30 segundos, asegurándonos de que la carragenina impregne por completo la cavidad del pouch. En los ratones control se inyectaron $0,5 \mathrm{ml}$ de PBS.

\subsubsection{DÍA 7: LAVADO DEL POUCH}

Transcurridas 24 horas de la inyección de carragenina, procedemos al lavado del pouch. Para ello, inyectamos $2 \mathrm{ml}$ de PBS frío heparinizado con una aguja de calibre 21 . Masajeamos el pouch con suavidad durante 30 segundos, sin sacar la aguja, ya que si se daña la piel provocaría la aparición de sangre en el lavado. Se recogió poco a poco la totalidad de la muestra, sin ejercer demasiada presión, descartándose aquellos lavados en los que se observaron restos de sangre.

El lavado se centrifugó a $300 \mathrm{~g}$, a $4^{\circ} \mathrm{C}$ durante 10 minutos. Se guardó el sobrenadante para determinar la concentración de proteínas y realizar ELISA y se reconstituyó el pellet celular en $2 \mathrm{ml}$ de PBS, determinándose el número de leucocitos con un hemocitómetro ADVIA $^{\circledR} 120$ (Figura 19). 


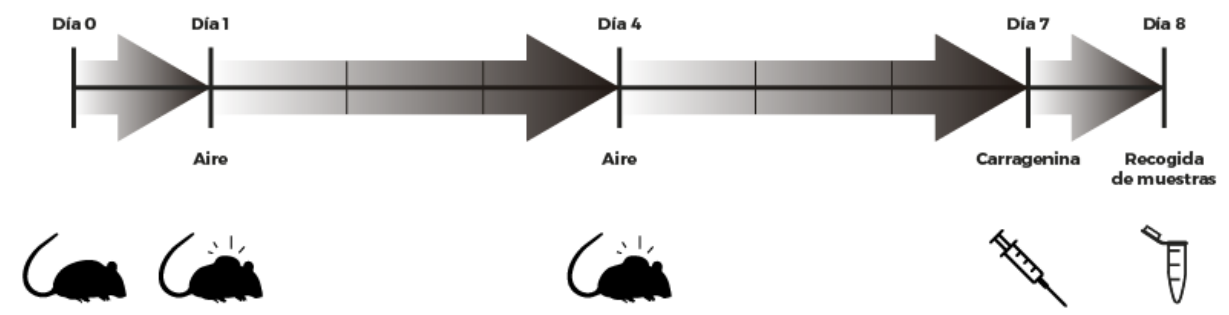

Figura 19. Cronograma del modelo de inflamación inducida por carragenina en air pouch

Para recoger el tejido del pouch para histología, se recortó alrededor de la periferia del pouch y se grapó el tejido a cartulina para asegurar que se mantuviera estirado (Figura 20). Se sumergió en formol al $4 \%$ durante al menos 24 horas a $4^{\circ} \mathrm{C}$ para su posterior análisis histológico.

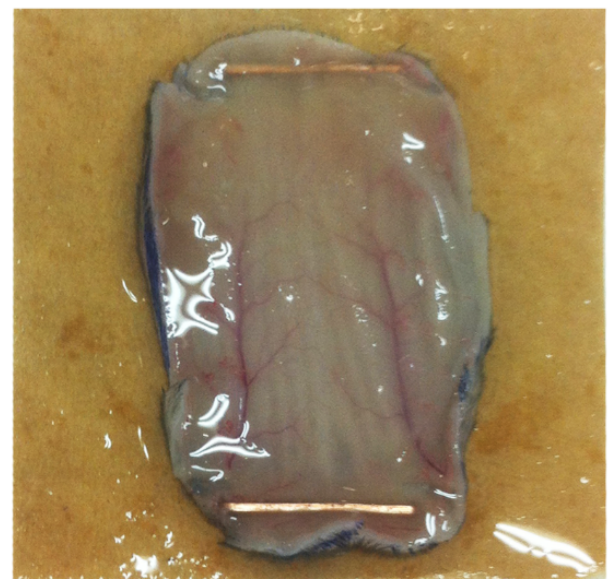

Figura 20. Tejido correspondiente al air pouch, recogido para análisis histológicos 


\section{ISQUEMIA-REPERFUSIÓN RENAL}

La isquemia-reperfusión renal se asocia con una inflamación túbulointersticial, y provoca una respuesta inflamatoria aguda (Thurman, 2007) que nos permite analizar la generación de citoquinas y quimiocinas en el riñón, y la consecuente infiltración de leucocitos.

\subsection{CIRUGÍA: ISQUEMIA RENAL}

El primer procedimiento que se llevó a cabo para analizar la reperfusión post-isquémica consistió en obstruir la arteria y la vena renal del ratón durante 30 minutos, para inducir así la isquemia.

Para la cirugía, se procedió a anestesiar al ratón con anestesia inhalatoria: isoflurano $2 \%$ en oxígeno. Antes de comenzar la cirugía, se administró al animal una dosis del analgésico buprenorfina $(0,15 \mathrm{mg} / \mathrm{kg})$, vía subcutánea, de tal forma que, una vez terminado el procedimiento quirúrgico, ya estuviese ejerciendo sus efectos.

Los ratones se colocaron decúbito supino sobre una almohadilla térmica para mantener su temperatura constante a $37^{\circ} \mathrm{C}$, y se desinfectó el abdomen con betadine. Se realizó una incisión de unos $2 \mathrm{~cm}$ en línea alba y se separó la piel de la pared abdominal. Se practicó una incisión en el peritoneo en línea alba con cuidado de no dañar ningún órgano. Se vigiló en todo momento la temperatura corporal y la hidratación del ratón, humedeciendo cada pocos minutos con salino a $37^{\circ} \mathrm{C}$.

Tras la laparotomía, e intentando manipular lo menos posible el intestino, se localizaron la arteria y la vena renal del riñón izquierdo del ratón. Con ayuda de unas pinzas, se limpió ligeramente el conjuntivo de alrededor, y se pinzó el paquete vascular con unas pinzas de arteria. Segundos después, se observó que el riñón comenzaba a oscurecerse, poniéndose completamente negro en unos 10 minutos (Figura 21). 

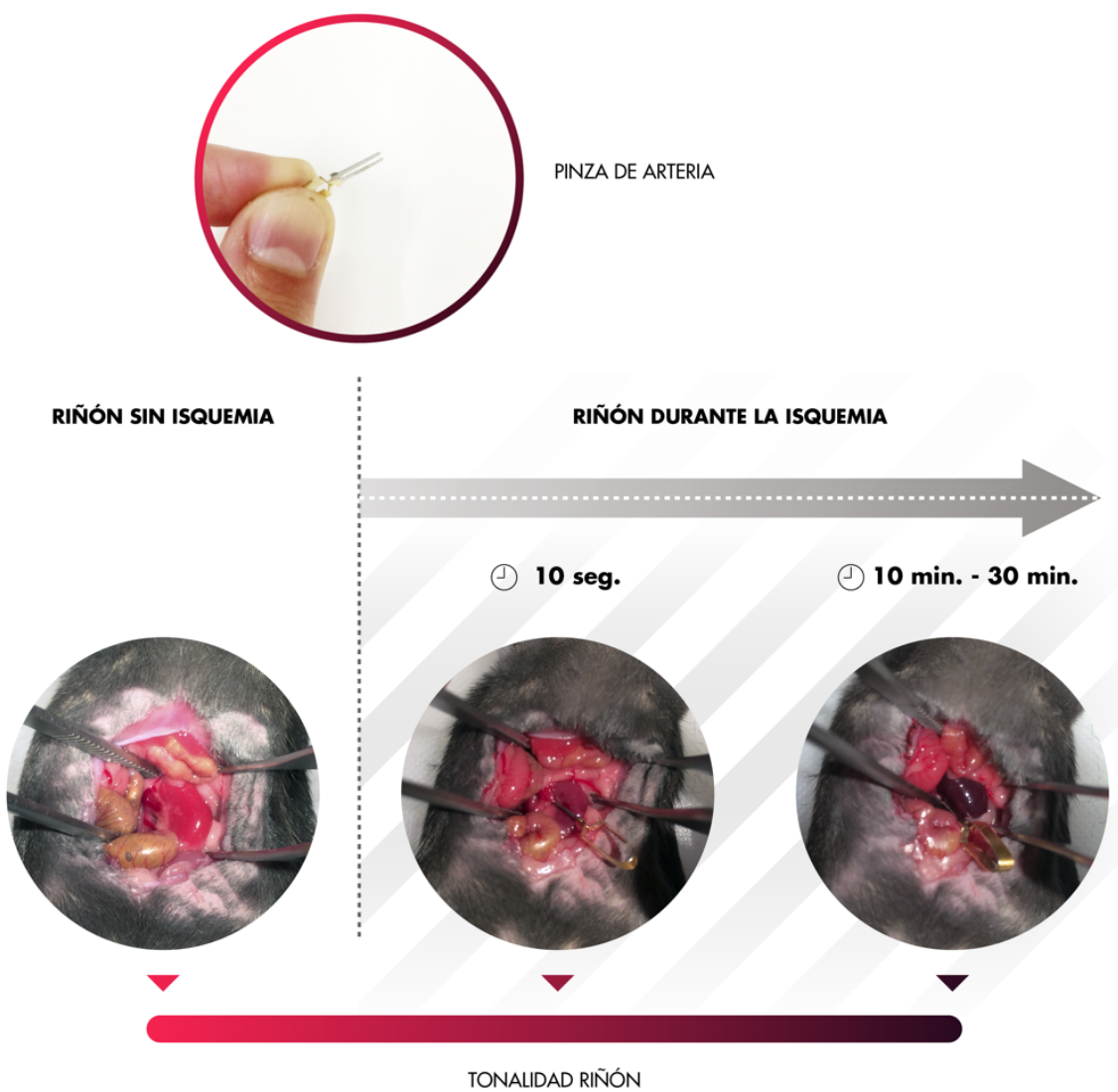

Figura 21. Procedimiento para la isquemia-reperfusión renal

Se mantuvo la isquemia durante 30 minutos, vigilando que no se dieran sangrados. Tras la isquemia, se retiraron las pinzas de arteria, y el riñón reperfundió en pocos segundos, volviendo a su color rojo original. Se cosió el peritoneo en continuo con sutura 5/0 no absorbible, y se cerró la piel con grapas. Se desinfectó la herida con unas gotas de betadine y se inyectaron al ratón $200 \mu \mathrm{l}$ de salino subcutáneo para que se mantuviera hidratado. 
Transcurridas 48 horas de la isquemia, anestesiamos al ratón con isoflurano $2 \%$ en oxígeno y se recogió sangre por extracción directa del corazón. En todos los casos, el riñón izquierdo se dividió en dos mitades, recogiéndose una en formol al $4 \%$ durante al menos $24 \mathrm{~h}$ a $4^{\circ} \mathrm{C}$ para su posterior análisis histológico, y el resto se congeló inmediatamente en nitrógeno líquido y se almacenó a $-80^{\circ} \mathrm{C}$ para posteriores análisis bioquímicos (Figura 22).

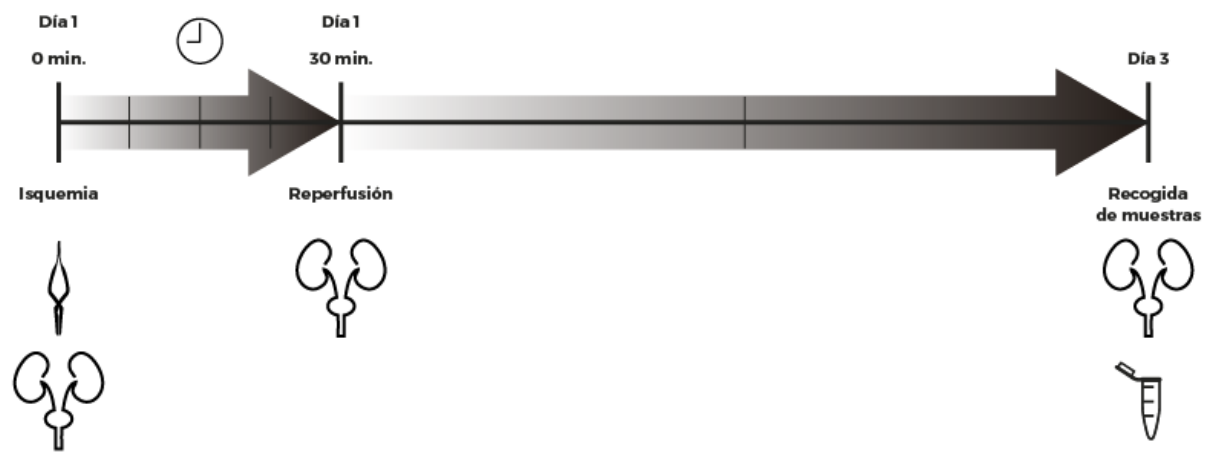

Figura 22. Cronograma del modelo de isquemia-reperfusión renal 


\section{MÉTODOS DE CULTIVO CELULAR}

\subsection{LÍNEA DE CÉLULAS ENDOTELIALES EA.HY926}

La línea celular endotelial EA.hy 926 wild type fue adquirida en ATCC. Se generó a partir del cultivo primario de células umbilicales humanas, al fusionarlas con un clon de células A549 tioguanina-resistentes mediante exposición a polietilenglicol.

Para mantener estas células se utilizó medio de cultivo DMEM, con 4,5 g/L de glucosa, suplementado con $50 \mathrm{U} / \mathrm{mL}$ de penicilina-estreptomicina y enriquecido con FBS al $10 \%$. El medio de cultivo se cambió cada 48 horas.

\subsection{TÉCNICAS BÁSICAS EN CULTIVOS CELULARES}

\subsubsection{TRIPSINIZACIÓN CELULAR}

Se utilizó la técnica de la tripsinización celular para levantar las células endoteliales adheridas y volverlas a sembrar en otro soporte. Después de retirar el medio y lavar con PBS, se añadió tripsina-EDTA (tripsina 0,25\%, EDTA 0,02\%) para separar las células de la superficie de la placa. La acción de la tripsina se detuvo aproximadamente a los 3 minutos con medio de cultivo y a continuación las células se transfirieron a un tubo. La suspensión celular se centrifugó a $600 \mathrm{~g}$ durante 3 minutos a temperatura ambiente. El precipitado se resuspendió en la cantidad adecuada de medio de cultivo, dependiendo de su posterior utilización. Si el experimento lo requería, en este punto se procedió al recuento celular.

\subsubsection{RECUENTO CELULAR}

Después de tripsinizar las células, una muestra de la suspensión celular se mezcló en proporción 1:1 con azul de trypan, que es capaz de penetrar a través de la membrana de 
células muertas o dañadas, pero no de células vivas. A continuación, $10 \mu \mathrm{L}$ de esta mezcla se depositaron en una cámara de contaje y se introdujo en el contador electrónico Countess ${ }^{\circledR}$ Automated Cell Counter. Este contador es capaz de discriminar las células viables de las no viables, obteniéndose el número de células por mililitro. El recuento se hizo siempre por duplicado y se utilizó el valor medio.

\subsubsection{CONGELACIÓN Y DESCONGELACIÓN DE LÍNEAS CELULARES}

Para congelar las células, en primer lugar, se tripsinizaron de la forma explicada anteriormente. Las células se resuspendieron en $2 \mathrm{~mL}$ de medio frío con FBS al $50 \%$ y DMSO al 10\%. La suspensión celular resultante se pasó a un vial de crioconservación que se almacenó dentro de un recipiente relleno de isopropanol, en el que la temperatura va disminuyendo lenta y gradualmente. Después de 24 horas, las células se almacenaron en un tanque de nitrógeno líquido.

Para su descongelación, se introdujeron los viales en un baño de agua a $37^{\circ} \mathrm{C}$ y, una vez descongelados, se transfirió rápidamente el contenido a $10 \mathrm{~mL}$ del medio de cultivo. Se centrifugó la suspensión celular a $600 \mathrm{~g}$ durante 3 minutos a temperatura ambiente. El precipitado se resuspendió en la cantidad adecuada de medio de cultivo y se sembraron las células en una placa de cultivo. 


\section{EVALUACIÓN DE LA PERMEABILIDAD VASCULAR}

\subsection{RECUENTO DEL NÚMERO DE CÉLULAS}

Los leucocitos presentes en el BAL se contaron utilizando una cámara de Neubauer. Las células se mezclaron en una proporción de 1:1 con el colorante de exclusión azul de trypan al 0,4\% y se contaron. Los leucocitos en el lavado del pouch se identificaron con un hemocitómetro, distinguiéndose entre linfocitos, neutrófilos, basófilos y monocitos.

\subsection{DETERMINACIÓN DE LA CONCENTRACIÓN DE PROTEÍNAS}

Para la cuantificación de la concentración proteica del BAL y del lavado del pouch, se siguió el protocolo del kit comercial colorimétrico DC ${ }^{\mathrm{TM}}$ Protein Assay, basado en el método de Lowry (Lowry et al, 1951). Se realizó una recta patrón con los reactivos del kit y se midió la absorbancia del producto de reacción a $720 \mathrm{~nm}$ en un lector de placas de ELISA. Los valores de absorbancia de las muestras problema se extrapolaron en la recta de absorbancias obtenida a partir de las diluciones seriadas, utilizando el software Gen5.

\subsection{PRESENCIA DE FITC-DEXTRANO EN EL LAVADO BRONCOALVEOLAR}

En el modelo de inyección intravenosa de FITC-Dextrano tras daño pulmonar agudo inducido por LPS, medimos en un fluorímetro la fluorescencia en el sobrenadante del BAL y en el plasma (diluido 1:20 en $\mathrm{NaCl} 0.9 \%$ ) a una onda de excitación de $485 \mathrm{~nm}$ y una onda de emisión de $528 \mathrm{~nm}$.

Por último, calculamos el ratio de fluorescencia: $\frac{\text { Fluorescencia en } B A L}{\text { Fluorescencia en plasma }}$ 


\subsection{RATIO PESO HÚMEDO/PESO SECO}

En el modelo de inyección intravenosa de FITC-Dextrano tras daño pulmonar agudo inducido por LPS, se extrajeron los pulmones y se enjuagaron en PBS para eliminar restos de sangre. Se secaron en papel y los pesamos en una balanza obteniéndose así el peso húmedo. Se dejan en una estufa a $65^{\circ} \mathrm{C}$ durante 48 horas, y se vuelven a pesar, obteniéndose el peso seco. Calculamos el ratio peso húmedo/peso seco como un indicador de edema.

\subsection{ENSAYO DE MIGRACIÓN A TRAVÉS DE TRANSWELL}

Esta técnica permite medir la capacidad del FITC-Dextrano para migrar a través de las células endoteliales, basándose en que el transwell tiene un poro de $3 \mu \mathrm{m}$, por el que migra el FITC-Dextrano pero no las células. Se sembraron $10^{5}$ células/placa de la línea celular endotelial EA.hy926 en el compartimento superior del transwell y se cultivaron 24 horas hasta confluencia. Se dejaron las células en medio de cultivo sin FBS durante la noche y se activaron con LPS $(1 \mu \mathrm{g} / \mathrm{ml})$ durante 4 horas.

El medio de la cámara superior se retiró y se añadió medio de cultivo DMEM con FITCDextrano $(1 \mathrm{mg} / \mathrm{ml})$, LPS $(1 \mu \mathrm{g} / \mathrm{ml})$ y endoglina soluble $(500 \mathrm{ng} / \mathrm{ml})$ en los casos apropiados. El medio de la cámara inferior se retiró y se añadio DMEM (Figura 23). Tras 24 horas a $37^{\circ} \mathrm{C}$, se retiraron los insertos y se midió la fluorescencia en la cámara inferior con un fluorímetro. 


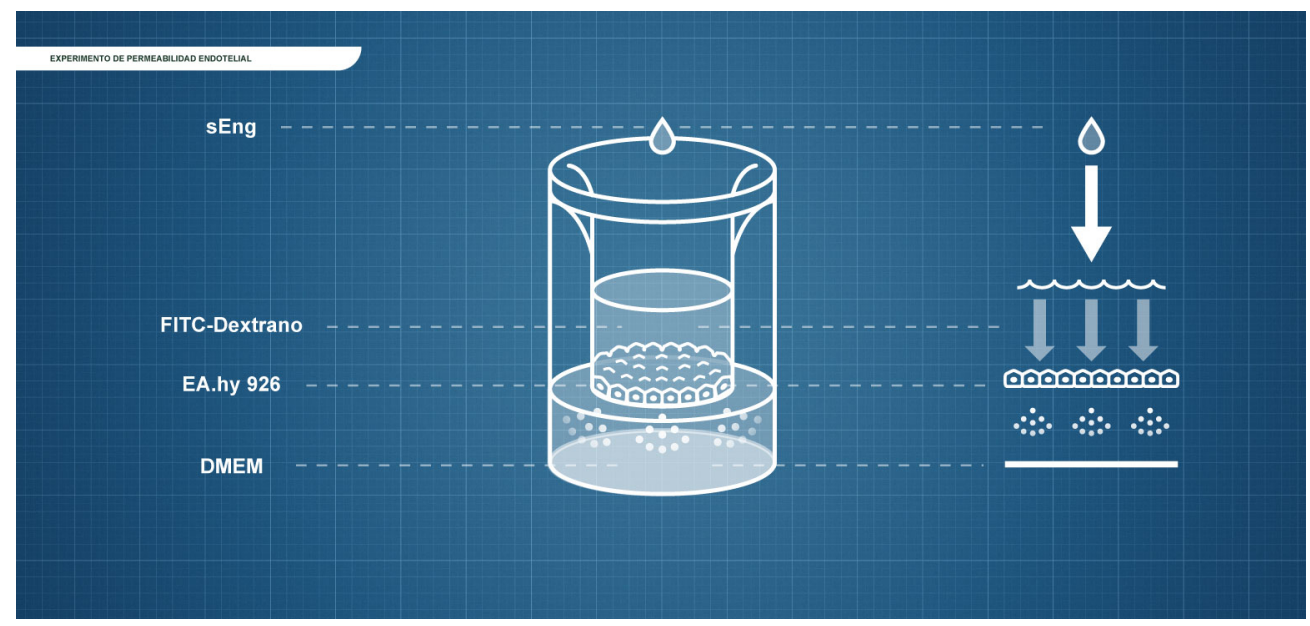

Figura 23. Esquema del experimento de permeabilidad endotelial con transwell 


\section{ANÁLISIS HISTOLÓGICO}

Todos los estudios histológicos realizados en este trabajo, así como las imágenes de microscopía obtenidas, se llevaron a cabo en el Servicio de Patología Molecular Comparada y Nodo Coordinador BEOCyL (Centro de Investigación del Cáncer, CSICUniversidad de Salamanca, NUCLEUS).

Los tejidos destinados a la realización de los estudios histológicos se fijaron con formaldehído al $4 \%$ durante, al menos 24 horas. Después, se deshidrataron en etanol de concentración creciente desde $50 \%$ hasta absoluto y posteriormente en xileno. Tras la deshidratación, se incluyeron en parafina en una estufa a $60^{\circ} \mathrm{C}$ durante 24 horas y se obtuvieron bloques, que se cortaron con un micrótomo en secciones transversales de 3 $\mu \mathrm{m}$ de grosor. Por último, los cortes se depositaron en un portaobjetos y se dejaron secar en la estufa durante 1 hora.

\subsection{TINCIÓN HEMATOXILINA-EOSINA}

Esta técnica permite visualizar la estructura morfológica de las células individualizadas al microscopio óptico, su posición relativa y la forma de los núcleos dentro de las mismas.

Para llevar a cabo esta técnica de tinción, los cortes se desparafinaron en xileno y se hidrataron en concentraciones decrecientes de alcohol (absoluto, 95\% y 80\%) hasta llegar a agua destilada. A continuación, se sumergieron en la solución de hematoxilina durante 10 minutos. Tras esta tinción, se lavaron los restos de colorante con agua y se sumergió en eosina durante 30 segundos. Por último, se deshidrataron los cortes sumergiéndolos nuevamente en soluciones de etanol de concentración creciente $(80 \%$, $95 \%$ y absoluto) y xilol. Finalmente, se añadió el medio de montaje DPX (resina acrílica con base de xileno) y se colocó un cubreobjetos para proteger los cortes. Cuando el medio de montaje estuvo seco, las preparaciones se visualizaron en un microscopio óptico y se tomaron fotografías representativas. 


\subsection{VALORACIÓN HISTOLÓGICA CUANTITATIVA}

Los cambios histológicos en el tejido fueron evaluados por un patólogo, ciego a la muestra. Se empleó un sistema cuantitativo para valorar el grado de afectación de las muestras histologías, calculándose una puntuación total para cada ratón. En todas las muestras se valoró la cantidad de infiltrado polimorfonuclear de 0-3. Además del infiltrado inflamatorio, en el riñón se valoró la necrosis tubular. 


\section{ANÁLISIS DEL NIVEL DE EXPRESIÓN DE PROTEÍNAS POR WESTERN BLOT}

El método del Western blot (Gallagher et al, 2004) permite la identificación de proteínas de un extracto celular o tejido. Se basa en la separación de las proteínas de una muestra en un gel de poliacrilamida en función de su tamaño, y su posterior transferencia a una membrana. En dicha membrana son reconocidas mediante la utilización de anticuerpos específicos contra las proteínas que se desean identificar (anticuerpos primarios), y anticuerpos secundarios, que reaccionan con los anticuerpos primarios y están conjugados con la enzima peroxidasa de rábano picante (HRP, del inglés, HorseRadish Peroxidase) que, al reaccionar con su sustrato, produce una reacción fácilmente detectable y proporcional a la cantidad de proteína de la muestra.

\subsection{OBTENCIÓN DE EXTRACTOS DE PROTEÍNAS DE TEJIDOS Y CÉLULAS}

Para la extracción de proteínas de tejido, se pulverizaron los tejidos en hielo seco y se pesaron 20-30 mg del pulverizado. Se lisó el tejido con $200 \mu \mathrm{L}$ de tampón de lisis (Tris base 20 mM, pH 7,5; NaCl 140 mM, EDTA 50 mM, glicerol al 10\% e IGEPAL CA-630 al $1 \%)$, en frío, al que se añadieron inhibidores de proteasas y fosfatasas. Se lisó la muestra con micropistilos.

El lisado celular se centrifugó a $600 \mathrm{~g}$, a $4^{\circ} \mathrm{C}$ durante 10 minutos. Después de la centrifugación, se recogió el sobrenadante y las muestras se almacenaron a $-80^{\circ} \mathrm{C}$ hasta su uso. 


\subsection{DETERMINACIÓN DE LA CONCENTRACIÓN DE PROTEÍNAS}

Para la cuantificación de la concentración proteica de nuestros extractos celulares, se siguió el protocolo del kit comercial colorimétrico DCTM Protein Assay, procediéndose como se ha explicado.

\subsection{PREPARACIÓN DE LAS MUESTRAS Y ELECTROFORESIS}

Se prepararon las muestras en condiciones desnaturalizantes añadiendo tampón de carga (Tris $125 \mathrm{mM}$, glicerol al $10 \%$, SDS al $2 \%, \beta$-mercaptoetanol al $1 \%$ y azul de bromofenol al $0.0005 \%$; $\mathrm{pH} 6,8$ ), y se hirvieron a $100^{\circ} \mathrm{C}$ durante 5 minutos (Laemmli, 1970).

Las proteínas se separaron mediante una electroforesis vertical en gel, o SDS-PAGE (del inglés, Sodium Dodecyl Sulphate - PolyAcrilamide Gel Electrophoresis), con distinto porcentaje de poliacrilamida según el tamaño de la proteína a analizar (Tris base 0,4 M, pH 8.8; APS al 0,1\%, TEMED al 0,08\% y acrilamida diluida al porcentaje deseado). El gel se sometió posteriormente a una electroforesis, en cubetas Mini-PROTEAN ${ }^{\circledR} / I$ sumergido en tampón de electroforesis (Tris $25 \mathrm{mM}$; glicina $192 \mathrm{mM}$ y SDS 1,7 mM) y aplicando un voltaje constante de 130 voltios (V). En paralelo a las muestras, cargamos en el gel un marcador de proteínas de pesos moleculares conocidos.

\subsection{TRANSFERENCIA}

Las proteínas separadas e incluidas en el gel de acrilamida se transfirieron a una membrana de difluoruro de polivinilideno (PVDF; del inglés, PolyVinyliDene Fluoride). 
La transferencia se llevó a cabo mediante el método en húmedo en la cubeta Mini PROTEAN ${ }^{\otimes} I I I$, a una intensidad de corriente constante de $400 \mathrm{~mA}$ durante 1 hora en frío, en tampón de transferencia (glicina 192 mM, Tris 25 mM, pH 8.3).

\subsection{BLOQUEO E INCUBACIÓN CON LOS ANTICUERPOS}

Previamente a la incubación con anticuerpos, se procedió al bloqueo de los lugares de la membrana no ocupados por proteínas. Para ello, una vez finalizada la transferencia se lavó la membrana con tampón de lavado (Tween-20 al 0.1\%, $\mathrm{NaCl} 150$ mM, Tris 20 mM, $\mathrm{pH}$ 7.5) y se incubó con tampón de bloqueo (BSA 1-5\% en tampón de lavado), durante 1 hora a temperatura ambiente en agitación.

A continuación, se incubó la membrana con el anticuerpo primario, diluido en solución de bloqueo, durante al menos 90 minutos a temperatura ambiente (o toda la noche a $4^{\circ} \mathrm{C}$ ) en agitación. Las condiciones a las que se emplearon los anticuerpos se encuentran en ¡Error! No se encuentra el origen de la referencia.. Tras la incubación con el anticuerpo primario, se hicieron 3 lavados de 5 minutos con tampón de lavado y se incubó la membrana con el correspondiente anticuerpo secundario (una inmunoglobulina, IgG, conjugada con HRP), diluido en tampón de lavado, durante 30-45 minutos, a temperatura ambiente, en agitación. Se hicieron 3 lavados de 15 minutos del anticuerpo secundario.

\begin{tabular}{r|lll} 
EPITOPO & KDA & $\begin{array}{l}\text { ANTICUERPO } \\
\text { PRIMARIO }\end{array}$ & $\begin{array}{l}\text { ANTICUERPO } \\
\text { SECUNDARIO }\end{array}$ \\
\hline $\begin{array}{r}\text { ENDOGLINA } \\
\text { HUMANA }\end{array}$ & 92 & AcP de conejo 1:1.000 & Anti-conejo 1:15.000 \\
ICAM-1 & 100 & AcP de cabra 1:1000 & Anti-cabra 1:15.000 \\
VCAM-1 & 100 & AcP de cabra 1:1000 & Anti-cabra 1:15.000 \\
VE-CADHERINA & 125 & AcP de rata 1:1000 & Anti-rata 1:15.000
\end{tabular}




\subsection{REVELADO}

Para la detección de la señal ofrecida por el anticuerpo secundario, se utilizó un sistema basado en la oxidación del luminol potenciada con fosfo-iodofenol.

Las membranas se incubaron durante un minuto con una solución de Tris 0,1M, pH 9,35; luminol 2,2 mM y p-iodofenol 2,2 mM, suplementada con $\mathrm{H}_{2} \mathrm{O}_{2}$ al 0,03-0,06\%. La catálisis del $\mathrm{H}_{2} \mathrm{O}_{2}$ por la HRP unida al anticuerpo secundario libera $\mathrm{O}_{2}$, que oxida el luminol. El luminol oxidado emite luminiscencia, que será mayor cuanta más proteína haya, puesto que unirá mayor cantidad de anticuerpo y habrá más catálisis enzimáticas en ese punto.

Inmediatamente y en la oscuridad, se impresionó la membrana en una película de autorradiografía, que quedará velada en aquellas zonas donde la membrana emita luminiscencia, más cuanto mayor sea ésta.

Tras su exposición, se introdujo la película en una máquina de revelado que sumerge las películas en los líquidos de revelado, fijado y lavado, sucesivamente. Por último, la película obtenida fue digitalizada y cuantificada con el software Scion Image. 


\section{ANÁLISIS DEL NIVEL DE EXPRESIÓN GÉNICA POR QPCR}

\subsection{EXTRACCIÓN DE ARN DE TEJIDO}

Se empleó el kit NucleoSpin ${ }^{\circledR}$ RNA II para extraer ARN de las muestras de tejido de pulmón y riñón de ratón. Al tratarse de un tejido, utilizamos micropistilos para su homogenizado en el tampón de lisis del kit.

\subsection{OBTENCIÓN DE ADNC}

Para el análisis de la expresión génica necesitamos utilizar ADN como sustrato de la reacción. Mediante el uso de enzimas transcriptasas reversas virales, se obtuvo ADNc a partir del ARNm purificado de nuestras muestras (Kacian \& Myers, 1976).

Con el fin de sintetizar ADNc, se diluyeron $250 \mathrm{ng}$ de ARN de cada muestra con agua libre de RNasas hasta un volumen final de $16 \mu \mathrm{L}$. Se añadieron $4 \mu \mathrm{l}$ de la iScript $R T$ Supermix $5 X$, que contiene transcriptasa reversa, dNTP, oligo (dT), random primers, inhibidor de RNAsas, estabilizadores de $\mathrm{MgCl}_{2}$ y el tampón de reacción. Los $20 \mu \mathrm{L}$ totales fueron incubados en un termociclador $\mathrm{MyCycler}$ a $25^{\circ} \mathrm{C}$ durante 5 minutos, seguidos de 30 minutos a $42^{\circ} \mathrm{C}$ y 5 minutos finales a $85^{\circ} \mathrm{C}$. El ADNc obtenido se almacenó a $-40^{\circ} \mathrm{C}$.

\subsection{DISEÑO DE CEBADORES PARA QPCR}

Para el análisis de la expresión de los genes de interés en las muestras, fue necesario diseñar secuencias de cebadores y comprobar su eficacia en la amplificación de una sola secuencia génica específica.

Para el diseño de cebadores, se utilizó la base de genes del NCBI (National Center for Biotechnology Information, USA). Gracias a su herramienta Primer-BLAST, se seleccionó 
la pareja de cebadores que se consideró que mejor reunía los requisitos: Iongitud del amplicón en torno a 100 pares de bases, porcentaje de pares GC en torno al 50\%, y grado de autocomplementariedad bajo.

Para comprobar el funcionamiento de la pareja de cebadores en cada caso, se llevaron a cabo dos pruebas. En primer lugar, un gradiente de temperaturas consistente en una qPCR que utiliza diferentes temperaturas de anillamiento. Esta prueba nos permitió, por una parte, elegir la temperatura de anillamiento a la que mejor funcionasen nuestros cebadores. Por otro lado, el análisis de la curva de melting del producto de PCR, nos permitió saber si se había amplificado un solo producto o había habido amplificaciones inespecíficas que invalidasen el uso de estos cebadores. Cabría la posibilidad de que dos productos de PCR de diferente longitud tuviesen una curva de melting similar por su composición en pares de bases, por lo que llevamos a cabo una electroforesis en gel de agarosa de los productos de qPCR obtenido en la anterior prueba. Esto nos permitió comprobar que nuestra pareja de cebadores sólo ofrecía un producto de PCR.

Posteriormente, comprobamos la eficiencia de amplificación de nuestra pareja de cebadores, amplificando diluciones seriadas 1:3 de la muestra, y comprobando que el producto de PCR obtenido en cada muestra conservaba la proporción con respecto a la muestra sin diluir. Así, se elaboró una recta que enfrentaba el Ct con la dilución de la muestra. Se dieron por válidas rectas con un valor de $\mathrm{R}^{2}$ superior a 0,99. Además, la eficiencia, es decir, la proporción de $A D N$ que rendía la reacción de $\mathrm{PCR}$ en cada muestra, o pendiente de la recta, debía estar entre el 90 y el $110 \%$.

Las parejas de cebadores diseñados utilizadas en este trabajo se detallan en la ¡Error! No se encuentra el origen de la referencia.. 


\subsection{PCR CUANTITATIVA, QPCR O PCR A TIEMPO REAL}

La técnica de PCR consiste en la amplificación de regiones específicas de ADN gracias a la utilización de cebadores específicos que anillan a ambos flancos de dicha región, y a la acción de una enzima ADN polimerasa que sintetiza ADN nuevo mediante la copia de la secuencia de dicha región gracias a la elongación de los cebadores (Bessman et al, 1958).

La PCR a tiempo real o qPCR permite monitorizar la cantidad de ADN al final de cada ciclo de amplificación gracias a la utilización de un fluoróforo que se une a ese ADN cuando está en estado de doble cadena (Woo et al, 1998). El software acoplado al termociclador registra la emisión de fluorescencia de cada una de las muestras a lo largo de la PCR y genera una curva de amplificación sigmoidea.

La PCR se preparó sobre un volumen final de $20 \mu \mathrm{l}$. Se mezcló $1 \mu \mathrm{l}$ de cDNA, $10 \mu \mathrm{l}$ de la Supermix $i^{T M}{ }^{T M}{ }^{\prime} R^{\oplus}$ Green, $0,4 \mu \mathrm{l}$ de cada cebador y $8,2 \mu \mathrm{l}$ de $\mathrm{H}_{2} \mathrm{O} \mathrm{mQ}$. La reacción se llevó a cabo en un termociclador $i Q^{T M} 5$, empleando un protocolo que incubó la reacción a $95^{\circ} \mathrm{C}$ durante 5 minutos, seguidos de 40 ciclos de 30 segundos a $95^{\circ} \mathrm{C}, 30$ segundos a la temperatura de anillamiento específica y 30 segundos a $72^{\circ} \mathrm{C}$. La cámara acoplada al termociclador toma una imagen de la muestra al final de cada ciclo, detectando la señal fluorescente, mayor cuanto más producto de $P C R$, al haber más ADN de doble cadena. Una vez terminado el protocolo, la temperatura del termociclador aumenta desde $70^{\circ} \mathrm{C}$ a $95^{\circ} \mathrm{C}$, de forma gradual en ciclos de 10 segundos, con un aumento de $0,5^{\circ} \mathrm{C}$ en cada ciclo y tomando una fotografía al final de cada ciclo. Esto provoca la desnaturalización del ADN, obteniendo la curva de melting o disociación de nuestro producto de $\mathrm{PCR}$, que debe ser única para confirmar que se trata de un producto único.

El software acoplado al termociclador establece una línea de threshold, es decir, una línea horizontal que corta a las curvas de amplificación de cada muestra cuando todas ellas están en su fase exponencial. Después calcula los niveles de expresión relativos de las diferentes muestras en función de sus $\mathrm{Ct}$, es decir, del ciclo de amplificación de cada 
muestra en el que la curva de amplificación en fase exponencial corta la línea de threshold. Un Ct más bajo indica una mayor cantidad de ADN del gen en cuestión, puesto que significa que esa muestra alcanza antes la fase exponencial de amplificación.

Se utilizaron como housekeeping la expresión de los ARNm de RPS13 (del inglés, Ribosomal Protein S13), de $\beta$-actina y de GAPDH (Gliceraldehído 3-fosfato deshidrogenasa).

\begin{tabular}{|c|c|c|}
\hline Gen diana & Secuencia de los cebadores $\left(5^{\prime}-3^{\prime}\right)$ & Ta de anillamiento \\
\hline$\beta$-Actina & $\begin{array}{l}\text { TCTACAAATGTGGCTGAGGACT } \\
\text { GAGGGACTTCCTGTAACCACTT }\end{array}$ & 59 \\
\hline CD45 & $\begin{array}{l}\text { TCTTTGCTTATGTGGCGTGTG } \\
\text { ATCCCCTTCTGATGCGCCTA }\end{array}$ & 56 \\
\hline CXCL12 & $\begin{array}{l}\text { TCTAGGCCATCCCACTCACA } \\
\text { CAGCCGTGCAACAATCTGAA }\end{array}$ & 59 \\
\hline ENG & $\begin{array}{l}\text { AGGTGCTTCTGGTCCTCAGT } \\
\text { CCACTCAAGGATCTGGGTCT }\end{array}$ & 65 \\
\hline S-ENG & GGAAGTCCATAGGACTGTCTTCA & 65 \\
\hline & CACTGTGGGGGCCTGGGGTA & \\
\hline $\begin{array}{l}\text { SELE (E- } \\
\text { selectina) }\end{array}$ & $\begin{array}{l}\text { ATGTGATGATGTCCCTCGGC } \\
\text { CTTCCTGGGTCCACTTTCCC }\end{array}$ & 59 \\
\hline GAPDH & $\begin{array}{l}\text { GTCGGTGTGAACGGATTT } \\
\text { GAATTTGCCGTGAGTGGAGT }\end{array}$ & 59 \\
\hline ICAM-1 & $\begin{array}{l}\text { CGCTGTGCTTTGAGAACTGT } \\
\text { GGTGAGGTCCTTGCCTACTT }\end{array}$ & 59 \\
\hline IL1 $\beta$ & $\begin{array}{l}\text { GCCTGTGTTTTCСTCCTTGC } \\
\text { TGCTGCCTAATGTCCCCTTG }\end{array}$ & 59 \\
\hline IL6 & TCCAGTTGCCTTCTTGGGAC & 59 \\
\hline
\end{tabular}




\begin{tabular}{|c|c|c|}
\hline & AGTCTCCTCTCCGGACTTGT & \\
\hline CD31 (PECAM) & $\begin{array}{l}\text { CGGTTATGATGATGTTTCTGGA } \\
\text { AAGGGAGGACACTTCCACTTCT }\end{array}$ & 59 \\
\hline PRS13 & $\begin{array}{l}\text { GATGCTAAATTCCGCCTGAT } \\
\text { TAGAGCAGAGGCTGTGGATG }\end{array}$ & 59 \\
\hline VCAM-1 & $\begin{array}{l}\text { GAACCCAAACAGAGGCAGAG } \\
\text { GGTATCCCATCACTTGAGCAG }\end{array}$ & 59 \\
\hline $\begin{array}{l}\text { CDH5 (VE- } \\
\text { cadherina) }\end{array}$ & $\begin{array}{l}\text { ATTGGCCTGTGTTTTCGCAC } \\
\text { CACAGTGGGGTCATCTGCAT }\end{array}$ & 59 \\
\hline
\end{tabular}

Tabla 3. Cebadores y condiciones de PCR 


\section{TÉCNICA DE ELISA}

La técnica de ELISA es un ensayo de inmunoadsorción, basado en la detección de un antígeno presente en la muestra mediante anticuerpos que, directa o indirectamente, producen una reacción cuantificable espectrofotométricamente (Engvall \& Perlmann, 1971; Voller, 1978).

En este trabajo, se determinó por ELISA la concentración de distintas moléculas clave en el proceso inflamatorio, mediante el empleo de kits comerciales especificados en la ¡Error! No se encuentra el origen de la referencia. y siguiendo las instrucciones del fabricante. También se estudió por ELISA la actividad mieloperoxidasa, proveniente de los gránulos azurófilos de los granulocitos.

\begin{tabular}{|c|c|c|c|}
\hline Proteína diana & Nombre & Casa comercial & Referencia \\
\hline hEndoglina & $\begin{array}{l}\text { kit Quantikine Human } \\
\text { Endoglin/CD105 Inmunoassay }\end{array}$ & R\&D Systems & DNG00 \\
\hline IL10 & $\begin{array}{l}\text { Mouse IL-10 ELISA Kit (Sandwich } \\
\text { ELISA) }\end{array}$ & LSBIO & LS-F9770 \\
\hline IL1 $\beta$ & $\begin{array}{l}\text { Mouse IL-1 beta/IL-1F2 Quantikine } \\
\text { ELISA Kit }\end{array}$ & $R \& D$ Systems & MLBO0C \\
\hline IL6 & Mouse IL-6 Quantikine ELISA Kit & R\&D Systems & M6000B \\
\hline TNFa & $\begin{array}{l}\text { Mouse TNF-alpha Quantikine } \\
\text { ELISA Kit }\end{array}$ & R\&D Systems & MTAOOB \\
\hline Mieloperoxidasa & MPO Mouse, ELISA kit & Hycult Biotech & HK210-02 \\
\hline
\end{tabular}




\section{TRATAMIENTO DE LOS DATOS Y ANÁLISIS ESTADÍSTICOS}

Todos los resultados se expresaron como la media \pm el error estándar de la media (EEM). Para datos normales, se utilizó el test estadístico de análisis de la varianza (ANOVA) para determinar las diferencias significativas entre más de dos grupos de datos. Consideramos significativo un valor de $p<0,05$.

En el análisis de los datos de qPCR, se aplicó una transformación logarítmica del valor de expresión relativa obtenido. Esto permitió transformar la distribución de los datos, con sesgo positivo, en una distribución normal. Una vez transformado el conjunto de datos, se puede conocer si hay outliers en la muestra y eliminarlos. Sobre el valor transformado aplicamos los test estadísticos mencionados.

Los análisis estadísticos se llevaron a cabo con Microsoft Excel 2016 y GraphPad Prism 6.

\begin{tabular}{|c|c|c|}
\hline Reactivo / Producto & Referencia & Casa comercial \\
\hline ADN polimerasa & 10.003 & Biotools \\
\hline Agarosa & 50000 & Lonza \\
\hline Agujas calibre 21 & 4657527 & Braun \\
\hline Agujas calibre 23 & 4657667 & Braun \\
\hline Agujas calibre 30 & 4656300 & Braun \\
\hline APS (Persulfato de amonio) & A3678 & Sigma-aldrich \\
\hline Azul de bromofenol & B8026 & Sigma-aldrich \\
\hline Azul de trypan & T10282 & Thermo fisher scientific \\
\hline BSA (albúmina sérica bovina) & A7906 & Sigma-aldrich \\
\hline
\end{tabular}




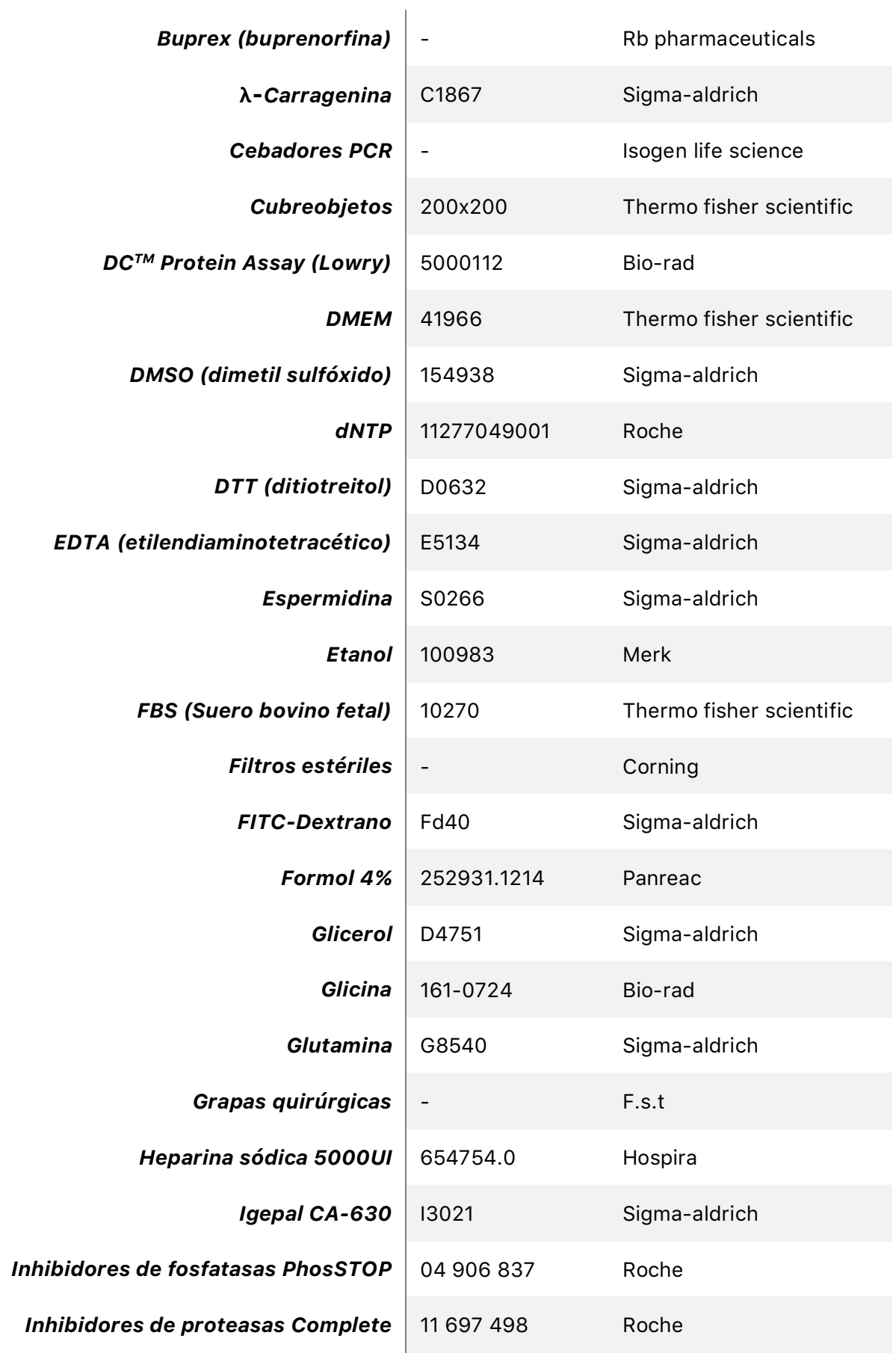




\begin{tabular}{|c|c|c|}
\hline iScript RT Supermix & $170-8841$ & Bio-rad \\
\hline Isoflurano IsoFlo & $34009 \times n$ & Esteve \\
\hline Jeringas $10 \mathrm{~mL}$ & $4616103 v$ & Braun \\
\hline Jeringas $3 \mathbf{m L}$ & $4616025 v$ & Braun \\
\hline Jeringuillas $1 \mathrm{~mL}$ & $9161406 v$ & Braun \\
\hline Lipopolisacárido (LPS) & L3129 & Sigma-aldrich \\
\hline Luminol & A8511 & Sigma-aldrich \\
\hline Marcador 1 kb & $10787-018$ & Thermo fisher scientific \\
\hline Marcador pesos moleculares PageRuler ${ }^{T M}$ & 26616 & Thermo fisher scientific \\
\hline Material quirúrgico & - & Fine science tools (f.s.t.) \\
\hline Membranas de PVDF & 66543 & Pall corporation \\
\hline Metanol & 34885 & Sigma-aldrich \\
\hline $\mathrm{Na}_{2} \mathrm{HPO}_{4}$ & 20908 & Sigma-aldrich \\
\hline $\mathrm{NaCl}$ & S3014 & Sigma-aldrich \\
\hline $\mathrm{NH}_{4} \mathrm{Cl}$ & 141121 & Panreac \\
\hline NucleoSpin ${ }^{\circledR}$ RNA II & 740.955 & Macherey nagel \\
\hline p-iodofenol & 110201 & Sigma-aldrich \\
\hline Películas Fuji Medical X-Ray Film Super RX & 47410 & Fuji medical \\
\hline Penicilina - Estreptomicina & $15140-122$ & Thermo fisher scientific \\
\hline Pipetas de plástico de 5, 10 y $25 \mathrm{~mL}$ & - & Corning \\
\hline Placas de cultivo & - & Corning \\
\hline Portaobjetos & $76 \times 26$ & Thermo fisher scientific \\
\hline Puntas micropipeta con filtro & - & Neptune \\
\hline Puntas micropipeta sin filtro & $2000 / 80 / 16$ & Deltalab \\
\hline
\end{tabular}




\begin{tabular}{|c|c|c|}
\hline Rascadores de células & 353086 & Corning \\
\hline RedSafe & 21141 & Intron biotechnology \\
\hline rhEng (Endoglina recominate humana) & 1097-en & R\&d systems \\
\hline SDS (Dodecil sulfato sódico) & $152002 c$ & Bio-rad \\
\hline Sutura 5/0 no absorbible & 06185 & Aragó \\
\hline TEMED (tetrametil-etilendiamina) & 142093 & Panreac \\
\hline Transwell con FluoroBlock ${ }^{T M}$ & 351152 & Corning \\
\hline Tripsina $0,25 \%$ - EDTA $0,02 \%$ & 25200 & Thermo fisher scientific \\
\hline Tris base & $443866 \mathrm{~g}$ & Merck \\
\hline Tubos de plástico de 1,5 mL & 175508 & Nirco \\
\hline Tubos de plástico de 15 y 50 mL & - & Corning \\
\hline Tubos de plástico de $2 \mathrm{~mL}$ & $4092.7 n$ & Deltalab \\
\hline Tween-20 & P7949 & Sigma-aldrich \\
\hline Xileno & 141769 & Panreac \\
\hline$\beta$-mercaptoetanol & M6250 & Sigma-aldrich \\
\hline
\end{tabular}

\begin{tabular}{|c|c|}
\hline Equipos / Aparatos & Casa comercial \\
\hline Almohadilla térmica & DAGA \\
\hline Cámara digital Olympus DP70 & Olympus \\
\hline $\begin{array}{r}\text { Campana de flujo laminar vertical Gelaire TC- } \\
48\end{array}$ & Flow Laboratories \\
\hline Cassette de revelado & Amersham \\
\hline
\end{tabular}




\begin{tabular}{|c|c|}
\hline Centrífugas & Eppendorf \\
\hline Countess ${ }^{\circledR}$ Automated Cell Counter & Thermo Fisher Scientific \\
\hline Equipo electroforesis PCR & Bio-Rad \\
\hline Equipo de Western blot Mini-Protean ${ }^{\circledR I I I}$ & Bio-Rad \\
\hline Escáner & Canon \\
\hline Fuente de alimentación Power Pac 3000 & Bio-Rad \\
\hline Fluorímetro Synergy H1 & BioTek \\
\hline Incubador & P.Selecta \\
\hline Hemocitómetro ADVIA ${ }^{\circledR} 120$ & Siemens Healthcare \\
\hline Lavador de placas de ELISA (ELX50) & Siemens Healthcare \\
\hline Lector de placas ELISA Epoch & BioTek \\
\hline Lupa & Nikon \\
\hline Máquina anestesia inhalatoria & MSS Isoflurane \\
\hline Máquina de revelado Medical X Ray Processor & Kodak \\
\hline Nanodrop (ND-1000) & Thermo Fisher Scientific \\
\hline Nebulizador & APEX \\
\hline Termociclador iQTM 5 & Bio-Rad \\
\hline Termociclador MyCycler ${ }^{T M}$ & Bio-Rad \\
\hline Transiluminador GeIDoc & Bio-Rad \\
\hline Ultracentrífuga & Beckman \\
\hline Ultracongelador & Thermo Fisher Scientific \\
\hline
\end{tabular}


RESULTADOS Y DISCUSIÓN 
La L-endoglina es la isoforma mayoritaria de endoglina, y por ello, con mucha diferencia, la más estudiada. La isoforma S-endoglina no resulta de tanto interés científico como la L-endoglina. Sin embargo, los estudios que comparan los efectos de L-endoglina y Sendoglina son muy interesantes y de gran utilidad, ya que, dado que estas isoformas son idénticas en su dominio extracelular, pero difieren en el intracelular, los diferentes efectos que cause la presencia de una $u$ otra de estas isoformas se deberán exclusivamente a la ausencia del dominio intracelular. Por consiguiente, si L-endoglina y S-endoglina causan el mismo efecto, será que éste está controlado por el dominio extracelular, mientras que, si el efecto es distinto, nos indica que podría regularse por el dominio citoplasmático.

Por ello, en esta primera parte del estudio, nos proponemos valorar el efecto de las distintas isoformas de endoglina de membrana en el proceso inflamatorio. El estudio comparativo de ratones wild type, y ratones que sobreexpresan L-endoglina o Sendoglina nos permite valorar el papel de la sobreexpresión de L-endoglina en condiciones control y condiciones inflamatorias, y, a su vez, valorar si estos efectos se regulan por el dominio extracelular o el intracelular. 


\section{ESTUDIO DEL PAPEL DE LAS ISOFORMAS DE MEMBRANA DE ENDOGLINA EN EL PROCESO INFLAMATORIO}

Se ha relacionado un aumento de los niveles de endoglina de membrana con distintos procesos inflamatorios. La expresión de endoglina de membrana en células endoteliales aumenta en piel, hígado, intestino y pulmón en condiciones inflamatorias, siendo mayor la expresión en zonas de acúmulos de infiltrado leucocitario y durante la cicatrización de heridas (Torsney et al, 2002). Además, endoglina aumenta su expresión en placas arteroescleróticas (Conley et al, 2000), en piel con soriasis (Rulo et al, 1995), en artritis reumatoide (Szekanecz et al, 1995), tras daño vascular (Conley et al, 2000), isquemiareperfusión (Docherty et al, 2006), infarto de miocardio (van Laake et al, 2006), y cáncer (Bernabeu et al, 2009).

Los estudios que existen actualmente relacionando endoglina de membrana con inflamación se centran en estudiar los efectos que produce la deficiencia de endoglina. Sin embargo, no hay estudios que valoren los efectos de la sobreexpresión de endoglina de membrana en las primeras etapas de la respuesta inflamatoria aguda.

Por ello, y dado la gran aplicabilidad clínica que tendría la obtención de conocimientos en este campo, en esta primera aproximación al análisis de la relación de la endoglina de membrana con las primeras etapas de la inflamación, nos proponemos dos hipótesis iniciales.

En primer lugar, valorar si un aumento en la expresión de la isoforma larga de endoglina de membrana da lugar a un aumento del reclutamiento leucocitario, tanto en condiciones control, como tras inducción inflamatoria aguda.

En segundo lugar, valorar si las posibles diferencias observadas entre los ratones que sobreexpresan endoglina de membrana y los ratones $W T$ se deben al dominio extracelular de endoglina o al intracelular. Dicho de otro modo: valorar si el dominio 
responsable del posible papel de la endoglina de membrana en la respuesta inflamatoria aguda es el dominio extracelular o el dominio intracelular. Para ello, compararemos los resultados obtenidos en presencia de sobreexpresión de endoglina de membrana larga con los obtenidos ante sobreexpresión de endoglina de membrana corta. Como ambas isoformas son idénticas en su dominio extracelular, si observáramos un comportamiento diferente únicamente podría deberse al dominio intracelular.

Para elucidar el efecto de la sobreexpresión de L-endoglina y S-endoglina en la inflamación, se evaluaron las alteraciones histopatológicas, el reclutamiento leucocitario, la expresión y concentración de citoquinas quimiotácticas e inflamatorias, la permeabilidad vascular y la expresión de moléculas de adhesión leucocitarias.

\subsection{ESTUDIO DEL PAPEL DE LAS ISOFORMAS DE MEMBRANA DE ENDOGLINA EN EL RECLUTAMIENTO LEUCOCITARIO}

\subsubsection{VALORACIÓN HISTOLÓGICA DEL EFECTO DE LAS ISOFORMAS DE MEMBRANA DE ENDOGLINA EN EL DAÑO TISULAR INDUCIDO POR ESTÍMULOS INFLAMATORIOS}

Estudiamos, mediante la tinción de hematoxilina-eosina, las posibles alteraciones estructurales presentes en el tejido del pulmón, la piel y el riñón, inducidas por la sobreexpresión de L-endoglina y S-endoglina en condiciones control. Además, valoramos el efecto de la sobreexpresión de endoglina de membrana sobre las alteraciones tisulares inducidas tras estímulos inflamatorios de distinta naturaleza, correspondientes a los modelos de LPS, air pouch e isquemia-reperfusión renal, respectivamente. 


\subsubsection{ALTERACIONES EN PULMÓN TRAS TRATAMIENTO CON LPS}

Como podemos ver en la Figura 24, los pulmones control presentan una apariencia sana, con bronquiolos, sacos alveolares y vasos sanguíneos conservados. No hay presencia de infiltrado leucocitario ni de otros síntomas inflamatorios. No se observan diferencias entre los ratones control WT, L-ENG+ y S-ENG+.

Tras el tratamiento con LPS observamos alveolos colapsados, con paredes alveolares muy engrosadas y zonas parcheadas de infiltrado inflamatorio intraalveolar y subpleural, compuesto mayoritariamente por macrófagos muy activados, con signos de fagocitosis, células polimorfonucleares de tipo neutrófilo, linfocitos y células plasmáticas (marcado con un círculo amarillo). No hay diferencias en el infiltrado inflamatorio entre los ratones $W T$ y los $L-E N G+$, la cantidad de infiltrado es significativamente menor en los pulmones de los ratones S-ENG+ (Figura 24).

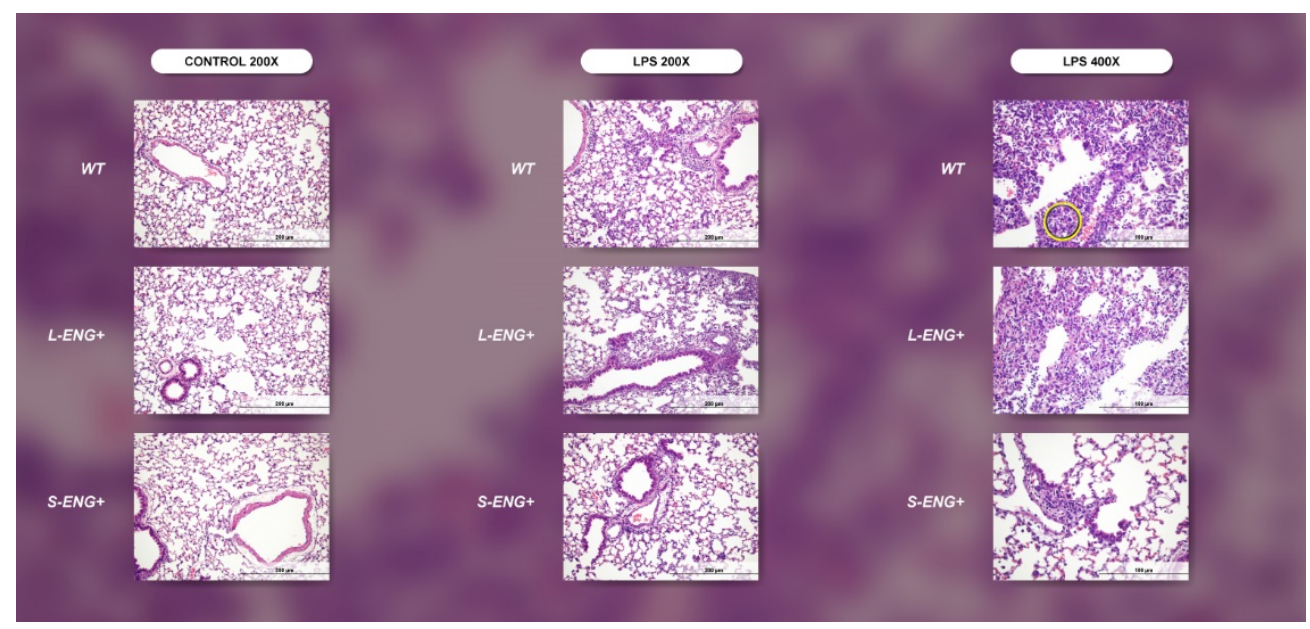

Figura 24. Estudio histológico del pulmón de ratones WT, L-ENG+ y S-ENG+. Imágenes representativas de la tinción H\&E correspondiente a pulmones de ratones WT, L-ENG+ y S-ENG+, control y tratados con LPS. Micrografías obtenidas mediante cámara acoplada a un microscopio óptico con 200 y 400 aumentos, respectivamente. WT $(n=6), L-E N G+(n=6)$ y $S-E N G+(n=6)$. El círculo amarillo marca una zona de infiltrado leucocitario. 
Con la finalidad de valorar cuantitativamente las diferencias observadas en el estudio histológico de los pulmones de ratones $W T$ y sEng+ a nivel de infiltrado leucocitario, se sistematizó la cuantificación del infiltrado inflamatorio en el tejido.

Para ello, se siguieron los criterios establecidos en la literatura (Guo et al, 2012), descritos en la Tabla 7. Se calculó una puntuación total para cada ratón.

\begin{tabular}{|c|c|c|c|c|}
\hline Índice & 0 & 1 & 2 & 3 \\
\hline $\begin{array}{r}\text { Infiltrado } \\
\text { leucocitario }\end{array}$ & $\begin{array}{l}\text { Menos de } 5 \\
\text { leucocitos por } \\
\text { campo }\end{array}$ & $\begin{array}{l}\text { De } 5 \text { a } 10 \\
\text { leucocitos por } \\
\text { campo }\end{array}$ & $\begin{array}{l}\text { De } 10 \text { a } 20 \\
\text { leucocitos por } \\
\text { campo }\end{array}$ & $\begin{array}{l}\text { Más de } 20 \\
\text { leucocitos por } \\
\text { campo }\end{array}$ \\
\hline
\end{tabular}

Tabla 7. Sistema cuantitativo utilizado en la histología para medir el grado de infiltrado leucocitario

Como muestra la Figura 25, al cuantificar el infiltrado inflamatorio en el pulmón observamos que los ratones control no presentan infiltrado, correspondiéndose a un índice 0 según la Tabla 7. Sistema cuantitativo utilizado en la histología para medir el grado de infiltrado leucocitario, sin diferencias entre los controles $W T, L-E N G+$ y $S$ ENG+. Al cuantificar el infiltrado en los ratones tratados con LPS, se da un significativo aumento en la cantidad de infiltrado leucocitario, siendo de índice 1,5-2 en los WT y LENG+ y significativamente menor en el caso de los pulmones correspondientes a los ratones S-ENG+: índice 0,5-1. 
(A)

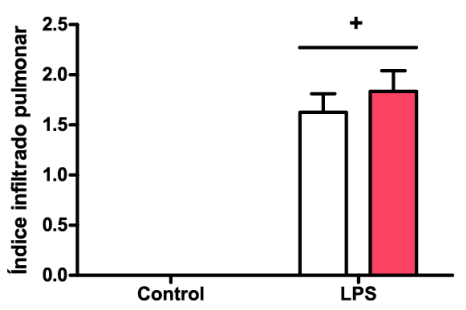

$\square w T$
(B)

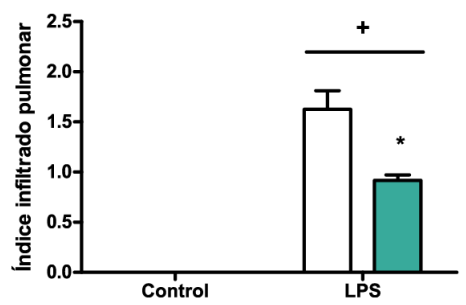

S-ENG+

Figura 25. Índice de infiltrado pulmonar en ratones WT, L-ENG+ y S-ENG+. Valoración histológica cuantitativa del infiltrado pulmonar en ratones WT, L-ENG+ y S-ENG+, control y tratados con LPS. Cada barra representa la media \pm EEM. WT $(n=6), L-E N G+(n=6)$ y S-ENG $+(n=6)$. Test estadístico ANOVA de doble vía, $+p<0,0001$ vs control, * $p<0,005$ vs LPS WT.

\subsubsection{ALTERACIONES EN LA PIEL TRAS TRATAMIENTO CON CARRAGENINA}

Con la finalidad de valorar las posibles alteraciones histológicas que la sobreexpresión de L-endoglina y S-endoglina puede causar en la piel, tanto en condiciones control como tras inducción inflamatoria, se realizó el estudio histológico de la piel correspondiente a la zona del pouch.

En los ratones control, la piel está estructuralmente conservada, observándose que la epidermis, la dermis, la hipodermis, el tejido muscular y el conjuntivo están conservados, y no hay presencia de infiltrado inflamatorio salvo un número reducido de fibroblastos en conjuntivo laxo, ocasionados por la formación subcutánea del air pouch (Figura 26). No se observan diferencias entre los ratones control WT, L-ENG+ y S-ENG+. En los ratones tratados con carragenina aumenta considerablemente la cantidad de infiltrado inflamatorio de tipo polimorfonuclear neutrófilo y células plasmáticas, estando principalmente en el tejido conjuntivo (zona de contacto con la carragenina) y llegando a penetrar el músculo y en ocasiones hasta la hipodermis. Este infiltrado inflamatorio parece ser mayor en los ratones $L-E N G+$ (marcado con un círculo amarillo) que en los 
$W T$, mientras que en la piel de los ratones $S-E N G+$ se observa menor cantidad de infiltrado.

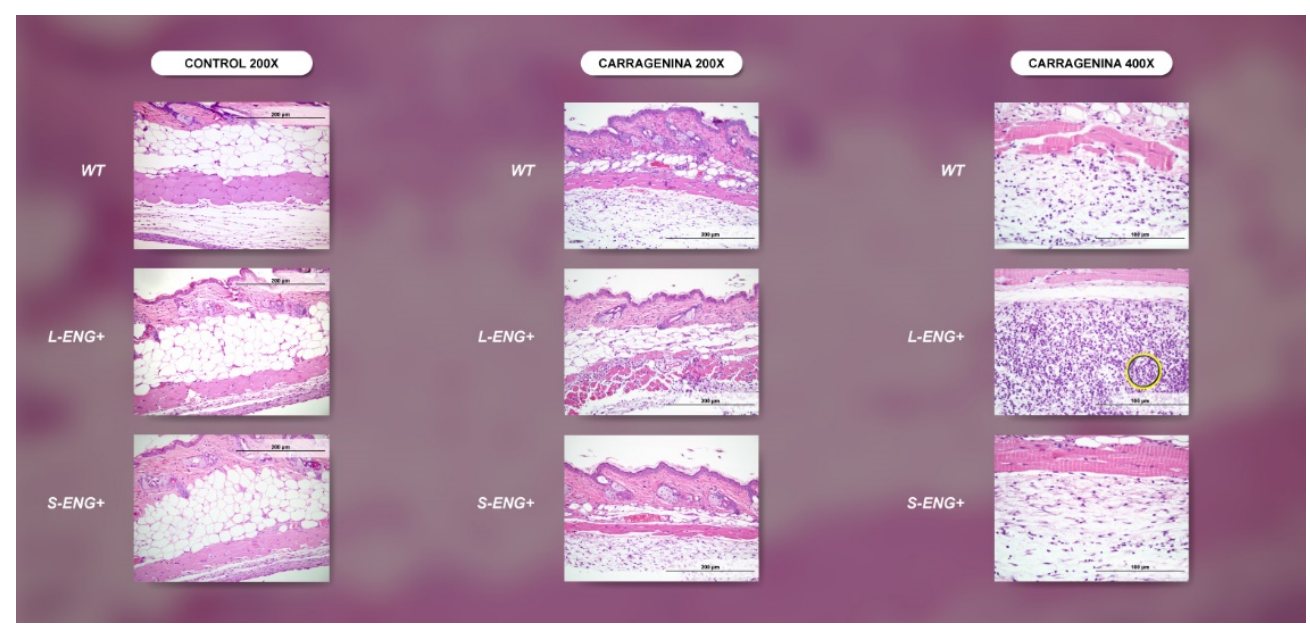

Figura 26. Estudio histológico de la piel del air pouch, de ratones WT, L-ENG+ y S-ENG+. Imágenes representativas de la tinción H\&E correspondiente a la piel de la zona del air pouch de ratones WT, LENG+ y S-ENG+, control y tratados con carragenina. Micrografías obtenidas mediante cámara acoplada a un microscopio óptico con 200 y 400 aumentos, respectivamente. WT (n=6), L-ENG+ (n=5) y S-ENG+ $(n=6)$. El círculo amarillo marca una zona de infiltrado leucocitario.

Al cuantificar el infiltrado en la piel del pouch, comprobamos que, mientras que los ratones control no presentan infiltrado inflamatorio (índice 0), los ratones L-ENG+ (índice 2) presentan mayor infiltrado que los $W T$ (índice 1), mientras que en los ratones S-ENG+ el infiltrado es significativamente menor (índice 0-1) (Figura 27). 
(A)

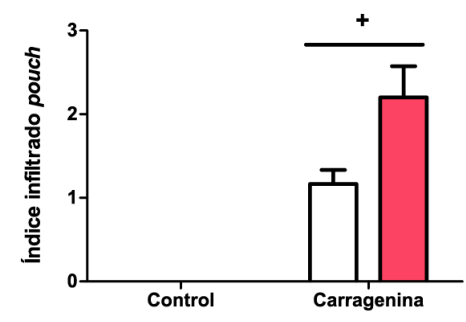

$\square w T$
(B)

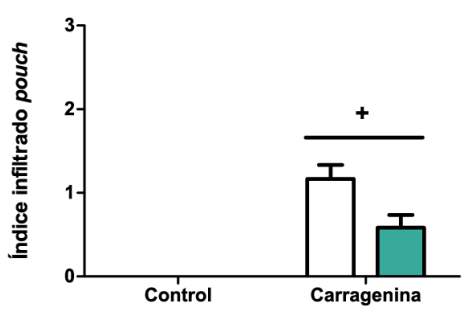

L-ENG+

S-ENG+

Figura 27. Índice de infiltrado en la piel del air pouch en ratones WT, L-ENG+ y S-ENG+. Valoración

\subsubsection{ALTERACIONES EN RIÑÓN TRAS ISQUEMIA-REPERFUSIÓN}

Los riñones control muestran una apariencia sana, con glomérulos y túbulos conservados, sin acúmulos de infiltrado leucocitario ni estructuras patológicas. No se aprecian diferencias entre los ratones control WT, L-ENG+ y S-ENG+ (Figura 28). Tras la isquemia-reperfusión, no se observa la aparición de infiltrado inflamatorio. Sin embargo, observamos necrosis tubular en túbulos proximales y distales, pérdida total del epitelio de revestimiento tubular y depósitos hialinos, especialmente en la zona cortico-medular (marcado con un círculo azul). La necrosis tubular es de un grado similar en ratones $W T$ y $L-E N G+$, mientras que los ratones $S-E N G+$ presentan menor necrosis tubular, observándose una mayor conservación del epitelio de revestimiento tubular. 


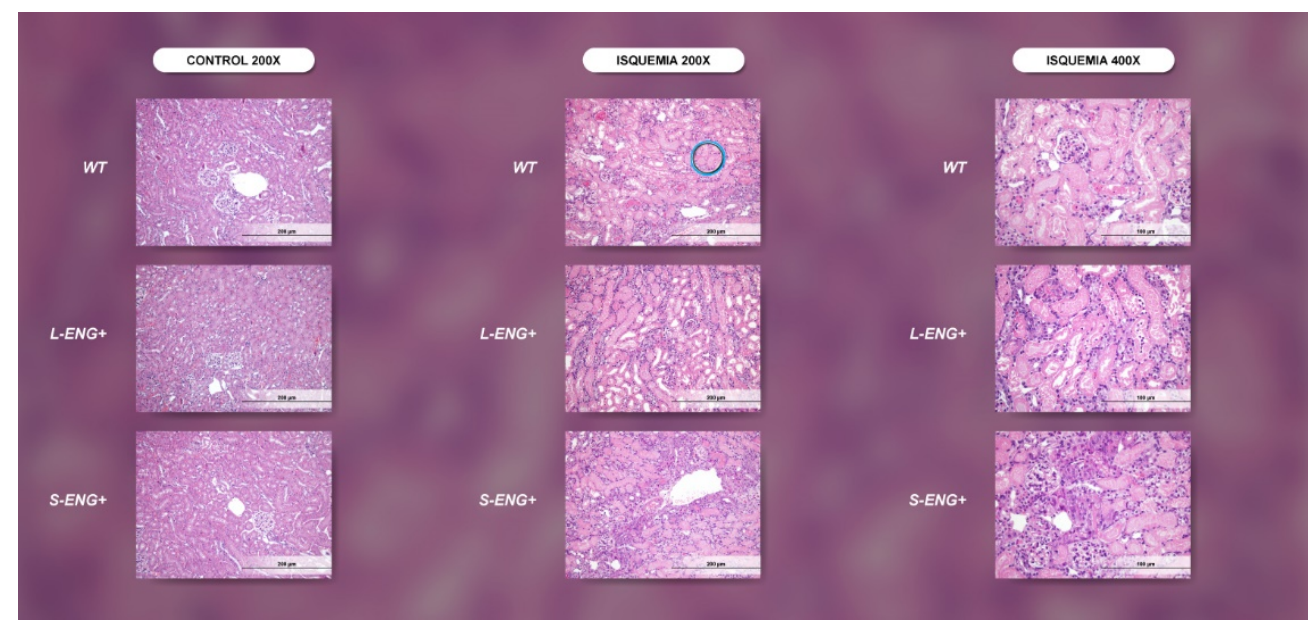

Figura 28. Estudio histológico del riñón de ratones WT, L-ENG+ y S-ENG+. Imágenes representativas de la tinción H\&E correspondiente al riñón de ratones WT, L-ENG+ y S-ENG+, control y sometidos a isquemiareperfusión. Micrografías obtenidas mediante cámara acoplada a un microscopio óptico con 200 y 400 aumentos, respectivamente. WT $(n=6), L-E N G+(n=5)$ y S-ENG+ $(n=6)$. El círculo azul marca una zona de necrosis tubular.

La cuantificación del grado de necrosis tubular se llevó a cabo siguiendo los criterios establecidos en la literatura (Okusa et al, 1999), establecidos en la Tabla 8

\begin{tabular}{|c|c|c|c|c|}
\hline Índice & 0 & 1 & 2 & 3 \\
\hline $\begin{array}{r}\text { Necrosis } \\
\text { tubular }\end{array}$ & Sin daño tubular & $\begin{array}{l}\text { Pérdida del } \\
\text { borde en cepillo } \\
\text { y/o presencia de } \\
\text { debris celular }\end{array}$ & $\begin{array}{l}\text { Necrosis tubular } \\
\text { parcial }\end{array}$ & $\begin{array}{l}\text { Necrosis y } \\
\text { dilatación } \\
\text { tubular total }\end{array}$ \\
\hline
\end{tabular}

Tabla 8. Sistema cuantitativo utilizado para medir el grado de necrosis tubular

Los riñones control no presentan necrosis tubular (índice 0). Tras la isquemiareperfusión, cuantificamos necrosis tubular considerable en los $W T$ y los $L-E N G+$, los cuales presentan un índice 3, mientras que el índice de necrosis tubular tras la isquemia 
(A)

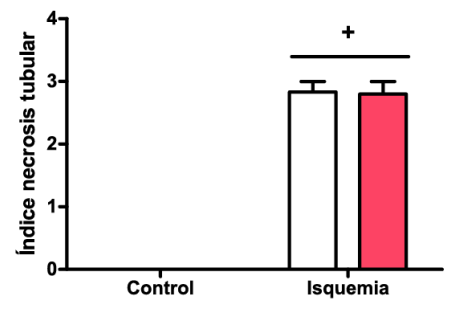

WT
(B)

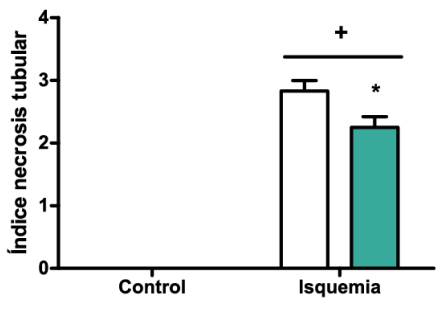

S-ENG+

Figura 29. Índice de necrosis tubular en el riñón de ratones WT, L-ENG + y S-ENG+. Valoración histológica cuantitativa del infiltrado pulmonar en ratones WT, L-ENG+ y S-ENG+, control y sometidos a isquemiareperfusión. Cada barra representa la media \pm EEM. WT $(n=6), L-E N G+(n=5)$ y S-ENG $+(n=6)$. Test estadístico ANOVA de doble vía, $+p<0,0001$ vs control, ${ }^{*} p<0,05$ vs isquemia WT.

El análisis de las alteraciones histopatológicas en pulmón, piel y riñón tras el tratamiento con LPS, carragenina o isquemia-reperfusión respectivamente, nos muestra, que la sobreexpresión de L-endoglina o S-endoglina no altera la histología de pulmón, piel y riñón en condiciones control, al no haber diferencias con los ratones WT. Sin embargo, tras el estímulo inflamatorio, la respuesta inflamatoria es menor, en todos los tejidos, en los ratones S-ENG+.

Esto indicaría que, tras inducción inflamatoria, el dominio intracelular de endoglina tiene un papel en el reclutamiento leucocitario al foco inflamatorio.

Una vez analizadas las valoraciones histológicas, y teniendo en cuenta nuestras hipótesis iniciales, observamos, en primer lugar, que la sobreexpresión de la isoforma larga de endoglina de membrana no provoca, por si misma, alteraciones histológicas en condiciones control, siendo las muestras de aspecto similar a las de los ratones WT. En condiciones inflamatorias, la presencia de endoglina de membrana no provoca alteraciones histológicas significativas ni en pulmón tratado con LPS, ni en riñón sometido a isquemia-reperfusión ni en el modelo del air pouch con carragenina. Por ello, 
la sobreexpresión de endoglina de membrana no parece tener un papel en las alteraciones histopatológicas causadas por la inflamación.

Sin embargo, cuando comparamos los resultados obtenidos en ratones que sobreexpresan endoglina larga de membrana con los que sobreexpresan la isoforma corta, observamos diferencias. Los ratones que carecen del dominio intracelular de endoglina de membrana presentan una reducción de las alteraciones histopatológicas, en los 3 modelos inflamatorios, lo cual nos indica, según nuestra segunda hipótesis, que el dominio intracelular de endoglina es responsable de las alteraciones histológicas que ocurren durante el proceso inflamatorio.

\subsubsection{INFILTRADO LEUCOCITARIO}

Para confirmar los resultados obtenidos en los análisis histológicos, valoramos el infiltrado extravasado tanto en el lavado broncoalveolar como en el lavado del pouch.

Al analizar el lavado broncoalveolar se observa que la cantidad de leucocitos presente en los ratones control es mínima. No se observan diferencias entre los controles $W T, L-$ $E N G+$ y $S-E N G+$ (Figura 30), por lo que la sobreexpresión de L-endoglina y S-endoglina no altera el infiltrado leucocitario en condiciones fisiológicas.

La concentración leucocitaria aumenta significativamente en los ratones tratados con LPS, y podemos observar cómo, tras el tratamiento, no se observan diferencias significativas entre los $W T$ y $L-E N G)$, mientras que el infiltrado leucocitario es significativamente menor en el BAL de los ratones $S-E N G+$. 


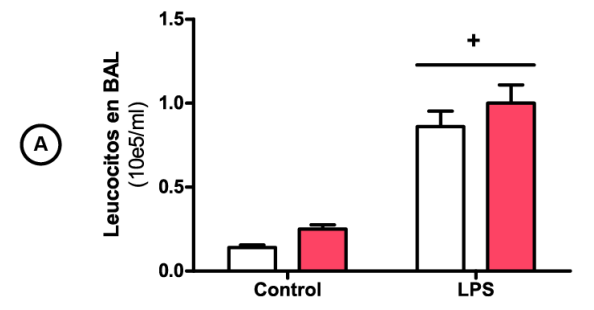

$\square w T$
(B)

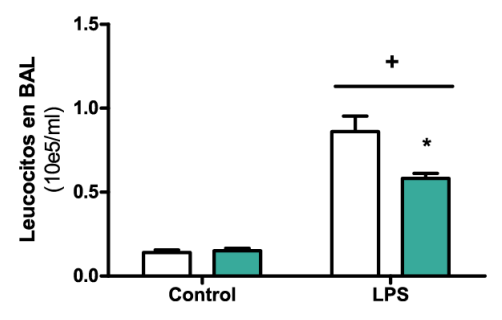

S-ENG+

Figura 30. Concentración de leucocitos en el lavado broncoalveolar en ratones WT, L-ENG+ y S-ENG+. Análisis de la concentración de leucocitos en el BAL de ratones WT, L-ENG+ y S-ENG+, control y tratados con LPS. Los datos se expresan por $10 e^{5} / \mathrm{ml}$. Cada barra representa la media \pm EEM. WT $(n=10), L-E N G+$ $(n=10)$ y S-ENG $+(n=10)$. Test estadístico ANOVA de doble vía: $+p<0,0001$ vs control, *p<0,01 vs LPS WT.

Del mismo modo, se analizó la cantidad de infiltrado leucocitario en el lavado del pouch, en ratones control y tratados con carragenina. Los ratones control, presentan niveles de leucocitos por debajo de la sensibilidad del hemocitómetro $\left(7 \times 10^{5}\right.$ células por $\left.\mathrm{ml}\right)$, por lo que sólo se valoró en los tratados con carragenina. En la Figura $\mathbf{3 1}$ se observa que no hay diferencias significativas en la concentración de leucocitos entre los ratones $W T$, los $L-E N G+$ y los S-ENG+.

(A)

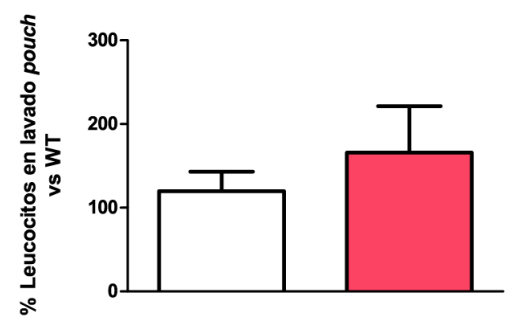

(B)

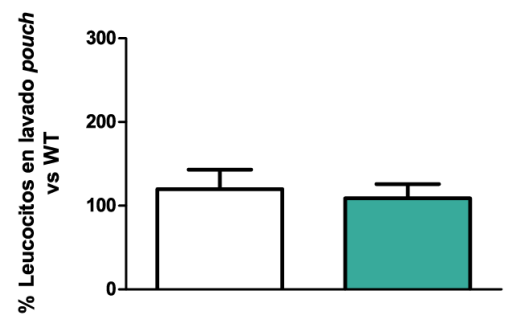
$\square$ wT
L-ENG+
S-ENG+ 
Figura 31. Concentración de leucocitos en el lavado del air pouch en ratones WT, L-ENG+ y S-ENG+. Análisis de la concentración de leucocitos en el lavado del air pouch de ratones WT, L-ENG+ y S-ENG+, tratados con carragenina. Los valores se expresan en porcentaje, normalizados respecto a los WT. Cada barra representa la media \pm EEM. WT $(n=6), L-E N G+(n=8)$ y S-ENG $+(n=7)$.

Para valorar el infiltrado en el tejido, se analizó mediante qPCR la expresión del ARNm del marcador de infiltrado leucocitario CD45. En pulmón, la expresión de CD45 es baja en condiciones control, sin diferencias entre los ratones control WT, L-ENG+ y S-ENG+. La expresión aumenta significativamente tras el tratamiento con LPS, sin diferencias entre el ratón $W T$ y el $L-E N G+$. Sin embargo, este aumento no es tan elevado en los ratones $S-E N G+$ (Figura 32, A y B), que presentan menor expresión que los WT.

Por otro lado, la expresión en riñón es mayor en los controles $L-E N G+$ y $S-E N G+$ que en los $W T$ (Figura 32, C y D). Tras la isquemia-reperfusión, la expresión se mantiene constante en los ratones $W T$, mientras que en los ratones $L-E N G+$ y $S-E N G+$ se observa una disminución significativa con respecto al control.

Estos resultados explican los obtenidos al estudiar la histopatología del pulmón y el riñón (Figura 24 y Figura 28): el tratamiento con LPS provoca un aumento del infiltrado leucocitario, similar en los ratones $W T$ y $L-E N G+$, pero inferior en los $S-E N G+$, mientras que en riñón, $48 \mathrm{~h}$ después de la isquemia-reperfusión, no se está dando síntesis de CD45, lo cual apoya el hecho de que no se observara infiltrado en el análisis histológico. 

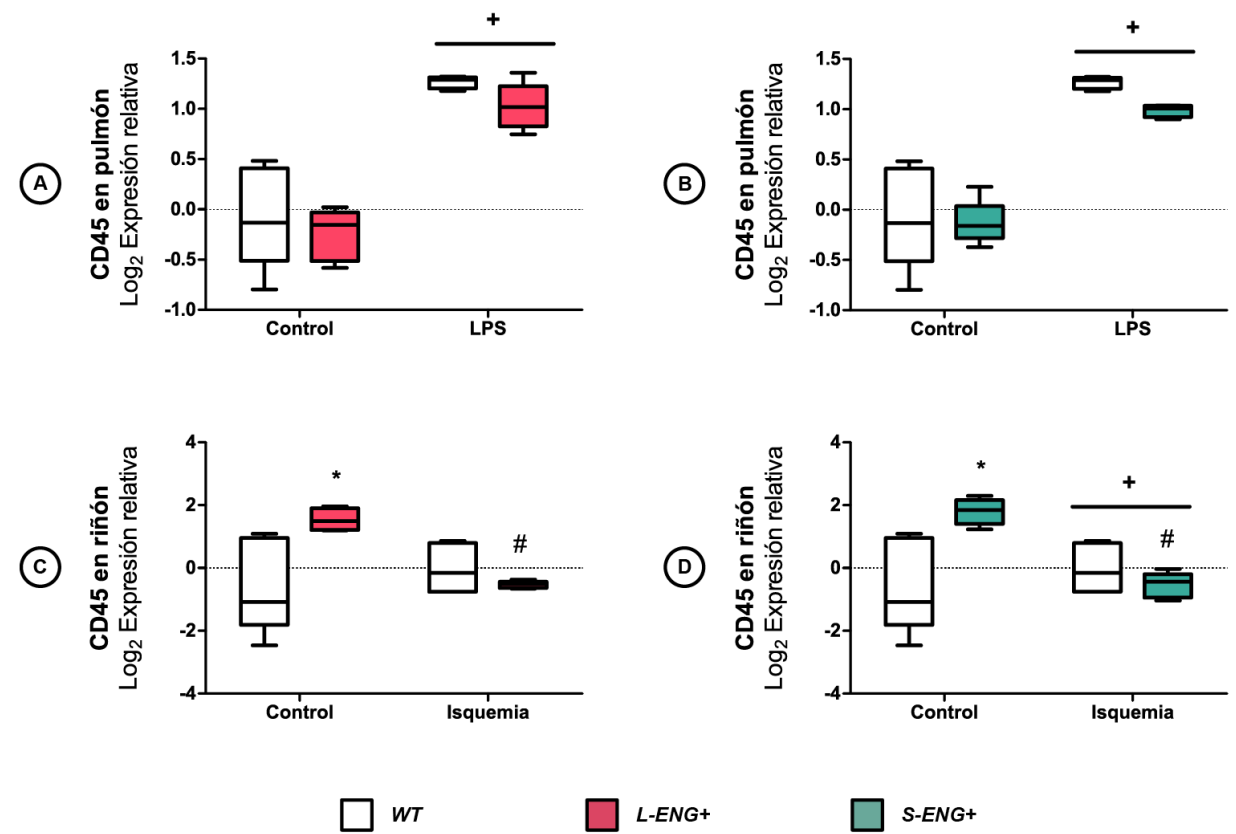

L-ENG+

S-ENG+

Figura 32. Análisis de la expresión de CD45 en ratones WT, L-ENG+ y S-ENG+. Análisis mediante qPCR de los niveles de expresión de CD45 en pulmón $(A, B)$ y en riñón $(C, D)$ de ratones WT, L-ENG+ y S-ENG+, control, tratados con LPS o isquemia-reperfusión renal, respectivamente. Los valores se representan como el logaritmo en base dos de la expresión relativa de cada muestra con respecto de las muestras WT. Se representa un box plot 10-90 percentil. WT $(n=5), L-E N G+(n=5)$ y S-ENG+ $(n=5)$. Test estadístico ANOVA de doble vía: $(A, B)+p<0,0001$ vs control, (C) *p<0,05 vs control WT, \#p<0,0001 vs control LENG+, (D) $+p<0,05$ vs control, $* p<0,01$ vs control WT, $\# p<0,0001$ vs control S-ENG+.

A la vista de los resultados, podemos deducir que, mientras que la sobreexpresión de Lendoglina y S-endoglina no interfiere de manera significativa con el infiltrado inflamatorio en condiciones control, la extravasación leucocitaria tras inducción inflamatoria con LPS, carragenina o isquemia es menor en los ratones S-ENG+, es decir, en ausencia del dominio intracelular de endoglina de membrana. Estos resultados confirmarían lo observado al analizar la histología: tras el estímulo inflamatorio, el dominio intracelular de endoglina tiene un papel en el reclutamiento leucocitario al foco inflamatorio. Mientras que en condiciones control no parece observarse ningún efecto. 
Apenas se conoce el papel que desempeña S-endoglina in vivo. Se han descrito diferentes respuestas celulares a la sobreexpresión de L-endoglina o de S-endoglina, sugiriendo un papel esencial del dominio intracelular de la proteína en la modulación de numerosos procesos (Velasco et al, 2008; Duwel et al, 2007; Quintanilla et al, 2003; Perez-Gomez et al, 2005).

Actualmente, no hay estudios que valoren el papel diferencial de las isoformas de endoglina en inflamación aguda. Los únicos estudios que hay al respecto se centran en inflamación crónica, valorándose la fibrosis tubulointersticial en modelos de daño renal agudo. 15 días después de una obstrucción ureteral unilateral (OUU), los ratones que sobreexpresan L-endoglina presentan mayor cantidad de fibrosis renal que los ratones $W T$. Los riñones obstruidos correspondientes a los ratones $L-E N G+$ tienen mayores niveles y mayor expresión de ARNm de colágeno I y fibronectina que los WT (Oujo et al, 2014).

Al utilizar el mismo modelo de fibrosis en ratones que sobreexpresan S-endoglina se obtuvo el resultado contrario. Se observó que la extensión del tejido fibrótico es mayor en los ratones WT que en los S-ENG+. Los niveles de colágeno I y fibronectina son mayores en los ratones $W T$ que en los S-ENG+. Además, los niveles de marcadores inflamatorios como CD68, COX-2, iNOS, y moléculas de adhesión como VCAM-1 e ICAM-1, eran menores en los ratones S-ENG+ que en los WT (Muñoz-Félix et al, 2016). Estos resultados indican que, mientras que la sobreexpresión de L-endoglina aumenta la fibrosis inducida por OUU, la sobreexpresión de S-endoglina la disminuye, lo que pone de manifiesto que el dominio citoplasmático de endoglina tiene un papel en la regulación de la fibrosis, un componente clave en la inflamación crónica.

A la vista de nuestros resultados, no se observan diferencias significativas en condiciones control a nivel de infiltrado inflamatorio entre los ratones $W T, L-E N G+$ y $S$ ENG+, corroborando los resultados de Oujo et al. y Muñoz-Félix et al. (Oujo et al, 2014; Muñoz-Félix et al, 2016). 
Esto nos lleva a concluir que la sobreexpresión de las distintas isoformas de endoglina, por sí sola, no altera el reclutamiento leucocitario. Además, podemos observar que, tras inducción inflamatoria, ya sea por nebulización de LPS, carragenina o isquemiareperfusión, no se observan diferencias a nivel de infiltrado leucocitario entre los ratones $W T$ y los $L-E N G+$. Esto nos permite deducir que la sobreexpresión de L-endoglina no altera el reclutamiento leucocitario.

Sin embargo, observamos que, tras inducción inflamatoria, los ratones S-ENG+ presentan menor reclutamiento leucocitario en comparación con los $W T$, lo cual apoya los resultados obtenidos por Muñoz-Félix et al., en los cuales observan menor expresión de moléculas leucocitarios como CD68, COX-2 e iNOS, tras obstrucción ureteral unilateral en ratones que sobreexpresan S-endoglina (Muñoz-Félix et al, 2016). Esto indica que la presencia de S-endoglina induce una reducción del estado inflamatorio, tanto en modelos de inflamación aguda como en modelos de fibrosis renal (Muñoz-Félix et al, 2016).

Las isoformas L-endoglina y S-endoglina tienen el dominio extracelular idéntico, diferenciándose sólo en su dominio intracelular. Por ello, el hecho de observar diferencias a nivel de reclutamiento leucocitario entre ratones que sobreexpresan Lendoglina y S-endoglina, nos indica que el dominio intracelular de endoglina tiene un papel en este proceso.

De acuerdo a los resultados expuestos por Rossi et al., el dominio extracelular de endoglina participa en el reclutamiento leucocitario mediante la unión del dominio RGD de endoglina con las integrinas a5 $\beta 1$ leucocitarias, observando una menor transmigración leucocitaria en ratones haploinsuficientes de endoglina (Rossi et al, 2013). Sin embargo, esta teoría no permite explicar todos nuestros resultados, y no concuerdan algunos aspectos.

En primer lugar, si es verdad que la endoglina de membrana facilita el reclutamiento leucocitario mediante la unión de su dominio RGD con las integrinas leucocitarias, sería lógico esperar un aumento significativo en la transmigración leucocitaria en presencia de elevadas cantidades de endoglina de membrana. Sin embargo, no observamos este 
incremento en los ratones que sobreexpresan L-endoglina, ni en condiciones control, ni tras la inducción inflamatoria.

Además, el dominio extracelular de L-endoglina y S-endoglina es idéntico, por lo que, según esta teoría, no esperaríamos observar diferencias en el reclutamiento leucocitario ante la sobreexpresión de L-endoglina o S-endoglina. Sin embargo, nuestros resultados muestran que la presencia de S-endoglina reduce el infiltrado leucocitario, lo cual indica que el dominio intracelular de tiene un papel en el reclutamiento leucocitario.

Se ha observado que, ratones que sobreexpresan S-endoglina presentan un retraso en el crecimiento tumoral, similar a aquel observado en ratones deficientes de endoglina (Quintanilla et al, 2003; Pérez-Gómez et al, 2005; Duwel et al, 2007). Los autores sugieren que esto puede deberse a que S-endoglina pueda comportarse como una molécula antiangiogénica, de manera contraria a la función proangiogénica que se le atribuye a la L-endoglina, lo cual pone de manifiesto el papel del dominio intracelular de endoglina de membrana.

El cáncer es una patología que cursan con un aumento crónico de la permeabilidad vascular, aumentando los espacios inter-endoteliales y, consecuentemente, la salida de moléculas y leucocitos de los vasos sanguíneos, y, en ocasiones, extravasación de células tumorales a distintos tejidos y al sistema linfático, ocasionando metástasis (Patel et al, 2016). De hecho, se ha demostrado en modelos de tumor preclínico, que, limitando el reclutamiento leucocitario tumoral, disminuye el desarrollo del tumor (Marelli et al, 2017). Teniendo en cuenta que el componente inflamatorio es crítico para el crecimiento tumoral (Marelli et al, 2017) y de acuerdo a nuestros resultados, el retraso tumoral observado en los ratones que sobreexpresan S-endoglina podría deberse, al menos parcialmente, a una disminución en el reclutamiento leucocitario.

Para comprobar si ante la sobreexpresión de S-endoglina, además de estar reducidas las alteraciones histopatológicas y el reclutamiento leucocitario, también existen modificaciones a nivel de citoquinas, se analizó la expresión y concentración de las citoquinas CXCL12, IL1 $\beta$ e IL6, ya que nos aporta información sobre el efecto de la 
sobreexpresión de L-endoglina y S-endoglina en el estado inflamatorio, tanto en condiciones control como tras inducción de la inflamación.

\subsubsection{EXPRESIÓN Y CONCENTRACIÓN DE CITOQUINAS QUIMIOTÁCTICAS E INFLAMATORIAS}

Para valorar el estado inflamatorio, analizamos si la quimiotaxis leucocitaria continua activa 48 horas después de la inducción inflamatoria. Se analizó la expresión de la citoquina quimiotáctica CXCL12 en pulmón y riñón.

\subsubsection{ANÁLISIS DE LA EXPRESIÓN DE CXCL12}

CXCL12 es una citoquina de potente capacidad quimiotáctica para leucocitos. Al analizar la expresión del ARNm de CXCL12 no se observan diferencias entre los ratones control WT, L-ENG+ y S-ENG+ (Figura 33, A y B). Tras el tratamiento con LPS, la expresión aumentó significativamente en los ratones $W T$. Sin embargo, en los ratones $L-E N G+$ y $S-E N G+$ no observamos ese aumento de expresión tras LPS, diferenciándose de manera significativa respecto al $W T$.

Con respecto a la expresión de CXCL12 en riñón, no hay diferencias entre los ratones control WT, L-ENG+ y S-ENG+. Tras la isquemia-reperfusión, observamos una disminución significativa, tanto en los ratones $W T$, como en los $L-E N G+$ y $S-E N G+$, sin diferencias en su expresión (Figura 33, C y D). 
(A)

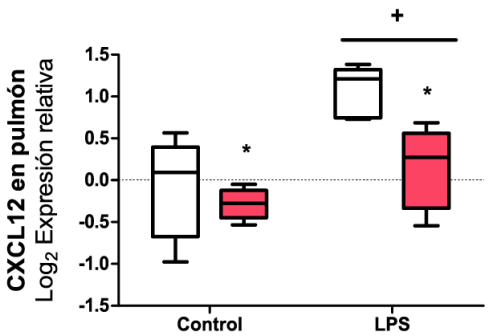

(c)

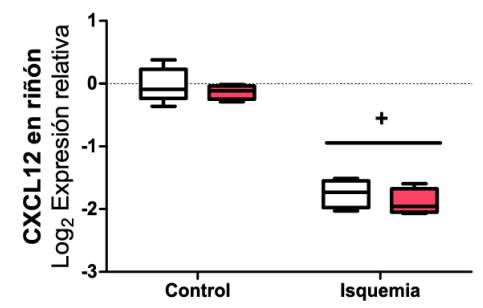

$\square w T$
(B)

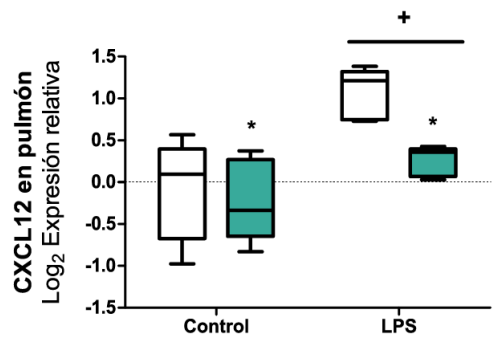

(D)

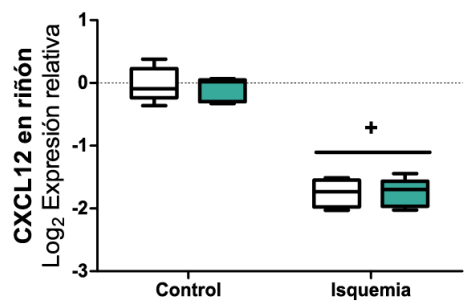

L-ENG+

S-ENG+

Figura 33. Análisis de la expresión de CXCL12 en ratones WT, L-ENG+ y S-ENG+. Análisis mediante qPCR de los niveles de expresión de CXCL12 en pulmón $(A, B)$ y en riñón $(C, D)$ de ratones WT, L-ENG+ y SENG+, control, tratados con LPS o isquemia-reperfusión renal, respectivamente. Los valores se representan como el logaritmo en base dos de la expresión relativa de cada muestra con respecto de las muestras WT. Se representa un box plot 10-90 percentil. En pulmón: WT $(n=5), L-E N G+(n=5)$ y S-ENG+ $(n=5)$, en riñón: WT $(n=5), L-E N G+(n=4)$ y S-ENG $+(n=5)$. Test estadístico ANOVA de doble vía: $+p<0,005$ vs control. ${ }^{*} p<0,01$ vs $\mathrm{WT}$, respectivamente.

Estos resultados indican que 48 horas tras el tratamiento con LPS, en los ratones LENG+ y $S-E N G+$ no continúa activa la quimiotaxis a leucocitos, al contrario que los ratones $W T$. De hecho, particularmente en el caso de los $S-E N G+$, no hay prácticamente diferencias en la expresión del ARNm de CXCL12 entre los ratones control y los tratados con LPS. Esto se explica según lo observado en la valoración histológica: en pulmón continuaría activa la quimiotaxis leucocitaria 48 horas después de la inducción inflamatoria por LPS, mientras que en riñones sometidos a isquemia-reperfusión no. 
Posteriormente, analizamos las citoquinas inflamatorias IL1 $\beta$ e IL6 para valorar los efectos de la sobreexpresión de las distintas isoformas de endoglina de membrana en el estado inflamatorio.

\subsubsection{ANÁLISIS DE LA EXPRESIÓN DE IL1B E IL6}

Al analizar la expresión del ARNm de la citoquina proinflamatoria IL1 $\beta$ en pulmón, no se observan diferencias entre los ratones control WT, L-ENG+ y S-ENG+. Tras el tratamiento con LPS, la expresión aumenta, siendo este aumento significativamente menor en el caso de los ratones S-ENG+ (Figura 34, A y B). En riñón, los controles $L-$ $E N G+$ y $S-E N G+$ tienen mayor expresión que los controles $W T$ (Figura 34, C y D). Tras la isquemia-reperfusión, se observa que en los ratones WT y L-ENG+ aumenta la expresión del ARNm de IL1 $\beta$, mientras en los $S-E N G+$ prácticamente no aumenta la expresión con respecto a los controles S-ENG+.

(A)

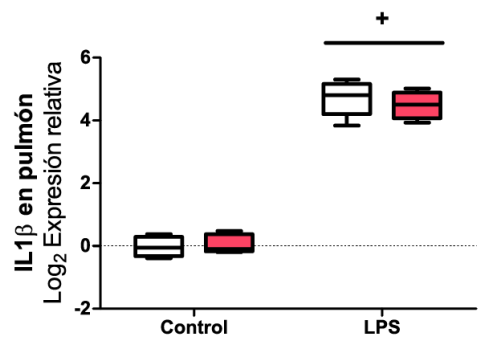

(c)

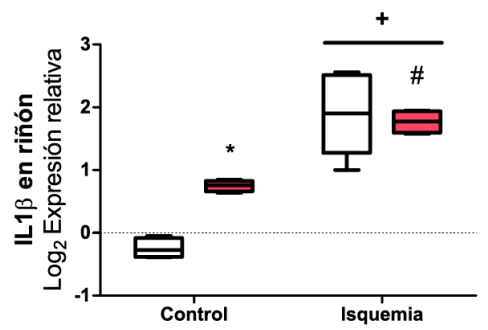

(B)

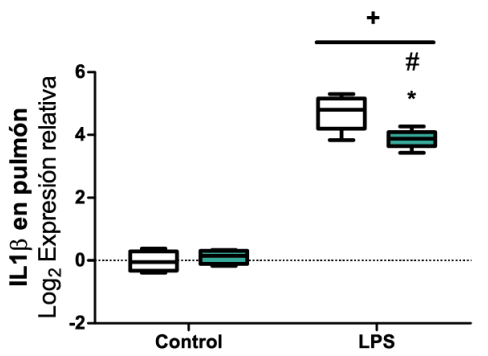

(D)

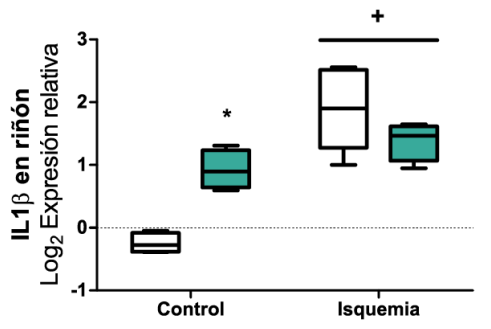


Figura 34. Análisis de la expresión de IL1ß en ratones WT, L-ENG+ y S-ENG+. Análisis mediante qPCR de los niveles de expresión de IL1 $1 \beta$ en pulmón $(A, B)$ y en riñón $(C, D)$ de ratones WT, L-ENG+ y S-ENG+, control, tratados con LPS o isquemia-reperfusión renal, respectivamente. Los valores se representan como el logaritmo en base dos de la expresión relativa de cada muestra con respecto de las muestras WT. Se representa un box plot 10-90 percentil. En pulmón: WT $(n=5), L-E N G+(n=5)$ y S-ENG+ $(n=5)$, en riñón: WT $(n=5), L-E N G+(n=4)$ y S-ENG+ $(n=4)$. Test estadístico ANOVA de doble vía, $+p<0,005$ vs control. (B) $* p<0,05$ vs LPS WT, \#p<0,0001 vs control S-ENG+. (C)*p<0,0001 vs control WT, \#p<0,0001 vs control L-ENG+. (D)*p<0,0005 vs control WT.

Al analizar la expresión del ARNm de la citoquina IL6 no se observan diferencias entre los ratones control WT, L-ENG+ y S-ENG+. Tras el tratamiento con LPS, se da un aumento en la expresión de IL6, siendo este aumento significativamente menor en los ratones S-ENG+ (Figura 35, A y B). Con respecto a la expresión de IL6 en riñón, no se observan diferencias significativas entre los ratones control WT, L-ENG+ y S-ENG+, aunque los $L-E N G+$ y $S-E N G+$ muestran, ligeramente, mayor expresión que los WT. Tras la isquemia-reperfusión, se observa una reducción significativa de la expresión, tanto en los ratones $L-E N G+$ como en los $S-E N G+$, ya que en los ratones control $L-E N G+$ y $S-$ ENG+ la expresión era más alta que en los controles WT (Figura 35, C y D). 
(A)

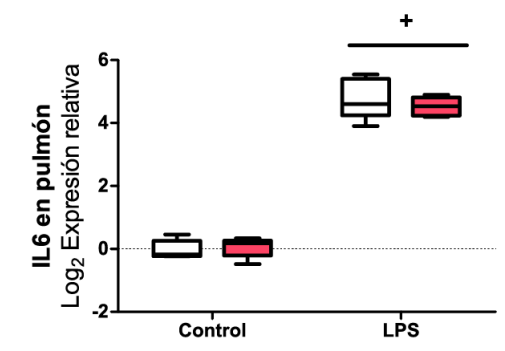

(c)

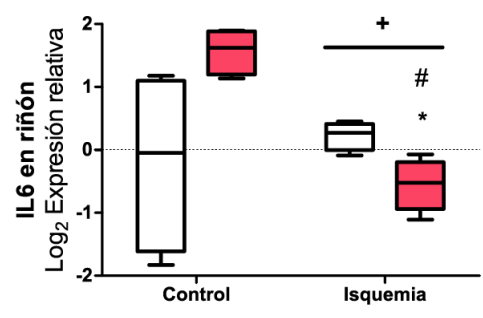

(B)

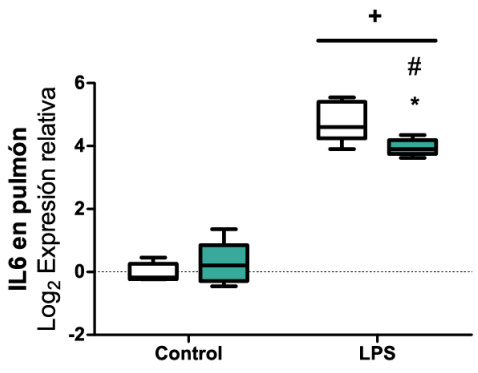

(D)

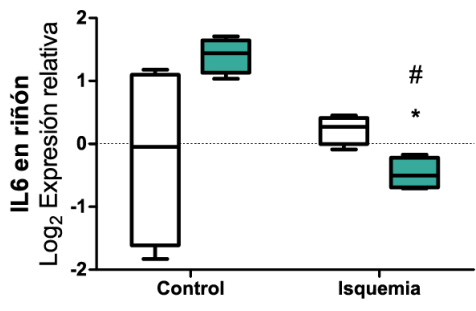

S-ENG+

Figura 35. Análisis de la expresión de IL6 en ratones WT, L-ENG+ y S-ENG+. Análisis mediante qPCR de los niveles de expresión de IL6 en pulmón $(A, B)$ y en riñón $(C, D)$ de ratones WT, L-ENG+ y S-ENG+, control, tratados con LPS o isquemia-reperfusión renal, respectivamente. Los valores se representan como el logaritmo en base dos de la expresión relativa de cada muestra con respecto de las muestras WT. Se representa un box plot 10-90 percentil. En pulmón: WT $(n=5), L-E N G+(n=5)$ y S-ENG $+(n=5)$, en riñón: WT $(n=4), L-E N G+(n=5)$ y S-ENG $+(n=4)$. Test estadístico ANOVA de doble vía, $(A)+p<0,0001$ vs control, (B) $+p<0,0001$ vs control, $* p<0,05$ vs LPS WT, $\# p<0,000$, vs control $S-E N G+,(C)+p<0,05$ vs control, ${ }^{*} p<0,05$ vs isquemia $W T,(D) * p<0,01$ vs isquemia $W T, \# p<0,0001$ vs control $S-E N G+$.

Para completar el análisis de la expresión de las citoquinas, se consideró interesante valorar la concentración de IL6, TNFa e IL10 en el lavado broncoalveolar y en el plasma. Se consideró interesante valorar además una citoquina no inflamatoria, como es el caso de IL10. 


\subsubsection{ANÁLISIS DE LA CONCENTRACIÓN DE IL6, TNFA E IL10}

La concentración de IL6 en el BAL es nula en los ratones control. Tras el tratamiento con LPS, aumenta significativamente en los ratones $W T$ y $L-E N G+$. Sin embargo, en los ratones S-ENG+, prácticamente no aumenta IL6 tras el tratamiento, existiendo diferencias significativas con respecto a los $W T$ tratados (Figura 36, A y B).

No hay IL6 en el plasma de los ratones control. Tras el tratamiento con LPS observamos un incremento considerable, siendo este aumento significativamente menor en los ratones S-ENG+ tratados (Figura 36, C y D). Como es de esperar, no se detecta IL6 ni en el BAL ni en el plasma de los ratones control, ya que es una citoquina que no está presente en condiciones control.
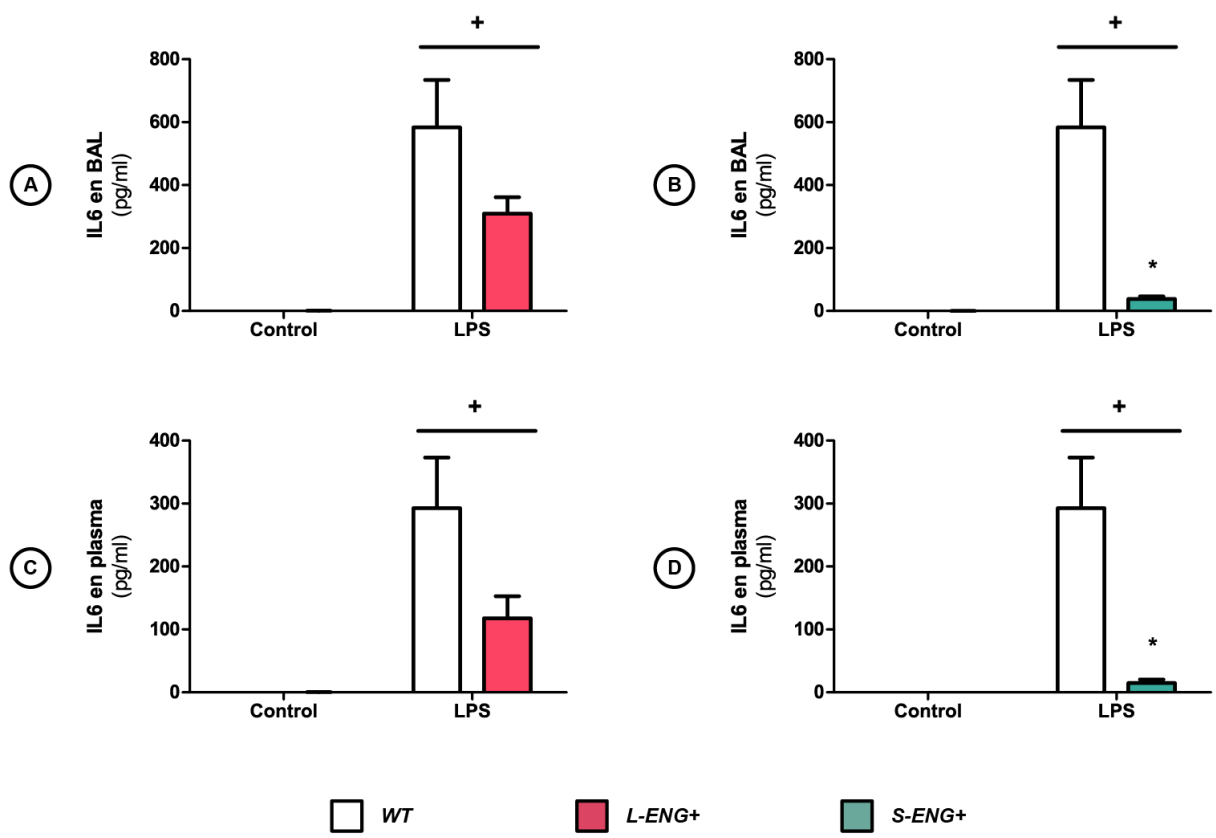

$\square$ L-ENG+

S-ENG+ 
y S-ENG+, control y tratados con LPS, analizado mediante ELISA. Los valores se expresan como pg/ml. Cada barra representa la media \pm EEM. En BAL: WT $(n=4), L-E N G+(n=5)$ y S-ENG $+(n=6)$, en plasma: WT $(n=4), L-E N G+(n=7)$ y S-ENG $+(n=6)$. Test estadístico ANOVA de doble vía, $(A)+p<0,0001$ vs control, $(B)+p<0,0005$ vs control, ${ }^{*} p<0,005$ vs LPS WT $(C)+p<0,0005$ vs control, $(D)+p<0,001$ vs control, ${ }^{*} p<0,005$ vs control S-ENG+.

La concentración de TNFa en el BAL de los ratones control es prácticamente nula. Tras el tratamiento con LPS, aumenta considerablemente (Figura 37, A y B). Los ratones L$E N G+$ tratados no mostraron diferencias significativas en el aumento de la concentración de TNFa con respecto a los WT, sin embargo, este aumento fue significativamente menor en los ratones S-ENG+.

La concentración de TNFa en el plasma de los ratones control es prácticamente nula, sin diferencias entre los ratones control WT, L-ENG+ y S-ENG+. Tras el tratamiento con LPS, la concentración aumenta notablemente, siendo este aumento inferior en los ratones $S-E N G+$ tratados (Figura $37, C$ y D).

(A)
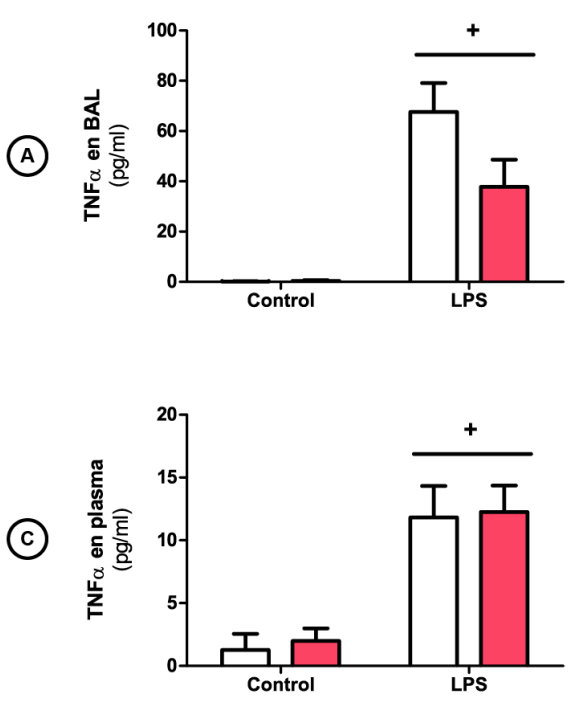

(B)

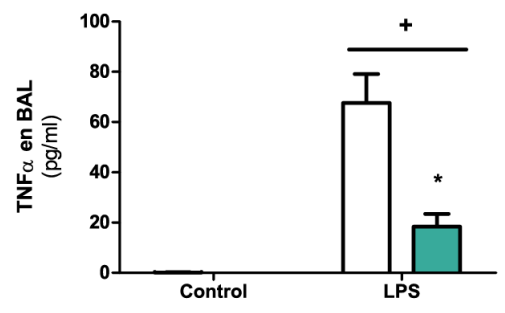

(D)

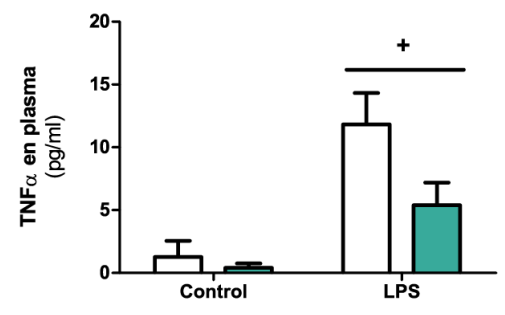

$\square w T$

L-ENG+

S-ENG+ 
Figura 37. Concentración de TNFa en el lavado broncoalveolar y en plasma en ratones WT, L-ENG+ y SENG+. Análisis de la concentración de TNFa en el BAL $(A, B)$ y en el plasma (C, D) de ratones WT, L-ENG+ y S-ENG+, control y tratados con LPS, analizado mediante ELISA. Los valores se expresan como pg/ml. Cada barra representa la media \pm EEM. En BAL: WT $(n=4), L-E N G+(n=5)$ y S-ENG $+(n=5)$, en plasma: WT $(n=7), L-E N G+(n=5)$ y S-ENG $+(n=7)$. Test estadístico ANOVA de doble vía, $(A)+p<0,0001$ vs control, (B) $+p<0,0001$ vs control, ${ }^{*} p<0,005$ vs LPS WT $(C)+p<0,001$ vs control, $(D)+p<0,005$ vs control.

El estudio de la expresión y concentración de citoquinas quimiotácticas, tanto en tejido (pulmón y riñón), en el lavado broncoalveolar y en el plasma de los ratones WT, L-ENG+ y $S$-ENG+, en el caso control y ante inflamación, nos permite concluir que, mientras que en condiciones control la sobreexpresión de L-endoglina o S-endoglina no provoca alteraciones. Tras los tratamientos inflamatorios la sobreexpresión de S-endoglina da lugar a un menor aumento de la expresión del ARNm de las citoquinas CXCL12, IL1 $\beta$ e IL6 en pulmón y riñón, y a una menor concentración de IL6 y TNFa en comparación con los ratones $W T$.

La IL10 es una citoquina con propiedades antiinflamatorias, con capacidad de inhibir la síntesis de citoquinas proinflamatorias por los linfocitos T y los macrófagos.

La concentración de IL10 tanto en el BAL (Figura 38, A y B), como en el plasma (Figura $38, C$ y D) se mantiene baja en condiciones control, sin diferencias entre los ratones control $W T, L-E N G+$ y $S-E N G+$. Tras el tratamiento con LPS, la concentración aumenta significativamente, sin diferencias entre $W T, L-E N G+$ y $S-E N G+$. 
(A)

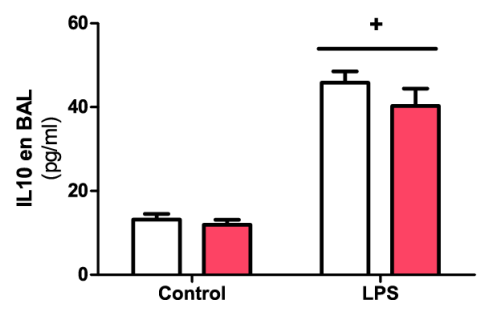

(c)

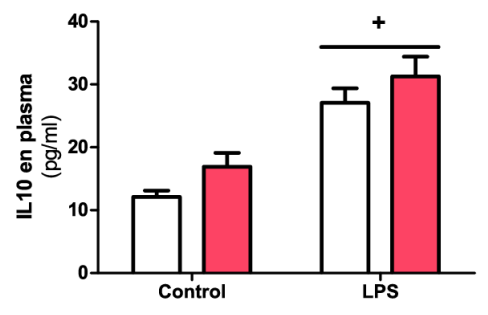

(B)

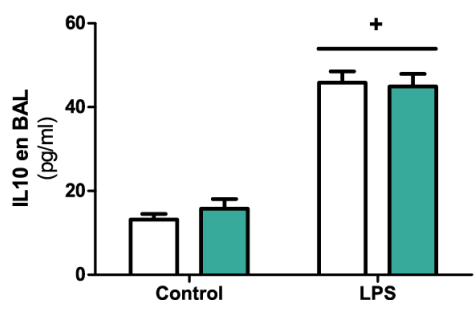

(D)

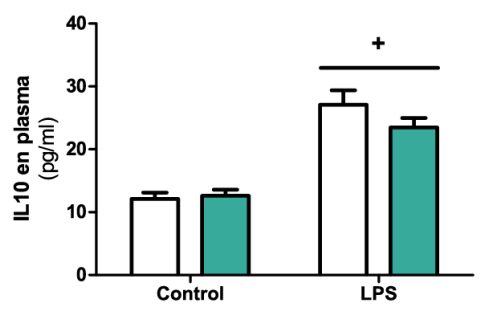

S-ENG+

Figura 38. Concentración de IL10 en el lavado broncoalveolar y en plasma en ratones WT, L-ENG+ y SENG+. Análisis de la concentración de IL10 en el BAL $(A, B)$ y en el plasma $(C, D)$ de ratones WT, L-ENG+ y S-ENG+, control y tratados con LPS, analizado mediante ELISA. Los valores se expresan como pg/ml. Cada barra representa la media \pm EEM. En BAL y plasma: WT $(n=5), L-E N G+(n=5)$ y S-ENG $+(n=5)$. Test estadístico ANOVA de doble vía, $+p<0,0001$ vs control.

El estudio de la expresión y concentración de citoquinas quimiotácticas e inflamatorias nos indica que, en primer lugar, la sobreexpresión de L-endoglina o S-endoglina no tiene ningún efecto sobre las citoquinas estudiadas en condiciones control. Sin embargo, tras la inducción inflamatoria por LPS o isquemia-reperfusión, la respuesta inflamatoria está reducida en el pulmón, riñón, BAL y plasma de los ratones $S-E N G+$, ya que la inducción inflamatoria provoca un menor aumento de la expresión del ARNm de CXCL12, IL1 $\beta$ e IL6, y una menor concentración de IL6 y TNFa. Sin embargo, el análisis de los niveles de IL10 no es determinante. 
A la vista de nuestros resultados, no se observan diferencias significativas en condiciones control a nivel de citoquinas inflamatorias entre los ratones $W T, L-E N G+$ y S-ENG+. Esto nos lleva a concluir que la sobreexpresión de las distintas isoformas de endoglina no altera ni la expresión ni los niveles de citoquinas inflamatorias en condiciones control.

Tras la inducción inflamatoria, no se observan diferencias en la expresión y niveles de citoquinas inflamatorias entre los ratones $W T$ y los $L-E N G+$, lo cual nos permite deducir que la sobreexpresión de L-endoglina no altera el reclutamiento leucocitario.

Tras inducción inflamatoria, observamos diferencias en los resultados obtenidos en los ratones que sobreexpresan endoglina de membrana larga y los que carecen del dominio intracelular de endoglina (sobreexpresan la isoforma corta), mostrando menor expresión y niveles de citoquinas inflamatorias en comparación con los WT. Esto indica que el dominio intracelular de endoglina de membrana tiene un papel en dichos procesos.

Estos resultados apoyan los obtenidos al analizar el reclutamiento leucocitario. Como se observa un menor infiltrado inflamatorio en los ratones que carecen del dominio intracelular de endoglina de membrana (sobreexpresan S-endoglina), tanto los niveles, como la expresión de citoquinas inflamatorias son menores en los ratones S-ENG+, observándose a nivel de tejido, de lavado broncoalveolar y plasma. Esto nos indica que el dominio intracelular de endoglina tiene un papel en la regulación de dichos procesos, y por ello, su ausencia, da lugar a variabilidad.

Teniendo en cuenta nuestras dos hipótesis iniciales, hemos contrastado, por un lado, que la sobreexpresión de la isoforma larga de endoglina de membrana no da lugar a un aumento significativo de las alteraciones histopatológicas, del reclutamiento leucocitario, ni de los niveles de citoquinas inflamatorias presentes, tanto en condiciones control, como en las primeras etapas de la inflamación aguda.

Por otro lado, hemos podido observar que, en condiciones inflamatorias, tanto las alteraciones histopatológicas, el reclutamiento leucocitario, así como los niveles de las 


\section{citoquinas proinflamatorias se reducen en la ausencia del dominio intracelular de endoglina de membrana, observándose en los ratones que sobreexpresan la isoforma que carece de dicho dominio intracelular, la S-endoglina (Figura 39).}

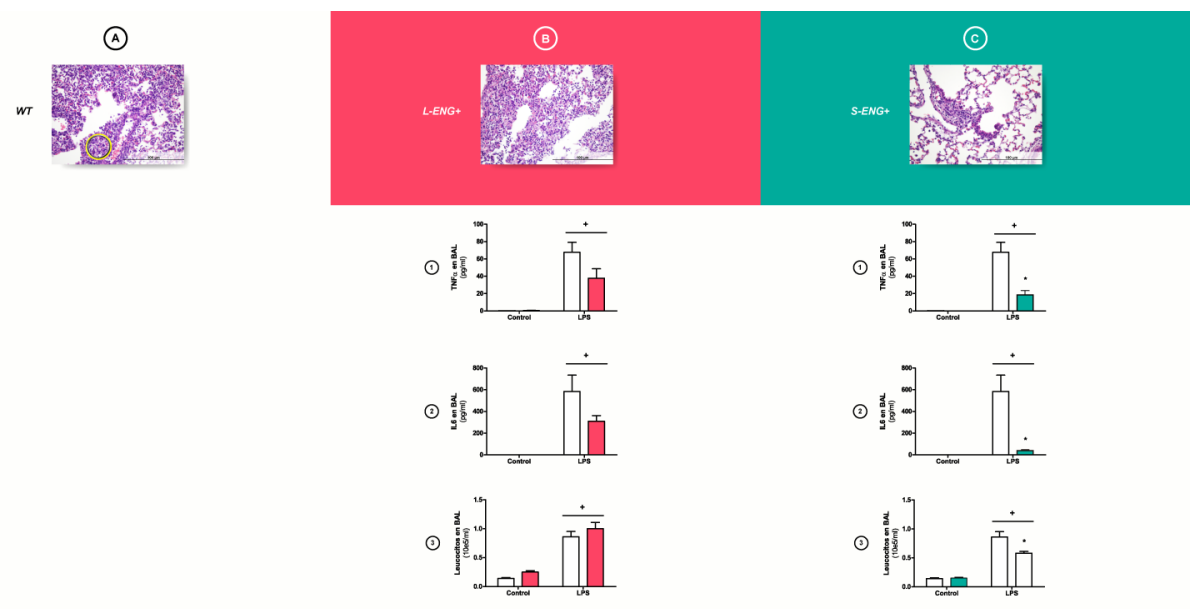

Figura 39. Figura resumen comparativa. Se muestran algunos de los resultados obtenidos al valorar los efectos de la sobreexpresión de la isoforma larga de endoglina de membrana, tanto en condiciones control como tras inducción inflamatoria, no observándose diferencias significativas. Para comprobar si el papel de endoglina de membrana se debe al dominio intracelular o al extracelular, se realizaron los mismos experimentos en ratones que sobreexpresan la isoforma corta de endoglina de membrana, por lo que las diferencias se deben a la ausencia de dominio intracelular. (A), Imágenes representativas de la tinción H\&E correspondiente a pulmones de ratones L-ENG+ y S-ENG+, control y tratados con LPS. Micrografías obtenidas mediante cámara acoplada a un microscopio óptico con 400 aumentos. L-ENG+ $(n=6)$ y SENG+ $(n=6)$. (B), Concentración de leucocitos en el lavado broncoalveolar en ratones, WT, L-ENG+ y SENG+, control y tratados con LPS. Los datos se expresan por $10 \mathrm{e}^{5} / \mathrm{ml}$. Cada barra representa la media \pm EEM. WT $(n=10), L-E N G+(n=10)$ y S-ENG+ $(n=10)$. Test estadístico ANOVA de doble vía: $+p<0,0001$ vs control, ${ }^{*} p<0,01$ vs LPS WT. (C), Concentración de IL6 en el lavado broncoalveolar de ratones WT, LENG+ y S-ENG+ control y tratados con LPS, analizado mediante ELISA. Los valores se expresan como $\mathrm{pg} / \mathrm{ml}$. Cada barra representa la media \pm EEM. WT $(n=4), \mathrm{L}-\mathrm{ENG}+(\mathrm{n}=5)$ y S-ENG $+(\mathrm{n}=6)$. Test estadístico ANOVA de doble vía, (A) $+p<0,0001$ vs control, (B) $+p<0,0005$ vs control, $* p<0,005$ vs LPS WT. (D), Concentración de TNFa en el lavado broncoalveolar en ratones WT, L-ENG+ y S-ENG+, control y tratados con LPS, analizado mediante ELISA. Los valores se expresan como pg/ml. Cada barra representa la media \pm EEM. WT $(n=4), L-E N G+(n=5)$ y S-ENG $+(n=5)$. Test estadístico ANOVA de doble vía, $(A)+p<0,0001$ vs control, (B) $+p<0,0001$ vs control, $* p<0,005$ vs LPS WT. 
El hecho de que la ausencia del dominio intracelular de endoglina de membrana provoque dicha reducción de la respuesta inflamatoria nos permite concluir que el dominio intracelular de endoglina de membrana tiene un papel en la respuesta inflamatoria.

Las citoquinas inflamatorias juegan un papel clave en todas las patologías que cursan con inflamación (Norouzinia et al, 2017). El balance de citoquinas pro-inflamatorias/antiinflamatorias es complejo, variando en función de la enfermedad inflamatoria y de los tejidos afectados (Norouzinia et al, 2017).. Es el caso de la artritis, una de las patologías crónicas más extendidas en la población. En esta patología, los procesos catabólicos que ocurren en las articulaciones se deben al equilibrio existente entre citoquinas inflamatorias como IL1 $\beta$, TNFa, IL6, IL15 e IL17 con citoquinas anti-inflamatorias como IL10 e IL4 (Wojdasiewicz et al, 2014).

En la arteroesclerosis, el balance de citoquinas plasmáticas se está utilizando como biomarcador de integridad endotelial y del nivel de células inmunes implicadas (Eastwood et al, 2017), existiendo grandes diferencias en los niveles de citoquinas inflamatorias entre pacientes con arteroesclerosis y pacientes sanos.

En otros casos, la detección de elevados niveles de citoquinas inflamatorias se está utilizando para valorar la gravedad de la patología. Es el caso de IL17 e IL36 en soriasis (Pfaff et al, 2017), IL17 e IL1 en hipertensión (Wen \& Crowley, 2017) e IL17 e IL9 en asma (Zhou et al, 2017).

En distintos procesos inflamatorios se han detectado niveles elevados de endoglina de membrana. La expresión aumenta en células endoteliales en piel, hígado, intestino y pulmón durante procesos inflamatorios. En concreto, se ha demostrado un aumento de la expresión de endoglina en placas arteroescleróticas (Conley et al, 2000), en piel con soriasis (Rulo et al, 1995), en artritis reumatoide (Szekanecz et al, 1995), tras daño vascular (Ma et al, 2000), isquemia-reperfusión (Docherty et al, 2006; Jerkic et al, 2006), infarto de miocardio (van Laake et al, 2006) y cáncer (Bernabeu et al, 2009). Las cuales son patologías que cursan con un incremento en las citoquinas inflamatorias. 
El hecho de que en las enfermedades inflamatorias observemos un aumento de las citoquinas proinflamatorias y un incremento en la expresión y niveles de endoglina de membrana, podría indicar que existe una relación.

Según nuestros resultados, en condiciones control las distintas isoformas de endoglina de membrana no alteran ni la expresión ni los niveles de las citoquinas inflamatorias, esto podría deberse al hecho de que las citoquinas inflamatorias se expresan de manera reducida en condiciones fisiológicas.

Tras inducción inflamatoria, no observamos diferencias en presencia de altas cantidades de L-endoglina. Sin embargo, la presencia de elevados niveles de S-endoglina provoca una reducción de TNF $\alpha$, IL1 $\beta$ e IL6. Esto nos indica que, en las enfermedades inflamatorias, la endoglina de membrana está teniendo un efecto sobre las citoquinas inflamatorias mediante su dominio intracelular.

Aunque sería necesario investigar más al respecto y profundizar en los mecanismos concretos, nuestros resultados parecen indicar que el aumento de endoglina de membrana en los procesos inflamatorios está relacionado de alguna manera con el incremento en las citoquinas proinflamatorias. La presencia de elevados niveles de la isoforma S-endoglina daría lugar a una reducción en el incremento de la expresión y niveles de citoquinas tras la inducción inflamatoria, al carecer prácticamente por completo del dominio intracelular.

Teniendo en cuenta que las citoquinas proinflamatorias liberadas durante las fases tempranas de las patologías que cursan con inflamación son mediadores de las manifestaciones sistémicas de la enfermedad (Lundberg et al, 2000), el bloqueo o la reducción de la cascada de citoquinas en una etapa temprana permitiría reducir la gravedad de la enfermedad y sus posteriores complicaciones sistémicas. 


\subsection{ESTUDIO DEL PAPEL DE LAS ISOFORMAS DE MEMBRANA DE ENDOGLINA EN LA PERMEABILIDAD VASCULAR}

Del mismo modo que se procedió al estudiar el papel de endoglina soluble en el proceso inflamatorio, nos propusimos valorar en ratones que sobreexpresan L-endoglina y Sendoglina un evento de fundamental importancia en la respuesta inflamatoria: la permeabilidad vascular. Para ello, comenzamos evaluando la concentración de proteínas presentes en el lavado broncoalveolar y en el pouch, ya que, como se ha explicado, cuando la permeabilidad vascular está aumentada, se incrementan los espacios interendoteliales, incrementándose el edema y con ello la cantidad de proteínas extravasadas.

\subsubsection{CONCENTRACIÓN DE PROTEÍNAS}

Se estudió la concentración de proteínas tanto en el lavado broncoalveolar como en el lavado del air pouch.

En la Figura 40 se observa que la concentración de proteínas es prácticamente nula en el BAL de ratones control, sin diferencias entre los ratones control $W T, L-E N G+$ y $S$ $E N G+$. La concentración de proteínas aumenta significativamente tras el tratamiento con LPS, sin diferencias entre los ratones $W T, L-E N G+$ y $S-E N G+$. 


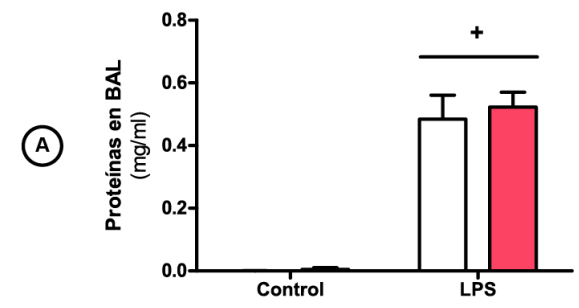

$\square w T$

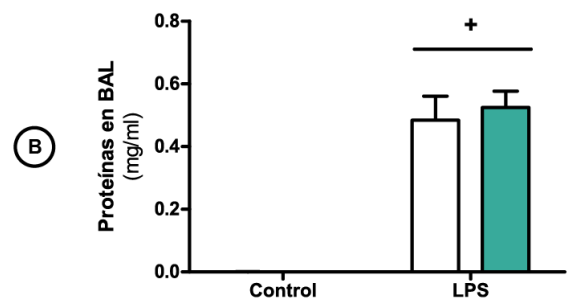

L-ENG+
S-ENG+

Figura 40. Concentración de proteínas en el lavado broncoalveolar en ratones WT, L-ENG+ y S-ENG+. Determinación de la concentración de proteínas en el BAL de ratones WT, L-ENG+ y S-ENG+, control y tratados con LPS. Los valores se expresan como $\mathrm{mg} / \mathrm{ml}$. Cada barra representa la media \pm EEM. WT $(n=10)$, L-ENG+ $(n=10)$ y S-ENG+ $(n=10)$. Test estadístico ANOVA de doble vía, $+p<0,0001$ vs control.

Además, se estudió la concentración de proteínas presentes en el lavado del air pouch. En la Figura 41 observamos que la concentración de proteínas es prácticamente nula en el BAL de ratones control, sin diferencias entre los ratones control WT, L-ENG+ y SENG+. Tras el tratamiento con carragenina, la concentración aumenta, sin diferencias entre los distintos ratones transgénicos.

(A)

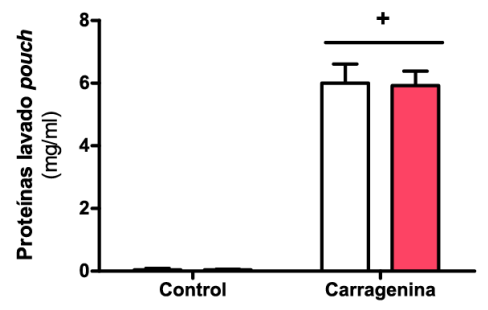

$\square w r$
(B)

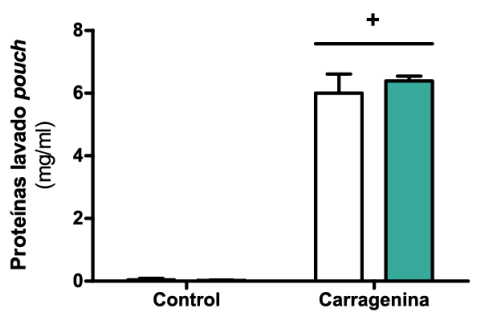

L-ENG+

S-ENG+

Figura 41. Concentración de proteínas en el lavado del air pouch en ratones WT, L-ENG+ y S-ENG+. Determinación de la concentración de proteínas en el lavado del air pouch de ratones WT, L-ENG+ y S- 
ENG+, control y tratados con carragenina. Los valores se expresan como $\mathrm{mg} / \mathrm{ml}$. Cada barra representa la media \pm EEM. WT $(n=6), L-E N G+(n=5)$ y S-ENG $+(n=4)$. Test estadístico ANOVA de doble vía, $+p<0,0001$ vs control.

\subsubsection{EDEMA PULMONAR}

Para valorar el edema pulmonar se calculó el ratio peso húmedo/peso seco de los pulmones de ratones $W T, L-E N G+$ y $S-E N G+$ tratados con LPS. Como muestra la Figura 42 , no se observan diferencias entre los ratones $W T, L-E N G+$ y $S-E N G+$.

(A)

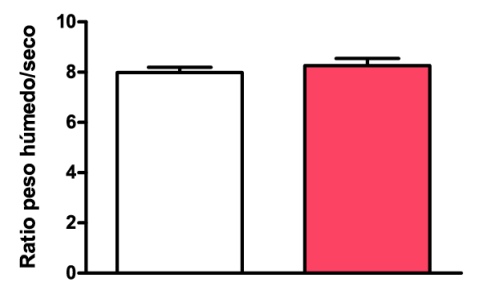

(B)

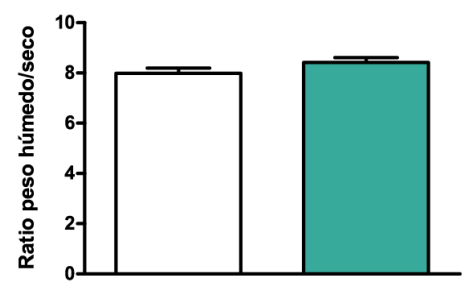

$\square$ S-ENG+

Figura 42. Análisis del edema pulmonar en ratones WT, L-ENG+ y S-ENG+. Análisis del edema pulmonar mediante el ratio peso húmedo/peso seco, en pulmones de ratones WT, L-ENG+ y S-ENG+, tratados con LPS. Cada barra representa la media \pm EEM. WT $(n=6), L-E N G+(n=5)$ y S-ENG $+(n=5)$.

\subsubsection{EVALUACIÓN DE LA PERMEABILIDAD VASCULAR PULMONAR AL FITC-DEXTRANO}

También se estudió la permeabilidad vascular pulmonar mediante inyección intravenosa de FITC-Dextrano en ratones WT, L-ENG+ y S-ENG+ tratados con LPS. Se midió la fluorescencia en el lavado broncoalveolar y se corrigió por la fluorescencia en el plasma de cada ratón. No se observaron diferencias significativas entre los ratones $W T, L-E N G+$ y $S-E N G+$ (Figura 43). 
(A)

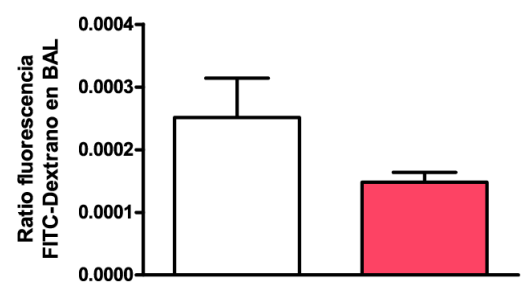

(B)

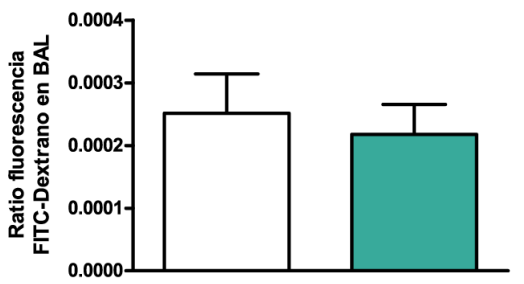

L-ENG+

S-ENG+

Figura 43. Concentración de FITC-Dextrano en el lavado broncoalveolar en ratones WT, L-ENG+ y SENG+. Determinación de la concentración de FITC-Dextrano en el BAL de ratones WT, L-ENG+ y S-ENG+, tratados con LPS y a los que se les ha inoculado FITC-Dextrano retroorbital. Los valores se expresan como el ratio fluorescencia en el lavado broncoalveolar/fluorescencia en plasma. Cada barra representa la media $\pm \operatorname{EEM} . W T(n=6), L-E N G+(n=5)$ y S-ENG+ $(n=5)$.

Según nuestros resultados, podemos concluir que la sobreexpresión de L-endoglina o S-endoglina no provoca alteraciones en la permeabilidad vascular, ya que no observamos diferencias entre los ratones $W T, L-E N G+$ y $S-E N G+$. Dicho de otro modo, la presencia o ausencia del dominio intracelular de endoglina no da lugar a alteraciones en la permeabilidad vascular. Esto indica por ello que, a pesar de que procesos clave de la respuesta inflamatoria, como el reclutamiento leucocitario y la expresión y niveles de citoquinas quimiotácticas y proinflamatorias, están controlados por el dominio intracelular de endoglina, la permeabilidad vascular no lo está.

\subsubsection{ANÁLISIS DE LA EXPRESIÓN DE VE-CADHERINA}

VE-cadherina es una molécula necesaria para el mantenimiento de las uniones adherentes, y por ello, tiene un papel clave en la migración transendotelial. Al analizar la expresión del ARNm de VE-cadherina ( $\mathrm{CDH} 5)$, no se observan diferencias significativas entre los ratones control $W T, L-E N G+$ y $S-E N G+$ (Figura 44, A y B). Tras el tratamiento con LPS, los ratones $W T$ no presenta diferencias con respecto a los ratones control, mientras que los $L-E N G+$ y $S-E N G+$ presentan menor expresión de CDH5. 
En riñón, no se observan diferencias significativas en la expresión de CDH5 entre los ratones control WT, L-ENG+ y S-ENG+. Tras la isquemia-reperfusión, la expresión disminuye significativamente, sin diferencias entre $W T, L-E N G+$ y $S-E N G+$, ya que los controles $L-E N G+$ y $S-E N G+$ presentan expresiones menores que los $W T$ (Figura 44, C y D).

(A)

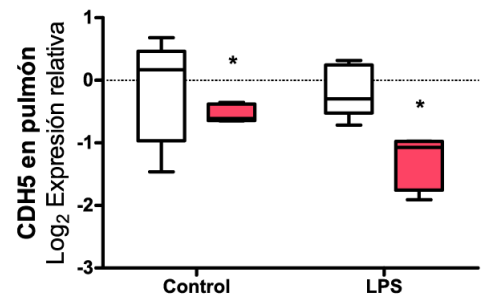

(c)

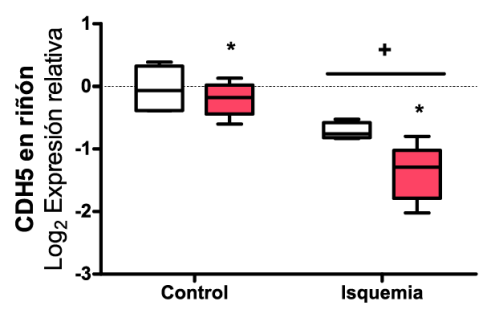

(B)

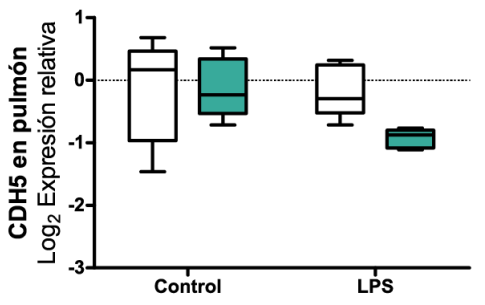

(D)

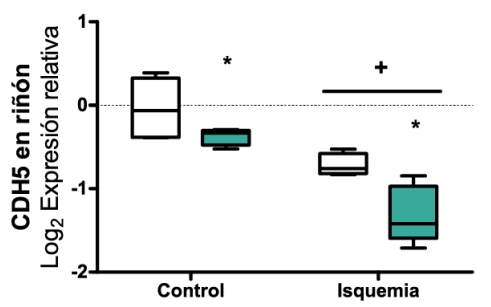

S-ENG+

Figura 44. Análisis de la expresión de CDH5 en ratones WT, L-ENG+ y S-ENG+. Análisis mediante qPCR de los niveles de expresión de CDH5 en pulmón $(A, B)$ y en riñón $(C, D)$ de ratones WT, L-ENG+ y S-ENG+, control, tratados con LPS o isquemia-reperfusión renal, respectivamente. Los valores se representan como el logaritmo en base dos de la expresión relativa de cada muestra con respecto de las muestras WT. Se representa un box plot 10-90 percentil. WT $(n=5), L-E N G+(n=5)$ y S-ENG+ $(n=5)$. Test estadístico ANOVA de doble vía, (A)*p<0,005 vs WT, (C)+p<0,0001 vs control, *p<0,05 vs WT, (D) $+p<0,0001$ vs control, $* p<0,005$ vs WT.

La menor expresión de CDH5 en los pulmones $L-E N G+$ tras LPS y en los riñones tras la isquemia indicaría que 48 horas después de los respectivos tratamientos las uniones 
adherentes están menos estables que en los ratones control, lo cual facilitaría la migración transendotelial.

En base a nuestros resultados, la sobreexpresión de las distintas isoformas de endoglina no altera la permeabilidad vascular en condiciones control. Además, tras inducción inflamatoria, no se observan diferencias en la permeabilidad vascular entre los ratones $W T, L-E N G+$ y S-ENG+, lo cual nos permite deducir que la sobreexpresión de Lendoglina o S-endoglina no altera la permeabilidad vascular. Dado que no se observan diferencias entre los ratones L-ENG+ y $S-E N G+$, podemos concluir que el dominio intracelular de endoglina no tiene un papel en la permeabilidad vascular.

Se ha descrito que la alteración de la barrera endotelial en tumores de ratones Eng ${ }^{+/}$ provoca una mayor incidencia de metástasis en comparación con ratones WT (Anderberg et al, 2013a). En el endotelio de estos ratones se ha descrito, tras inducción de inflamación crónica, un aumento de la permeabilidad en colon (Jerkic et al, 2010). De hecho, también se ha observado un aumento en la permeabilidad en el estudio in vitro de monocapas de células endoteliales nulas para endoglina y con niveles reducidos de endoglina, en comparación con células control (Jerkic \& Letarte, 2015), observándose que a menor cantidad de endoglina de membrana, mayor permeabilidad.

Este aumento de la permeabilidad en deficiencia de endoglina se ha relacionado con una alteración en los niveles de VE-cadherina y la activación constitutiva de RhoA, que normalmente es inducida por VEGF y TGF- $\beta$, causando la desestabilización del endotelio (Jerkic \& Letarte, 2015). Asimismo, ante haploinsuficiencia de endoglina, las uniones celulares disminuyen mediante la reducción de la expresión de VE-cadherina, $\beta$ catenina, PECAM y ZO-1 (Park et al, 2013). Se sabe que VE-cadherina interacciona con T $\beta R I I, A L K 1, A L K 5$ y endoglina, y que favorece el ensamblaje del complejo de receptores de TGF- $\beta$, modulando la transducción de la señal y activando a las proteínas Smads. Se piensa que la relación entre endoglina y VE-cadherina puede estar mediada por zyxina, proteína del citoesqueleto que se encuentra unida al complejo cadherina/catenina /actinina, con la que endoglina interacciona (Lee et al, 2004). 
Esto podría explicar que, ante sobreexpresión de endoglina, las uniones interendoteliales se mantengan más estables, disminuyéndose la permeabilidad vascular. Por ello, no se observan diferencias a nivel de permeabilidad vascular entre ratones $W T, L-E N G+$ y $S$ $E N G+, y$, sin embargo, observamos que in vivo la deficiencia de endoglina causa un aumento en la permeabilidad vascular, y que in vitro las células endoteliales Eng $^{+/-}$, y en especial las Eng ${ }^{-/}$presenten un incremento en la permeabilidad vascular en comparación con células control (Jerkic \& Letarte, 2015).

Con el objetivo de obtener más información sobre el efecto de la sobreexpresión de Lendoglina y S-endoglina en la respuesta inflamatoria, analizamos algunas de las moléculas de adhesión clave en la cascada de transmigración leucocitaria.

\subsection{EXPRESIÓN DE MOLÉCULAS DE ADHESIÓN}

Se analizó mediante la técnica de qPCR la expresión del ARNm de moléculas de adhesión implicadas en distintas etapas de la transmigración leucocitaria: E-selectina, VCAM-1, ICAM-1 y PECAM-1. Se estudió en el tejido pulmonar y en riñón, en ratones control y tratados con LPS o isquemia-reperfusión respectivamente.

E-selectina es una molécula implicada en el rodamiento leucocitario. Al analizar la expresión del ARNm de E-selectina (SELE) en pulmón, no se observan diferencias significativas entre los ratones control $W T, L-E N G+$ y $S-E N G+$. Tras el tratamiento con LPS, la expresión se mantiene prácticamente constante en los $W T$ y aumenta en los $L-$ $E N G+$, mientras que en los $S-E N G+$ observamos incluso una ligera disminución en la expresión (Figura 45, A y B). Al analizar la expresión del ARNm de E-selectina en el riñón de los ratones control, se observa que los $L-E N G+$ y los $S-E N G+$ presentan mayores niveles que los $W T$. Sin embargo, tras la isquemia, la expresión se mantiene constante en los $W T$, mientras que en los $L-E N G+$ y $S-E N G+$ disminuye significativamente (Figura $45, C$ y $D)$. 
(A)

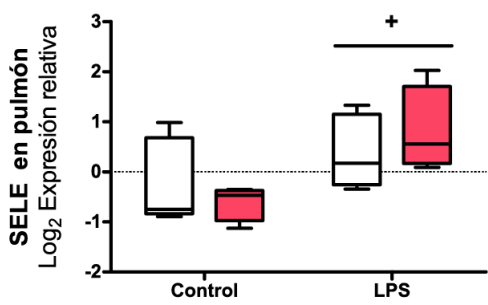

(c)

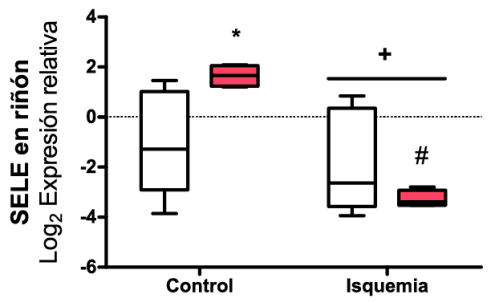

(B)

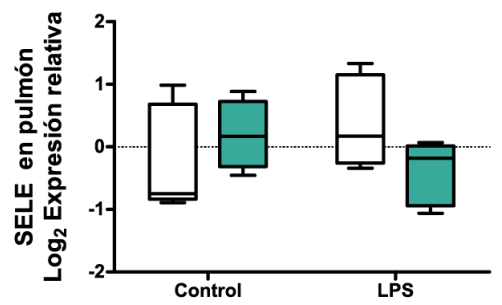

(D)

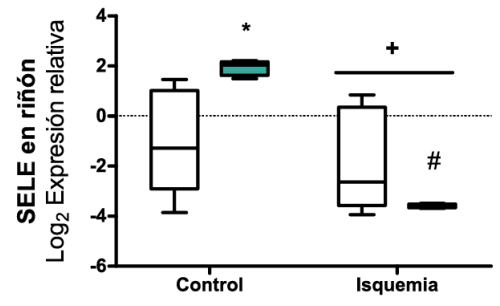

S-ENG+

Figura 45. Análisis de la expresión de SELE en ratones WT, L-ENG+ y S-ENG+. Análisis mediante qPCR de los niveles de expresión de SELE en pulmón $(A, B)$ y en riñón $(C, D)$ de ratones WT, L-ENG+ y S-ENG+, control, tratados con LPS o isquemia-reperfusión renal, respectivamente. Los valores se representan como el logaritmo en base dos de la expresión relativa de cada muestra con respecto de las muestras WT. Se representa un box plot 10-90 percentil. En pulmón: WT $(n=5), L-E N G+(n=5)$ y S-ENG $(n=5)$, en riñón: WT $(n=5), L-E N G+(n=4)$ y S-ENG+ $(n=4)$. Test estadístico ANOVA de doble vía, $(A)+p<0,01$ vs control, (C) $+p<0,005$ vs control, ${ }^{*} p<0,05$ vs control WT, $\# p<0,0001$ vs control $S-E N G+,(D)+p<0,001$ vs control, $* p<0,05$ vs control WT, $\# p<0,0001$ vs control S-ENG+.

Estos resultados indicarían que, $48 \mathrm{~h}$ después del tratamiento con LPS, los ratones WT no presentan un aumento en el rodamiento leucocitario con respecto a las condiciones control, mientras que en los $L-E N G+$ el rodamiento leucocitario está activo, y en los $S$ ENG+ está disminuido a nivel de expresión de ARNm. Por el contrario, en riñón, a la vista de los resultados, 48 horas tras la isquemia no continuaría dándose el rodamiento leucocitario. 
VCAM-1 es una molécula de adhesión implicada principalmente en el arresto y adhesión leucocitaria. Al analizar la expresión de VCAM-1 en pulmón no se observan diferencias significativas entre los ratones control $W T, L-E N G+$ y $S-E N G+$. Tras el tratamiento con LPS, la expresión aumenta de manera significativa en pulmón, sin diferencias entre $W T$, $L-E N G+$ y $S-E N G+($ Figura 46, A y B). En riñón, los $L-E N G+$ y $S-E N G+$ control presentan mayor expresión de VCAM-1 que los $W T$ (Figura 46, C y D). Tras isquemia-reperfusión se da un significativo aumento de la expresión de VCAM-1, sin diferencias significativas entre $W T, L-E N G+$ y $S-E N G+$.

(A)

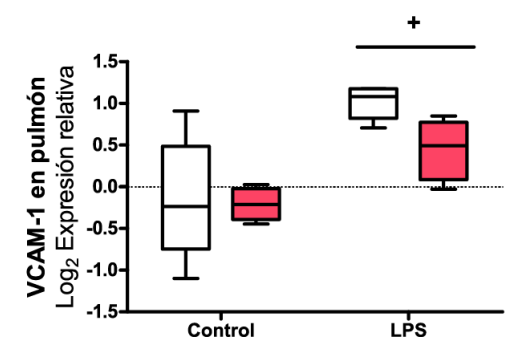

(c)

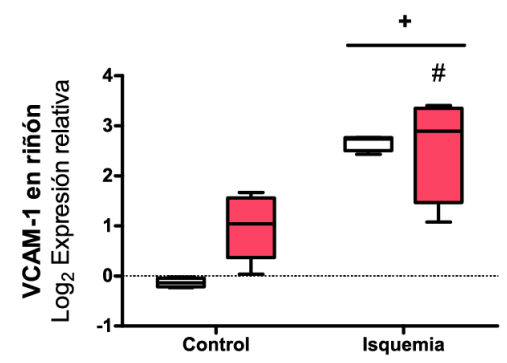

(B)

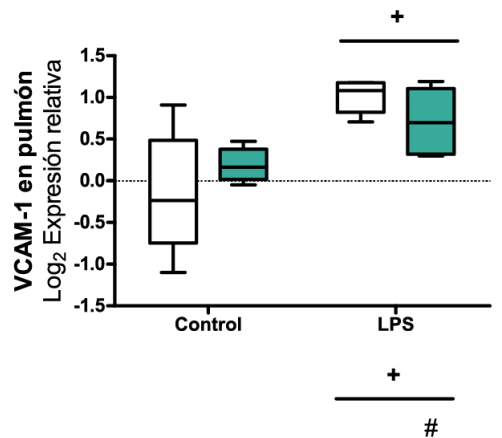

(D)

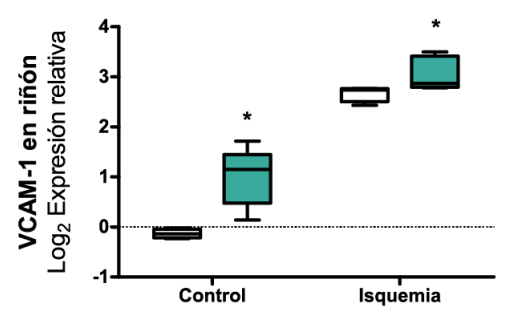

S-ENG+

Figura 46. Análisis de la expresión de VCAM-1 en ratones WT, L-ENG+ y S-ENG+. Análisis mediante qPCR de los niveles de expresión de VCAM-1 en pulmón $(A, B)$ y en riñón $(C, D)$ de ratones WT, L-ENG+ y SENG+, control, tratados con LPS o isquemia-reperfusión renal, respectivamente. Los valores se representan como el logaritmo en base dos de la expresión relativa de cada muestra con respecto de las muestras WT. Se representa un box plot 10-90 percentil. En pulmón: WT $(n=5), L-E N G+(n=5)$ y S-ENG+ $(n=5)$, en riñón: WT $(n=4), L-E N G+(n=5)$ y S-ENG $+(n=5)$. Test estadístico ANOVA de doble vía, 
$48 \mathrm{~h}$ después del tratamiento con LPS o isquemia-reperfusión sigue estando aumentada la expresión de VCAM-1 tanto en pulmón como en riñón, lo que nos indica que la adhesión leucocitaria al endotelio sigue muy activa. Mientras que en pulmón no observamos diferencias significativas entre los ratones $W T, L-E N G+$ y $S-E N G+$, en riñón, tanto en condiciones control como tras la isquemia-reperfusión, la expresión de VCAM1 es mayor en los ratones que sobreexpresan S-endoglina. Este aumento en la expresión de VCAM-1, junto con el hecho de que al analizar la histopatología del riñón no se observa infiltrado inflamatorio, podría indicar que el infiltrado aún no ha alcanzado los riñones $48 \mathrm{~h}$ después de la isquemia-reperfusión.

ICAM-1 interviene en distintas etapas de la transmigración leucocitaria: en la adhesión, el gateo, la formación de las "copas migratorias" y la movilidad intersticial. Al analizar la expresión de ICAM-1 en pulmón, no se observan diferencias significativas entre los ratones control WT, L-ENG+ y S-ENG+. Tras el tratamiento con LPS, la expresión aumenta significativamente, siendo este aumento menor en el ratón S-ENG+ (Figura 47, A y B).

En riñón observamos, en los ratones control, que la expresión de ICAM-1 en los ratones S-ENG+ es mayor que en los $W T$ y en los $L-E N G+$. Tras la isquemia-reperfusión, se observa un aumento en la expresión de ICAM-1 en los ratones $W T$, mientras que la expresión en los $L-E N G+$ se mantiene y en los $S-E N G+$ incluso se reduce (Figura $47, C$ y D). 
(A)

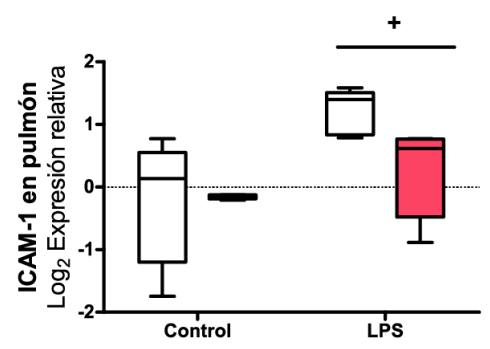

(c)

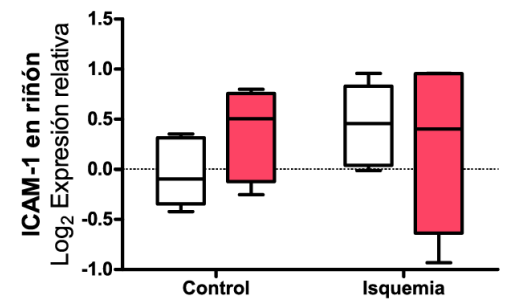

(B)

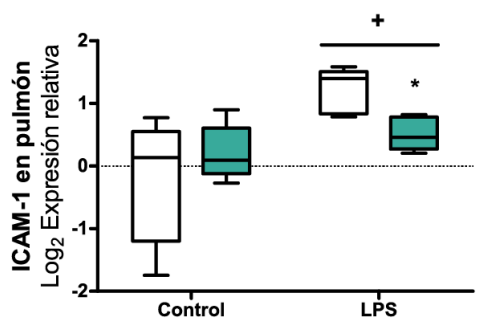

(D)

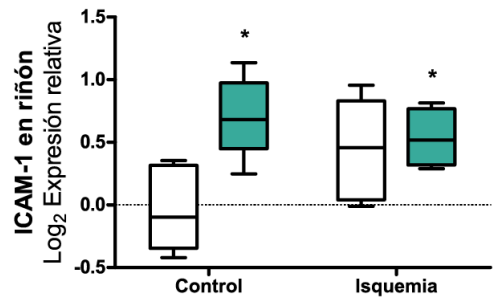

S-ENG+

Figura 47. Análisis de la expresión de ICAM-1 en ratones WT, L-ENG+ y S-ENG+. Análisis mediante qPCR de los niveles de expresión de ICAM-1 en pulmón ( $A, B)$ y en riñón $(C, D)$ de ratones WT, L-ENG+ y SENG+, control, tratados con LPS o isquemia-reperfusión renal, respectivamente. Los valores se representan como el logaritmo en base dos de la expresión relativa de cada muestra con respecto de las muestras WT. Se representa un box plot 10-90 percentil. WT $(n=5), L-E N G+(n=5)$ y S-ENG+ $(n=5)$. Test estadístico ANOVA de doble vía, (A) $+p<0,005$ vs control, (B) $+p<0,005$ vs control, ${ }^{*} p<0,01$ vs LPS WT, (D)* $p<0,05$ vs WT.

El aumento en la expresión de ICAM-1 tras el tratamiento con LPS coincide con lo explicado anteriormente: en pulmón la transmigración leucocitaria sigue activa $48 \mathrm{~h}$ después del tratamiento con LPS, y de hecho es menor en los ratones S-ENG+ (Figura 48. A y B). Sin embargo, en riñón observamos un aumento de expresión de ICAM-1 tras la isquemia en los $W T$, mientras que en los $S-E N G+$ disminuye (Figura 48, C y D). 
PECAM-1 es una molécula de adhesión fundamental durante la diapédesis. Al estudiar la expresión del ARNm de PECAM-1 (CD31) no se observan diferencias significativas entre los ratones control $W T, L-E N G+$ y $S-E N G+$. Tras el tratamiento con LPS, la expresión se mantiene constante en los ratones $W T$, mientras que disminuye significativamente en los ratones $L-E N G+$. Además, se observa, una disminución en la expresión en los ratones S-ENG+ (Figura 48, A y B). Por su parte, al analizar la expresión de CD31 en riñón no se observan diferencias entre los ratones control $W T, L-E N G+$ y $S-E N G+$. Tras la isquemiareperfusión, la expresión disminuye significativamente, sin diferencias entre $W T, L-$ $E N G+$ y $S-E N G+($ Figura 48, C y D).

(A)

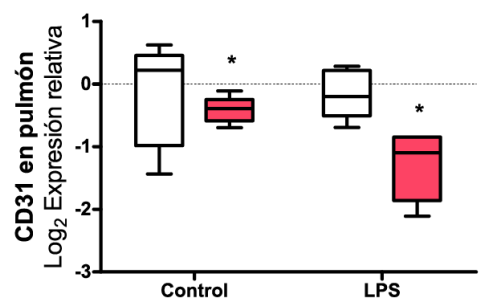

(c)

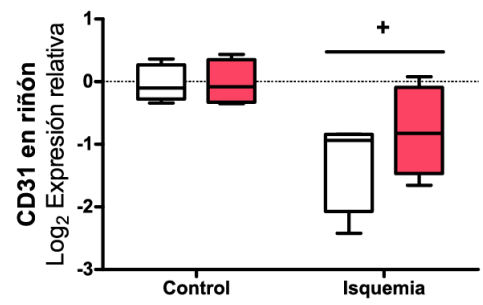

(B)

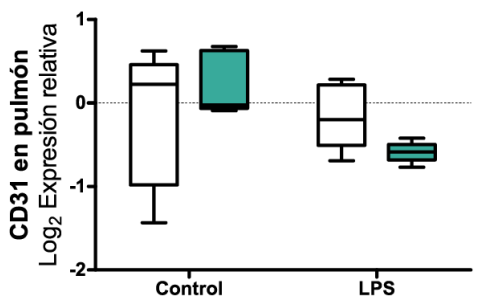

(D)

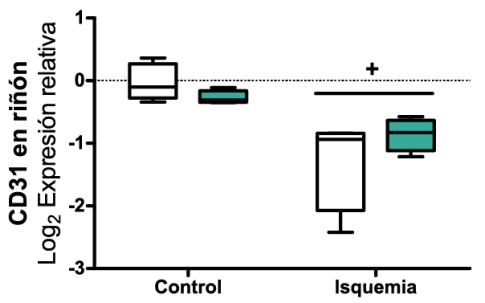

$\square$ S-ENG+ 
WT $(n=5), L-E N G+(n=5)$ y S-ENG+ $(n=4)$. Test estadístico ANOVA de doble vía, $(A) * p<0,01$ vs WT, $(C)+p<0,005$ vs control, (D) $+p<0,001$ vs control.

A la vista de estos resultados, $48 \mathrm{~h}$ después de los respectivos tratamientos, no continuaría activa la transmigración leucocitaria ni en pulmones tratados con LPS ni en riñones tras isquemia-reperfusión. Sin embargo, el hecho de, tras la inducción de la inflamación, la expresión de E-selectina, ICAM-1 y PECAM-1 sea menor en los ratones que sobreexpresan S-endoglina encaja con los resultados anteriores: la presencia de Sendoglina reduce la respuesta inflamatoria, lo que nos indica que endoglina regula la inflamación mediante su dominio intracelular.

Las moléculas de adhesión controlan las distintas etapas del reclutamiento leucocitario. Este proceso es muy variable, existiendo variaciones en función del leucocito reclutado.

Las selectinas regulan la adhesión inicial del leucocito al endotelio tras inducción inflamatoria, y promueven la subsecuente activación de las células del sistema inmune (Zuchtriegel et al, 2015). Cuando analizamos la expresión de ARNm, estamos valorando la síntesis de novo, la cual regula el reclutamiento secundario de monocitos y neutrófilos al foco inflamatorio (Zarbock et al, 2011). Según nuestros resultados, la expresión del ARNm de E-selectina no muestra diferencias en condiciones control en pulmón, mientras que en riñón la expresión de L-endoglina y S-endoglina da lugar a un aumento de la expresión del ARNm de E-selectina. Esto podría indicar que los ratones L-endoglina y S-endoglina presentaran mayor infiltrado leucocitario en condiciones control. Sin embargo, al analizar la histología no observamos infiltrado inflamatorio. La expresión de E-selectina cambia de manera muy dinámica, en función de características espaciotemporales de compleja regulación (Zuchtriegel et al, 2015). Por ello, sería necesario valorar los niveles de E-selectina a nivel de proteína para poder realizar conclusiones al respecto.

VCAM-1 e ICAM-1 son ligandos endoteliales de las integrinas leucocitarias $\alpha 4 \beta 1$ y $\alpha\llcorner\beta 2$, respectivamente, y tienen un papel fundamental en el rodamiento y adhesión firme de los leucocitos al endotelio (Barreiro et al, 2008). En el caso de ICAM-1, se expresa de manera basal en células quiescentes endoteliales $y$, al contrario que VCAM-1 es 
necesario para la diapédesis (Carlos \& Harlan, 1994). Esto podría explicar por qué, mientras que la inducción inflamatoria provoca un aumento en la expresión de VCAM-1 tanto en pulmón como en riñón, la expresión de ICAM-1 no aumenta en riñón sometido a isquemia-reperfusión, en los cuales no observamos infiltrado leucocitario. Además, en pulmón observamos que la expresión de ICAM-1 en pulmón es menor en presencia de S-endoglina. Dada la implicación de ICAM-1 en la diapédesis, su menor expresión en presencia de S-endoglina provoca un menor infiltrado leucocitario.

Los resultados obtenidos al valorar el papel de la isoforma larga de endoglina de membrana, tanto en condiciones control como en las primeras etapas de la inflamación aguda, fueron muy interesantes.

En primer lugar, la sobreexpresión de la isoforma larga de membrana, por si misma, no da lugar a un aumento de la inflamación aguda. Por otro lado, se utilizó un ratón modelo que sobreexpresa la isoforma corta de endoglina de membrana, la cual carece del dominio intracelular, para valorar si el posible papel de endoglina de membrana en las primeras etapas de la inflamación aguda se debe a su dominio extracelular o a su dominio intracelular. Dado que observamos una reducción inflamatoria en los ratones que carecen del dominio intracelular, pudimos concluir que dicho dominio es responsable de procesos clave de la respuesta inflamatoria aguda.

Por ello, y dado que nuestros resultados parecen señalar al dominio intracelular como responsable de dichos procesos inflamatorios, nos pareció muy interesante valorar qué ocurre entonces en presencia de elevados niveles de endoglina soluble circulante en plasma, los cuales son el dominio extracelular circulando libremente. 


\section{ESTUDIO DEL PAPEL DE LA ENDOGLINA SOLUBLE EN EL PROCESO INFLAMATORIO}

La endoglina soluble se encuentra elevada en patologías que cursan con inflamación, como las enfermedades cardiovasculares (López-Novoa \& Bernabeu, 2010) la preeclampsia (Venkatesha et al, 2006) y el cáncer (Bernabeu et al, 2009), asociándose, en los estudios realizados hasta la fecha, niveles elevados de endoglina soluble con un peor pronóstico (Bernabeu et al, 2009; Cruz-Gonzalez et al, 2008; Pérez-Gómez et al, 2007). La poca información que se tiene a día de hoy sobre el papel de endoglina soluble en el proceso inflamatorio, lo convierte en un campo de gran interés, por lo que nos proponemos estudiar procesos clave de la respuesta inflamatoria en ratones con elevados niveles de endoglina soluble circulante en plasma, y ratones wild type, tanto en condiciones control como ante distintos estímulos inflamatorios: nebulización pulmonar con lipopolisacárido bacteriano, carragenina e isquemia-reperfusión renal.

\subsection{ESTUDIO DEL EFECTO DE ENDOGLINA SOLUBLE EN EL RECLUTAMIENTO LEUCOCITARIO}

\subsubsection{VALORACIÓN HISTOLÓGICA DEL EFECTO DE ENDOGLINA SOLUBLE EN EL DAÑO TISULAR INDUCIDO POR ESTÍMULOS INFLAMATORIOS}

Estudiamos, mediante la tinción de hematoxilina-eosina, las posibles alteraciones estructurales presentes en el tejido del pulmón, la piel y el riñón inducidas por la presencia de endoglina soluble en condiciones control. Además, valoramos el efecto de endoglina soluble sobre las alteraciones tisulares inducidas tras estímulos inflamatorios de distinta naturaleza, correspondientes a los modelos de LPS, air pouch e isquemiareperfusión renal, respectivamente. 


\subsubsection{ALTERACIONES EN EL PULMÓN TRAS TRATAMIENTO CON LPS}

Los pulmones control no presentan alteraciones morfológicas en los bronquiolos, sacos alveolares y vasos sanguíneos, estando estos conservados, sin alteraciones estructurales ni presencia de infiltrado inflamatorio. No se observan diferencias entre los ratones control WT y los sEng+ (Figura 49). Tras el tratamiento con LPS, observamos alveolos colapsados, con paredes alveolares muy engrosadas y zonas parcheadas de infiltrado inflamatorio tanto intraalveolar como subpleural. Este infiltrado está compuesto mayoritariamente por macrófagos muy activados, con signos de fagocitosis, células polimorfonucleares de tipo neutrófilo y células plasmáticas tanto en ratones WT como en los sEng+. Los ratones WT presentan gran cantidad de infiltrado leucocitario intraalveolar, formando grandes zonas condensadas (marcado con un círculo amarillo). La cantidad de infiltrado en los pulmones de los ratones sEng+ es mínima, y en ningún caso da lugar a grandes acúmulos leucocitarios como se observan en los WT.

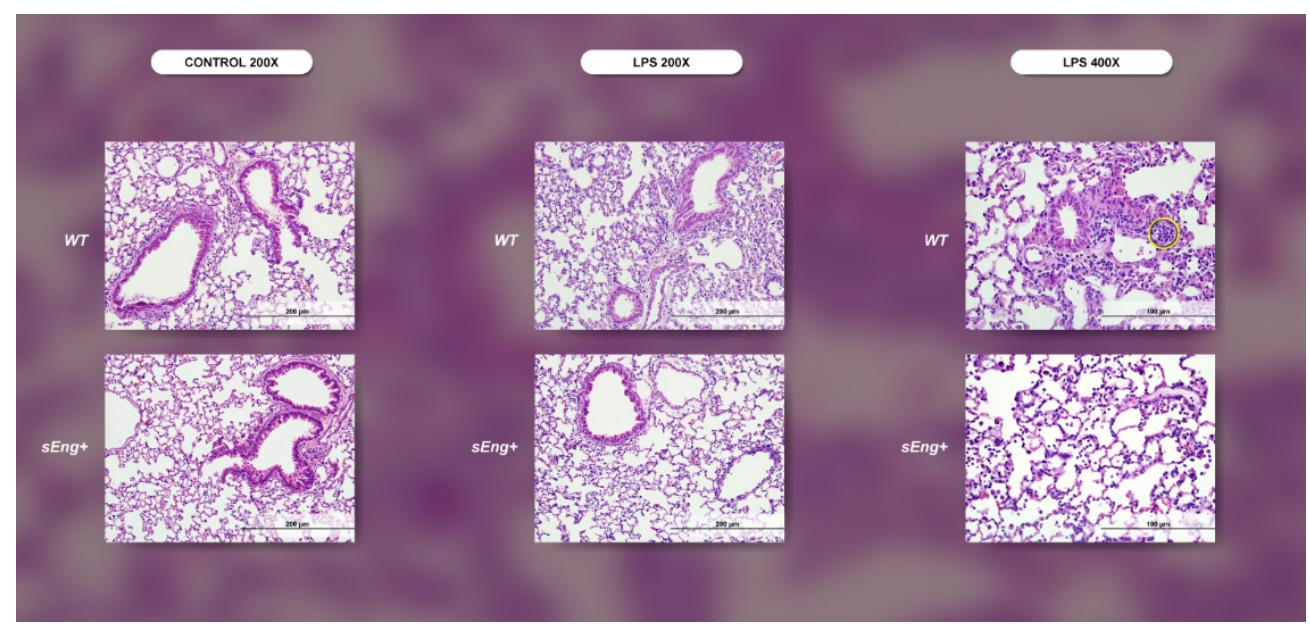

Figura 49. Estudio histológico del pulmón de ratones WT y sEng+. Imágenes representativas de la tinción H\&E correspondiente a pulmones de ratones WT y sEng+, control y tratados con LPS. Micrografías obtenidas mediante cámara acoplada a un microscopio óptico con 200 y 400 aumentos, respectivamente. WT $(n=5)$ y sEng + $(n=5)$. El círculo amarillo marca una zona de infiltrado leucocitario. 
Los ratones control no presentan infiltrado, correspondiéndose a un índice 0 , sin diferencias entre los controles $W T$ y sEng+ (Figura 50). Por su parte, como resultado de la cuantificación del infiltrado leucocitario, los ratones tratados con LPS presentan un aumento significativo en la cantidad de infiltrado, correspondiéndose con un índice 2-3. Este aumento en la cantidad de infiltrado es menor en el caso de los pulmones correspondientes a ratones sEng+, que presentan un índice 1.

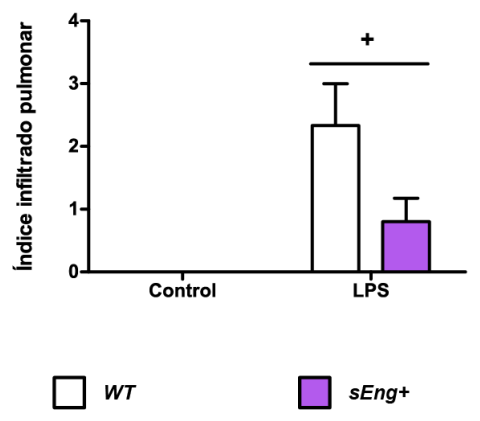

Figura 50. Índice de infiltrado pulmonar en ratones WT y sEng+. Valoración histológica cuantitativa del infiltrado pulmonar en ratones WT y sEng+, control y tratados con LPS. Cada barra representa la media \pm EEM. WT $(n=5)$ y sEng+ $(n=5)$. Test estadístico ANOVA de doble vía, $+p<0,0001$ vs control

\subsubsection{ALTERACIONES EN LA PIEL TRAS EL TRATAMIENTO CON CARRAGENINA}

Con la finalidad de valorar las posibles alteraciones histológicas que la endoglina soluble puede causar en la piel, tanto en condiciones control como tras el estímulo inflamatorio, se realizó un estudio histológico de la piel correspondiente a la zona del pouch.

En los ratones control, la piel está estructuralmente conservada, observándose que la epidermis, la dermis, la hipodermis, el tejido muscular y el conjuntivo están sanos, y no hay presencia de infiltrado inflamatorio salvo un número reducido de fibroblastos en conjuntivo laxo, ocasionados por la formación subcutánea del air pouch. No se observan 
diferencias entre los controles $W T$ y los sEng+ (Figura 51). Sin embargo, en los ratones tratados con carragenina observamos que aumenta considerablemente la cantidad de infiltrado inflamatorio de tipo polimorfonuclear neutrófilo y células plasmáticas, estando principalmente en el tejido conjuntivo (zona de contacto con la carragenina) y llegando a penetrar el músculo y en ocasiones hasta la hipodermis. El aumento de infiltrado es la única alteración histológica que induce el tratamiento con carragenina.

Este infiltrado inflamatorio es más abundante en la piel de los ratones WT (marcado con un círculo amarillo), mientras que los ratones sEng+ presentan menor cantidad de infiltrado.

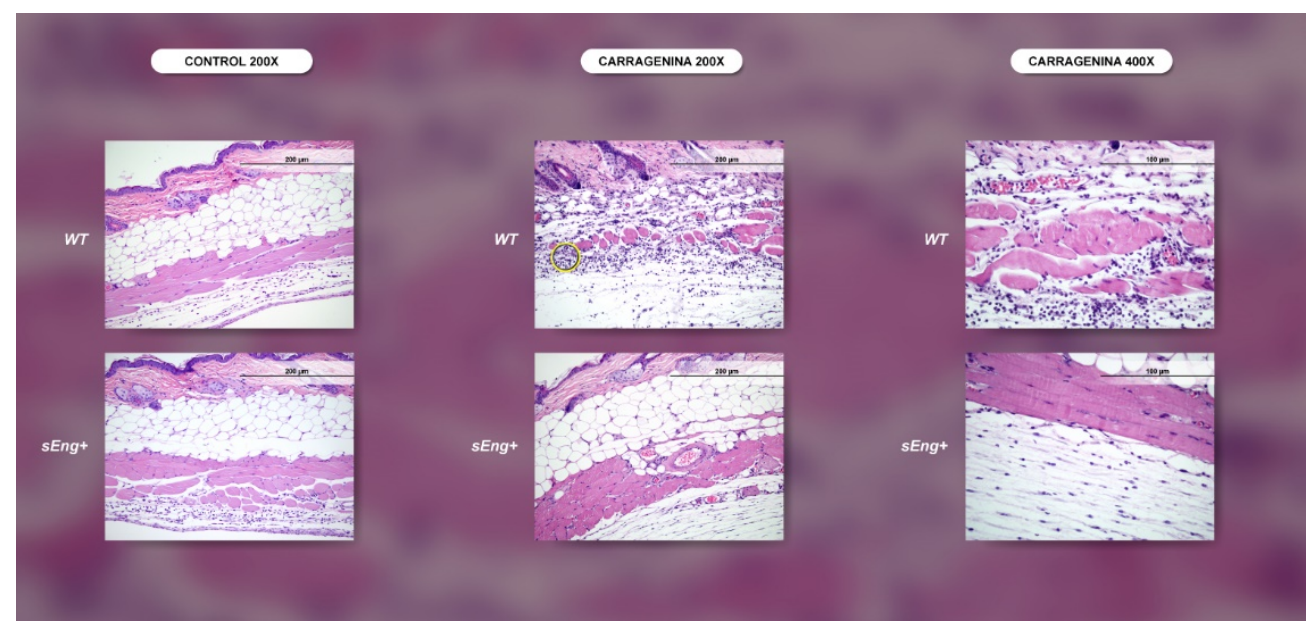

Figura 51. Estudio histológico de la piel del air pouch, de ratones WT y sEng+. Imágenes representativas de la tinción H\&E correspondiente a la piel de la zona del air pouch de ratones WT y sEng+, control y tratados con carragenina. Micrografías obtenidas mediante cámara acoplada a un microscopio óptico con 200 y 400 aumentos, respectivamente. WT $(n=5)$ y sEng+ $(n=5)$. El círculo amarillo marca una zona de infiltrado leucocitario. 
Para valorar las diferencias a nivel de infiltrado leucocitario observadas en el estudio histológico de la piel de ratones WT y sEng+, se cuantificó el infiltrado inflamatorio según los criterios explicados anteriormente, establecidos en la Tabla 7.

Los ratones control no muestran infiltrado inflamatorio, presentando un índice 0 , sin diferencias entre los controles WT y sEng+. El tratamiento con carragenina aumenta el infiltrado inflamatorio, presentando un índice 3 , siendo significativamente menor en los ratones sEng+, que presentan un índice 2 (Figura 52).

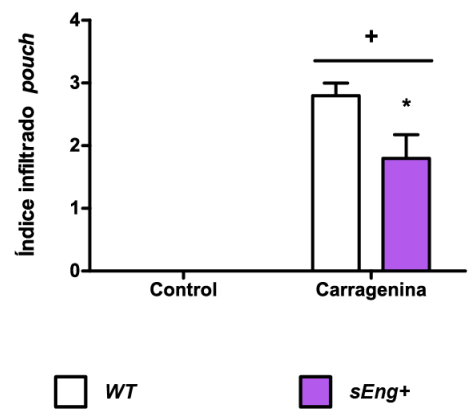

Figura 52. Índice de infiltrado en la piel del air pouch en ratones WT y sEng+. Valoración histológica cuantitativa del infiltrado pulmonar en ratones WT y sEng+, control y tratados con carragenina. Cada barra representa la media \pm EEM. WT $(n=5)$ y sEng $+(n=5)$. Test estadístico ANOVA de doble vía, $+p<0,0001$ vs control, ${ }^{*} p<0,05$ vs carragenina WT.

\subsubsection{ALTERACIONES EN EL RIÑÓN TRAS LA ISQUEMIA- REPERFUSIÓN}

Los riñones control muestran una apariencia sana, con glomérulos y túbulos conservados, sin acúmulos de infiltrado leucocitario ni estructuras patológicas. No se observan diferencias entre los control WT y los sEng+ (Figura 53). El análisis histológico de los riñones sometidos a isquemia-reperfusión, muestra un síntoma característico de la inflamación aguda: la necrosis tubular. La necrosis tubular está acompañada de la aparición de cilindros hialinos en túbulos proximales y distales, dando lugar a 
importantes dilataciones tubulares en las cuales se pierde por completo el epitelio de revestimiento tubular (marcado con un círculo azul), siendo de especial gravedad en la zona cortico-medular. No se observan diferencias en la necrosis tubular de ratones WT y sEngt.

Además, tras la isquemia-reperfusión se observan acúmulos de infiltrado polimorfonuclear neutrófilo, células plasmáticas y linfocitos. El infiltrado es perivascular, especialmente rodeando arterias y venas. En los ratones $W T$, este infiltrado da lugar a grandes y numerosos acúmulos leucocitarios perivasculares en prácticamente todos los grandes vasos (marcado con un círculo amarillo), mientras que en los ratones sEng+ el infiltrado es mínimo, y en ningún caso da lugar a acúmulos.

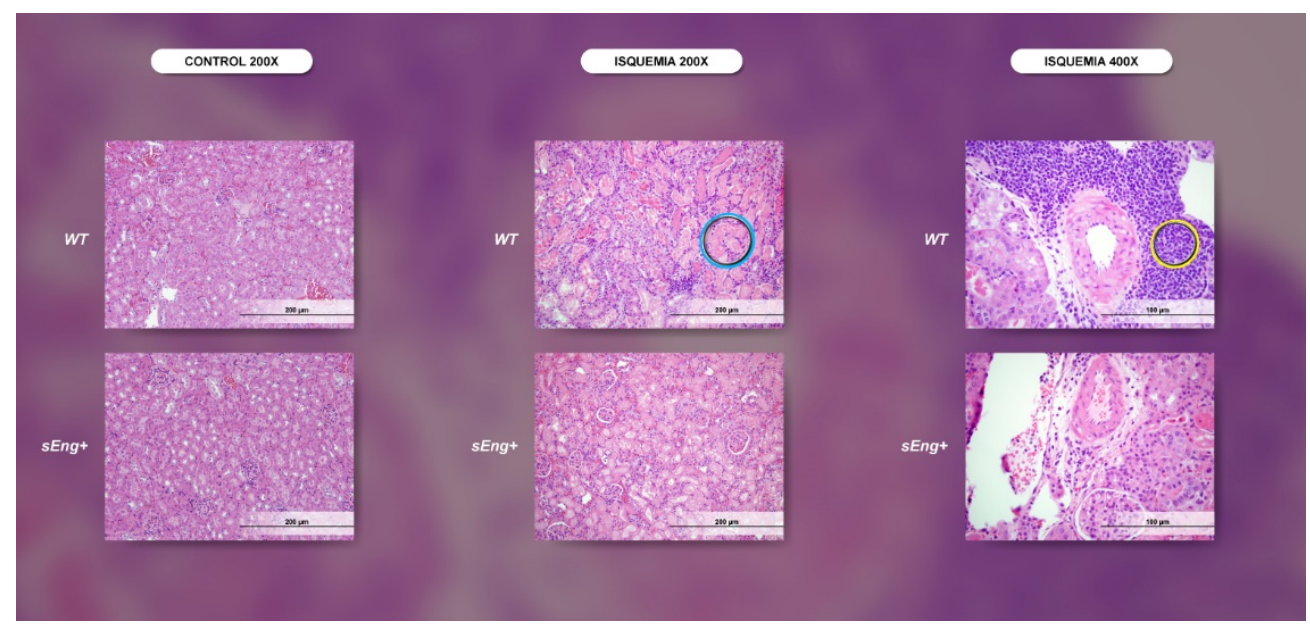

Figura 53. Estudio histológico del riñón de ratones WT y sEng+. Imágenes representativas de la tinción H\&E correspondiente al riñón de ratones WT y sEng+, control y sometidos a isquemia-reperfusión. Micrografías obtenidas mediante cámara acoplada a un microscopio óptico con 200 y 400 aumentos, respectivamente. WT $(n=6)$ y sEng+ $(n=6)$. El círculo amarillo marca una zona de infiltrado leucocitario y el azul necrosis tubular. 
Valoramos cuantitativamente la necrosis tubular, siguiendo los criterios establecidos en la Tabla 8. La necrosis tubular en los riñones control es prácticamente nula, correspondiéndose a un índice 0-1, sin diferencias entre los controles WT y sEng+. Tras realizarse la isquemia-reperfusión, los riñones presentan un significativo aumento en el grado de necrosis tubular, siendo de índice 2 en los ratones WT, y menor en el caso de los riñones correspondientes a ratones sEng+, en los cuales es de índice 1 (Figura 54, A).

Por otro lado, como también se observan diferencias entre los ratones WT y los sEng+ a nivel de infiltrado leucocitario, se realizó la cuantificación del infiltrado perivascular renal, de acuerdo a lo establecido en la Tabla 7. Según dichos criterios, observamos que los riñones control WT presentan un valor mínimo (índice 0-1 de infiltrado inflamatorio), mientras que ninguno de los ratones control sEng+ presentan infiltrado leucocitario (índice 0). Tras la isquemia-reperfusión, el infiltrado renal aumenta considerablemente en los $W T$, los cuales presentan un índice 2-3, mientras que el aumento en el infiltrado tras la isquemia es mínimo en los $s E n g+$ que prácticamente no presentan: índice 0-1 (Figura 54, B).

(A)

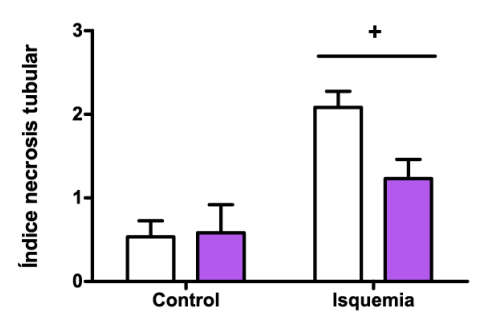

$\square w T$
(B)

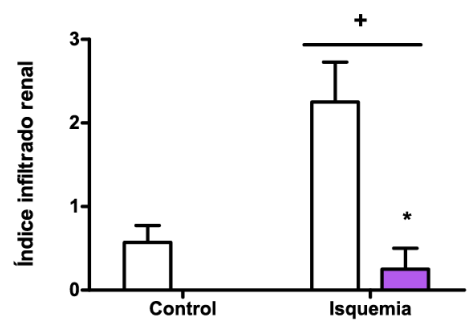

sEng+

Figura 54. Índice de necrosis tubular e infiltrado en el riñón de ratones WT y sEng+. Valoración histológica cuantitativa, de la necrosis tubular (A) y el infiltrado renal (B) en ratones WT y sEng +, control y sometidos a isquemia-reperfusión. Cada barra representa la media \pm EEM. WT $(n=6)$ y sEng $+(n=6)$. Test estadístico ANOVA de doble vía: $(A)+p<0,0001$ vs control, $(B)+p<0,005$ vs control, $* p<0,01$ vs isquemia WT. 
El análisis de las alteraciones histopatológicas nos muestra, en primer lugar, que la presencia de niveles elevados de endoglina soluble circulante no modifica la histología del pulmón, piel y riñón en condiciones control, no existiendo diferencias con los ratones WT. Tras el estímulo inflamatorio, ya sea por tratamiento con LPS, carragenina o isquemia-reperfusión, la cantidad de infiltrado leucocitario en todos los tejidos, y la necrosis tubular en el caso del riñón, es menor en los ratones sEng+.

\subsubsection{INFILTRADO LEUCOCITARIO}

Para profundizar en los resultados obtenidos en los análisis histológicos, valoramos el infiltrado extravasado tanto en el lavado broncoalveolar (en los ratones del modelo de LPS) como en el lavado del pouch. El hecho de tener la posibilidad de practicar un lavado en el foco inflamatorio, pulmonar en el modelo del LPS, y del pouch en el modelo de carragenina, nos permite la obtención de una muestra excelente, donde recogemos las células, proteínas y moléculas implicadas en el proceso inflamatorio. Esto resulta extremadamente útil a la hora de valorar la respuesta inflamatoria.

El análisis del lavado broncoalveolar muestra que la cantidad de leucocitos en las muestras control es mínima. No se observan diferencias entre las muestras control WT y sEng+ (Figura 55). La concentración leucocitaria aumenta significativamente en las muestras de los ratones tratados con LPS, siendo el infiltrado leucocitario significativamente menor en los ratones sEng+ con respecto a los WT. 


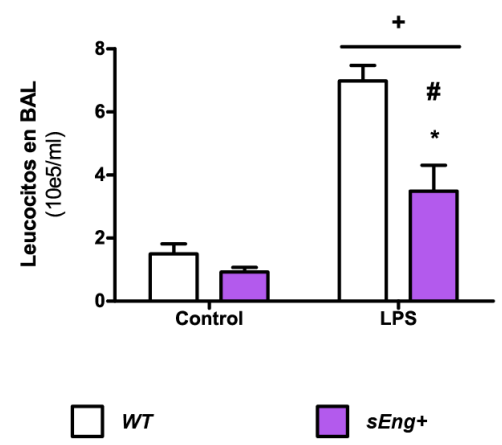

Figura 55. Concentración de leucocitos en el lavado broncoalveolar en ratones WT y sEng+. Análisis de la concentración de leucocitos en el BAL de ratones WT y sEng+, control y tratados con LPS. Los datos se expresan por $10 \mathrm{e}^{5} / \mathrm{ml}$. Cada barra representa la media \pm EEM. WT $(n=6)$ y sEng $+(n=6)$. Test estadístico ANOVA de doble vía: $+p<0,0001$ vs control, ${ }^{*} p<0,005$ vs LPS WT, $\# p<0,005$ vs control sEng+.

Del mismo modo, se analizó el infiltrado leucocitario en el lavado del pouch, en ratones control y tratados con carragenina. En la Figura 56 se observa que el infiltrado leucocitario en el lavado del pouch es significativamente menor en los ratones sEng+ con respecto a los $W T$.

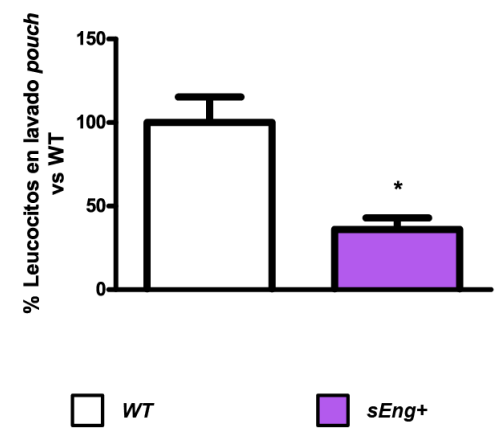

Figura 56. Concentración de leucocitos en el lavado del air pouch en ratones WT y sEng+. Análisis de la concentración de leucocitos en el lavado del air pouch de ratones WT y sEng+, tratados con carragenina. 
Al analizar las subpoblaciones leucocitarias mayoritarias (linfocitos y neutrófilos), observamos la misma tendencia: las muestras de los ratones $s E n g+$ presentan en el lavado del pouch menor cantidad, tanto de linfocitos como de neutrófilos, que los ratones WT (Figura 57).

(A)

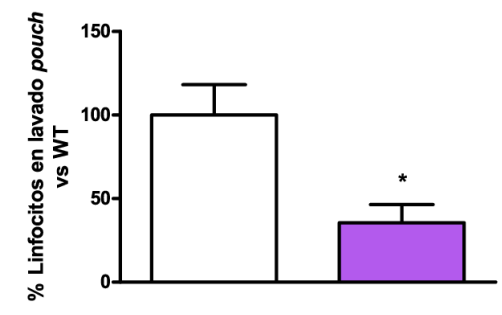

\WT
(B)

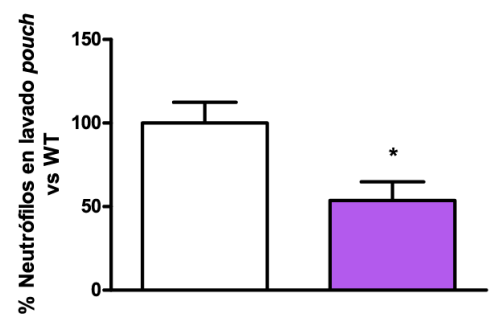

sEng+

Figura 57. Concentración de linfocitos y neutrófilos en el lavado del air pouch en ratones WT y sEng+. Análisis de la concentración de linfocitos (A, B) y neutrófilos (C, D) en el lavado del air pouch de ratones WT y sEng+, tratados con carragenina. Los valores se expresan en porcentaje, normalizados respecto a los WT. Cada barra representa la media \pm EEM. WT $(n=10)$ y sEng $+(n=10)$. Test estadístico t de student: (A) $* p<0,005$ vs WT, (B)*p<0,01 vs WT.

Se realizó el análisis de la expresión del ARNm del antígeno leucocitario CD45, ya que, una mayor expresión de ARNm de CD45 nos indica que se ha dado una mayor infiltración leucocitaria en el tejido. En pulmón, la expresión de CD45 en los ratones control es ligeramente menor en los WT que en los sEng+. Tras el tratamiento no se observa un aumento claro de expresión de CD45, a pesar de que el infiltrado leucocitario aumente significativamente tras el tratamiento con LPS. No hay diferencias significativas entre el ratón sEng+ y el WT tras el tratamiento con LPS (Figura 58, A). En el riñón, la expresión del ARNm de CD45 es ligeramente menor en los controles WT que en los sEng+. Tras la isquemia-reperfusión, observamos que la expresión aumenta en los ratones WT 
mientras que se mantiene constante en los sEng+ (Figura 58, B). Esto indica que, en los ratones $W T$ isquémicos las células inflamatorias continúan sintetizando CD45 de manera muy activa, mientras que en los $s E n g+$ no hay diferencias significativas.

(A)

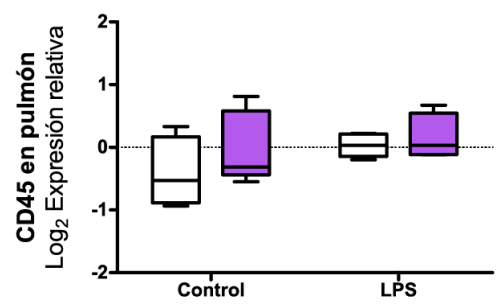

$\square w T$
(B)

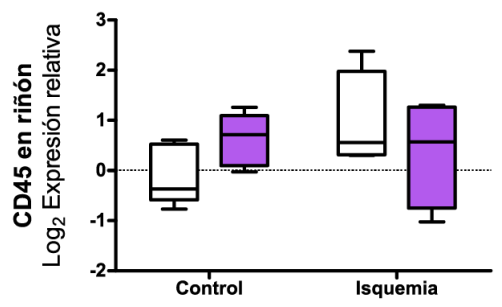

sEng+

Figura 58. Análisis de la expresión de CD45 en ratones WT y sEng+. Análisis mediante qPCR de los niveles de expresión de CD45 en pulmón (A) y en riñón (B) de ratones WT y sEng+, control, tratados con LPS o isquemia-reperfusión renal, respectivamente. Los valores se representan como el logaritmo en base dos de la expresión relativa de cada muestra con respecto de las muestras WT. Se representa un box plot 1090 percentil. WT $(n=5)$ y sEng+ $(n=5)$.

\subsection{3. ÍNDICE DE MIELOPEROXIDASA (MPO)}

Analizamos la actividad leucocitaria a través de la determinación de la enzima MPO, la cual está presente en los fagosomas de neutrófilos y en los monocitos.

En el tejido pulmonar, la actividad MPO es muy elevada, debido a que el pulmón presenta gran cantidad de macrófagos alveolares, que contienen gránulos azurófilos de mieloperoxidasa. En condiciones control, el índice de MPO está en torno a 50-100 U/mg tejido, sin diferencias significativas entre los controles WT y los sEng+. Tras el tratamiento con LPS, observamos un aumento significativo de la actividad MPO, siendo este aumento menor en los ratones sEng+ (Figura 59, A). 
En el riñón no se observan diferencias entre los controles WT y sEng+. Tras la isquemiareperfusión aumenta la actividad MPO, siendo este aumento significativamente menor en los ratones sEng+ (Figura 59, B).

(A)

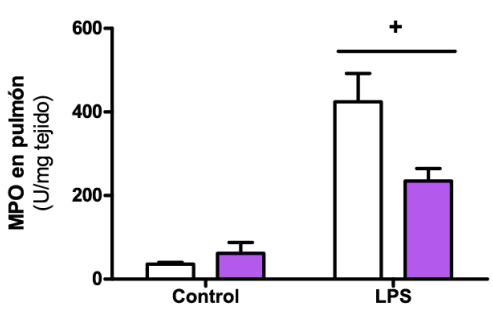

$\square w T$
(B)

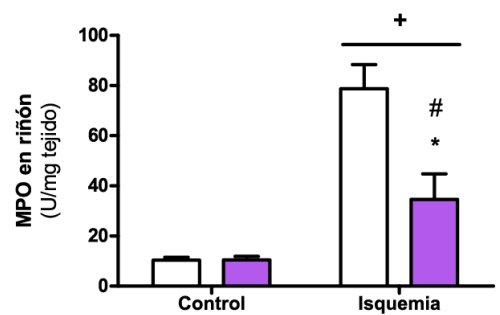

sEng+

Figura 59. Actividad mieloperoxidasa ratones WT y sEng+. Determinación de la actividad mieloperoxidasa en ratones WT y sEng+, en pulmón (A) y riñón (B) de ratones WT y sEng+, control, tratados con LPS o isquemia-reperfusión renal, analizado mediante ELISA. Los valores se expresan como U/mg tejido. Cada barra representa la media \pm EEM. En pulmón: WT $(n=5)$ y sEng $+(n=4)$, en riñón: WT $(n=6)$ y sEng+ $(n=5)$. Test estadístico ANOVA de doble vía: $(A)+p<0,01$ vs control, $(B)+p<0,0001$ vs control, ${ }^{*} p<0,05$ vs isquemia $W T, \# p<0,05$ vs control sEng+.

A la vista de los resultados, podemos concluir que, mientras que la endoglina soluble no provoca cambios en el infiltrado inflamatorio en condiciones control, tras inducción inflamatoria, ya sea con LPS, carragenina o isquemia-reperfusión, la extravasación leucocitaria es menor en presencia de endoglina soluble.

Cada vez se investiga más, y se dedican mayor cantidad de recursos, al estudio del papel de la inflamación en las enfermedades vasculares.

La inflamación es una de las principales causas de los ataques cardíacos, accidentes cerebrovasculares, patologías renales y otras complicaciones que experimentan las personas con diabetes (Wei et al, 2016; Pollack et al, 2016; Hotamisligil et al, 1993; Maedler et al, 2002). La hipertensión es la enfermedad crónica más común y la principal causa de 
insuficiencia cardíaca, accidente cerebrovascular, enfermedad renal crónica y mortalidad. La evidencia experimental y clínica sugiere que, en el desarrollo de la hipertensión, la inflamación tiene un papel crítico (Solak et al, 2016).

Otra enfermedad muy extendida en la población, la aterosclerosis, también se ha reconocido como una enfermedad inflamatoria de la pared arterial (Ross, 1999). Además, la preeclampsia, una afección grave que afecta al 5-10\% de todos los embarazos (Lyall, 2007) y se caracteriza por hipertensión y proteinuria (Redman \& Jefferies, 1988) y otras alteraciones sistémicas (Lain \& Roberts, 2002), también se asocia con una respuesta inflamatoria (Sacks et al, 1998; Redman et al, 1999; Sargent et al, 2003; Redman \& Sargent, 2005), presentando niveles circulantes de IL6, TNFa y proteína quimioatáctica monocítica 1 (MCP-1) elevados (Szarka et al, 2010) .

Los ratones sEng + utilizados en la elaboración de este trabajo tienen niveles plasmáticos elevados de endoglina humana soluble y desarrollan hipertensión leve y proteinuria (Valbuena-Diez et al, 2012). En este trabajo, demostramos que elevados niveles de endoglina soluble, por sí solos, no modifican el estado inflamatorio de los ratones sEng+, ya que la presencia de endoglina soluble circulante no provoca diferencias en comparación con los ratones control a nivel de infiltrado leucocitario y expresión de CD45 en tejido, reclutamiento leucocitario tanto en el lavado broncoalveolar como en el lavado del pouch y actividad mieloperoxidasa.

El hecho de que la presencia de endoglina soluble circulante no ocasione diferencias a nivel de infiltración leucocitaria está apoyado por los resultados de Nemeckova et al., en los que muestran, en un modelo de aorta ex vivo, que elevados niveles de endoglina soluble en plasma no inducen cambios en la función vascular ni en los niveles de ICAM1 y VCAM-1 (Nemeckova et al, 2015).

Sin embargo, estos resultados no descartan la posibilidad de que la endoglina soluble pueda alterar la respuesta inflamatoria tras una inducción de la inflamación. 
Enfermedades muy extendidas en la población, destacando hipercolesterolemia (Nemeckova et al, 2015), hipertensión (Valbuena-Diez et al, 2012), aterosclerosis (Jang \& Choi, 2014), diabetes mellitus tipo II (Blázquez-Medela et al, 2010) y preeclampsia (De Vivo et al, 2008) presentan niveles elevados de endoglina soluble circulante. La endoglina soluble ha demostrado ser un biomarcador potencial de estas enfermedades (López-Novoa \& Bernabeu, 2010), sin embargo, la relación directa entre los niveles elevados de endoglina soluble y los procesos inflamatorios involucrados en estas enfermedades aún queda por dilucidar.

Con este propósito, se llevaron a cabo tres modelos de inflamación aguda en ratones que presentan elevados niveles de endoglina soluble circulante, utilizando tres enfoques: nebulización de LPS, air pouch con carragenina e isquemia-reperfusión renal.

El hecho de desarrollar 3 modelos, en los cuales la inducción inflamatoria es de distinta naturaleza y afecte a distintos órganos (infección pulmonar en el caso del LPS, abrasión en la piel en el caso de la carragenina y por isquemia en el caso del riñón) es de gran interés. Nos permite corroborar si el papel de endoglina soluble es similar en distintas condiciones inflamatorias.

La nebulización de LPS induce daño tisular, caracterizado por edema pulmonar, alteración de la estructura pulmonar, extravasación de glóbulos rojos y acumulación de células inflamatorias, como han demostrado otros autores (Matute-Bello et al, 2008; Abraham, 2003; Ulich et al, 1991).

La lesión por isquemia-reperfusión se caracteriza por la restricción del suministro de sangre a un órgano seguida por la restauración del flujo sanguíneo y el cese de la hipoxia. Este fenómeno exacerba el daño tisular al iniciar una cascada inflamatoria incluyendo especies reactivas de oxígeno, citoquinas, quimiocinas y activación de leucocitos (Jang \& Rabb, 2009; Sharfuddin \& Molitoris, 2011; Malek \& Nematbakhsh, 2015).

La inducción inflamatoria por carragenina es uno de los modelos más utilizados en el estudio de fármacos antiinflamatorios y analgésicos (Posadas et al, 2004). La 220 
administración local de carragenina genera edema, infiltrado leucocitario y un aumento en los niveles de citoquinas proinflamatorias TNFa, IL1ß e IL6 (Cuzzocrea et al, 1999).

Los elevados niveles de endoglina soluble circulante reducen la infiltración leucocitaria en todos los tejidos inflamados analizados. Para profundizar en este efecto, se evaluó el número de leucocitos en el BAL y el lavado del air pouch, observándose que, tras inducción inflamatoria, el infiltrado leucocitario está reducido en presencia de endoglina soluble. Nuestros resultados demuestran que la endoglina soluble reduce el reclutamiento y la transmigración de leucocitos en estos modelos de inflamación.

Además, en los ratones sEng+ se observa que los niveles circulantes de endoglina soluble reducen la actividad MPO, tanto en los pulmones tratados con LPS como en los riñones sometidos a isquemia-reperfusión.

Existen evidencias que sugieren un posible papel de endoglina en el reclutamiento leucocitario. La expresión de endoglina de membrana se incrementa en las células endoteliales de tejidos inflamados, los cuales presentan infiltración leucocitaria (Torsney et al, 2002). Además, en riñones sometidos a isquemia-reperfusión se observa un aumento en la expresión de endoglina, y además, los ratones haploinsuficientes de endoglina de membrana ( Eng $^{+/-}$) presentan un daño menor tras la isquemia-reperfusión debido a la reducción en la respuesta inflamatoria que ocurre durante la reperfusión (Docherty et al, 2006). En concordancia con estos datos, está el hecho de que el endotelio de los órganos linfoides, en los cuales la transmigración leucocitaria permanece muy activa incluso en condiciones fisiológicas, sea muy reactivo a anticuerpos antiendoglina, marcándose con gran intensidad (Dağdeviren et al, 1998). Además, la expresión de endoglina es menos elevada en arterias y venas que en los capilares, donde se da gran parte de la transmigración leucocitaria (Jonker \& Arthur, 2002). Todo esto pone de manifiesto la estrecha relación entre endoglina y los fenómenos inflamatorios.

Por otro lado, se ha demostrado in vitro que la transmigración leucocitaria a través de una monocapa de mioblastos transfectados con endoglina humana (L6E9) aumenta en presencia de endoglina de membrana (Rossi et al, 2013), lo cual indicaría que la presencia 
de endoglina de membrana aumenta la transmigración leucocitaria. Sin embargo, la transmigración se ve reducida en presencia de endoglina soluble.

Además, se ha propuesto que endoglina soluble reduce la adhesión leucocitaria. Tras estimular la adhesión de linfocitos B a células endoteliales (HUVECS) con TNFa, se comprobó que la adhesión disminuye tanto en presencia de endoglina soluble como ante anticuerpos anti-E-selectina (TEA2/1) (Rossi et al, 2013). Estos datos nos llevan a concluir que la endoglina de membrana interacciona mediante su dominio RGD con la integrina leucocitaria a5 $\beta 1$. Los autores proponen que, la endoglina soluble, al contener el dominio RGD, compite con la endoglina de membrana por la unión a las integrinas leucocitarias, interfiriendo con la de adhesión y trasmigración características del proceso inflamatorio (Rossi et al, 2013).

Estos mismos autores observan que, 24 horas tras inyección de carragenina intraperitoneal, el aumento de leucocitos en el peritoneo es menor en haploinsuficiencia de endoglina que en los ratones WT. Concluyendo que la transmigración leucocitaria es menor en haploinsuficiencia de endoglina.

Nuestros resultados nos demuestran que la presencia de endoglina soluble reduce significativamente la transmigración leucocitaria. Por lo que la haploinsuficiencia de endoglina de membrana y la presencia de endoglina soluble tendrían efectos similares en la transmigración leucocitaria tras inducción inflamatoria. Esto podría corroborar la teoría anteriormente explicada: endoglina de membrana tiene un papel en la inflamación, participando en la transmigración leucocitaria mediante interacciones de su dominio RGD con integrinas leucocitarias a $5 \beta 1$. En nuestros modelos de inflamación en presencia de elevados niveles de endoglina soluble circulantes en plasma, la endoglina soluble se une a las integrinas a5 $\beta 1$ de leucocitos circulantes, impidiendo su unión a endoglina de membrana, y complicando por ello tanto la adhesión como la transmigración leucocitaria.

Según esta misma teoría, podríamos explicar que la transmigración leucocitaria disminuyera cuando endoglina de membrana se encuentra reducida. Sin embargo, sería necesario definir todos los posibles mecanismos involucrados antes de concluir que el 
efecto de endoglina soluble en inflamación sea únicamente por constituir en sí misma un impedimento para la transmigración. Por ejemplo, en condiciones control no se observan diferencias con los ratones $W T$, y según esta teoría, los ratones control sEng+ tendrían que presentan unos niveles de infiltrado leucocitario inferiores a los observados en los WT.

Durante el proceso inflamatorio, se observa un reclutamiento leucocitario desde el torrente sanguíneo hasta los tejidos que constituyen el foco inflamatorio. Durante este proceso, los leucocitos migran siguiendo un gradiente de citoquinas quimiotácticas e inflamatorias. Por ello, el análisis de citoquinas en el proceso inflamatorio, como CXCL12, IL1 $\beta$, IL6 y TNF $\alpha$, resulta muy interesante para investigar si la endoglina soluble altera la respuesta inflamatoria, por lo que se procedió a su análisis.

\subsubsection{EXPRESIÓN Y CONCENTRACIÓN DE CITOQUINAS QUIMIOTÁCTICAS E INFLAMATORIAS}

La citoquina CXCL12 presenta una fuerte quimiotaxis tanto a linfocitos como a leucocitos. Analizamos la quimiotaxis leucocitaria después de la inflamación en pulmón y riñón.

\subsubsection{ANÁLISIS DE LA EXPRESIÓN DE CXCL12}

Al analizar la expresión de la citoquina quimiotáctica leucocitaria CXCL12 en pulmón no observamos diferencias entre los controles WT y sEng+ (Figura 60, A). Tras el tratamiento con LPS, la expresión de CXCL12 es menor en los ratones sEng+ que, en los $W T$, aunque las diferencias no son significativas. En riñón observamos que los controles sEng + tienen mayor expresión de CXCL12 que los controles WT, de manera significativa (Figura 60, B). En los riñones sometidos a isquemia-reperfusión, la expresión disminuye significativamente con respecto a los controles, siendo esta disminución más drástica en los ratones $s E n g+$ que en los $W T$, ya que partían de valores control más altos. Estos resultados indican que, $48 \mathrm{~h}$ tras el tratamiento con LPS o isquemia-reperfusión, los 
ratones WT y sEng+, no tienen una quimiotaxis leucocitaria activa, siendo ligeramente menor en los ratones sEng+ que en los $W T$.

(A)

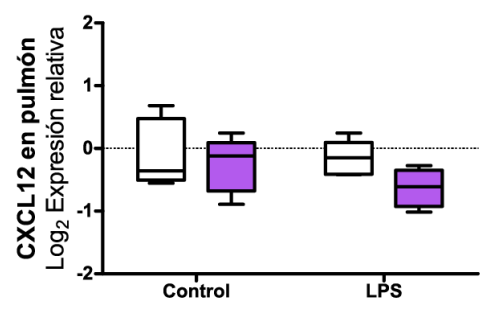

$\square w T$
(B)

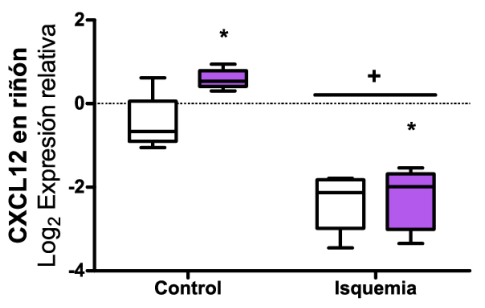

sEng+

Figura 60. Análisis de la expresión de CXCL12 en ratones WT y sEng+. Análisis mediante qPCR de los niveles de expresión de CXCL12 en pulmón (A) y en riñón (B) de ratones WT y sEng+, control, tratados con LPS o isquemia-reperfusión renal, respectivamente. Los valores se representan como el logaritmo en base dos de la expresión relativa de cada muestra con respecto de las muestras WT. Se representa un box plot 10-90 percentil. WT $(n=5)$ y sEng $+(n=5)$. Test estadístico ANOVA de doble vía: $(B)+p<0,0001$ vs control, $* p<0,05$ vs WT.

Además, se estudió la expresión de citoquinas esenciales en el proceso inflamatorio, como la IL1 $\beta$ y la IL6. La IL1 $\beta$ es liberada por macrófagos, monocitos y células dendríticas, mientras que la IL6 se libera por macrófagos, células T y células endoteliales (Bhatia, 2002). Son citoquinas con actividad proinflamatoria, causando la liberación de histamina por los mastocitos, vasodilatación y síntomas de inflamación localizada (Cohen, 2002; Norman et al, 1995; Putensen \& Wrigge, 2000).

Por ello, se consideró que el análisis de IL1 $\beta$ e IL6 constituye una excelente manera de valorar el proceso inflamatorio en los distintos tejidos. 


\subsubsection{ANÁLISIS DE LA EXPRESIÓN DE IL1B E IL6}

Se estudió mediante la técnica de GPCR la expresión del ARNm de las citoquinas inflamatorias IL1 $\beta$ e IL6 en el tejido pulmonar y en riñón, en ratones control y tratados con LPS o isquemia-reperfusión respectivamente.

Al analizar la expresión de IL1 $\beta$ e IL6 no se observan diferencias significativas entre los ratones control WT y sEng+ (Figura 61). La inflamación induce un aumento significativo en el pulmón y en el riñón. La expresión de IL1 $\beta$ en los ratones sEng+ tratados con LPS es menor que en los $W T$, aunque las diferencias no son significativas (Figura 61, A). No hay diferencias entre WT y sEng+ en la expresión de IL6 (Figura 61, C y D).

(A)

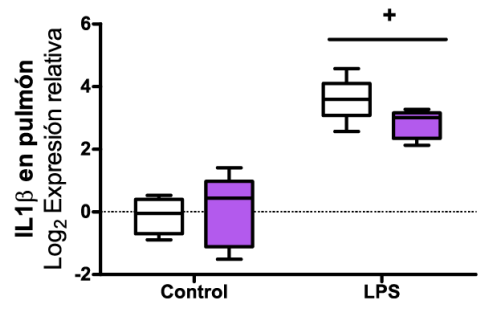

(c)

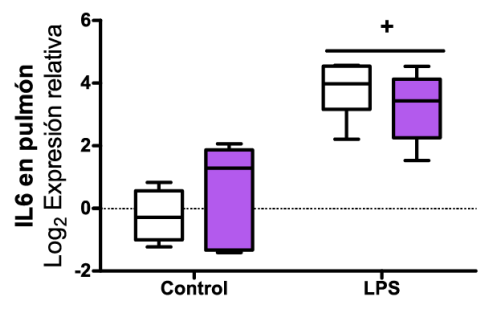

$\square w T$
(B)

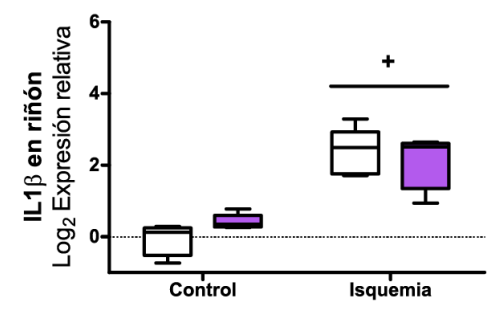

(D)

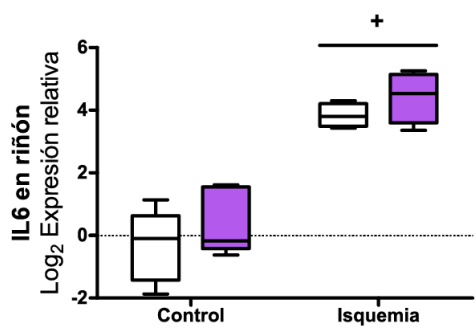

sEng+

Figura 61. Análisis de la expresión de IL1ß e IL6 en ratones WT y sEng+. Análisis mediante qPCR de los niveles de expresión de IL1ß (A, B) e IL6 (C, D) en pulmón y en riñón de ratones WT y sEng+, control, tratados con LPS o isquemia-reperfusión renal, respectivamente. Los valores se representan como el logaritmo en base dos de la expresión relativa de cada muestra con respecto de las muestras WT. Se 
Además, profundizamos en el estudio de las citoquinas inflamatorias, valorando los niveles de dichas citoquinas en tejido.

\subsubsection{ANÁLISIS DE LA CONCENTRACIÓN DE IL1B, IL6 Y TNFA}

Se analizó, mediante la técnica ELISA, la concentración de IL1 $\beta$, IL6 y TNFa en pulmón y riñón, en ratones control y tratados con LPS o isquemia-reperfusión respectivamente, tanto en los ratones WT como en los sEng+.

Al analizar la concentración de IL1ß, IL6 y TNFa en pulmón y en riñón observamos, en primer lugar, que los niveles de dichas citoquinas en el tejido correspondiente a ratones control son prácticamente nulos (Figura 62), a excepción del riñón (Figura 62, F), donde los niveles basales de TNFa son algo más elevados. No se observan diferencias entre los controles WT y los sEng+ en ninguno de los casos. El tratamiento con LPS o isquemia aumenta significativamente la concentración de dichas citoquinas inflamatorias en tejido, siendo este aumento menor en los ratones sEng+, en todos los casos, aunque las diferencias no alcanzan la significación estadística. 
(A)

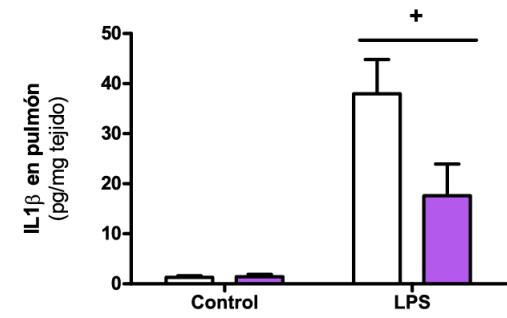

(c)

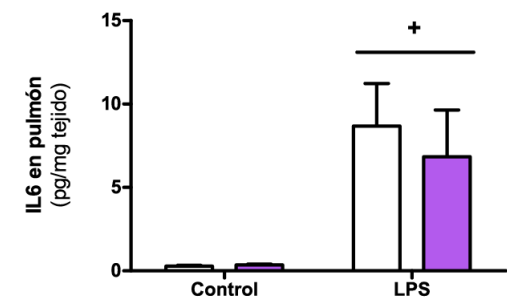

(E)

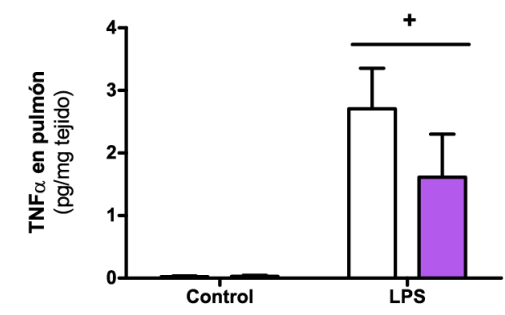

$\square w T$
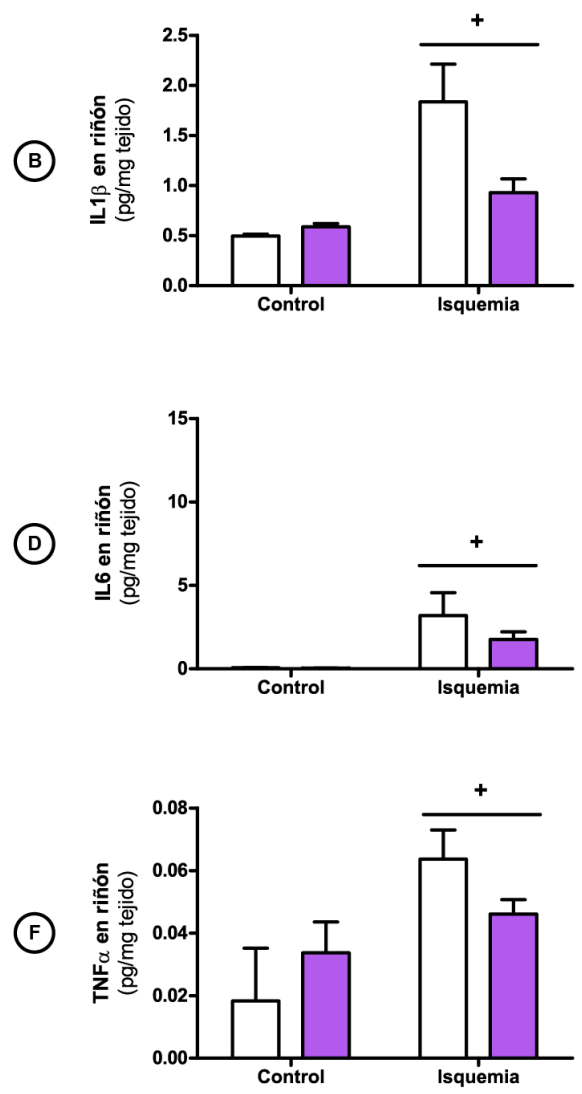

sEng+

Figura 62. Concentración de IL1ß, IL6 y TNFa en pulmón y riñón en ratones WT y sEng+. Análisis de la concentración de IL1 $\beta$, IL6 y TNFa en pulmón (A-C) y en riñón (D-E) de ratones WT y sEng+, control, tratados con LPS o isquemia-reperfusión renal, analizado mediante ELISA. Los valores se expresan como $\mathrm{pg} / \mathrm{mg}$ tejido. Cada barra representa la media \pm EEM. WT $(n=5), L-E N G+(n=5)$ y S-ENG $+(n=5)$. Test estadístico ANOVA de doble vía: $(A, C, E)+p<0,005$ vs control, $(B, D, F)+p<0,01$ vs control.

Valoramos también la concentración de IL1 $\beta$, IL6 y TNFa también en el lavado broncoalveolar y en el lavado del pouch. 
Al analizar por la técnica de ELISA la concentración de IL1 $\beta$, IL6 y TNFa en el BAL y el lavado del pouch, observamos que los niveles de dichas citoquinas en ratones control son prácticamente nulos en todos los casos. Además, el tratamiento con LPS o carragenina provoca un aumento significativo en la concentración de IL1 $\beta$, IL6 y TNFa (Figura 63). Este incremento en la concentración de IL1 $\beta$ en el BAL y de IL6 tanto en el BAL como en el lavado del pouch es significativamente menor en los ratones sEng+ (Figura 63, A, C y D). Además, en los ratones sEng+ la concentración en el lavado del pouch de IL1 $\beta$ y TNFa es menor, aunque no alcanza la significación estadística (Figura $63, \mathrm{~B}$ y F). 

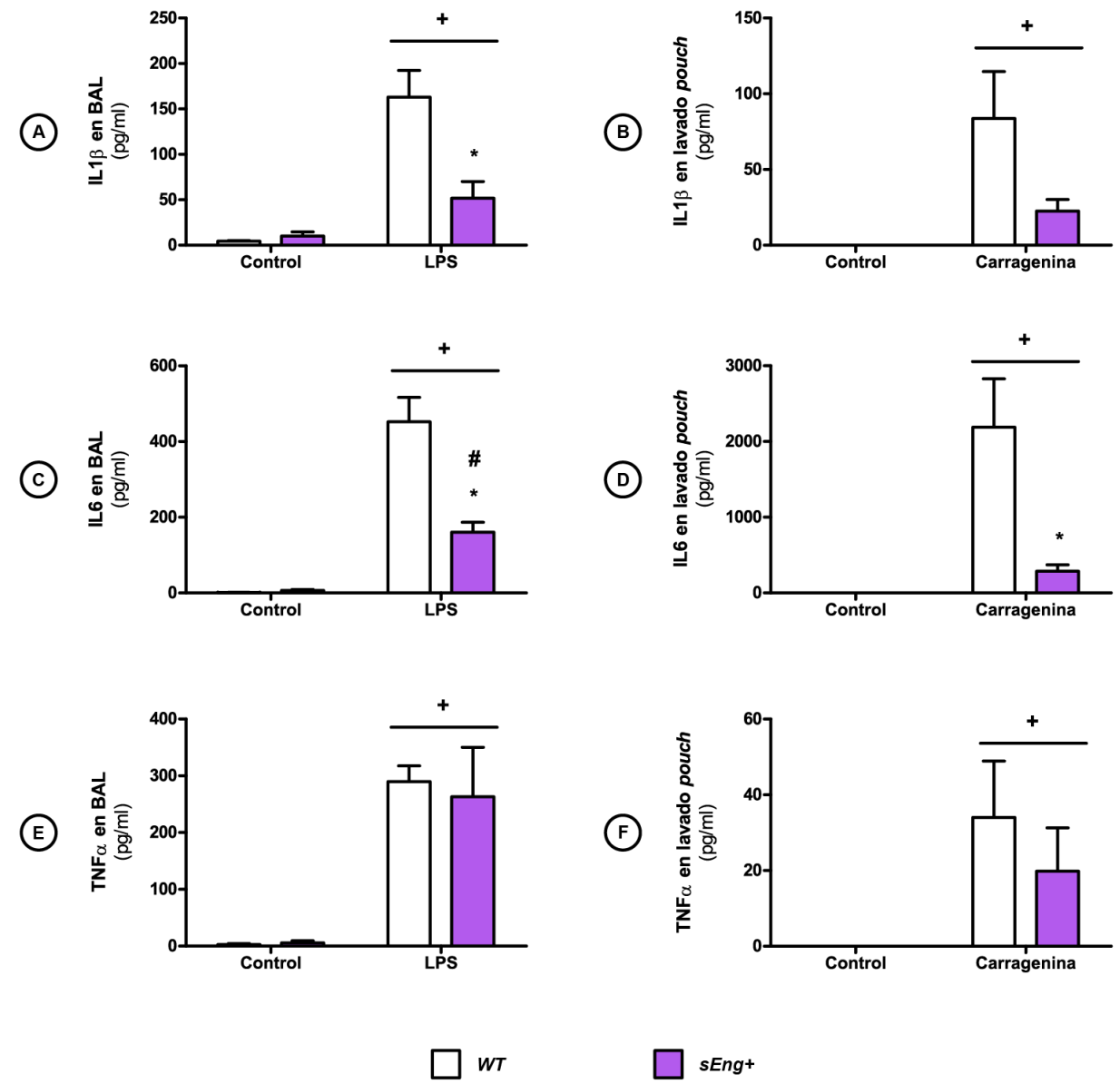

sEng+

Figura 63. Concentración de IL1ß, IL6 y TNFa en el lavado broncoalveolar y en el lavado del pouch de ratones WT y sEng+. Análisis de la concentración de IL1 $\beta$, IL6 y TNFa en el BAL $(A, C, E)$ y en el lavado del pouch $(B, D, F)$ de ratones WT y sEng+, control, tratados con LPS o carragenina, analizado mediante ELISA. Los valores se expresan como pg/ml. Cada barra representa la media \pm EEM. WT $(n=5), L-E N G+$ $(n=5)$ y S-ENG+ $(n=5)$. Test estadístico ANOVA de doble vía: $(A)+p<0,0001$ vs control, $* p<0,05$ vs LPS WT, $(B)+p<0,01$ vs control, (C) $+p<0,0001$ vs control, $* p<0,05$ vs LPS WT, \#p<0,001 vs control sEng+, (D) $+p<0,01$ vs control, $* p<0,05$ vs LPS WT, $(E)+p<0,0001$ vs control, $(F)+p<0,05$ vs control. 
Se valoraron los niveles plasmáticos de IL1 $\beta$, IL6 y TNFa (Figura 64). Los niveles de estas citoquinas en ratones control son prácticamente nulos en todos los casos, mientras que el plasma de los ratones tratados con LPS muestra un aumento de la concentración de citoquinas, especialmente elevado en el caso de IL6 (Figura 64 B). Tanto en IL1 $\beta$, IL6 y TNFa se observa una menor concentración en los ratones sEng+ tratados con LPS.

(A)

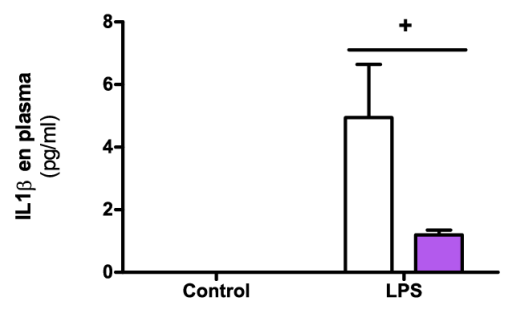

(B)

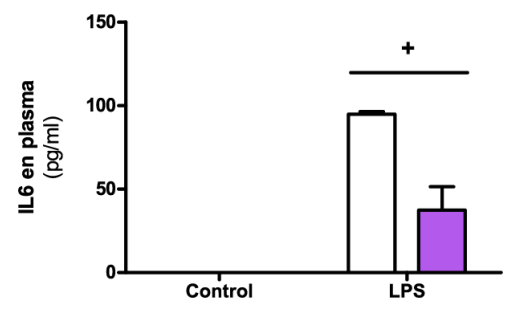

(C)

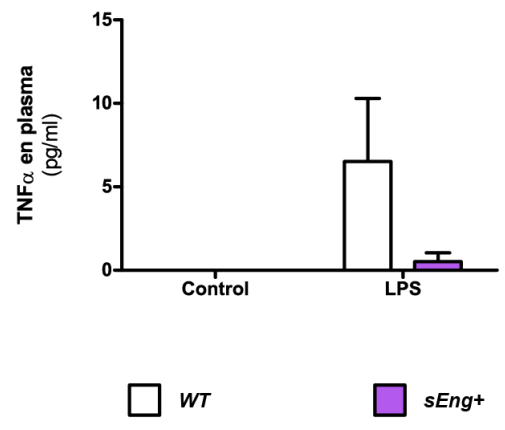

Figura 64. Concentración de IL1 $\beta$, IL6 y TNFa en el plasma de ratones WT y sEng+. Análisis de la concentración de IL1ß (A), IL6 (B) y TNFa (C) en el plasma de ratones WT y sEng+, control, tratados con 230 
Mientras que en los casos control endoglina soluble no provoca alteraciones, en condiciones inflamatorias, los elevados niveles de endoglina soluble circulante inducen una reducción en el aumento de la expresión del ARNm de las citoquinas CXCL12 e IL1 $\beta$, y a una menor concentración de IL1 $\beta$, IL6 y TNFa respecto a las condiciones control.

La inflamación sistémica se activa rápidamente por LPS, carragenina o isquemiareperfusión en distintos modelos experimentales, lo que a su vez aumenta los niveles plasmáticos de citoquinas inflamatorias (TNFa o IL1 $\beta$ ) y los radicales libres de oxígeno (Schneiders et al, 2015; Jones et al, 2005; Nonas et al, 2006; Ulich et al, 1991).

Nuestros resultados demuestran que, en ausencia de inflamación, los elevados niveles de endoglina circulante no modifican la expresión y concentración de citoquinas inflamatorias. Estos resultados están en concordancia con los obtenidos por Vareckova et al., en los que muestran que elevados niveles de endoglina soluble en plasma no inducen diferencias en las citoquinas inflamatorias, por sí solos, sino que es necesario la presencia de factores de riesgo vascular (Varejckova et al, 2017).

EI LPS y la carragenina estimulan a los macrófagos que liberan secuencialmente citoquinas proinflamatorias, participando el TNFa y la IL6 en el desarrollo temprano de la inflamación (Jones et al, 2005; Nonas et al, 2006). La inflamación inducida por LPS, carragenina e isquemia-reperfusión aumenta significativamente las citoquinas proinflamatorias, TNFa, IL1 $\beta$ e IL6, mientras que la presencia de endoglina soluble circulante las reduce.

La endoglina soluble se encuentra elevada en la preeclampsia (Venkatesha et al, 2006). Esta enfermedad cursa, generalmente, con hipertensión, proteinuria, estrés oxidativo y aumento de las citoquinas proinflamatorias, aunque no en todos los casos se observan 
todos los síntomas (Harmon et al, 2016; Sones \& Davisson, 2016; Borzychowski et al, 2006), existiendo gran variabilidad.

En un embarazo normal se observa un aumento de los niveles de endoglina soluble circulante en los dos últimos meses de gestación (Venkatesha et al, 2006). En las mujeres que desarrollan preeclampsia, este aumento ocurre de manera más temprana y mucho más pronunciada, por lo que pueden detectarse niveles elevados de endoglina soluble en plasma antes de la manifestación de los síntomas clínicos (Levine et al, 2006; Maynard et al, 2010). Por todo ello, se ha considerado que los niveles circulantes de endoglina soluble actúan como biomarcador de esta enfermedad (López-Novoa, 2007).

Los niveles plasmáticos de endoglina soluble se han correlacionado con un peor pronóstico, siendo significativamente mayores en pacientes con las formas más graves de la enfermedad, como eclampsia o síndrome de HELLP (Venkatesha et al, 2006) y en preeclampsia temprana (Maynard et al, 2010).

Existen numerosos trabajos que defienden el papel predictivo de los niveles de endoglina soluble en preeclampsia. Sin embargo, otras patologías como hipertensión gestacional o hipertensión crónica (Salahuddin et al, 2007) también cursan con un aumento de endoglina soluble. Por ello, para una mejor predicción, se ha planteado la determinación de endoglina soluble junto con otros factores como la concentración de sFlt1, PIGF y TGFß (Lim et al, 2008). De esta manera, se consigue una predicción del riesgo de padecer preeclampsia mucho más fiable.

La preeclampsia también presenta un aumento de citoquinas inflamatorias en el primer trimestre de embarazo, como TNFa, IL6 e IL1ß (Conrad et al, 1998; Szarka et al, 2010), mientras que se da una disminución de citoquinas antiinflamatorias, como IL10 e IL4 (Hennessy et al, 1999). Según Varejckova y cols., la endoglina soluble se asocia con la liberación de citoquinas inflamatorias en células endoteliales (Varejckova et al, 2017). Por medio de la modificación de la vía de señalización de TGF $\beta$, la endoglina soluble estimula la expresión de NFKB, que, a través de su vía de señalización, activaría la expresión de estas citoquinas (Libermann \& Baltimore, 1990). 
Se piensa que este incremento en los factores proinflamatorios a nivel placentario induce la muerte de trofoblastos y la activación de células endoteliales, causando la disfunción endotelial que se observa durante la preeclampsia (Chen et al, 2010), aunque también hay autores que mantienen que la muerte de trofoblastos puede deberse únicamente al estrés oxidativo (Williamson et al, 2017).

Sin embargo, estos estudios del efecto de endoglina soluble sobre el estado inflamatorio únicamente se han realizado en modelos in vitro de células endoteliales, por lo que habría que ser cuidadosos a la hora de extrapolar estos resultados a lo que ocurre en preeclampsia. No existen evidencias del efecto de endoglina soluble sobre la inflamación a nivel placentario o en modelos animales de preeclampsia, por lo que serían necesarios estudios más exhaustivos que clarifiquen el papel concreto que juega la endoglina soluble en el incremento de la inflamación observado en esta enfermedad.

Además, se ha demostrado que, mientras que la endoglina soluble se encuentra elevada a partir de las semanas 11-13 de gestación, la activación neutrófila y el aumento de citoquinas proinflamatorias ocurre cuando ya se ha diagnosticado la preeclampsia (Ramma \& Ahmed, 2011).

Los modelos de inflamación aguda en presencia de endoglina circulante utilizados en este estudio podrían permitirnos abordar un inicio hipotético de la preeclampsia, donde la presencia de altos niveles de endoglina soluble precede a los procesos inflamatorios.

En este contexto, y en concordancia con nuestros resultados, la reducción de la inflamación inducida por la presencia de endoglina soluble circulante podría explicar el efecto antiangiogénico de la endoglina soluble en las primeras etapas de la preeclampsia.

El inicio de la angiogénesis a menudo se asocia con un aumento de la permeabilidad capilar que sirve para enriquecer el compartimiento intersticial adyacente con componentes del plasma. La inflamación y la angiogénesis son, por lo tanto, procesos 
relacionados, pero no se conoce bien cómo se relacionan (Imhof \& Aurrand-Lions, 2006).

Mientras que la preeclampsia cursa con un aumento de endoglina soluble y de citoquinas proinflamatorias en plasma, nuestros resultados señalan que la presencia de endoglina soluble reduce el componente inflamatorio. Estas observaciones dan pie a una discusión muy interesante: ¿Está endoglina soluble en preeclampsia causando el aumento de citoquinas inflamatorias, o disminuyendo su expresión y sus niveles?; Dicho de otra forma: ¿Qué niveles de citoquinas inflamatorias presentarían las mujeres con preeclampsia si no presentaran un aumento de endoglina soluble en plasma? Porque, según nuestros resultados, podríamos pensar que quizás, si no se diera ese aumento de endoglina soluble en plasma durante la preeclampsia, la respuesta inflamatoria estaría aún más elevada. Sin embargo, antes de llegar a una conclusión, sería necesario realizar más estudios que permitieran esclarecer el papel de endoglina soluble en preeclampsia.

Además, se han observado efectos similares en los casos de haploinsuficiencia de endoglina de membrana y presencia de endoglina soluble circulante. Se ha demostrado que riñones irradiados de ratones haploinsuficientes de endoglina presentan una menor expresión de las citoquinas IL1 $\beta$ e IL 6 en células derivadas de la médula ósea estimuladas con LPS (Scharpfenecker et al, 2012). De manera similar, se ha observado que la baja expresión de IL1 $\beta$ e IL6 provoca una menor respuesta inflamatoria en estos ratones (Peter et al, 2014).

Esto está en línea con la teoría expuesta por Rossi et al.: la endoglina soluble se une a las integrinas leucocitarias por su dominio RGD (Rossi et al, 2013), impidiendo así que los leucocitos se unan a la endoglina de membrana, entorpeciendo su transmigración, y la consecuente liberación de citoquinas en el foco inflamatorio. De ahí, que se vean efectos similares cuando hay una diminución de la endoglina de membrana y en presencia de endoglina soluble. Esto es sólo una posible hipótesis, y podría explicar el hecho de que, al reducirse la transmigración leucocitaria, las citoquinas inflamatorias liberadas por dichos leucocitos en el foco inflamatorio estén reducidas. Sin embargo, la regulación de las citoquinas es mucho más compleja, y sería necesario investigar qué posibles 
mecanismos pueden causar esta disminución de la expresión y de los niveles de citoquinas en presencia de endoglina soluble.

Uno de los mecanismos que podrían explicar que la transmigración leucocitaria se encuentre reducida en presencia de elevados niveles de endoglina soluble es la permeabilidad vascular.

Modificaciones en la permeabilidad vascular podrían ocasionar cambios en la transmigración leucocitaria, y, consecuentemente, cambios en la expresión y niveles de citoquinas inflamatorias. Por ello, nos propusimos valorar la permeabilidad vascular en presencia de endoglina soluble circulante, tanto en condiciones control como tras inducción inflamatoria.

\subsection{ESTUDIO DEL EFECTO DE LA SOBREEXPRESIÓN DE ENDOGLINA SOLUBLE EN LA PERMEABILIDAD VASCULAR}

La permeabilidad vascular es un proceso fundamental en el proceso inflamatorio, y dado que está alterado en distintas enfermedades que cursan con inflamación, consideramos de gran importancia estudiar si endoglina soluble está modificando también la permeabilidad vascular.

\subsubsection{CONCENTRACIÓN DE PROTEÍNAS}

La permeabilidad vascular está aumentada durante la inflamación, se incrementan los espacios interendoteliales, aumentando el edema y con ello la cantidad de proteínas extravasadas. Por ello, se valoró la permeabilidad vascular in vivo mediante el estudio de la concentración de proteínas, tanto en el BAL como en el lavado del air pouch.

En la Figura 65 se observa que la concentración de proteínas es prácticamente nula en el BAL de los ratones control, y aumenta significativamente en los tratados con LPS o 
carragenina. No se observan diferencias entre los ratones control. Al analizar los BAL correspondientes a ratones tratados con LPS, se observa que el aumento en la concentración de proteínas es significativamente menor en los ratones sEng+ que en los WT (Figura 65, A). Análogamente, en el lavado del pouch (Figura 65, B), no se observan diferencias en los ratones control, mientras que la cantidad de proteínas en el lavado del pouch aumenta considerablemente tras el tratamiento con carragenina, siendo este aumento menor en los ratones sEng+.

(A)

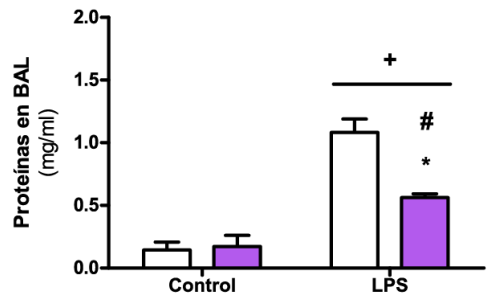

$\square w T$

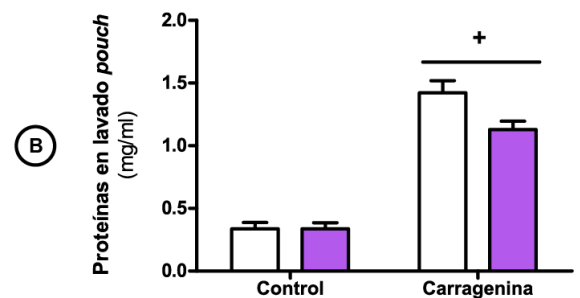

sEng+

Figura 65. Concentración de proteínas en el lavado broncoalveolar y en el lavado del air pouch en ratones WT y sEng+. Determinación de la concentración de proteínas en el BAL (A) y en el lavado del air pouch (B) de ratones WT y sEng+, control y tratados con LPS o carragenina, respectivamente. Los valores se expresan como mg/ml. Cada barra representa la media \pm EEM. En el BAL: WT $(n=5)$ y sEng+ $(n=4)$, en el lavado del air pouch: WT $(n=10)$ y sEng+ $(n=10)$. Test estadístico ANOVA de doble vía: $(A)+p<0,0001$ vs control, $* p<0,01$ vs LPS WT, $\# p<0,05$ vs control sEng $+,(B)+p<0,0001$ vs control.

Para ahondar en el estudio de la permeabilidad vascular, se midió el edema en los pulmones tratados con LPS, correspondientes a ratones $W T$ y $s E n g+$. Este ratio sólo se calculó en ratones previamente tratados con LPS, no se valoró en ratones control, ya que el edema es mínimo en condiciones control. 


\subsubsection{EDEMA PULMONAR}

Para valorar el edema pulmonar se calculó el ratio peso húmedo/peso seco de los pulmones de ratones $W T$ y sEng + tratados con LPS. Un mayor ratio peso húmedo/seco se corresponde con pulmones con mayor retención de líquido, y por ello, más edema. Como muestra la Figura 65, el ratio peso húmedo/seco es significativamente inferior en los ratones sEng+. Esto indica que tras el tratamiento con LPS, los pulmones sEng+ presentan menor cantidad de edema, lo que significa que la permeabilidad vascular está reducida en los ratones sEng+.

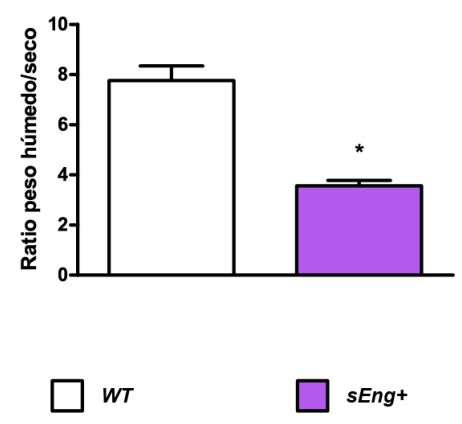

Figura 66. Análisis del edema pulmonar en ratones WT y sEng+. Análisis del edema pulmonar mediante el ratio peso húmedo/peso seco, en pulmones de ratones WT y sEng+, tratados con LPS. Cada barra representa la media \pm EEM. WT $(n=5)$ y sEng $+(n=5)$. Test estadístico t de student: ${ }^{*} p<0,0005$ vs WT.

\subsubsection{EVALUACIÓN DE LA PERMEABILIDAD VASCULAR PULMONAR AL FITC-DEXTRANO}

También se estudió la permeabilidad vascular pulmonar mediante inyección intravenosa de FITC-Dextrano en ratones WT y sEng+ tratados con LPS. Este experimento permite valorar el paso de FITC-Dextrano desde el torrente sanguíneo al pulmón. Se midió la fluorescencia en el BAL y se corrigió por la fluorescencia en el plasma de cada ratón, obteniéndose el ratio de FITC-Dextrano permeable en el pulmón (Figura 67). 
El ratio de FITC-Dextrano en el BAL fue significativamente inferior en los ratones sEng+, lo que indica, de nuevo, que su permeabilidad vascular está reducida en comparación al WT.

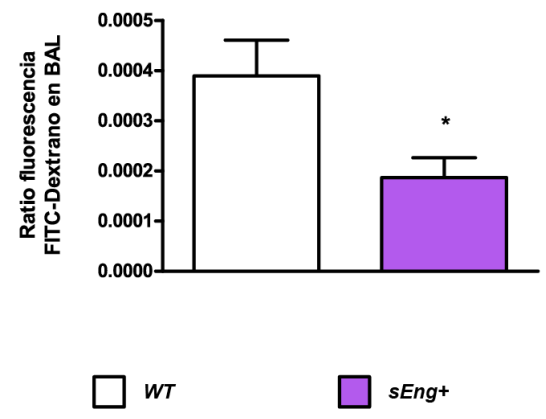

Figura 67. Concentración de FITC-Dextrano en el lavado broncoalveolar en ratones WT y sEng+. Determinación de la concentración de FITC-Dextrano en el BAL de ratones WT y sEng+, tratados con LPS y a los que se les ha inoculado FITC-Dextrano retroorbital. Los valores se expresan como el ratio fluorescencia en el lavado broncoalveolar/fluorescencia en plasma. Cada barra representa la media \pm EEM. WT $(n=5)$ y sEng $+(n=5)$. Test estadístico t de student: ${ }^{*} p<0,05$ vs WT.

Los resultados anteriores muestran, que los niveles elevados de endoglina soluble circulante reducen la permeabilidad vascular in vivo. Esto resulta muy interesante, ya que quizás podrían estar relacionadas la menor transmigración leucocitaria con la disminución de la permeabilidad vascular.

Para completar los resultados, decidimos valorar la permeabilidad vascular in vitro, con el objetivo de comprobar si endoglina soluble también reduce la permeabilidad vascular en un modelo celular endotelial.

\subsubsection{ENSAYO DE PERMEABILIDAD ENDOTELIAL IN VITRO}

Para analizar el papel de endoglina soluble en la permeabilidad endotelial in vitro, se midió el paso de FITC-Dextrano, de $40 \mathrm{kDa}$, a través de una monocapa de células 
endoteliales, tratadas o no con endoglina soluble. En condiciones fisiológicas, una molécula de 40kDa no atravesaría la barrera endotelial, pero tras tratamiento con LPS, se da un aumento del tamaño de los espacios inter-endoteliales. Por ello, se cuantificó el paso de FITC-Dextrano del compartimento superior al inferior del transwell, a través de células endoteliales tratadas con LPS, tanto en células control como en presencia de endoglina soluble. Se hicieron las medidas de fluorescencia en la cámara inferior a las 0 , $4,16,20$ y 24 horas.

En la Figura 68 se observa que en los compartimentos inferiores de las células endoteliales tratadas con sEng hay menor cantidad de FITC-Dextrano que en el caso control. Esto indica que las células tratadas con endoglina soluble son menos permeables al FITC-Dextrano que las control.

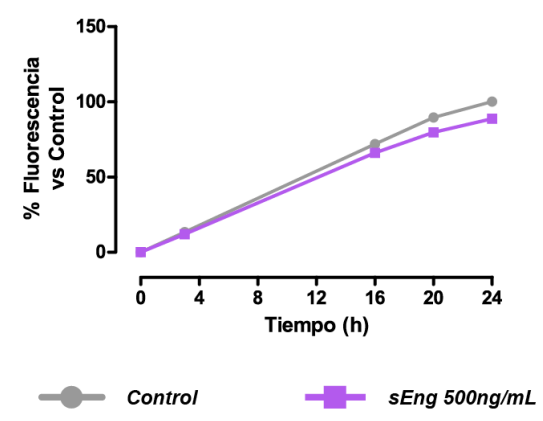

Figura 68. Ensayo de permeabilidad endotelial in vitro. Estudio de la permeabilidad de FITC-Dextrano a una monocapa endotelial in vitro. Se representa el tanto por ciento de fluorescencia, proveniente del FITCDextrano que atraviesa la monocapa endotelial y llega al compartimento inferior del transwell en presencia de sEng, con respecto a las células control. Se ha medido fluorescencia a las 0, 4, 16, 20 y 24 horas. Los resultados representan la media de 3 experimentos en cada caso. 


\subsubsection{ANÁLISIS DE LA EXPRESIÓN Y NIVELES DE VE- CADHERINA}

Por último, para profundizar en el estudio del papel de endoglina soluble en la permeabilidad vascular, se estudió la expresión de un elemento fundamental en dicho proceso, la VE-cadherina, molécula principal en el mantenimiento de las uniones adherentes entre células endoteliales.

La expresión del ARNm de VE-cadherina (CDH5) en condiciones control es menor en los ratones sEng+ que en los WT (Figura 69, A). Tras el tratamiento con LPS, la expresión de $\mathrm{CDH} 5$ disminuye significativamente en el pulmón, tanto en los ratones WT como en los sEng+. En riñón, no se observan diferencias en la expresión de $\mathrm{CDH} 5$ en los ratones control WT y sEng+ (Figura 69, B). Tras la isquemia, se observa una reducción en la expresión de CDH5, sin diferencias entre $W T$ y sEng+.

(A)

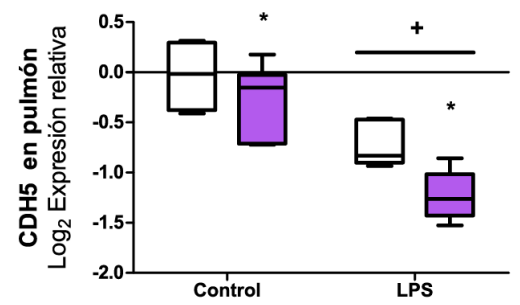

wT
(B)

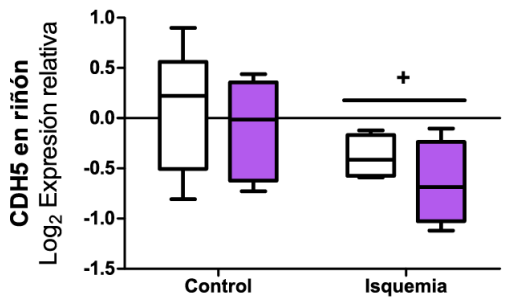

sEng+

Figura 69. Análisis de la expresión de CDH5 en ratones WT y sEng+. Análisis mediante qPCR de los niveles de expresión de CDH5 en pulmón (A) y en riñón (B) de ratones WT y sEng+, control, tratados con LPS o isquemia-reperfusión renal, respectivamente. Los valores se representan como el logaritmo en base dos de la expresión relativa de cada muestra con respecto de las muestras WT. Se representa un box plot 1090 percentil. WT $(n=5)$ y sEng+ $(n=6)$. Test estadístico ANOVA de doble vía: $(A)+p<0,0001$ vs control, $* p<0,01$ vs WT, (B) $+p<0,05$ vs control. 
La expresión del ARNm de VE-cadherina desciende con la inflamación. En el caso de pulmón, la disminución en la expresión de CDH5 es la misma para los WT que para los $s E n g+$, ya que los controles sEng+ parten de una menor expresión que los WT.

Se evaluaron además los niveles de VE-cadherina en pulmón por Western blot. No se observan diferencias en los niveles de VE-cadherina en los ratones control WT y sEng+. El tratamiento con LPS disminuye significativamente la cantidad de VE-cadherina, siendo mayores los niveles en los ratones sEng+, aunque las diferencias no alcanzan la significación estadística (Figura 70).

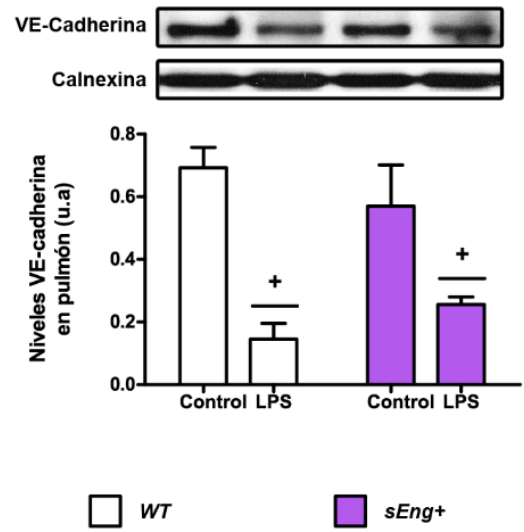

Figura 70. Análisis de los niveles de VE-cadherina en ratones WT y sEng+. Análisis de los niveles de VEcadherina en el pulmón de ratones WT y sEng+, control y tratados con LPS, analizados por Western blot. Cada barra representa la media \pm EEM. WT $(n=5)$ y sEng $+(n=5)$. Test estadístico ANOVA de doble vía: $+p<0,0001$ vs control.

En el análisis de la expresión y niveles de VE-cadherina en el tejido de ratones WT y sEng + las diferencias no son significativas, a pesar de que, al estudiar la permeabilidad vascular, tanto in vivo como in vitro, se observa que la presencia de endoglina soluble disminuye de manera muy significativa la permeabilidad vascular. 
Dado que los cambios en la permeabilidad pueden deberse también a que VE-cadherina, en condiciones inflamatorias, se internaliza, dejando de localizarse en las uniones endoteliales, sería muy interesante realizar un estudio de localización de VE-cadherina.

En nuestro estudio, se demuestra que la presencia de elevados niveles de endoglina soluble no modifican la permeabilidad vascular en condiciones control, ya que no observamos diferencias ocasionadas por la presencia de endoglina soluble al analizar la concentración de proteínas tanto en el lavado broncoalveolar como en el lavado del air pouch. De hecho, se ha demostrado que la endoglina soluble, por sí sola, no induce cambios endoteliales en condiciones control (Nemeckova et al, 2015; Nachtigal et al, 2012).

Las modificaciones en la respuesta inflamatoria ocasionan un aumento en la permeabilidad vascular (Greer et al, 1994; Hayakawa et al, 2000; Djurovic et al, 2002). En este estudio, demostramos que la permeabilidad vascular inducida por la inflamación se reduce en presencia de endoglina soluble, siendo esta la primera vez que se muestra la relación entre la endoglina soluble circulante y la permeabilidad vascular inducida por la inflamación.

La inflamación es una característica distintiva del cáncer que contribuye sustancialmente al desarrollo y la progresión de los tumores malignos (Diakos et al, 2014). En los cánceres establecidos, existe una evidencia creciente de los papeles que tienen la respuesta inmune local y la inflamación sistémica en la progresión de los tumores y la supervivencia de los pacientes con cáncer. Este conocimiento brinda la oportunidad de dirigir estas respuestas inflamatorias para mejorar los resultados del paciente (Diakos et al, 2014).

El cáncer, es una de las numerosas patologías que cursan con un aumento crónico de la permeabilidad vascular. Según nuestros resultados, la endoglina soluble podría ser una molécula de especial interés para crear nuevas terapias y tecnologías de prevención o tratamiento de muchos trastornos. Por ejemplo, se ha demostrado en modelos de tumor preclínico, que, limitando el reclutamiento leucocitario tumoral, disminuye el desarrollo del tumor (Marelli et al, 2017). 
En los tejidos normales, la permeabilidad vascular controla las moléculas que se van a transferir, en función de su radio (Frank \& Lisanti, 2008). El aumento de la permeabilidad vascular se puede observar aguda o crónicamente en los tejidos inflamados. En respuesta a las señales proinflamatorias, se observa la modificación de las uniones interendoteliales, lo cual regula a su vez el proceso inflamatorio (Frank \& Lisanti, 2008).

Durante el desarrollo de la inflamación, las interacciones leucocito-endotelio dan como resultado modificaciones de la permeabilidad vascular que permitirán la transferencia de solutos a los tejidos periféricos. Tanto las arteriolas como las vénulas pueden responder a un estímulo proinflamatorio (Sumagin et al, 2008).

Las moléculas de adhesión vascular han demostrado tener un papel importante en la aterosclerosis (Galkina \& Ley, 2007) y también se ha propuesto que desempeñan un papel importante en el cáncer (Kobayashi et al, 2007). Se ha demostrado que el TNFa desempeña una función importante en el inicio de la inflamación (Sethi et al, 2008). La vía de señalización de TNFa está mediada por NF-kB y es responsable de la expresión de moléculas de adhesión tales como VCAM-1 e ICAM-1 en el endotelio (Collins et al, 1995). Estas moléculas de adhesión permiten la unión de leucocitos al endotelio y pueden permitir su posterior transmigración al tejido periférico. Al mismo tiempo, esto supone un aumento de la permeabilidad vascular. Esto pone de manifiesto la importancia de la permeabilidad vascular en el proceso inflamatorio.

Sería necesario realizar más investigaciones que pudieran elucidar mediante qué mecanismos la endoglina soluble circulante regula la permeabilidad. Según la teoría discutida anteriormente, se podría explicar que endoglina soluble impidiera que los leucocitos se unieran a endoglina de membrana y transmigraran, pero esta teoría no explica por qué la presencia de endoglina soluble causa una disminución de la permeabilidad vascular en condiciones inflamatorias. Como la transmigración leucocitaria y la permeabilidad vascular, son mecanismos diferentes, regulados por moléculas diferentes, posiblemente endoglina soluble provoca una disminución de la permeabilidad vascular mediante otros mecanismos. 
Dada la extraordinaria disminución en la permeabilidad vascular que observamos en presencia de endoglina soluble en nuestros modelos in vivo e in vitro, sería de gran interés científico y biosanitario realizar futuras investigaciones que elucidaran los mecanismos por los cuales la endoglina soluble provoca este efecto tan drástico.

La expresión de VE-cadherina es diferente en cada tejido, estando únicamente presente en las células endoteliales (Prandini et al, 2005). Los embriones knockout para VEcadherina mueren durante el desarrollo (Gavard, 2013) y, de hecho, alteraciones en VEcadherina afecta la integridad vascular, ya que se trata de una proteína fundamental para la formación de las uniones adherentes y el mantenimiento de la barrera endotelial (Gavard \& Gutkind, 2006; Taddei et al, 2008; Heupel et al, 2009; Hebda et al, 2013).

Según nuestros resultados, la reducción de la permeabilidad vascular que causa endoglina soluble no se debe a alteraciones ni en la expresión ni en los niveles de proteína en tejido de VE-cadherina. Durante la formación de los vasos sanguíneos y en respuesta a agentes promotores de la permeabilidad vascular, la función de la barrera endotelial podría alterarse directamente a través del nivel de expresión de VE-cadherina. Esto podría lograrse alterando la transcripción del ARNm de VE-cadherina (Gavard, 2013). De hecho, se han identificado varios factores de transcripción por su acción positiva en la expresión de VE-cadherina durante la angiogénesis y la inflamación. Sin embargo, no podemos descartar que la presencia de endoglina soluble circulante pudiera estar regulando VE-cadherina a nivel de fosforilación, internalización o biodisponibilidad.

\subsection{ANÁLISIS DE LAS MOLÉCULAS DE ADHESIÓN}

\subsubsection{EXPRESIÓN DE MOLÉCULAS DE ADHESIÓN}

Se analizó mediante la técnica de qPCR la expresión del ARNm de las moléculas de adhesión E-selectina, VCAM-1, ICAM-1 y PECAM-1 en el tejido pulmonar y en riñón, en ratones control y tratados con LPS o isquemia-reperfusión respectivamente. 
E-selectina es una molécula implicada en el rodamiento leucocitario. La expresión del ARNm de E-selectina (SELE) en el pulmón de los ratones control WT es mayor que en los respectivos controles $s E n g+($ Figura 71, A). Sin embargo, tras el tratamiento con LPS no observamos diferencias en la expresión de SELE entre WT y sEng+. Por su parte, en riñón la expresión en los ratones control es mayor en los sEng+, y tras la isquemiareperfusión tanto los WT como los sEng+ aumentan la expresión de SELE significativamente, siendo este aumento menor en los ratones sEng+ (Figura 71, B).

(A)

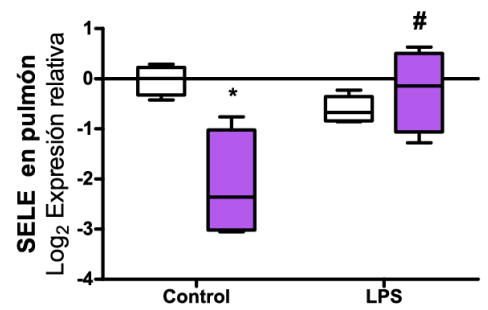

$\square W T$

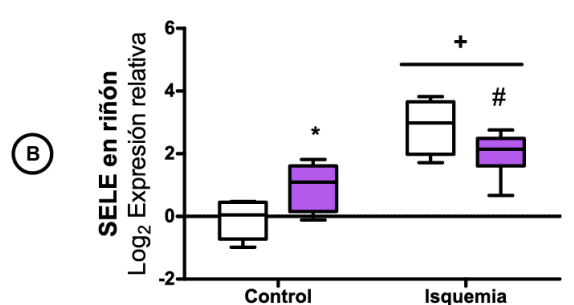

sEng+

Figura 71. Análisis de la expresión de SELE en ratones WT y sEng+. Análisis mediante qPCR de los niveles de expresión de SELE en pulmón (A) y en riñón (B) de ratones WT y sEng+, control, tratados con LPS o isquemia-reperfusión renal, respectivamente. Los valores se representan como el logaritmo en base dos de la expresión relativa de cada muestra con respecto de las muestras WT. Se representa un box plot 1090 percentil. WT $(n=5)$ y sEng+ $(n=5)$, en riñón: WT $(n=5)$ y sEng + $(n=6)$. Test estadístico ANOVA de doble vía: $(A) * p<0,001$ vs control WT, $\# p<0,05$ vs control sEng $+,(B)+p<0,0001$ vs control, ${ }^{*} p<0,001$ vs control WT, $\# p<0,05$ vs control sEng+.

La expresión del ARNm de E-selectina sigue un patrón muy distinto en el pulmón y en el riñón de los ratones $s E n g+$. Mientras que los pulmones control sEng+, expresan menos ARNm de E-selectina que los WT, los riñones control sEng+ expresan más que los WT. $48 \mathrm{~h}$ tras el tratamiento con LPS, el rodamiento leucocitario no parece estar activo en los ratones WT en pulmón, mientras que el aumento de expresión de SELE en los sEng+ podría indicar que el rodamiento sigue activo en los sEng+ (Hordijk, 2006). Por otro lado, 
en riñón el rodamiento leucocitario parece ser menor en los ratones sEng+ que en los WT $48 \mathrm{~h}$ tras la isquemia.

VCAM-1 es una molécula de adhesión implicada principalmente en el arresto y adhesión leucocitaria. No hay diferencias en la expresión de VCAM-1 en pulmón entre los ratones control WT y sEng+. Tras el tratamiento con LPS, no observamos cambios en la expresión en ratones $W T$, mientras que vemos menor expresión en los ratones sEng+ con respecto a los controles (Figura 72, A). Por otro lado, al analizar la expresión de VCAM-1 en riñón observamos que los controles sEng+ presentan, ligeramente, mayor expresión que los controles WT (Figura 72, B). Tras isquemia-reperfusión, observándose un aumento en la expresión de VCAM-1, siendo este aumento menor en los ratones sEng+.

(A)

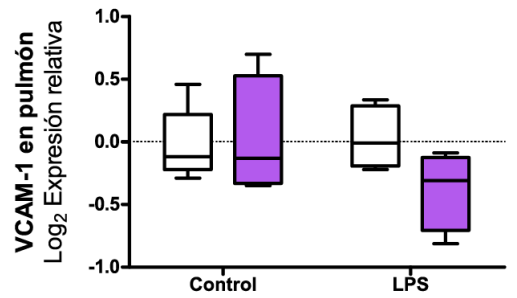

$\square W T$

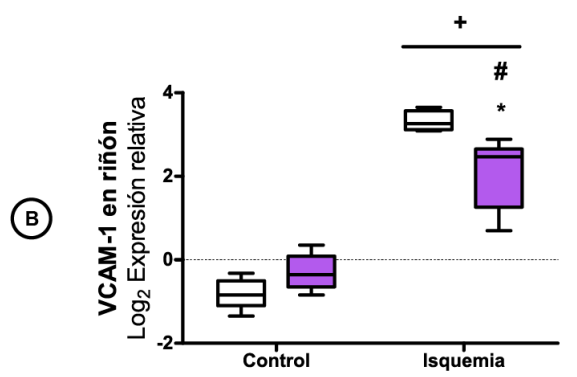

sEng+

Figura 72. Análisis de la expresión de VCAM-1 en ratones WT y sEng+. Análisis mediante qPCR de los niveles de expresión de VCAM-1 en pulmón (A) y en riñón (B) de ratones WT y sEng+, control, tratados con LPS o isquemia-reperfusión renal, respectivamente. Los valores se representan como el logaritmo en base dos de la expresión relativa de cada muestra con respecto de las muestras WT. Se representa un box plot 10-90 percentil. WT $(n=5)$ y sEng+ $(n=5)$. Test estadístico ANOVA de doble vía: $(B)+p<0,0001$ vs control, $* p<0,01$ vs isquemia WT, $\# p<0,005$ vs control sEng+.

La disminución en la expresión de VCAM-1 en los ratones sEng+ indica que en pulmón no está activa la adhesión leucocitaria endotelial $48 \mathrm{~h}$ tras el tratamiento con LPS. Sin 
embargo, a la vista de estos resultados, en riñón, $48 \mathrm{~h}$ después de la isquemia continuaría la transmigración leucocitaria, siendo menor en los ratones sEng+. Tras la inducción inflamatoria, observamos tanto en pulmón como en riñón que la expresión de ARNm de VCAM-1 es menor en presencia de endoglina soluble circulante.

ICAM-1 interviene en distintas etapas de la transmigración leucocitaria: en la adhesión, el gateo, la formación de las "copas migratorias" y la movilidad intersticial (Galkina \& Ley, 2007). Al analizar la expresión de ICAM-1 en pulmón, no observamos diferencias entre los ratones control WT y sEng+. Además, tras el tratamiento con LPS, no se modifica la expresión (Figura 73, A). En riñón, no observamos diferencias significativas entre los ratones control WT y sEng+ (Figura 73, B) mientras que, tras la isquemiareperfusión, se da un aumento significativo en la expresión.

(A)

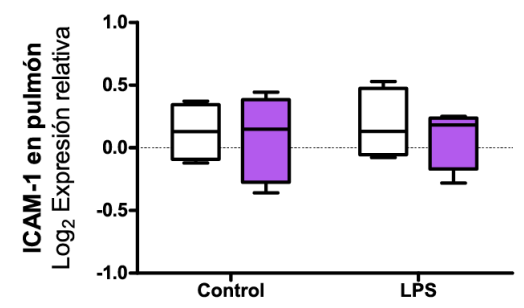

$\square W T$

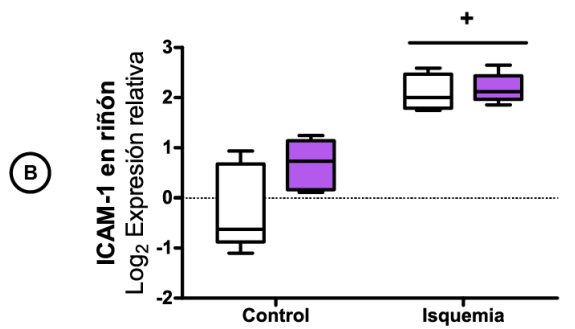

sEng+

Figura 73. Análisis de la expresión de ICAM-1 en ratones WT y sEng+. Análisis mediante qPCR de los niveles de expresión de ICAM-1 en pulmón (A) y en riñón (B) de ratones WT y sEng+, control, tratados con LPS o isquemia-reperfusión renal, respectivamente. Los valores se representan como el logaritmo en base dos de la expresión relativa de cada muestra con respecto de las muestras WT. Se representa un box plot 10-90 percentil. WT $(n=5)$ y sEng $(n=5)$. Test estadístico ANOVA de doble vía: $(B)+p<0,0001$ vs control.

PECAM-1 es una molécula de adhesión clave en la diapédesis. El estudio de la expresión del ARNm de PECAM-1 (CD31) no muestra diferencias en pulmón entre los ratones control WT y sEng+ (Figura 74, A). Tras el tratamiento con LPS, la expresión disminuye significativamente en pulmón, sin diferencias entre los ratones WT y los sEng+. Por su 
parte, en riñón tampoco se observan diferencias entre los controles WT y sEng+ (Figura 74, B). Sin embargo, la isquemia-reperfusión produce una ligera disminución en la expresión de CD31 en los $W T$, mientras que aumenta significativamente la expresión en los sEng+.

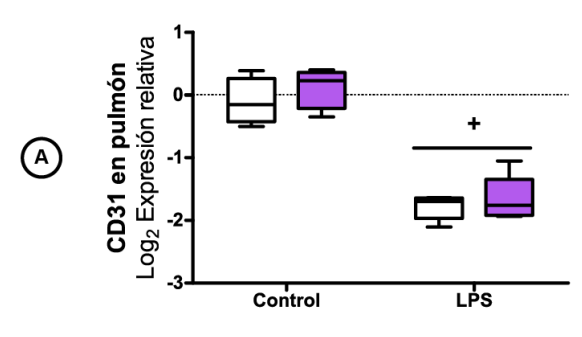

$\square w T$

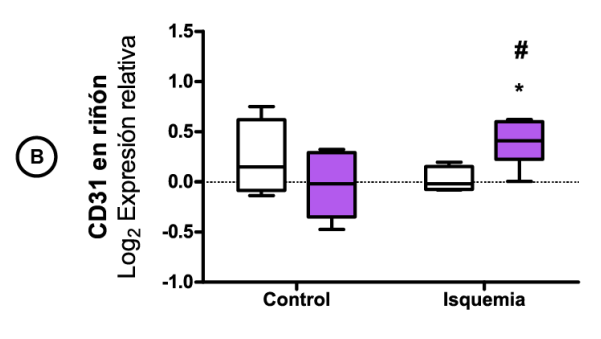

sEng+

Figura 74. Análisis de la expresión de CD31 en ratones WT y sEng+. Análisis mediante qPCR de los niveles de expresión de CD31 en pulmón (A) y en riñón (B) de ratones WT y sEng+, control, tratados con LPS o isquemia-reperfusión renal, respectivamente. Los valores se representan como el logaritmo en base dos de la expresión relativa de cada muestra con respecto de las muestras WT. Se representa un box plot 1090 percentil. En pulmón: WT $(n=5)$ y sEng $+(n=5)$, en riñón: $W T(n=4)$ y sEng+ $(n=6)$. Test estadístico ANOVA de doble vía: $(A)+p<0,0001$ vs control, $(B)^{*} p<0,05$ vs isquemia $W T, \# p<0,05$ vs control sEng+.

Los resultados observados en ICAM-1 y PECAM-1 nos indican que, 48h después de la inducción inflamatoria con LPS, en pulmón continuaría la transmigración leucocitaria, mientras que en los riñones isquémicos seguiría activa. A pesar de ello, en pulmón resulta particularmente interesante los resultados observados en VCAM-1. EI hecho de que la expresión disminuya con el tratamiento en los ratones $s E n g+$ indica que la cascada de adhesión leucocitaria está reducida en los pulmones $48 \mathrm{~h}$ tras la inducción inflamatoria, lo cual apoya los resultados observados al analizar el reclutamiento leucocitario. En riñón, se observa tanto en E-selectina como en VCAM-1 que, tras la isquemia, el aumento en la expresión es menor en los ratones sEng+. Dado que Eselectina está implicada principalmente en el rodamiento leucocitario, y VCAM-1 es fundamental durante todas las etapas previas a la diapédesis, la reducción de su 
expresión explicaría la menor infiltración leucocitaria que observamos en presencia de endoglina soluble. Esto confirmaría los resultados anteriores: la endoglina soluble, sólo tras estímulo inflamatorio, reduce el reclutamiento leucocitario.

Para corroborar los resultados obtenidos tras el estudio de la expresión de las moléculas de adhesión, se analizaron también los niveles de dichas moléculas en tejido.

\subsubsection{NIVELES DE LAS MOLÉCULAS DE ADHESIÓN}

Se analizó mediante la técnica de Western blot los niveles de proteína de las moléculas de adhesión VCAM-1 e ICAM-1 en el tejido pulmonar, en ratones control y tratados con LPS. Se utilizó calnexina como control de carga (Figura 75).

Los niveles de VCAM-1 en pulmón no muestran diferencias entre los WT y los sEng+ en condiciones control (Figura 75, A). Tras el tratamiento con LPS, los niveles aumentan significativamente, observándose que los pulmones sEng+ presentan menores niveles de VCAM-1 que los WT.

Los niveles de ICAM-1 en pulmón no muestran diferencias entre los ratones WT y los sEng+ en condiciones control (Figura 75, B). Tras el tratamiento con LPS, observamos un aumento en los niveles de ICAM-1 en los ratones WT, pero no en los sEng+. 

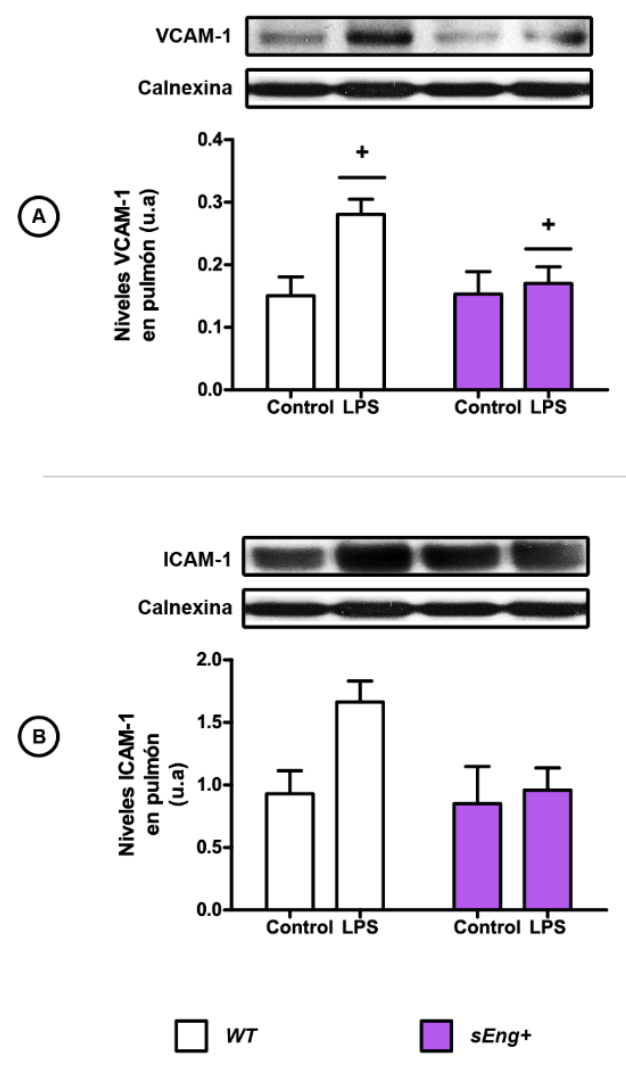

Figura 75. Análisis de los niveles de las VCAM-1 e ICAM-1 en ratones WT y sEng+. Análisis de los niveles de las VCAM-1 (A) e ICAM-1 (B) en el pulmón de ratones WT y sEng+, control y tratados con LPS, analizados por Western blot. Cada barra representa la media \pm EEM. WT $(n=5)$ y sEng+ $(n=5)$. Test estadístico ANOVA de doble vía: $(A)+p<0,05$ vs control.

El hecho de que los niveles de VCAM-1 e ICAM-1 sean menores en los ratones sEng+, indica que en presencia de endoglina soluble la transmigración leucocitaria es menor que en condiciones control, lo cual concuerda con los resultados obtenidos al analizar la expresión de las moléculas de adhesión: tras inducción inflamatoria, la presencia de endoglina soluble reduce en pulmón los niveles de las moléculas de adhesión. 
Según nuestros resultados, no se observan diferencias en condiciones fisiológicas a nivel de expresión y niveles de moléculas de adhesión causadas por la presencia de endoglina soluble circulante. Esto corrobora los resultados obtenidos por otros grupos, que muestran que elevados niveles de endoglina soluble en plasma no inducen diferencias por sí solos en la expresión de moléculas de adhesión como VCAM-1 e ICAM1 (Nemeckova et al, 2015, 2015; Jezkova et al, 2016).

Nuestros resultados también muestran que la endoglina soluble previene el aumento de expresión de moléculas de adhesión propio de la inducción inflamatoria. ICAM-1, VCAM1 y E-selectina son esenciales para la adhesión estable y la transmigración leucocitaria. De hecho, se ha demostrado que el bloqueo de ICAM-1 mediante anticuerpos inhibe la adhesión de los leucocitos al endotelio (Sans et al, 2001). La reducción en la expresión de las moléculas de adhesión puede conducir a una disminución en el número de leucocitos transmigrados, y una consecuente disminución de citoquinas inflamatorias en presencia de endoglina soluble.

El aumento de los espacios interendoteliales, típico de los procesos inflamatorios, se debe a la rotura de parte de las uniones adherentes entre células endoteliales, en las cuales, la molécula más importante es la VE-cadherina. Como consecuencia, aumenta la permeabilidad vascular $y$, en consecuencia, el edema. Este hecho, junto con los resultados anteriores, nos lleva a pensar que la endoglina soluble circulante podría prevenir el reclutamiento leucocitario, y con ello el consecuente aumento de la permeabilidad vascular que ocurre durante las enfermedades inflamatorias.

Se ha demostrado que el efecto de endoglina soluble en la respuesta inflamatoria es complejo. Jezckova et al., al estudiar la disfunción endotelial en aorta con arteoesclerosis, y combinar elevados niveles de endoglina soluble con dieta hipercalórica, concluyen que los ratones que presentan elevados niveles de endoglina soluble circulante en plasma presentan un aumento en la expresión de P-selectina y de ICAM-1, en comparación con ratones que sobreexpresan bajos niveles de endoglina soluble (Jezkova et al, 2016). Sin embargo, observan que endoglina soluble no tiene ningún efecto en la expresión de dichas moléculas de adhesión en condiciones fisiológicas, por 
lo que, según sus resultados, endoglina soluble sólo sería proinflamatoria bajo dieta hipercalórica (Jezkova et al, 2016). De hecho, observaron que los marcadores proinflamatorios son más altos en las aortas de ratones $s E n g+3$ meses después de la ingesta de una dieta alta en grasas en ratones hembra, pero no en ratones machos (Jezkova et al, 2016). Nuestro estudio difiere sustancialmente ya que inducimos una inflamación aguda bajo el efecto de la endoglina soluble circulante, mientras que en el estudio de Jezkova se analizan marcadores inflamatorios 3 meses después de la inducción, pudiendo haber otros procesos involucrados en la respuesta analizada a largo plazo. También se debe considerar que las diferencias en los marcadores inflamatorios atribuidos a la endoglina soluble aparecen solo en ratones hembra, lo que significa que los mecanismos involucrados en el proceso podrían estar relacionados con factores sexuales.

También se ha demostrado que la administración de endoglina soluble en células endoteliales humanas (HUVECs) da lugar a un aumento de expresión de IL6, aunque no observan efectos en las moléculas de adhesión: VCAM-1 e ICAM-1 (Varejckova et al, 2017). La endoglina soluble induce en condiciones hipercalóricas un aumento de NF-kB, el cual activa la expresión de distintas moléculas proinflamatorias, entre las que se encuentra IL6 (Libermann \& Baltimore, 1990). De hecho, a pesar de que el tratamiento con endoglina soluble induce un aumento en la expresión de IL6, no observan cambios en otras proteínas proinflamatorias reguladas por NF-kB, como eNOs, ICAM-1, VCAM-1, COX-1 y COX-2 (Varejckova et al, 2017). Esto sugiere que el tratamiento de endoglina soluble no induce por sí solo un estado proinflamatorio. Endoglina soluble solo tendría un efecto inflamatorio en colaboración con factores de riesgo cardiovascular.

Tanto la adhesión entre células como la adhesión de las células a la matriz extracelular tienen un rol fundamental en condiciones fisiológicas y en la patogénesis de afecciones que cursan con inflamación, como la metástasis, el rechazo de trasplantes, el daño por isquemia-reperfusión y las enfermedades autoinmunes (Yonekawa \& Harlan, 2005; Frenette \& Wagner, 1996a, 1996b). La terapia de antiadhesión se ha valorado en distintos modelos experimentales de enfermedades inflamatorias, entre las que se 
encuentra la esclerosis múltiple (Yonekawa \& Harlan, 2005) con distintos grados de éxito.

Se ha utilizado la terapia de antiadhesión en modelos de sepsis y shock séptico (Fisher et al, 1996) y de artritis reumatoide (Kohanzadeh et al, 2013), demostrándose que el bloqueo de TNF $\alpha$ disminuye el infiltrado leucocitario y la expresión de las moléculas de adhesión en el sinovio reumatoide, así como los niveles plasmáticos de ICAM-1 y VCAM-1 (Bradley, 2008; Paleolog, 1997).

El asma agudo cursa con un fenómeno inflamatorio de la pared bronquial, con una extensa infiltración eosinófila (Ezegbunam \& Foronjy, 2017). El bloqueo de las moléculas de adhesión ha demostrado reducir la infiltración inflamatoria a los bronquios e interrumpe la desgranulación eosinófila (Mukherjee et al, 2017). Sin embargo, el bloqueo de las moléculas de adhesión puede causar importantes efectos adversos, ya que son necesarias en condiciones fisiológicas (Mukherjee et al, 2017).

Nuestros resultados demuestran el impacto que endoglina soluble tiene en las moléculas de adhesión. Dado que en condiciones control la presencia de endoglina soluble circulante no altera la expresión de las moléculas de adhesión, mientras que tras inducción inflamatoria reduce su expresión, podría dar lugar a tratamientos menos agresivos que los que se basan en el bloqueo de las moléculas de adhesión.

Esto representa un punto de inflexión en la comprensión del papel de endoglina soluble en la fisiopatología de diversas enfermedades cardiovasculares. Los resultados obtenidos en este trabajo proporcionan una mejor interpretación de la base inflamatoria de estas enfermedades, y permiten abrir nuevas perspectivas que conduzcan al desarrollo de enfoques nuevos y dirigidos a la prevención y el tratamiento de enfermedades cardiovasculares. 
DISCUSIÓN GENERAL 
Se ha asociado a endoglina con distintas patologías, entre las que se encuentran la Telangiectasia Hemorrágica Hereditaria (HHT), cáncer, preeclampsia o hipertensión (Bernabeu et al, 2009; Shovlin, 2010; Kapur et al, 2012; Rana et al, 2012; Valbuena-Diez et al, 2012). A día de hoy, se sabe que tanto la expresión de endoglina de membrana, como la presencia de endoglina soluble está asociada con la inflamación.

Se han relacionado niveles elevados de endoglina de membrana con distintos procesos inflamatorios. La expresión de endoglina de membrana en células endoteliales aumenta en piel, hígado, intestino y pulmón durante procesos inflamatorios, siendo mayor la expresión en zonas de infiltrado inflamatorio y durante la cicatrización de heridas (Torsney et al, 2002). Además, endoglina aumenta su expresión en placas arteroescleróticas (Conley et al, 2000), en piel con soriasis (Rulo et al, 1995), en artritis reumatoide (Szekanecz et al, 1995), tras daño vascular (Ma et al, 2000), isquemia-reperfusión (Docherty et al, 2006; Jerkic et al, 2006), infarto de miocardio (van Laake et al, 2006) y cáncer (Bernabeu et al, 2009).

Diversos estudios proponen que la forma soluble de endoglina se encuentra en concentraciones elevadas en el plasma y orina de pacientes con distintas patologías que cursan con inflamación, entre las que se incluye el cáncer (Li et al, 2000; Takahashi et al, 2001; Calabrò et al, 2003; Fujita et al, 2009), la diabetes (Blázquez-Medela et al, 2010) y la preeclampsia (Sibai et al, 2005; Young et al, 2010). Sin embargo, no está claro el papel de la endoglina soluble en estas enfermedades, por lo que se hace necesario definir el papel de endoglina soluble en el proceso inflamatorio.

El hecho de que endoglina aumente su expresión en condiciones inflamatorias la convierte en una molécula de gran interés biomédico. A pesar de ser una proteína que se expresa de manera constitutiva en las células endoteliales, las cuales presentan un papel muy activo en la inflamación. Actualmente no hay estudios que analicen el papel de la endoglina en la respuesta inflamatoria.

De hecho, existen evidencias que sugieren un posible papel de endoglina en el proceso inflamatorio. Como hemos explicado, la endoglina se sobreexpresa en las células endoteliales de tejidos inflamados, los cuales presentan infiltración leucocitaria (Torsney 
et al, 2002). Además, los ratones haploinsuficientes de endoglina (Eng $\left.{ }^{+/-}\right)$muestran menos signos de daño tras la lesión debido a una reducción de la respuesta inflamatoria que ocurre durante la reperfusión (Docherty et al, 2006).

A pesar de que se ha demostrado que la endoglina está relacionada con la inflamación, según nuestros conocimientos no se ha estudiado nunca el papel de las distintas isoformas de endoglina en el proceso inflamatorio.

En este trabajo, hemos descrito por primera vez que las isoformas de endoglina de membrana (L-endoglina y S-endoglina), así como la endoglina soluble, tienen un papel en procesos clave de la respuesta inflamatoria como son el reclutamiento leucocitario, la expresión y niveles de citoquinas inflamatorias y moléculas de adhesión y la permeabilidad vascular.

Para llevar a cabo este estudio, se han diseñado y puesto a punto 3 modelos animales, en los cuales la inducción inflamatoria es de distinta naturaleza y afecta a distintos órganos: infección pulmonar por nebulización de LPS, abrasión en la piel por carragenina en air pouch e isquemia-reperfusión en el caso del riñón. Esto nos permite corroborar si el papel de las isoformas de endoglina es similar ante distintas inducciones inflamatorias y en distintas condiciones, aportando solidez a los resultados.

A la vista de nuestros resultados podemos observar, en primer lugar, que la presencia de elevadas cantidades de endoglina soluble circulante en plasma, así como la sobreexpresión de las isoformas de membrana L-endoglina y S-endoglina, no alteran la respuesta inflamatoria en condiciones fisiológicas, ni a nivel de reclutamiento leucocitario, citoquinas inflamatorias, permeabilidad vascular ni moléculas de adhesión. Estos resultados corroboran los obtenidos previamente por otros autores (Nemeckova et al, 2015; Varejckova et al, 2017; Jezkova et al, 2016; Oujo et al, 2014; Muñoz-Félix et al, 2016).

Por ello, la sobreexpresión de las distintas isoformas de endoglina solamente tendría un papel en la respuesta inflamatoria cuando se da tras inducción inflamatoria, mientras que no tendría efecto en condiciones fisiológicas. De hecho, Vareckova et al y Jezckova 
et al. concluyen que la presencia de elevadas cantidades de endoglina soluble circulante en plasma sólo tiene un papel en combinación con riesgos cardiovasculares, como dieta hipercalórica.

En este trabajo, además, hemos descrito por primera vez el papel de las distintas isoformas de endoglina en la permeabilidad vascular. A la vista de nuestros resultados, la sobreexpresión de las isoformas de endoglina no causa ningún efecto en la permeabilidad vascular en condiciones fisiológicas. Sin embargo, mientras que la sobreexpresión de las isoformas L-endoglina y S-endoglina no altera la permeabilidad vascular, la presencia de endoglina soluble circulante en plasma reduce significativamente la permeabilidad vascular, tanto in vivo como in vitro.

Esto pone de manifiesto, que la permeabilidad vascular se regula por el dominio extracelular de endoglina, ya que se observan diferencias en presencia de endoglina soluble (que es únicamente el dominio extracelular de endoglina circulante) mientras que no hay diferencias al comparar ratones que sobreexpresan L-endoglina y Sendoglina, que sólo se diferencian en su dominio intracelular.

Como se ha discutido anteriormente, mientras que los resultados obtenidos al analizar el papel de endoglina soluble en el reclutamiento leucocitario podrían corroborar la teoría de Rossi et al. de que la presencia de endoglina soluble dificulta la transmigración (Rossi et al, 2013), esta teoría no permite justificar por qué observamos una drástica disminución de la permeabilidad vascular en presencia de endoglina soluble, tanto in vivo como in vitro. Dicha teoría tampoco contempla un efecto del dominio intracelular de endoglina de membrana en el proceso inflamatorio, el cual queda demostrado a la vista de nuestros resultados.

Por ello, en su conjunto, este trabajo permite abrir dos vías de gran interés científico.

Por un lado, los resultados obtenidos nos permiten modificar el concepto que se tiene a día de hoy del papel de endoglina soluble en enfermedades inflamatorias como cáncer y preeclampsia. A la vista de nuestros resultados, endoglina soluble disminuye la 
respuesta inmune en condiciones inflamatorias, lo que supone un dilema en sí mismo: ¿Está endoglina soluble en patologías inflamatorias causando el aumento de la respuesta inflamatoria, o disminuyéndola? ¿Mediante qué mecanismos regula endoglina soluble el componente inflamatorio? Dado que nuestros resultados han permitido demostrar que endoglina soluble tiene un efecto en la inflamación, sería necesario realizar más investigaciones al respecto que nos permitieran esclarecer los mecanismos que intervienen.

Por otro lado, nuestros resultados demuestran que el dominio intracelular de endoglina de membrana tiene también un papel en la respuesta inflamatoria. Según nuestros resultados, podemos comprobar que los resultados obtenidos por por Muñóz-Félix et al en inflamación crónica y fibrosis se observan también tras inducción de inflamación aguda. Utilizando un modelo de fibrosis renal por obstrucción ureteral, observan que la sobreexpresión de S-endoglina reduce tanto la expresión de moléculas leucocitarias, como CD68, COX-2 e iNOS, como la expresión y niveles de moléculas de adhesión clave en la cascada inflamatoria: VCAM-1 e ICAM-1 (Muñoz-Félix et al, 2016). Observamos el mismo efecto de la reducción del reclutamiento leucocitario y expresión de ICAM-1 ante la sobreexpresión de S-endoglina, aunque no se detectan diferencias en cuanto a la expresión de VCAM-1.

Tras haber demostrado, por primera vez, que las distintas isoformas de endoglina regulan el proceso inflamatorio, se hacen necesarias futuras investigaciones que vislumbren los detalles de cómo se da esta regulación, qué mecanismos la llevan a cabo y qué posibilidades existen, con los conocimientos adquiridos, de situar a endoglina como una molécula diana en el tratamiento de enfermedades inflamatorias. 
CONCLUSIONES 
Basándonos en los resultados expuestos en este trabajo, hemos obtenido las siguientes conclusiones:

3. La presencia de elevados niveles de endoglina soluble humana en el plasma no altera, en condiciones fisiológicas, ni el reclutamiento leucocitario ni la permeabilidad vascular.

4. La presencia de elevados niveles de endoglina soluble humana en el plasma reduce significativamente el reclutamiento leucocitario tras tres estímulos inflamatorios de distinta naturaleza, en tres tejidos diferentes.

5. La presencia de elevados niveles de endoglina soluble humana en el plasma reduce significativamente la permeabilidad vascular inducida por estímulo inflamatorio. Por ello, el dominio extracelular de endoglina tiene un papel en el aumento de la permeabilidad vascular tras inducción inflamatoria.

6. La sobreexpresión de las isoformas de membrana: L-endoglina y S-endoglina, no alteran, en condiciones fisiológicas, ni el reclutamiento leucocitario ni la permeabilidad vascular.

7. La sobreexpresión de L-endoglina no altera el reclutamiento leucocitario mientras que la sobreexpresión de S-endoglina lo reduce significativamente tras tres estímulos inflamatorios de distinta naturaleza, en tres tejidos diferentes. Por ello, el dominio intracelular de endoglina de membrana tiene un papel en el reclutamiento leucocitario tras inducción inflamatoria.

8. La sobreexpresión de L-endoglina y S-endoglina no tienen ningún efecto en la permeabilidad vascular inducida por estímulo inflamatorio. Por ello, el dominio intracelular de endoglina de membrana no tiene un papel en la permeabilidad vascular. 
BIBLIOGRAFÍA

263 
Abbas AK \& Lichtman AH (2010) Basic Immunology: Functions and Disorders of the Immune System Saunders

Abraham E (2003) Neutrophils and acute lung injury. Crit. Care Med. 31: S195-199

Akagi K, Ikeda Y, Sumiyoshi Y, Kimura Y, Kinoshita J, Miyazaki M \& Abe T (2002) Estimation of angiogenesis with anti-CD105 immunostaining in the process of colorectal cancer development. Surgery 131: S109-113

Akdemir HU, Güzel A, Katı C, Duran L, Alaçam H, Gacar A, Güvenç T, Murat N \& Sişman B (2014) The evaluation of different treatment protocols for trauma-induced lung injury in rats. $J$. Thorac. Dis. 6: 66-73

Al-Gubory KH, Fowler PA \& Garrel C (2010) The roles of cellular reactive oxygen species, oxidative stress and antioxidants in pregnancy outcomes. Int. J. Biochem. Cell Biol. 42: 1634-1650

Alon R \& Shulman Z (2011) Chemokine triggered integrin activation and actin remodeling events guiding lymphocyte migration across vascular barriers. Exp. Cell Res. 317: 632-641

Alt A, Miguel-Romero L, Donderis J, Aristorena M, Blanco FJ, Round A, Rubio V, Bernabeu C \& Marina $A$ (2012) Structural and functional insights into endoglin ligand recognition and binding. PLoS One 7: e29948

Anderberg C, Cunha SI, Zhai Z, Cortez E, Pardali E, Johnson JR, Franco M, Paez-Ribes M, Cordiner R, Fuxe J, Johansson BR, Goumans MJ, Casanovas O, ten Dijke P, Arthur HM \& Pietras K (2013a) Deficiency for endoglin in tumor vasculature weakens the endothelial barrier to metastatic dissemination. J Exp Med 210: 563-579

Anderberg C, Cunha SI, Zhai Z, Cortez E, Pardali E, Johnson JR, Franco M, Páez-Ribes M, Cordiner R, Fuxe J, Johansson BR, Goumans M-J, Casanovas O, ten Dijke P, Arthur HM \& Pietras K (2013b) Deficiency for endoglin in tumor vasculature weakens the endothelial barrier to metastatic dissemination. J. Exp. Med. 210: 563-579

Anestakis D, Petanidis S, Kalyvas S, Nday CM, Tsave O, Kioseoglou E \& Salifoglou A (2015) Mechanisms and applications of interleukins in cancer immunotherapy. Int. J. Mol. Sci. 16: 1691-1710

Aristorena M, Blanco FJ, de Las Casas-Engel M, Ojeda-Fernandez L, Gallardo-Vara E, Corbi A, Botella LM \& Bernabeu C (2014a) Expression of endoglin isoforms in the myeloid lineage and their role during aging and macrophage polarization. J Cell Sci 127: 2723-2735

Aristorena M, Blanco FJ, de Las Casas-Engel M, Ojeda-Fernandez L, Gallardo-Vara E, Corbi A, Botella LM \& Bernabeu C (2014b) Expression of endoglin isoforms in the myeloid lineage and their role during aging and macrophage polarization. J. Cell Sci. 127: 2723-2735 
Armstrong L \& Millar AB (1997) Relative production of tumour necrosis factor alpha and interleukin 10 in adult respiratory distress syndrome. Thorax 52: 442-446

Armulik A, Genové G, Mäe M, Nisancioglu MH, Wallgard E, Niaudet C, He L, Norlin J, Lindblom P, Strittmatter K, Johansson BR \& Betsholtz C (2010) Pericytes regulate the blood-brain barrier. Nature 468: 557-561

Arthur HM, Ure J, Smith AJ, Renforth G, Wilson DI, Torsney E, Charlton R, Parums D V, Jowett T, Marchuk DA, Burn J \& Diamond AG (2000) Endoglin, an ancillary TGFbeta receptor, is required for extraembryonic angiogenesis and plays a key role in heart development. Dev Biol 217: 42-53

Assaad S, Kratzert WB, Shelley B, Friedman MB \& Perrino A (2017) Assessment of Pulmonary Edema: Principles and Practice. J. Cardiothorac. Vasc. Anesth.

Aye ILMH, Waddell BJ, Mark PJ \& Keelan JA (2012) Oxysterols exert proinflammatory effects in placental trophoblasts via TLR4-dependent, cholesterol-sensitive activation of NF-KB. Mol. Hum. Reprod. 18: 341-353

Baluk P, Hirata A, Thurston G, Fujiwara T, Neal CR, Michel CC \& McDonald DM (1997) Endothelial gaps: time course of formation and closure in inflamed venules of rats. Am. J. Physiol. 272: L155-170

Bamforth SD, Lightman S \& Greenwood J (1996) The effect of TNF-alpha and IL-6 on the permeability of the rat blood-retinal barrier in vivo. Acta Neuropathol. (Berl.) 91: 624-632

Barbara NP, Wrana JL \& Letarte M (1999) Endoglin is an accessory protein that interacts with the signaling receptor complex of multiple members of the transforming growth factor-beta superfamily. J. Biol. Chem. 274: 584-594

Barreiro O \& Sánchez-Madrid F (2009) Bases moleculares de las interacciones leucocito-endotelio durante la respuesta inflamatoria. Rev. Esp. Cardiol. 62: 552-562

Barreiro O, Zamai M, Yáñez-Mó M, Tejera E, López-Romero P, Monk PN, Gratton E, Caiolfa VR \& Sánchez-Madrid $\mathrm{F}$ (2008) Endothelial adhesion receptors are recruited to adherent leukocytes by inclusion in preformed tetraspanin nanoplatforms. J. Cell Biol. 183: 527-542

Baskurt OK, Yalcin O \& Meiselman HJ (2004) Hemorheology and vascular control mechanisms. Clin. Hemorheol. Microcirc. 30: 169-178

Bellon T, Corbi A, Lastres P, Cales C, Cebrian M, Vera S, Cheifetz S, Massague J, Letarte M \& Bernabeu $C$ (1993) Identification and expression of two forms of the human transforming growth factor-beta-binding protein endoglin with distinct cytoplasmic regions. Eur J Immuno/ 23: 2340-2345 
Bernabeu C, Lopez-Novoa JM \& Quintanilla M (2009) The emerging role of TGF-beta superfamily coreceptors in cancer. Biochim. Biophys. Acta 1792: 954-973

Bertolino P, Deckers M, Lebrin F \& ten Dijke P (2005) Transforming growth factor-beta signal transduction in angiogenesis and vascular disorders. Chest 128: 585S-590S

Bessman MJ, Lehman IR, Simms ES \& Kornberg A (1958) Enzymatic synthesis of deoxyribonucleic acid. II. General properties of the reaction. J. Biol. Chem. 233: 171-7

Bhatia M (2002) Novel Therapeutic Targets for Acute Pancreatitis and Associated Multiple Organ Dysfunction Syndrome. Curr. Drug Targets - Inflamm. Allergy 1: 343-351

Bhatia M, Brady M, Shokuhi S, Christmas S, Neoptolemos JP \& Slavin J (2000) Inflammatory mediators in acute pancreatitis. J. Pathol. 190: 117-125

Bhatia M \& Moochhala S (2004) Role of inflammatory mediators in the pathophysiology of acute respiratory distress syndrome. J. Pathol. 202: 145-156

Bhattacharyya S, Gill R, Chen ML, Zhang F, Linhardt RJ, Dudeja PK \& Tobacman JK (2008) Toll-like receptor 4 mediates induction of the Bcl10-NFkappaB-interleukin-8 inflammatory pathway by carrageenan in human intestinal epithelial cells. J. Biol. Chem. 283: 10550-10558

Blanco FJ, Grande MT, Langa C, Oujo B, Velasco S, Rodriguez-Barbero A, Perez-Gomez E, Quintanilla M, Lopez-Novoa JM \& Bernabeu C (2008) S-endoglin expression is induced in senescent endothelial cells and contributes to vascular pathology. Circ Res 103: 1383-1392

Blann AD, Wang JM, Wilson PB \& Kumar S (1996) Serum levels of the TGF-beta receptor are increased in atherosclerosis. Atherosclerosis 120: 221-226

Blázquez-Medela AM, García-Ortiz L, Gómez-Marcos MA, Recio-Rodríguez JI, Sánchez-Rodríguez A, López-Novoa JM \& Martínez-Salgado C (2010) Increased plasma soluble endoglin levels as an indicator of cardiovascular alterations in hypertensive and diabetic patients. BMCMed. 8: 86

Block H, Herter JM, Rossaint J, Stadtmann A, Kliche S, Lowell CA \& Zarbock A (2012) Crucial role of SLP-76 and ADAP for neutrophil recruitment in mouse kidney ischemia-reperfusion injury. J. Exp. Med. 209: 407-421

Bonventre JV \& Weinberg JM (2003) Recent advances in the pathophysiology of ischemic acute renal failure. J. Am. Soc. Nephrol. JASN 14: 2199-2210

Boros P \& Bromberg JS (2006) New cellular and molecular immune pathways in ischemia/reperfusion injury. Am. J. Transplant. Off. J. Am. Soc. Transplant. Am. Soc. Transpl. Surg. 6: 652-658 
Borthakur A, Bhattacharyya S, Dudeja PK \& Tobacman JK (2007) Carrageenan induces interleukin-8 production through distinct Bcl10 pathway in normal human colonic epithelial cells. Am. J. Physiol. Gastrointest. Liver Physiol. 292: G829-838

Borzychowski AM, Sargent IL \& Redman CWG (2006) Inflammation and pre-eclampsia. Semin. Fetal. Neonatal Med. 11: 309-316

Bradley JR (2008) TNF-mediated inflammatory disease. J. Pathol. 214: 149-160

Brewer CA, Setterdahl JJ, Li MJ, Johnston JM, Mann JL \& McAsey ME (2000) Endoglin expression as a measure of microvessel density in cervical cancer. Obstet. Gynecol. 96: 224-228

Buhring HJ, Muller CA, Letarte M, Gougos A, Saalmuller A, van Agthoven AJ \& Busch FW (1991) Endoglin is expressed on a subpopulation of immature erythroid cells of normal human bone marrow. Leukemia 5: 841-847

Cain D, Kondo M, Chen H \& Kelsoe G (2009) Effects of acute and chronic inflammation on B-cell development and differentiation. J. Invest. Dermatol. 129: 266-277

Calabrò L, Fonsatti E, Bellomo G, Alonci A, Colizzi F, Sigalotti L, Altomonte M, Musolino C \& Maio M (2003) Differential levels of soluble endoglin (CD105) in myeloid malignancies. J. Cell. Physiol. 194: 171-175

Carlin LM, Stamatiades EG, Auffray C, Hanna RN, Glover L, Vizcay-Barrena G, Hedrick CC, Cook HT, Diebold S \& Geissmann F (2013) Nr4a1-dependent Ly6C(low) monocytes monitor endothelial cells and orchestrate their disposal. Cell 153: 362-375

Carlos TM \& Harlan JM (1994) Leukocyte-endothelial adhesion molecules. Blood 84: 2068-2101

Carman CV, Sage PT, Sciuto TE, de la Fuente MA, Geha RS, Ochs HD, Dvorak HF, Dvorak AM \& Springer TA (2007) Transcellular diapedesis is initiated by invasive podosomes. Immunity 26: $784-797$

Carman CV \& Springer TA (2003) Integrin avidity regulation: are changes in affinity and conformation underemphasized? Curr. Opin. Cell Biol. 15: 547-556

Carman CV \& Springer TA (2004) A transmigratory cup in leukocyte diapedesis both through individual vascular endothelial cells and between them. J. Cell Biol. 167: 377-388

Castonguay R, Werner ED, Matthews RG, Presman E, Mulivor AW, Solban N, Sako D, Pearsall RS, Underwood KW, Seehra J, Kumar R \& Grinberg A V (2011) Soluble endoglin specifically binds bone morphogenetic proteins 9 and 10 via its orphan domain, inhibits blood vessel formation, and suppresses tumor growth. J Biol Chem 286: 30034-30046

CHANDRASOMA (2013) Concise Pathology 3/e EB McGraw Hill Professional 
Cheifetz S, Bellon T, Cales C, Vera S, Bernabeu C, Massague J \& Letarte M (1992) Endoglin is a component of the transforming growth factor-beta receptor system in human endothelial cells. J Biol Chem 267: 19027-19030

Chen LM, Liu B, Zhao HB, Stone P, Chen Q \& Chamley L (2010) IL-6, TNFalpha and TGFbeta promote nonapoptotic trophoblast deportation and subsequently causes endothelial cell activation. Placenta 31: 75-80

Chen S \& Springer TA (1999) An automatic braking system that stabilizes leukocyte rolling by an increase in selectin bond number with shear. J. Cell Biol. 144: 185-200

Chertow GM, Burdick E, Honour M, Bonventre JV \& Bates DW (2005) Acute kidney injury, mortality, length of stay, and costs in hospitalized patients. J. Am. Soc. Nephrol. JASN 16: 3365-3370

Cho S \& Atwood JE (2002) Peripheral edema. Am. J. Med. 113: 580-586

Cho SK, Bourdeau A, Letarte M \& Zúñiga-Pflücker JC (2001) Expression and function of CD105 during the onset of hematopoiesis from Flk1(+) precursors. Blood 98: 3635-3642

Cohen J (2002) The immunopathogenesis of sepsis. Nature 420: 885-891

Collins T, Read MA, Neish AS, Whitley MZ, Thanos D \& Maniatis T (1995) Transcriptional regulation of endothelial cell adhesion molecules: NF-kappa B and cytokine-inducible enhancers. FASEB J. Off. Publ. Fed. Am. Soc. Exp. Biol. 9: 899-909

Colville-Nash P \& Lawrence T (2003) Air-pouch models of inflammation and modifications for the study of granuloma-mediated cartilage degradation. Methods Mol. Biol. Clifton NJ 225: 181-189

Conley BA, Smith JD, Guerrero-Esteo M, Bernabeu C \& Vary CP (2000) Endoglin, a TGF-beta receptorassociated protein, is expressed by smooth muscle cells in human atherosclerotic plaques. Atherosclerosis 153: 323-335

Conrad KP, Miles TM \& Benyo DF (1998) Circulating levels of immunoreactive cytokines in women with preeclampsia. Am. J. Reprod. Immunol. N. Y. N 1989 40: 102-111

Cruz-Gonzalez I, Pabón P, Rodríguez-Barbero A, Martín-Moreiras J, Pericacho M, Sánchez PL, Ramirez $V$, Sánchez-Ledesma M, Martín-Herrero F, Jiménez-Candil J, Maree AO, Sánchez-Rodríguez A, Martín-Luengo C \& López-Novoa JM (2008) Identification of serum endoglin as a novel prognostic marker after acute myocardial infarction. J. Cell. Mol. Med. 12: 955-961

Cuzzocrea S, Sautebin L, De Sarro G, Costantino G, Rombolà L, Mazzon E, lalenti A, De Sarro A, Ciliberto G, Di Rosa M, Caputi AP \& Thiemermann C (1999) Role of IL-6 in the pleurisy and lung injury caused by carrageenan. J. Immunol. Baltim. Md 1950 163: 5094-5104 
Dağdeviren A, Müftüoğlu SF, Cakar AN \& Ors U (1998) Endoglin (CD 105) expression in human lymphoid organs and placenta. Ann. Anat. Anat. Anz. Off. Organ Anat. Ges. 180: 461-469

Day Y-J, Huang L, Ye H, Linden J \& Okusa MD (2005) Renal ischemia-reperfusion injury and adenosine 2A receptor-mediated tissue protection: role of macrophages. Am. J. Physiol. Renal Physiol. 288: F722-731

De Vivo A, Baviera G, Giordano D, Todarello G, Corrado F \& D'anna R (2008) Endoglin, PIGF and sFlt-1 as markers for predicting pre-eclampsia. Acta Obstet. Gynecol. Scand. 87: 837-842

Deem TL, Abdala-Valencia H \& Cook-Mills JM (2007) VCAM-1 activation of endothelial cell protein tyrosine phosphatase 1B. J. Immunol. Baltim. Md 1950 178: 3865-3873

Dejana E, Bazzoni G \& Lampugnani MG (1999) Vascular endothelial (VE)-cadherin: only an intercellular glue? Exp. Cell Res. 252: 13-19

Devarajan P (2006) Update on mechanisms of ischemic acute kidney injury. J. Am. Soc. Nephrol. JASN 17: $1503-1520$

Diakos Cl, Charles KA, McMillan DC \& Clarke SJ (2014) Cancer-related inflammation and treatment effectiveness. Lancet Oncol. 15: e493-503

Diez-Marques L, Ortega-Velazquez R, Langa C, Rodriguez-Barbero A, Lopez-Novoa JM, Lamas S \& Bernabeu C (2002) Expression of endoglin in human mesangial cells: modulation of extracellular matrix synthesis. Biochim Biophys Acta 1587: 36-44

ten Dijke P \& Arthur HM (2007) Extracellular control of TGFbeta signalling in vascular development and disease. Nat. Rev. Mol. Cell Biol. 8: 857-869

Djurovic S, Clausen T, Wergeland R, Brosstad F, Berg K \& Henriksen T (2002) Absence of enhanced systemic inflammatory response at 18 weeks of gestation in women with subsequent preeclampsia. BJOG Int. J. Obstet. Gynaecol. 109: 759-764

Docherty NG, López-Novoa JM, Arevalo M, Düwel A, Rodriguez-Peña A, Pérez-Barriocanal F, Bernabeu C \& Eleno N (2006) Endoglin regulates renal ischaemia-reperfusion injury. Nephrol. Dial. Transplant. Off. Publ. Eur. Dial. Transpl. Assoc. - Eur. Ren. Assoc. 21: 21062119

Dupuis-Girod S, Giraud S, Decullier E, Lesca G, Cottin V, Faure F, Merrot O, Saurin J-C, Cordier J-F \& Plauchu $\mathrm{H}$ (2007) Hemorrhagic hereditary telangiectasia (Rendu-Osler disease) and infectious diseases: an underestimated association. Clin. Infect. Dis. Off. Publ. Infect. Dis. Soc. Am. 44: 841-845

Duranteau J, Chandel NS, Kulisz A, Shao Z \& Schumacker PT (1998) Intracellular signaling by reactive oxygen species during hypoxia in cardiomyocytes. J. Biol. Chem. 273: 11619-11624 
Duwel A, Eleno N, Jerkic M, Arevalo M, Bolanos JP, Bernabeu C \& Lopez-Novoa JM (2007) Reduced tumor growth and angiogenesis in endoglin-haploinsufficient mice. Tumour Biol 28: 1-8

Eastwood J-A, Taylor DA, Johnson BD, Resende M, Sharaf BL, Ahmed B, Minissian M, Shufelt C \& Merz NB (2017) Premature atherosclerosis in premenopausal women: Does cytokine balance play a role? Med. Hypotheses 109: 38-41

Egawa G, Nakamizo S, Natsuaki Y, Doi H, Miyachi Y \& Kabashima K (2013) Intravital analysis of vascular permeability in mice using two-photon microscopy. Sci. Rep. 3: 1932

Engelhardt B \& Ransohoff RM (2012) Capture, crawl, cross: the T cell code to breach the blood-brain barriers. Trends Immunol. 33: 579-589

Engvall E \& Perlmann P (1971) Enzyme-linked immunosorbent assay (ELISA). Quantitative assay of immunoglobulin G. Immunochemistry 8: 871-874

Estakhr J, Sanchooli N, Najafi S \& Javdan N (2011) Anti-inflammatory activity of ethanolic extract of Physalis alkekengi. Res. J. Pharm. Biol. Chem. Sci. 2: 421-425

Ezegbunam W \& Foronjy R (2017) Posttranscriptional control of airway inflammation. Wiley Interdiscip. Rev. RNA

Fadok VA, Bratton DL, Konowal A, Freed PW, Westcott JY \& Henson PM (1998) Macrophages that have ingested apoptotic cells in vitro inhibit proinflammatory cytokine production through autocrine/paracrine mechanisms involving TGF-beta, PGE2, and PAF. J. Clin. Invest. 101: 890-898

Ferrara N (2005) VEGF as a therapeutic target in cancer. Oncology 69 Suppl 3: 11-16

Fiorentino DF, Zlotnik A, Mosmann TR, Howard M \& O'Garra A (1991) IL-10 inhibits cytokine production by activated macrophages. J. Immunol. Baltim. Md 1950 147: 3815-3822

Fisher CJ, Agosti JM, Opal SM, Lowry SF, Balk RA, Sadoff JC, Abraham E, Schein RM \& Benjamin E (1996) Treatment of septic shock with the tumor necrosis factor receptor:Fc fusion protein. The Soluble TNF Receptor Sepsis Study Group. N. Engl. J. Med. 334: 1697-1702

Frank PG \& Lisanti MP (2008) ICAM-1: role in inflammation and in the regulation of vascular permeability. Am. J. Physiol. - Heart Circ. Physiol. 295: H926-H927

Frenette PS \& Wagner DD (1996a) Adhesion molecules--Part 1. N. Engl. J. Med. 334: 1526-1529

Frenette PS \& Wagner DD (1996b) Adhesion molecules--Part II: Blood vessels and blood cells. N. Engl. J. Med. 335: 43-45

Friedewald JJ \& Rabb H (2004) Inflammatory cells in ischemic acute renal failure. Kidney Int. 66: 486491 
Fujita K, Ewing CM, Chan DYS, Mangold LA, Partin AW, Isaacs WB \& Pavlovich CP (2009) Endoglin (CD105) as a urinary and serum marker of prostate cancer. Int. J. Cancer 124: 664-669

Fukuhra S, Sakurai A, Yamagishi A, Sako K \& Mochizuki N (2006) Vascular endothelial cadherinmediated cell-cell adhesion regulated by a small GTPase, Rap1. J. Biochem. Mol. Biol. 39: 132-139

Galanos C, Freudenberg MA, Jay F, Nerkar D, Veleva K, Brade H \& Strittmatter W (1984) Immunogenic properties of lipid A. Rev. Infect. Dis. 6: 546-552

Galkina E \& Ley K (2007) Vascular adhesion molecules in atherosclerosis. Arterioscler. Thromb. Vasc. Biol. 27: 2292-2301

Gallagher S, Winston SE, Fuller SA \& Hurrell JGR (2004) Immunoblotting and immunodetection. Curr. Protoc. Mol. Biol. Ed. Frederick M Ausubel A/ Chapter 10: Unit 10.8

Gavard J (2013) Endothelial permeability and VE-cadherin: a wacky comradeship. Cell Adhes. Migr. 7: 455-461

Gavard J \& Gutkind JS (2006) VEGF controls endothelial-cell permeability by promoting the betaarrestin-dependent endocytosis of VE-cadherin. Nat. Cell Biol. 8: 1223-1234

Görlach A \& Bonello S (2008) The cross-talk between NF-kappaB and HIF-1: further evidence for a significant liaison. Biochem. J. 412: e17-19

Gougos A \& Letarte M (1990) Primary structure of endoglin, an RGD-containing glycoprotein of human endothelial cells. J Biol Chem 265: 8361-8364

Gougos A, St Jacques S, Greaves A, O'Connell PJ, d'Apice AJ, Buhring HJ, Bernabeu C, van Mourik JA \& Letarte M (1992) Identification of distinct epitopes of endoglin, an RGD-containing glycoprotein of endothelial cells, leukemic cells, and syncytiotrophoblasts. Int Immunol 4: 83-92

Goumans M-J, Valdimarsdottir G, Itoh S, Rosendahl A, Sideras P \& ten Dijke P (2002) Balancing the activation state of the endothelium via two distinct TGF-beta type I receptors. EMBO J. 21: 1743-1753

Govani FS \& Shovlin CL (2009) Hereditary haemorrhagic telangiectasia: a clinical and scientific review. Eur. J. Hum. Genet. EJHG 17: 860-871

Greer IA, Lyall F, Perera T, Boswell F \& Macara LM (1994) Increased concentrations of cytokines interleukin-6 and interleukin-1 receptor antagonist in plasma of women with preeclampsia: a mechanism for endothelial dysfunction? Obstet. Gynecol. 84: 937-940 
Guerrero-Esteo M, Sanchez-Elsner T, Letamendia A \& Bernabeu C (2002) Extracellular and cytoplasmic domains of endoglin interact with the transforming growth factor-beta receptors I and II. J Biol Chem 277: 29197-29209

Guo Z, Li Q, Han Y, Liang Y, Xu Z \& Ren T (2012) Prevention of LPS-induced acute lung injury in mice by progranulin. Mediators Inflamm. 2012: 540794

Harmon AC, Cornelius DC, Amaral LM, Faulkner JL, Cunningham MW, Wallace K \& LaMarca B (2016) The role of inflammation in the pathology of preeclampsia. Clin. Sci. Lond. Engl. 1979 130: 409-419

Hawinkels LAC, Kuiper P, Wiercinska E, Verspaget HW, Liu Z, Pardali E, Sier CFM \& ten Dijke P (2010) Matrix metalloproteinase-14 (MT1-MMP)-mediated endoglin shedding inhibits tumor angiogenesis. Cancer Res. 70: 4141-4150

Hayakawa S, Fujikawa T, Fukuoka H, Chisima F, Karasaki-Suzuki M, Ohkoshi E, Ohi H, Kiyoshi Fuji T, Tochigi M, Satoh K, Shimizu T, Nishinarita S, Nemoto N \& Sakurai I (2000) Murine fetal resorption and experimental pre-eclampsia are induced by both excessive Th1 and Th2 activation. J. Reprod. Immunol. 47: 121-138

Hebda JK, Leclair HM, Azzi S, Roussel C, Scott MG, Bidère N \& Gavard J (2013) The C-terminus region of $\beta$-arrestin1 modulates VE-cadherin expression and endothelial cell permeability. Cell Commun. Signal. CCS 11: 37

Hennessy A, Pilmore HL, Simmons LA \& Painter DM (1999) A deficiency of placental IL-10 in preeclampsia. J. Immunol. Baltim. Md 1950 163: 3491-3495

Hensley K, Robinson KA, Gabbita SP, Salsman S \& Floyd RA (2000) Reactive oxygen species, cell signaling, and cell injury. Free Radic. Biol. Med. 28: 1456-1462

Herter J \& Zarbock A (2013) Integrin Regulation during Leukocyte Recruitment. J. Immunol. Baltim. Md 1950 190: 4451-4457

Heupel W-M, Efthymiadis A, Schlegel N, Müller T, Baumer Y, Baumgartner W, Drenckhahn D \& Waschke J (2009) Endothelial barrier stabilization by a cyclic tandem peptide targeting VEcadherin transinteraction in vitro and in vivo. J. Cell Sci. 122: 1616-1625

Hofmann S, Grasberger H, Jung P, Bidlingmaier M, Vlotides J, Janssen OE \& Landgraf R (2002) The tumour necrosis factor-alpha induced vascular permeability is associated with a reduction of VE-cadherin expression. Eur. J. Med. Res. 7: 171-176

Hordijk PL (2006) Endothelial signalling events during leukocyte transmigration. FEBS J. 273: 44084415

Hotamisligil GS, Shargill NS \& Spiegelman BM (1993) Adipose expression of tumor necrosis factoralpha: direct role in obesity-linked insulin resistance. Science 259: 87-91 
Hu Y, Kiely JM, Szente BE, Rosenzweig A \& Gimbrone MA (2000) E-selectin-dependent signaling via the mitogen-activated protein kinase pathway in vascular endothelial cells. J. Immunol. Baltim. Md 1950 165: 2142-2148

Huang AJ, Manning JE, Bandak TM, Ratau MC, Hanser KR \& Silverstein SC (1993) Endothelial cell cytosolic free calcium regulates neutrophil migration across monolayers of endothelial cells. J. Cell Biol. 120: 1371-1380

Hyun Y-M, Sumagin R, Sarangi PP, Lomakina E, Overstreet MG, Baker CM, Fowell DJ, Waugh RE, Sarelius IH \& Kim M (2012) Uropod elongation is a common final step in leukocyte extravasation through inflamed vessels. J. Exp. Med. 209: 1349-1362

Imhof BA \& Aurrand-Lions M (2006) Angiogenesis and inflammation face off. Nat. Med. 12: 171-172

Jang HR \& Rabb H (2009) The innate immune response in ischemic acute kidney injury. Clin. Immunol. Orlando Fla 130: 41-50

Jang Y-S \& Choi I-H (2014) Contrasting roles of different endoglin forms in atherosclerosis. Immune Netw. 14: 237-240

Jerkic M \& Letarte M (2015) Increased endothelial cell permeability in endoglin-deficient cells. FASEB J 29: $3678-3688$

Jerkic M, Peter M, Ardelean D, Fine M, Konerding MA \& Letarte M (2010) Dextran sulfate sodium leads to chronic colitis and pathological angiogenesis in Endoglin heterozygous mice. Inflamm Bowel Dis 16: 1859-1870

Jerkic M, Rodríguez-Barbero A, Prieto M, Toporsian M, Pericacho M, Rivas-Elena JV, Obreo J, Wang A, Pérez-Barriocanal F, Arévalo M, Bernabéu C, Letarte M \& López-Novoa JM (2006) Reduced angiogenic responses in adult Endoglin heterozygous mice. Cardiovasc. Res. 69: 845-854

Jezkova K, Rathouska J, Nemeckova I, Fikrova P, Dolezelova E, Varejckova M, Vitverova B, Tysonova K, Serwadczak A, Buczek E, Bernabeu C, Lopez-Novoa JM, Chlopicki S \& Nachtigal P (2016) High Levels of Soluble Endoglin Induce a Proinflammatory and Oxidative-Stress Phenotype Associated with Preserved NO-Dependent Vasodilatation in Aortas from Mice Fed a HighFat Diet. J. Vasc. Res. 53: 149-162

Jones SA, Richards PJ, Scheller J \& Rose-John S (2005) IL-6 transsignaling: the in vivo consequences. J. Interferon Cytokine Res. Off. J. Int. Soc. Interferon Cytokine Res. 25: 241-253

Jonker L \& Arthur HM (2002) Endoglin expression in early development is associated with vasculogenesis and angiogenesis. Mech. Dev. 110: 193-196

Jovine L, Darie CC, Litscher ES \& Wassarman PM (2005) Zona pellucida domain proteins. Annu Rev Biochem 74: 83-114 
Kabir K, Gelinas J-P, Chen M, Chen D, Zhang D, Luo X, Yang J-H, Carter D \& Rabinovici R (2002) Characterization of a murine model of endotoxin-induced acute lung injury. Shock Augusta Ga 17: 300-303

Kacian DL \& Myers JC (1976) Synthesis of extensive, possibly complete, DNA copies of poliovirus RNA in high yields and at high specific activities. Proc Natl Acad Sci USA 73: 2191-2195

Kaitu'u-Lino TJ, Palmer KR, Whitehead CL, Williams E, Lappas M \& Tong S (2012) MMP-14 is expressed in preeclamptic placentas and mediates release of soluble endoglin. $\mathrm{Am}$. J. Pathol. 180: 888-894

Kapur NK, Wilson S, Yunis AA, Qiao X, Mackey E, Paruchuri V, Baker C, Aronovitz MJ, Karumanchi SA, Letarte M, Kass DA, Mendelsohn ME \& Karas RH (2012) Reduced endoglin activity limits cardiac fibrosis and improves survival in heart failure. Circulation 125: 2728-2738

Kasama T, Strieter RM, Lukacs NW, Burdick MD \& Kunkel SL (1994) Regulation of neutrophil-derived chemokine expression by IL-10. J. Immunol. Baltim. Md 1950 152: 3559-3569

Kassouf W, Ismail HRA, Aprikian AG \& Chevalier S (2004) Whole-mount prostate sections reveal differential endoglin expression in stromal, epithelial, and endothelial cells with the development of prostate cancer. Prostate Cancer Prostatic Dis. 7: 105-110

Katagiri K, Imamura M \& Kinashi T (2006) Spatiotemporal regulation of the kinase Mst1 by binding protein RAPL is critical for lymphocyte polarity and adhesion. Nat. Immunol. 7: 919-928

Kellum JA (2008) Acute kidney injury. Crit. Care Med. 36: S141-145

Khong TY, De Wolf F, Robertson WB \& Brosens I (1986) Inadequate maternal vascular response to placentation in pregnancies complicated by pre-eclampsia and by small-for-gestational age infants. Br. J. Obstet. Gynaecol. 93: 1049-1059

Kielar ML, John R, Bennett M, Richardson JA, Shelton JM, Chen L, Jeyarajah DR, Zhou XJ, Zhou H, Chiquett B, Nagami GT \& Lu CY (2005) Maladaptive role of IL-6 in ischemic acute renal failure. J. Am. Soc. Nephrol. JASN 16: 3315-3325

Knapp S (2009) LPS and bacterial lung inflammation models. Drug Discov. Today Dis. Models 6: 113118

Kobayashi H, Boelte KC \& Lin PC (2007) Endothelial cell adhesion molecules and cancer progression. Curr. Med. Chem. 14: 377-386

Kohanzadeh S, Lugo L \& Long JN (2013) Safety of antiadhesion barriers in hand surgery. Ann. Plast. Surg. 70: $527-529$ 
Koleva RI, Conley BA, Romero D, Riley KS, Marto JA, Lux A \& Vary CP (2006) Endoglin structure and function: Determinants of endoglin phosphorylation by transforming growth factor-beta receptors. J Biol Chem 281: 25110-25123

Kribben A, Herget-Rosenthal S, Pietruck F \& Philipp T (2003) [Acute renal failure--an review]. Dtsch. Med. Wochenschr. 1946 128: 1231-1236

Kyzas PA, Agnantis NJ \& Stefanou D (2006) Endoglin (CD105) as a prognostic factor in head and neck squamous cell carcinoma. Virchows Arch. Int. J. Pathol. 448: 768-775

van Laake LW, van den Driesche S, Post S, Feijen A, Jansen MA, Driessens MH, Mager JJ, Snijder RJ, Westermann CJJ, Doevendans PA, van Echteld CJA, ten Dijke P, Arthur HM, Goumans M-J, Lebrin F \& Mummery CL (2006) Endoglin has a crucial role in blood cell-mediated vascular repair. Circulation 114: 2288-2297

Laemmli UK (1970) Cleavage of structural proteins during the assembly of the head of bacteriophage T4. Nature 227: 680-685

Lain KY \& Roberts JM (2002) Contemporary concepts of the pathogenesis and management of preeclampsia. JAMA 287: 3183-3186

Lameire N, Van Biesen W \& Vanholder R (2005) Acute renal failure. Lancet Lond. Engl. 365: 417-430

Lanitis E, Irving M \& Coukos G (2015) Targeting the tumor vasculature to enhance T cell activity. Curr. Opin. Immunol. 33: 55-63

Lastres P, Bellon T, Cabanas C, Sanchez-Madrid F, Acevedo A, Gougos A, Letarte M \& Bernabeu C (1992) Regulated expression on human macrophages of endoglin, an Arg-Gly-Aspcontaining surface antigen. Eur J Immunol 22: 393-397

Lastres P, Martin-Perez J, Langa C \& Bernabeu C (1994) Phosphorylation of the human-transforminggrowth-factor-beta-binding protein endoglin. Biochem J 301: 765-768

Lebrin F, Deckers M, Bertolino P \& Ten Dijke P (2005) TGF-beta receptor function in the endothelium. Cardiovasc. Res. 65: 599-608

Lee N, Dolores M, Conway A \& Cheng C (2004) Zyxin, axin, and Wiskott-Aldrich syndrome protein are adaptors that link the cadherin/catenin protein complex to the cytoskeleton at adherens junctions in the seminiferous epithelium of the rat testis. J. Androl. 25: 200-215

Lee S, Chen TT, Barber CL, Jordan MC, Murdock J, Desai S, Ferrara N, Nagy A, Roos KP \& Iruela-Arispe $\mathrm{ML}$ (2007) Autocrine VEGF signaling is required for vascular homeostasis. Cell 130: 691-703

Lehr HA, Menger MD \& Messmer K (1993) Impact of leukocyte adhesion on myocardial ischemia/reperfusion injury: conceivable mechanisms and proven facts. J. Lab. Clin. Med. 121: 539-545 
Leser HG, Gross V, Scheibenbogen C, Heinisch A, Salm R, Lausen M, Rückauer K, Andreesen R, Farthmann EH \& Schölmerich J (1991) Elevation of serum interleukin-6 concentration precedes acute-phase response and reflects severity in acute pancreatitis.

Gastroenterology 101: 782-785

Levine RJ, Lam C, Qian C, Yu KF, Maynard SE, Sachs BP, Sibai BM, Epstein FH, Romero R, Thadhani R, Karumanchi SA \& CPEP Study Group (2006) Soluble endoglin and other circulating antiangiogenic factors in preeclampsia. N. Engl. J. Med. 355: 992-1005

Ley K, Laudanna C, Cybulsky MI \& Nourshargh S (2007) Getting to the site of inflammation: the leukocyte adhesion cascade updated. Nat. Rev. Immunol. 7: 678-689

Ley K \& Reutershan J (2006) Leucocyte-endothelial interactions in health and disease. Handb. Exp. Pharmacol.: 97-133

Li C, Guo B, Bernabeu C \& Kumar S (2001) Angiogenesis in breast cancer: the role of transforming growth factor beta and CD105. Microsc. Res. Tech. 52: 437-449

Li C, Guo B, Wilson PB, Stewart A, Byrne G, Bundred N \& Kumar S (2000) Plasma levels of soluble CD105 correlate with metastasis in patients with breast cancer. Int. J. Cancer 89: 122-126

Libermann TA \& Baltimore D (1990) Activation of interleukin-6 gene expression through the NFkappa B transcription factor. Mol. Cell. Biol. 10: 2327-2334

Lim JH, Kim SY, Park SY, Yang JH, Kim MY \& Ryu HM (2008) Effective prediction of preeclampsia by a combined ratio of angiogenesis-related factors. Obstet. Gynecol. 111: 1403-1409

Llorca O, Trujillo A, Blanco FJ \& Bernabeu C (2007) Structural model of human endoglin, a transmembrane receptor responsible for hereditary hemorrhagic telangiectasia. J Mol Biol 365: 694-705

Lo CJ, Fu M \& Cryer HG (1998) Interleukin 10 inhibits alveolar macrophage production of inflammatory mediators involved in adult respiratory distress syndrome. J. Surg. Res. 79: 179-184

López-Casillas F, Payne HM, Andres JL \& Massagué J (1994) Betaglycan can act as a dual modulator of TGF-beta access to signaling receptors: mapping of ligand binding and GAG attachment sites. J. Cell Biol. 124: 557-68

López-Novoa JM (2007) Soluble endoglin is an accurate predictor and a pathogenic molecule in preeclampsia. Nephrol. Dial. Transplant. Off. Publ. Eur. Dial. Transpl. Assoc. - Eur. Ren. Assoc.

22: $712-714$

López-Novoa JM \& Bernabeu C (2010) The physiological role of endoglin in the cardiovascular system. Am. J. Physiol. Heart Circ. Physiol. 299: H959-974 
Lowry OH, Rosebrough NJ, Farr L \& Randall R (1951) Protein measurement with the folin phenol reagent. J Biol Chem 193: 265-275

Lundberg AH, Granger DN, Russell J, Sabek O, Henry J, Gaber L, Kotb M \& Gaber AO (2000) Quantitative measurement of $\mathrm{P}$ - and E-selectin adhesion molecules in acute pancreatitis: correlation with distant organ injury. Ann. Surg. 231: 213-222

Lyall F (2007) Pre-eclampsia: Etiology and Clinical Practice Cambridge University Press

Ma X, Labinaz M, Goldstein J, Miller H, Keon WJ, Letarte M \& O'Brien E (2000) Endoglin is overexpressed after arterial injury and is required for transforming growth factor-betainduced inhibition of smooth muscle cell migration. Arterioscler. Thromb. Vasc. Biol. 20: 2546-2552

Maedler K, Sergeev P, Ris F, Oberholzer J, Joller-Jemelka HI, Spinas GA, Kaiser N, Halban PA \& Donath MY (2002) Glucose-induced beta cell production of IL-1beta contributes to glucotoxicity in human pancreatic islets. J. Clin. Invest. 110: 851-860

Mahmoud M, Borthwick GM, Hislop AA \& Arthur HM (2009) Endoglin and activin receptor-like-kinase 1 are co-expressed in the distal vessels of the lung: implications for two familial vascular dysplasias, HHT and PAH. Lab Invest 89: 15-25

Malek M \& Nematbakhsh M (2015) Renal ischemia/reperfusion injury; from pathophysiology to treatment. J. Ren. Inj. Prev. 4: 20-27

Mamdouh Z, Chen X, Pierini LM, Maxfield FR \& Muller WA (2003) Targeted recycling of PECAM from endothelial surface-connected compartments during diapedesis. Nature 421: 748-753

Marelli G, Sica A, Vannucci L \& Allavena P (2017) Inflammation as target in cancer therapy. Curr. Opin. Pharmacol. 35: 57-65

Martinelli R, Gegg M, Longbottom R, Adamson P, Turowski P \& Greenwood J (2009) ICAM-1mediated Endothelial Nitric Oxide Synthase Activation via Calcium and AMP-activated Protein Kinase Is Required for Transendothelial Lymphocyte Migration. Mol. Biol. Cell 20: 995-1005

Massagué J (1998) TGF-beta signal transduction. Annu. Rev. Biochem. 67: 753-791

Massagué J (2000) How cells read TGF-beta signals. Nat. Rev. Mol. Cell Biol. 1: 169-178

Mathis S, Dupuis-Girod S, Plauchu H, Giroud M, Barroso B, Ly KH, Ingrand P, Gilbert B, Godenèche G \& Neau J-P (2012) Cerebral abscesses in hereditary haemorrhagic telangiectasia: a clinical and microbiological evaluation. Clin. Neurol. Neurosurg. 114: 235-240

Matute-Bello G, Frevert CW \& Martin TR (2008) Animal models of acute lung injury. Am. J. Physiol. Lung Cell. Mol. Physiol. 295: L379-399 
Maynard SE, Moore Simas TA, Bur L, Crawford SL, Solitro MJ \& Meyer BA (2010) Soluble endoglin for the prediction of preeclampsia in a high risk cohort. Hypertens. Pregnancy 29: 330-341

McAllister KA, Grogg KM, Johnson DW, Gallione CJ, Baldwin MA, Jackson CE, Helmbold EA, Markel DS, McKinnon WC \& Murrell J (1994) Endoglin, a TGF-beta binding protein of endothelial cells, is the gene for hereditary haemorrhagic telangiectasia type 1. Nat. Genet. 8: 345-351

McDonald B, Pittman K, Menezes GB, Hirota SA, Slaba I, Waterhouse CCM, Beck PL, Muruve DA \& Kubes $P$ (2010) Intravascular danger signals guide neutrophils to sites of sterile inflammation. Science 330: 362-366

McDonald DM (1994) Endothelial gaps and permeability of venules in rat tracheas exposed to inflammatory stimuli. Am. J. Physiol. 266: L61-83

Medzhitov R (2008) Origin and physiological roles of inflammation. Nature 454: 428-435

Mehta D \& Malik AB (2006) Signaling mechanisms regulating endothelial permeability. Physiol. Rev. 86: $279-367$

Meininger GA \& Davis MJ (1992) Cellular mechanisms involved in the vascular myogenic response. Am. J. Physiol. 263: H647-659

Meurer SK, Tihaa L, Lahme B, Gressner AM \& Weiskirchen R (2005) Identification of endoglin in rat hepatic stellate cells: new insights into transforming growth factor beta receptor signaling. J Biol Chem 280: 3078-3087

Millán J, Hewlett L, Glyn M, Toomre D, Clark P \& Ridley AJ (2006) Lymphocyte transcellular migration occurs through recruitment of endothelial ICAM-1 to caveola- and F-actin-rich domains. Nat. Cell Biol. 8: 113-123

Miller DW, Graulich W, Karges B, Stahl S, Ernst M, Ramaswamy A, Sedlacek HH, Müller R \& Adamkiewicz J (1999) Elevated expression of endoglin, a component of the TGF-betareceptor complex, correlates with proliferation of tumor endothelial cells. Int. J. Cancer 81: $568-572$

Mizgerd JP (2006) Lung infection--a public health priority. PLoS Med. 3: e76

Mizgerd JP (2008) Acute Lower Respiratory Tract Infection. N. Engl. J. Med. 358: 716-727

Mukherjee M, Bulir DC, Radford K, Kjarsgaard M, Huang CM, Jacobsen EA, Ochkur SI, Catuneanu A, Lamothe-Kipnes H, Mahony J, Lee JJ, Lacy P \& Nair PK (2017) Sputum autoantibodies in patients with severe eosinophilic asthma. J. Allergy Clin. Immunol.

Muller WA (2011) Mechanisms of Leukocyte Transendothelial Migration. Annu. Rev. Pathol. 6: 323344 
Muller WA (2015) The regulation of transendothelial migration: new knowledge and new questions. Cardiovasc. Res. 107: 310-320

Muñoz-Félix JM, Pérez-Roque L, Núñez-Gómez E, Oujo B, Arévalo M, Ruiz-Remolina L, Cuesta C, Langa C, Pérez-Barriocanal F, Bernabeu C \& Lopez-Novoa JM (2016) Overexpression of the short endoglin isoform reduces renal fibrosis and inflammation after unilateral ureteral obstruction. Biochim. Biophys. Acta 1862: 1801-1814

Nachtigal P, Zemankova Vecerova L, Rathouska J \& Strasky Z (2012) The role of endoglin in atherosclerosis. Atherosclerosis 224: 4-11

Nagy JA, Benjamin L, Zeng H, Dvorak AM \& Dvorak HF (2008) Vascular permeability, vascular hyperpermeability and angiogenesis. Angiogenesis 11: 109-119

Nakagawara A, DeSantis NM, Nogueira N \& Nathan CF (1982) Lymphokines enhance the capacity of human monocytes to secret reactive oxygen intermediates. J. Clin. Invest. 70: 1042-1048

Nemeckova I, Serwadczak A, Oujo B, Jezkova K, Rathouska J, Fikrova P, Varejckova M, Bernabeu C, Lopez-Novoa JM, Chlopicki S \& Nachtigal P (2015) High soluble endoglin levels do not induce endothelial dysfunction in mouse aorta. PloS One 10: e0119665

Nijsten MW, Hack CE, Helle M, ten Duis HJ, Klasen HJ \& Aarden LA (1991) Interleukin-6 and its relation to the humoral immune response and clinical parameters in burned patients. Surgery 109: 761-767

Nonas S, Miller I, Kawkitinarong K, Chatchavalvanich S, Gorshkova I, Bochkov VN, Leitinger N, Natarajan V, Garcia JGN \& Birukov KG (2006) Oxidized phospholipids reduce vascular leak and inflammation in rat model of acute lung injury. Am. J. Respir. Crit. Care Med. 173: 1130-1138

Norman JG, Fink GW \& Franz MG (1995) Acute pancreatitis induces intrapancreatic tumor necrosis factor gene expression. Arch. Surg. Chic. III 1960 130: 966-970

Norouzinia M, Chaleshi V, Alizadeh AHM \& Zali MR (2017) Biomarkers in inflammatory bowel diseases: insight into diagnosis, prognosis and treatment. Gastroenterol. Hepatol. Bed Bench 10: 155-167

Nourshargh S \& Alon R (2014) Leukocyte migration into inflamed tissues. Immunity 41: 694-707

Nourshargh S, Hordijk PL \& Sixt M (2010) Breaching multiple barriers: leukocyte motility through venular walls and the interstitium. Nat. Rev. Mol. Cell Biol. 11: 366-378

Núñez-Gómez E, Pericacho M, Ollauri-Ibáñez C, Bernabéu C \& López-Novoa JM (2017) The role of endoglin in post-ischemic revascularization. Angiogenesis 20: 1-24 
O'Connell PJ, McKenzie A, Fisicaro N, Rockman SP, Pearse MJ \& d'Apice AJ (1992) Endoglin: a 180-kD endothelial cell and macrophage restricted differentiation molecule. Clin Exp Immuno/ 90: 154-159

Ojeda-Fernández L, Recio-Poveda L, Aristorena M, Lastres P, Blanco FJ, Sanz-Rodríguez F, GallardoVara E, de las Casas-Engel M, Corbí Á, Arthur HM, Bernabeu C \& Botella LM (2016) Mice Lacking Endoglin in Macrophages Show an Impaired Immune Response. PLoS Genet. 12: e1005935

Okin D \& Medzhitov R (2012) Evolution of Inflammatory Diseases. Curr. Biol. CB 22: R733-R740

Okusa MD, Linden J, Macdonald T \& Huang L (1999) Selective A2A adenosine receptor activation reduces ischemia-reperfusion injury in rat kidney. Am. J. Physiol. 277: F404-412

Omote K, Hazama K, Kawamata T, Kawamata M, Nakayaka Y, Toriyabe M \& Namiki A (2001) Peripheral nitric oxide in carrageenan-induced inflammation. Brain Res. 912: 171-175

Oujo B, Muñoz-Félix JM, Arévalo M, Núñez-Gómez E, Pérez-Roque L, Pericacho M, González-Núñez M, Langa C, Martínez-Salgado C, Perez-Barriocanal F, Bernabeu C \& Lopez-Novoa JM (2014) L-Endoglin overexpression increases renal fibrosis after unilateral ureteral obstruction. PloS One 9: e110365

Paleolog E (1997) Target effector role of vascular endothelium in the inflammatory response: insights from the clinical trial of anti-TNF alpha antibody in rheumatoid arthritis. Mol. Pathol. MP 50: $225-233$

Pan CC, Kumar S, Shah N, Hoyt DG, Hawinkels LJ, Mythreye K \& Lee NY (2014) Src-mediated posttranslational regulation of endoglin stability and function is critical for angiogenesis. J Biol Chem 289: 25486-25496

Park S, Dimaio TA, Liu W, Wang S, Sorenson CM \& Sheibani N (2013) Endoglin regulates the activation and quiescence of endothelium by participating in canonical and non-canonical TGF-beta signaling pathways. J Cell Sci 126: 1392-1405

Parker WL, Goldring MB \& Philip A (2003) Endoglin is expressed on human chondrocytes and forms a heteromeric complex with betaglycan in a ligand and type II TGFbeta receptor independent manner. J Bone Min. Res 18: 289-302

Patel A, Sabbineni H, Clarke A \& Somanath PR (2016) Novel roles of Src in cancer cell epithelial-tomesenchymal transition, vascular permeability, microinvasion and metastasis. Life Sci. 157: 52-61

Patschan D, Patschan S \& Müller GA (2011) Endothelial progenitor cells in acute ischemic kidney injury: strategies for increasing the cells' renoprotective competence. Int. J. Nephrol. 2011: 828369 
Patschan D, Plotkin M \& Goligorsky MS (2006) Therapeutic use of stem and endothelial progenitor cells in acute renal injury: ça ira. Curr. Opin. Pharmacol. 6: 176-183

Perez-Gomez E, Eleno N, Lopez-Novoa JM, Ramirez JR, Velasco B, Letarte M, Bernabeu C \& Quintanilla M (2005) Characterization of murine S-endoglin isoform and its effects on tumor development. Oncogene 24: 4450-4461

Pérez-Gómez E, Eleno N, López-Novoa JM, Ramirez JR, Velasco B, Letarte M, Bernabéu C \& Quintanilla M (2005) Characterization of murine S-endoglin isoform and its effects on tumor development. Oncogene 24: 4450-4461

Pérez-Gómez E, Villa-Morales M, Santos J, Fernández-Piqueras J, Gamallo C, Dotor J, Bernabéu C \& Quintanilla M (2007) A role for endoglin as a suppressor of malignancy during mouse skin carcinogenesis. Cancer Res. 67: 10268-10277

Peter MR, Jerkic M, Sotov V, Douda DN, Ardelean DS, Ghamami N, Lakschevitz F, Khan MA, Robertson SJ, Glogauer M, Philpott DJ, Palaniyar N \& Letarte M (2014) Impaired resolution of inflammation in the Endoglin heterozygous mouse model of chronic colitis. Mediators Inflamm. 2014: 767185

Pfaff CM, Marquardt Y, Fietkau K, Baron JM \& Lüscher B (2017) The psoriasis-associated IL-17A induces and cooperates with IL-36 cytokines to control keratinocyte differentiation and function. Sci. Rep. 7: 15631

Pfau S, Leitenberg D, Rinder H, Smith BR, Pardi R \& Bender JR (1995) Lymphocyte adhesiondependent calcium signaling in human endothelial cells. J. Cell Biol. 128: 969-978

Phillipson M, Heit B, Parsons SA, Petri B, Mullaly SC, Colarusso P, Gower RM, Neely G, Simon SI \& Kubes $P$ (2009) Vav1 is essential for mechanotactic crawling and migration of neutrophils out of the inflamed microvasculature. J. Immunol. Baltim. Md 1950 182: 6870-6878

Pober JS \& Sessa WC (2007) Evolving functions of endothelial cells in inflammation. Nat. Rev. Immunol. 7: 803-815

Pollack RM, Donath MY, LeRoith D \& Leibowitz G (2016) Anti-inflammatory Agents in the Treatment of Diabetes and Its Vascular Complications. Diabetes Care 39 Suppl 2: S244-252

Posadas I, Bucci M, Roviezzo F, Rossi A, Parente L, Sautebin L \& Cirino G (2004) Carrageenan-induced mouse paw oedema is biphasic, age-weight dependent and displays differential nitric oxide cyclooxygenase-2 expression. Br. J. Pharmacol. 142: 331-338

Prandini M-H, Dreher I, Bouillot S, Benkerri S, Moll T \& Huber P (2005) The human VE-cadherin promoter is subjected to organ-specific regulation and is activated in tumour angiogenesis. Oncogene 24: 2992-3001

Preedy VR \& Hunter R (2011) Cytokines CRC Press 
Preshaw PM (2017) Host modulation therapy with anti-inflammatory agents. Periodontol. 2000

Proebstl D, Voisin M-B, Woodfin A, Whiteford J, D'Acquisto F, Jones GE, Rowe D \& Nourshargh S (2012) Pericytes support neutrophil subendothelial cell crawling and breaching of venular walls in vivo. J. Exp. Med. 209: 1219-1234

Puhlmann M, Weinreich DM, Farma JM, Carroll NM, Turner EM \& Alexander HR (2005) Interleukin-1 $\beta$ induced vascular permeability is dependent on induction of endothelial Tissue Factor (TF) activity. J. Transl. Med. 3: 37

Putensen C \& Wrigge H (2000) Ventilator-associated systemic inflammation in acute lung injury. Intensive Care Med. 26: 1411-1413

Quintanilla M, Ramirez JR, Perez-Gomez E, Romero D, Velasco B, Letarte M, Lopez-Novoa JM \& Bernabeu C (2003) Expression of the TGF-beta coreceptor endoglin in epidermal keratinocytes and its dual role in multistage mouse skin carcinogenesis. Oncogene 22: 5976-5985

Ramesh G \& Reeves WB (2004) Inflammatory cytokines in acute renal failure. Kidney Int. Suppl.: S5661

Ramma W \& Ahmed A (2011) Is inflammation the cause of pre-eclampsia? Biochem. Soc. Trans. 39: 1619-1627

Rana S, Cerdeira AS, Wenger J, Salahuddin S, Lim K-H, Ralston SJ, Thadhani RI \& Karumanchi SA (2012) Plasma concentrations of soluble endoglin versus standard evaluation in patients with suspected preeclampsia. PloS One 7: e48259

Redman CW \& Jefferies M (1988) Revised definition of pre-eclampsia. Lancet Lond. Engl. 1: 809-812

Redman CW, Sacks GP \& Sargent IL (1999) Preeclampsia: an excessive maternal inflammatory response to pregnancy. Am. J. Obstet. Gynecol. 180: 499-506

Redman CW \& Sargent IL (2005) Latest advances in understanding preeclampsia. Science 308: 15921594

Redman CWG \& Sargent IL (2003) Pre-eclampsia, the placenta and the maternal systemic inflammatory response--a review. Placenta 24 Suppl A: S21-27

Remick DG, Bolgos GR, Siddiqui J, Shin J \& Nemzek JA (2002) Six at six: interleukin-6 measured $6 \mathrm{~h}$ after the initiation of sepsis predicts mortality over 3 days. Shock Augusta Ga 17: 463-467

Rietschel ET, Kirikae T, Schade FU, Mamat U, Schmidt G, Loppnow H, Ulmer AJ, Zähringer U, Seydel U \& Di Padova $F$ (1994) Bacterial endotoxin: molecular relationships of structure to activity and function. FASEB J. Off. Publ. Fed. Am. Soc. Exp. Biol. 8: 217-225 
Rivera LB \& Brekken RA (2011) SPARC promotes pericyte recruitment via inhibition of endoglindependent TGF-beta1 activity. J Cell Biol 193: 1305-1319

Rodriguez-Barbero A, Obreo J, Eleno N, Rodriguez-Pena A, Duwel A, Jerkic M, Sanchez-Rodriguez A, Bernabeu C \& Lopez-Novoa JM (2001) Endoglin expression in human and rat mesangial cells and its upregulation by TGF-beta1. Biochem Biophys Res Commun 282: 142-147

Rokhlin OW, Cohen MB, Kubagawa H, Letarte M \& Cooper MD (1995) Differential expression of endoglin on fetal and adult hematopoietic cells in human bone marrow. J Immunol 154: 4456-4465

Romano M, Faggioni R, Sironi M, Sacco S, Echtenacher B, Di Santo E, Salmona M \& Ghezzi P (1997) Carrageenan-induced acute inflammation in the mouse air pouch synovial model. Role of tumour necrosis factor. Mediators Inflamm. 6: 32-38

Romero Hurtado S \& Iregui CA (2010) Lipopolysaccharide. Rev. Med. Vet.: 37-45

Ross R (1999) Atherosclerosis--an inflammatory disease. N. Engl. J. Med. 340: 115-126

Rossi E, Sanz-Rodriguez F, Eleno N, Düwell A, Blanco FJ, Langa C, Botella LM, Cabañas C, Lopez-Novoa JM \& Bernabeu C (2013) Endothelial endoglin is involved in inflammation: role in leukocyte adhesion and transmigration. Blood 121: 403-415

Rossi E, Smadja DM, Boscolo E, Langa C, Arevalo MA, Pericacho M, Gamella-Pozuelo L, Kauskot A, Botella LM, Gaussem P, Bischoff J, Lopez-Novoa JM \& Bernabeu C (2016) Endoglin regulates mural cell adhesion in the circulatory system. Cell. Mol. Life Sci. CMLS 73: 1715-1739

Rot A \& von Andrian UH (2004) Chemokines in innate and adaptive host defense: basic chemokinese grammar for immune cells. Annu. Rev. Immunol. 22: 891-928

Rowe RG \& Weiss SJ (2008) Breaching the basement membrane: who, when and how? Trends Cell Biol. 18: 560-574

Rulo HF, Westphal JR, van de Kerkhof PC, de Waal RM, van Vlijmen IM \& Ruiter DJ (1995) Expression of endoglin in psoriatic involved and uninvolved skin. J. Dermatol. Sci. 10: 103-109

Saad RS, El-Gohary Y, Memari E, Liu YL \& Silverman JF (2005) Endoglin (CD105) and vascular endothelial growth factor as prognostic markers in esophageal adenocarcinoma. Hum. Pathol. 36: 955-961

Saad RS, Jasnosz KM, Tung MY \& Silverman JF (2003) Endoglin (CD105) expression in endometrial carcinoma. Int. J. Gynecol. Pathol. Off. J. Int. Soc. Gynecol. Pathol. 22: 248-253

Sacks GP, Studena K, Sargent K \& Redman CW (1998) Normal pregnancy and preeclampsia both produce inflammatory changes in peripheral blood leukocytes akin to those of sepsis. Am. J. Obstet. Gynecol. 179: 80-86 
Salahuddin S, Lee Y, Vadnais M, Sachs BP, Karumanchi SA \& Lim K-H (2007) Diagnostic utility of soluble fms-like tyrosine kinase 1 and soluble endoglin in hypertensive diseases of pregnancy. Am. J. Obstet. Gynecol. 197: 28.e1-6

Sandlund J, Hedberg Y, Bergh A, Grankvist K, Ljungberg B \& Rasmuson T (2006) Endoglin (CD105) expression in human renal cell carcinoma. BJU Int. 97: 706-710

Sans E, Delachanal E \& Duperray A (2001) Analysis of the roles of ICAM-1 in neutrophil transmigration using a reconstituted mammalian cell expression model: implication of ICAM-1 cytoplasmic domain and Rho-dependent signaling pathway. J. Immunol. Baltim. Md 1950 166: 544-551

Sargent IL, Germain SJ, Sacks GP, Kumar S \& Redman CWG (2003) Trophoblast deportation and the maternal inflammatory response in pre-eclampsia. J. Reprod. Immunol. 59: 153-160

Scharpfenecker M, Floot B, Russell NS \& Stewart FA (2012) The TGF- $\beta$ co-receptor endoglin regulates macrophage infiltration and cytokine production in the irradiated mouse kidney. Radiother. Oncol. J. Eur. Soc. Ther. Radiol. Oncol. 105: 313-320

Scharpfenecker M, Floot B, Russell NS, Ten Dijke P \& Stewart FA (2009) Endoglin haploinsufficiency reduces radiation-induced fibrosis and telangiectasia formation in mouse kidneys.

Radiother. Oncol. J. Eur. Soc. Ther. Radiol. Oncol. 92: 484-491

Schenkel AR, Mamdouh Z \& Muller WA (2004) Locomotion of monocytes on endothelium is a critical step during extravasation. Nat. Immunol. 5: 393-400

Schletter J, Heine H, Ulmer AJ \& Rietschel ET (1995) Molecular mechanisms of endotoxin activity. Arch. Microbiol. 164: 383-389

Schneiders J, Fuchs F, Damm J, Herden C, Gerstberger R, Soares DM, Roth J \& Rummel C (2015) The transcription factor nuclear factor interleukin 6 mediates pro- and anti-inflammatory responses during LPS-induced systemic inflammation in mice. Brain. Behav. Immun. 48: 147-164

SEDISA. Sociedad Española de Directivos de la Salud. - Sociedad Española de Directivos de la Salud Available at: http://sedisa.net/

SER - Sociedad Española de Reumatología SER Available at: https://www.ser.es/ [Accessed November 19, 2017]

Serhan CN, Ward PA \& Gilroy DW (2010) Fundamentals of Inflammation Cambridge University Press

Sethi G, Sung B \& Aggarwal BB (2008) TNF: a master switch for inflammation to cancer. Front. Biosci. J. Virtual Libr. 13: 5094-5107

Sharfuddin AA \& Molitoris BA (2011) Pathophysiology of ischemic acute kidney injury. Nat. Rev. Nephrol. 7: 189-200 
Shen F, Degos V, Chu P-L, Han Z, Westbroek EM, Choi E-J, Marchuk D, Kim H, Lawton MT, Maze M, Young WL \& Su H (2014) Endoglin deficiency impairs stroke recovery. Stroke 45: 2101-2106

Shi Y \& Massagué J (2003) Mechanisms of TGF-beta signaling from cell membrane to the nucleus. Cell 113: $685-700$

Shovlin CL (2010) Hereditary haemorrhagic telangiectasia: pathophysiology, diagnosis and treatment. Blood Rev. 24: 203-219

Shulman Z, Shinder V, Klein E, Grabovsky V, Yeger O, Geron E, Montresor A, Bolomini-Vittori M, Feigelson SW, Kirchhausen T, Laudanna C, Shakhar G \& Alon R (2009) Lymphocyte crawling and transendothelial migration require chemokine triggering of high-affinity LFA-1 integrin. Immunity 30: 384-396

Sibai B, Dekker G \& Kupferminc M (2005) Pre-eclampsia. Lancet Lond. Engl. 365: 785-799

Siddall E, Khatri M \& Radhakrishnan J (2017) Capillary leak syndrome: etiologies, pathophysiology, and management. Kidney Int. 92: 37-46

Simmons EM, Himmelfarb J, Sezer MT, Chertow GM, Mehta RL, Paganini EP, Soroko S, Freedman S, Becker K, Spratt D, Shyr Y, Ikizler TA \& PICARD Study Group (2004) Plasma cytokine levels predict mortality in patients with acute renal failure. Kidney Int. 65: 1357-1365

Soehnlein O, Lindbom L \& Weber C (2009) Mechanisms underlying neutrophil-mediated monocyte recruitment. Blood 114: 4613-4623

Solak Y, Afsar B, Vaziri ND, Aslan G, Yalcin CE, Covic A \& Kanbay M (2016) Hypertension as an autoimmune and inflammatory disease. Hypertens. Res. Off. J. Jpn. Soc. Hypertens. 39: 567-573

Soleymanlou N, Jurisica I, Nevo O, letta F, Zhang X, Zamudio S, Post M \& Caniggia I (2005) Molecular evidence of placental hypoxia in preeclampsia. J. Clin. Endocrinol. Metab. 90: 4299-4308

Sones JL \& Davisson RL (2016) Preeclampsia, of mice and women. Physiol. Genomics 48: 565-572

Stark K, Eckart A, Haidari S, Tirniceriu A, Lorenz M, von Brühl M-L, Gärtner F, Khandoga AG, Legate KR, Pless R, Hepper I, Lauber K, Walzog B \& Massberg S (2013) Capillary and arteriolar pericytes attract innate leukocytes exiting through venules and 'instruct' them with pattern-recognition and motility programs. Nat. Immunol. 14: 41-51

St-Jacques S, Cymerman U, Pece N \& Letarte M (1994a) Molecular characterization and in situ localization of murine endoglin reveal that it is a transforming growth factor-beta binding protein of endothelial and stromal cells. Endocrinology 134: 2645-2657 
St-Jacques S, Forte M, Lye SJ \& Letarte M (1994b) Localization of endoglin, a transforming growth factor-beta binding protein, and of CD44 and integrins in placenta during the first trimester of pregnancy. Biol Reprod 51: 405-413

Sumagin R, Lomakina E \& Sarelius IH (2008) Leukocyte-endothelial cell interactions are linked to vascular permeability via ICAM-1-mediated signaling. Am. J. Physiol. - Heart Circ. Physiol. 295: H969-H977

Sumagin R, Prizant H, Lomakina E, Waugh RE \& Sarelius IH (2010) LFA-1 and Mac-1 define characteristically different intralumenal crawling and emigration patterns for monocytes and neutrophils in situ. J. Immunol. Baltim. Md 1950 185: 7057-7066

Szarka A, Rigó J, Lázár L, Beko G \& Molvarec A (2010) Circulating cytokines, chemokines and adhesion molecules in normal pregnancy and preeclampsia determined by multiplex suspension array. BMC Immunol. 11: 59

Szekanecz Z, Haines GK, Harlow LA, Shah MR, Fong TW, Fu R, Lin SJ, Rayan G \& Koch AE (1995) Increased synovial expression of transforming growth factor (TGF)-beta receptor endoglin and TGF-beta 1 in rheumatoid arthritis: possible interactions in the pathogenesis of the disease. Clin. Immunol. Immunopathol. 76: 187-194

Taddei A, Giampietro C, Conti A, Orsenigo F, Breviario F, Pirazzoli V, Potente M, Daly C, Dimmeler S \& Dejana E (2008) Endothelial adherens junctions control tight junctions by VE-cadherinmediated upregulation of claudin-5. Nat. Cell Biol. 10: 923-934

Takahashi N, Kawanishi-Tabata R, Haba A, Tabata M, Haruta Y, Tsai H \& Seon BK (2001) Association of serum endoglin with metastasis in patients with colorectal, breast, and other solid tumors, and suppressive effect of chemotherapy on the serum endoglin. Clin. Cancer Res. Off. J. Am. Assoc. Cancer Res. 7: 524-532

Tanaka F, Otake Y, Yanagihara K, Kawano Y, Miyahara R, Li M, Yamada T, Hanaoka N, Inui K \& Wada H (2001) Evaluation of angiogenesis in non-small cell lung cancer: comparison between antiCD34 antibody and anti-CD105 antibody. Clin. Cancer Res. Off. J. Am. Assoc. Cancer Res. 7: 3410-3415

Tasaka S, Hasegawa N \& Ishizaka A (2002) Pharmacology of acute lung injury. Pulm. Pharmacol. Ther. 15: 83-95

Taylor CT (2008) Interdependent roles for hypoxia inducible factor and nuclear factor-kappaB in hypoxic inflammation. J. Physiol. 586: 4055-4059

Thibeault S, Rautureau Y, Oubaha M, Faubert D, Wilkes BC, Delisle C \& Gratton J-P (2010) Snitrosylation of beta-catenin by eNOS-derived NO promotes VEGF-induced endothelial cell permeability. Mol. Cell 39: 468-476 
Thurman JM (2007) Triggers of inflammation after renal ischemia/reperfusion. Clin. Immunol. Orlando Fla 123: 7-13

Torres MD, Chenlo F \& Moreira R (2016) Rheology of K/L-hybrid carrageenan from Mastocarpus stellatus: Critical parameters for the gel formation. Int. J. Biol. Macromol. 86: 418-424

Torsney E, Charlton R, Parums D, Collis M \& Arthur HM (2002) Inducible expression of human endoglin during inflammation and wound healing in vivo. Inflamm. Res. Off. J. Eur. Histamine Res. Soc. Al 51: 464-470

Ulich TR, Watson LR, Yin SM, Guo KZ, Wang P, Thang H \& del Castillo J (1991) The intratracheal administration of endotoxin and cytokines. I. Characterization of LPS-induced IL-1 and TNF mRNA expression and the LPS-, IL-1-, and TNF-induced inflammatory infiltrate. Am. J. Pathol. 138: 1485-1496

Valbuena-Diez AC, Blanco FJ, Oujo B, Langa C, Gonzalez-Nuñez M, Llano E, Pendas AM, Díaz M, Castrillo A, Lopez-Novoa JM \& Bernabeu C (2012) Oxysterol-induced soluble endoglin release and its involvement in hypertension. Circulation 126: 2612-2624

Varejckova M, Gallardo-Vara E, Vicen M, Vitverova B, Fikrova P, Dolezelova E, Rathouska J, Prasnicka A, Blazickova K, Micuda S, Bernabeu C, Nemeckova I \& Nachtigal P (2017) Soluble endoglin modulates the pro-inflammatory mediators NF-KB and IL-6 in cultured human endothelial cells. Life Sci. 175: 52-60

Velasco S, Alvarez-Munoz P, Pericacho M, Dijke PT, Bernabeu C, Lopez-Novoa JM \& RodriguezBarbero A (2008) L- and S-endoglin differentially modulate TGFbeta1 signaling mediated by ALK1 and ALK5 in L6E9 myoblasts. J Cell Sci 121: 913-919

van de Velde F, Rollema HS, Grinberg NV, Burova TV, Grinberg VY \& Tromp RH (2002) Coil-helix transition of iota-carrageenan as a function of chain regularity. Biopolymers 65: 299-312

Venkatesha S, Toporsian M, Lam C, Hanai J, Mammoto T, Kim YM, Bdolah Y, Lim K-H, Yuan H-T, Libermann TA, Stillman IE, Roberts D, D'Amore PA, Epstein FH, Sellke FW, Romero R, Sukhatme VP, Letarte M \& Karumanchi SA (2006) Soluble endoglin contributes to the pathogenesis of preeclampsia. Nat. Med. 12: 642-649

Vestweber D (2012) Relevance of endothelial junctions in leukocyte extravasation and vascular permeability. Ann. N. Y. Acad. Sci. 1257: 184-192

Villagrana RDC, Villagrana ARC \& Bernal JMP (2014) Mecanismos de señalización involucrados en la resolución de la inflamación. Gac. Médica México 150: 440-449

Vockel M \& Vestweber D (2013) How T cells trigger the dissociation of the endothelial receptor phosphatase VE-PTP from VE-cadherin. Blood 122: 2512-2522 
Voisin M-B \& Nourshargh S (2013) Neutrophil transmigration: emergence of an adhesive cascade within venular walls. J. Innate Immun. 5: 336-347

Voisin M-B, Pröbstl D \& Nourshargh S (2010) Venular Basement Membranes Ubiquitously Express Matrix Protein Low-Expression Regions. Am. J. Pathol. 176: 482-495

Voller A (1978) The enzyme-linked immunosorbent assay (ELISA) (theory, technique and applications). Ric. Clin. Lab. 8: 289-298

Walcheck B, Moore KL, McEver RP \& Kishimoto TK (1996) Neutrophil-neutrophil interactions under hydrodynamic shear stress involve L-selectin and PSGL-1. A mechanism that amplifies initial leukocyte accumulation of P-selectin in vitro. J. Clin. Invest. 98: 1081-1087

Wang G, Hu Z, Song X, Cui Q, Fu Q, Jia R, Zou Y, Li L \& Yin Z (2017) Analgesic and Anti-Inflammatory Activities of Resveratrol through Classic Models in Mice and Rats. Evid.-Based Complement. Altern. Med. ECAM 2017: Available at: https://www.ncbi.nlm.nih.gov/pmc/articles/PMC5366799/ [Accessed November 19, 2017]

Webb A, Bond R, McLean P, Uppal R, Benjamin N \& Ahluwalia A (2004) Reduction of nitrite to nitric oxide during ischemia protects against myocardial ischemia-reperfusion damage. Proc. Natl. Acad. Sci. U. S. A. 101: 13683-13688

Weber C, Fraemohs L \& Dejana E (2007) The role of junctional adhesion molecules in vascular inflammation. Nat. Rev. Immunol. 7: 467-477

Weber EW, Han F, Tauseef M, Birnbaumer L, Mehta D \& Muller WA (2015) TRPC6 is the endothelial calcium channel that regulates leukocyte transendothelial migration during the inflammatory response. J. Exp. Med. 212: 1883-1899

Wegmann TG, Lin H, Guilbert L \& Mosmann TR (1993) Bidirectional cytokine interactions in the maternal-fetal relationship: is successful pregnancy a TH2 phenomenon? Immunol. Today 14: 353-356

Wei X, Song H, Yin L, Rizzo MG, Sidhu R, Covey DF, Ory DS \& Semenkovich CF (2016) Fatty acid synthesis configures the plasma membrane for inflammation in diabetes. Nature 539: 294298

Weinacker AB \& Vaszar LT (2001) Acute respiratory distress syndrome: physiology and new management strategies. Annu. Rev. Med. 52: 221-237

Wen Y \& Crowley SD (2017) Renal effects of cytokines in hypertension. Curr. Opin. Nephrol. Hypertens.

Wessel F, Winderlich M, Holm M, Frye M, Rivera-Galdos R, Vockel M, Linnepe R, Ipe U, Stadtmann A, Zarbock A, Nottebaum AF \& Vestweber D (2014) Leukocyte extravasation and vascular 
permeability are each controlled in vivo by different tyrosine residues of VE-cadherin. Nat. Immunol. 15: 223-230

Wheeler AP \& Bernard GR (1999) Treating patients with severe sepsis. N. Engl. J. Med. 340: 207-214

Williamson RD, McCarthy C, McCarthy FP \& Kenny LC (2017) Oxidative stress in pre-eclampsia; have we been looking in the wrong place? Pregnancy Hypertens. Int. J. Womens Cardiovasc. Health 8: 1-5

Winger RC, Koblinski JE, Kanda T, Ransohoff RM \& Muller WA (2014) Rapid remodeling of tight junctions during paracellular diapedesis in a human model of the blood-brain barrier. J. Immunol. Baltim. Md 1950 193: 2427-2437

Wojdasiewicz P, Poniatowski ŁA \& Szukiewicz D (2014) The role of inflammatory and antiinflammatory cytokines in the pathogenesis of osteoarthritis. Mediators Inflamm. 2014: 561459

Wolf M, Albrecht S \& Märki C (2008) Proteolytic processing of chemokines: implications in physiological and pathological conditions. Int. J. Biochem. Cell Biol. 40: 1185-1198

Woo TH, Patel BK, Cinco M, Smythe LD, Symonds ML, Norris M a \& Dohnt MF (1998) Real-time homogeneous assay of rapid cycle polymerase chain reaction product for identification of Leptonema illini. Anal. Biochem. 259: 112-7

Woodfin A, Voisin M-B, Beyrau M, Colom B, Caille D, Diapouli F-M, Nash GB, Chavakis T, Albelda SM, Rainger GE, Meda P, Imhof BA \& Nourshargh S (2011) The junctional adhesion molecule JAM-C regulates polarized transendothelial migration of neutrophils in vivo. Nat. Immunol. 12: $761-769$

Yamashita H, Ichijo H, Grimsby S, Moren A, ten Dijke P \& Miyazono K (1994) Endoglin forms a heteromeric complex with the signaling receptors for transforming growth factor-beta. $J$ Biol Chem 269: 1995-2001

Yardeni T, Eckhaus M, Morris HD, Huizing M \& Hoogstraten-Miller S (2011) Retro-orbital injections in mice. Lab Anim. 40: 155-160

Yonekawa K \& Harlan JM (2005) Targeting leukocyte integrins in human diseases. J. Leukoc. Biol. 77: 129-140

Young BC, Levine RJ \& Karumanchi SA (2010) Pathogenesis of preeclampsia. Annu. Rev. Pathol. 5: 173-192

Zacharopoulos VR \& Phillips DM (1997) Vaginal formulations of carrageenan protect mice from herpes simplex virus infection. Clin. Diagn. Lab. Immunol. 4: 465-468

Zappitelli M (2008) Epidemiology and diagnosis of acute kidney injury. Semin. Nephrol. 28: 436-446 
Zarbock A, Ley K, McEver RP \& Hidalgo A (2011) Leukocyte ligands for endothelial selectins: specialized glycoconjugates that mediate rolling and signaling under flow. Blood 118: 67436751

Zhang H, Shaw AR, Mak A \& Letarte M (1996) Endoglin is a component of the transforming growth factor (TGF)-beta receptor complex of human pre-B leukemic cells. J Immunol 156: 564-573

Zhang Y, Fan H, Xu J, Xiao Y, Xu Y, Li Y \& Li X (2013) Network Analysis Reveals Functional Cross-links between Disease and Inflammation Genes. Sci. Rep. 3: Available at:

https://www.ncbi.nlm.nih.gov/pmc/articles/PMC3851881/ [Accessed December 2, 2017]

Zhou T, Huang X, Zhou Y, Ma J, Zhou M, Liu Y, Xiao L, Yuan J, Xie J \& Chen W (2017) Associations between Th17-related inflammatory cytokines and asthma in adults: A Case-Control Study. Sci. Rep. 7: 15502

Zuchtriegel G, Uhl B, Hessenauer MET, Kurz ARM, Rehberg M, Lauber K, Krombach F \& Reichel CA (2015) Spatiotemporal expression dynamics of selectins govern the sequential extravasation of neutrophils and monocytes in the acute inflammatory response. Arterioscler. Thromb. Vasc. Biol. 35: 899-910 